\title{
GISELE REISDOERFER
}

\section{EFEITOS DO ENVELHECIMENTO NOS COMPONENTES FIBROELÁSTICOS DA JUNÇÃO VÉSICO-URETRAL DE RATOS WISTAR}




\title{
GISELE REISDOERFER
}

\section{EFEITOS DO ENVELHECIMENTO NOS COMPONENTES FIBROELÁSTICOS DA JUNÇÃO VÉSICO-URETRAL DE RATOS WISTAR}

\author{
Dissertação apresentada ao Programa de \\ Pós-Graduação em Ciências Morfofuncionais do \\ Instituto de Ciências Biomédicas da Universidade de \\ São Paulo, para obtenção do Título de Mestre em \\ Ciências.
}

\section{São Paulo}

2007 


\section{GISELE REISDOERFER}

\section{EFEITOS DO ENVELHECIMENTO NOS COMPONENTES FIBROELÁSTICOS DA JUNÇÃO VÉSICO-URETRAL DE RATOS WISTAR}

Dissertação apresentada ao Programa de Pós-Graduação em Ciências Morfofuncionais do Instituto de Ciências Biomédicas da Universidade de São Paulo, para obtenção do Título de Mestre em Ciências.

Área de Concentração: Ciências Morfofuncionais

Orientador: Prof. Dr. Edson Aparecido Liberti

\section{São Paulo}

2007 


\section{DEDICATÓRIA}

Dedico este trabalho a todas as pessoas que acreditam em seus sonhos e os fazem se tornar realidade sem medir os esforços, as consequências, o suor e as lágrimas. 


\section{AGRADECIMENTOS}

Agradeço a DEUS e à NOSSA SENHORA APARECIDA, pela proteção, amparo e sabedoria para discernir o certo do errado e o justo do injusto e pelas pessoas maravilhosas que Deus colocou em meu caminho nesta trajetória.

Ao Prof. Dr. Renato Paulo Chopard, pelo seu excelente profissionalismo, pelo verdadeiro mestre que és, pelos ensinamentos científicos e anatômicos, pela sua amizade, companheirismo, lealdade e também pelos bons bate-papos, onde tudo isso levarei sempre em minha memória por onde for.

Ao Prof. Dr. Edson Aparecido Liberti, por sua dedicação, préstimos, apoio, pela sua importante contribuição profissional neste trabalho, pelas suas maravilhosas histórias e pela sua Disciplina de Técnicas Anatômicas, a qual foi de grande valia para minha vida pessoal e profissional.

Ao Prof. Dr. Romeu de Souza, pelos seus ensinamentos, disponibilidade e ajuda científica para melhoria de nosso estudo.

À minha família, Marcos, Margarete e Laura, pela torcida, compreensão, carinho e comemorações a cada obstáculo superado.

Ao meu noivo, Tiago, por seu amor imenso, superação, apoio, conselhos, paciência infinita e ajuda para que este projeto de vida se realizasse.

Aos meus avós Celestino e Francisca, pelo amor e carinho ofertado.

Às queridas pessoas Sra. Lourdes, Sr. Sérgio e Carla Galina pelo afeto e amizade.

À Profa. Dra. Maria Luiza Barreto Chaves, pelo carinho, amizade e apoio.

À Profa.Dra. Maria Inês Nogueira, pelos seus préstimos laboratoriais, conversas e amizade.

Aos demais professores do Departamento de Anatomia Humana do Instituto de Ciências Biomédicas III, sejam através de seus préstimos profissionais e laboratoriais ou pela amizade adquirida, ajudaram para que este trabalho fosse concluído da melhor maneira possível.

Ao laboratório de Histologia e aos seus funcionários (as) Marta, Sônia e Boleta, que foram pessoas importantíssimas para que as preparações histológicas e eletrônicas realizadas neste trabalho pudessem concretizar-se, também pelo empenho, boa vontade, amizade pura, carinho e maravilhosas tardes passadas nos micrótomos com muita conversa boa, lanchinhos e cafezinhos, vocês foram excelentes.

Ao Instituto Butantãn, pela Microscopia Eletrônica de Transmissão, como ao Sr. Alexsander e a Prof. Dra. Marta.

À Biblioteca do Instituto de Ciências Biomédicas pelo material bibliográfico concedido, especialmente a Sra. Ana Paula. 
Aos verdadeiros amigos que tive a honra de conhecer durante este tempo, Jaqueline Carvalho, Maria Tereza, Fabrício, Renata Vasconcelos, Leila, Luciano, Guilherme, Alexandre, Dorival, Márcia, Priscilla, William, Josemberg, Amanda, Leonardo, Flávio, Lincon, Ana Cláudia, Marcela, Maria Alícia, Gabriela, Cibele, Rúbia, Amábile, Kleber, Luana e Joelcimar que me ajudaram a ter firmeza e que me cederam suas casas, caronas, ajuda profissional, carinho, conselhos, e também horas de lazer e descontração, principalmente na padaria, agradeço por tudo e serei sempre grata.

À amiga Mary Maoli, pela amizade, bate-papos, quebra-galhos e por tudo mais.

À minha segunda família paulistana Maria Tereza, Fabrício e Maria Eduarda (bolacha); Renata Vasconcelos; Leila Campos; Luciano Gonçalves; Dorival e Márcia.

Aos demais colegas do Departamento de Anatomia Humana.

Às funcionárias da Secretaria de Pós-Graduação do Departamento de Anatomia Humana do Instituto de Ciências Bimédicas III, Patrícia e Cristiane.

Aos funcionários (as) do Biotério do Departamento de Anatomia Humana, Luciana, Renival e Rodrigo; do Museu, Nilson e Cristina; do Xérox; da SBA e demais secretárias.

Aos funcionários do Bloco Didático do Departamento de Anatomia Humana, meus sinceros agradecimentos.

À Sra. Rosana D. Prisco, pela sua contribuição estatística e amizade.

Às queridas Káren Dalla Costa, Nilce Santana, Juliana Pacheco, Ana Paula Pacheco, Francielly Waldhauer, Rosane Cella, pelas suas orações e grande apoio, e aos Funcionários da Empresa Reunidas.

A Comunidade Cristus Dominus, pelas orações e fortalecimento espiritual.

A Secretária Municipal de Saúde de Clevelândia.

Aos colegas da Clínica Odontológica Municipal de Clevelândia.

Aos Professores Dr. Renato Paulo Chopard, Dr. Edson Aparecido Liberti e Dr. Richard Halti Cabral, verdadeiros mestres no ensinamento da Anatomia Humana, onde suas condutas serão o espelho e guia da minha carreira profissional. 
"Um dia sonhei que o vôo seria alto Voaste mais que pensei

Não com asas de ícaro

Mas com asas do saber

Asas de aço

Moldadas na Oficina do Pai."

Marcos Reisdoerfer 


\section{RESUMO}

REISDOERFER, G. Efeitos do Envelhecimento nos Componentes Fibroelásticos da Junção Vésico-Uretral de Ratos Wistar. 2007. 104 f. Dissertação (Mestrado em Ciências) Instituto de Ciências Biomédicas, Universidade de São Paulo, São Paulo, 2007.

Para avaliar as fibras elásticas do sistema elástico, na junção vésico-uretral de Ratos Wistar, em diferentes faixas etárias, foram realizados estudos histológicos, de microscopia elêtronica de transmissão e histomorfométricos. O estudo histológico do sistema de fibras elásticas revelado por métodos seletivos de coloração, mostrou a presença dos três tipos de fibras elásticas, em todas as faixas etárias estudadas, a microscopia eletrônica de transmissão, com uso da técnica do ácido tânico associado ao fixador glutaraldeído, mostrou satisfatoriamente as diferenças ultra-estruturais entre as fibras elásticas maduras, elaunínicas e oxitalânicas, presentes entre os espaços intercelulares das células musculares e feixes de fibras colágenas. A avaliação histomerfométrica revelou que com o avanço da idade há uma diminuição, estatisticamente significante, da densidade linear das fibras elásticas maduras e oxitalânicas e a densidade linear das fibras elaunínicas apresentou-se aumentada. Dessa forma podemos inferir que na junção vésico-uretral de animais velhos, há uma queda nas propriedades de elasticidade, recuo elástico e ancoragem, devido uma perda de elastina e microtúbulos, mas que são compensadas pelas fibras elaunínicas, por estas possuírem características intermediárias entre elásticas maduras e oxitalânicas. Concluímos que o processo de envelhecimento das fibras elásticas na junção vésico-uretral não contribui sozinha e diretamente no estado de incontinência urinária, mas compensa e dá suporte a muscular, principalmente devido ao aumento das fibras elaunínicas, o que torna o sistema elástico na junção vésico-uretral indiretamente responsável pela manutenção da continência urinária.

Palavras-chave: Junção vésico-uretral. Fibras Elásticas. Envelhecimento. 


\begin{abstract}
REISDOERFER, G. Effects of the Aging in Fibroelastics Components of Junction Vesico-Urethral in Rat Wistar. 2007. $104 \mathrm{f}$. Master thesis (Sciences) - Instituto de Ciências Biomédicas, Universidade de São Paulo, São Paulo, 2007.

To evaluate the elastic fibers of the elastic system, in the junction vesico-urethral of rat wistar, in different age groups, studies histologics was accomplished, electron microscopy of transmission and histomorphometrics studies. Study histologic of the system elastic fibers for selective methods of coloration, showed the presence of the three types of elastic fibers, in all the studied age groups, eletron microcopy of transmission, with use technique tannic acid associated glutaraldehyde, showed the ultra-structural differences satisfactorily among the mature elastic fibers, elaunin and oxytalan, which were located among in the intercellular spaces of the muscular layer as well as between fibres collagens. Study histomorfometric revealed that with the progress age there is a decrease of the linear density of the mature elastic fibers and oxyitalans, whilst the linear density of the fibers elauninns came increased. So, we can infer that in the junction vesico-urethral of old animals, there is a fall in the properties of elasticity, elastic recoil and anchorage, due an elastin loss and microfibrils, but they are compensated by the fibers elaunins, for these they possess intermediary characteristics among elastic mature and oxytalans. We concluded that the process aging of the elastic fibers in the junction vesico-urethral doesn't contribute alone and directly in the state of urinary incontinence, but it compensates and she gives muscular support, mainly due to the increase of the fibers elaunins, what turns the elastic system in the junction vesicourethral responsible for the maintenance of the urinary continence.
\end{abstract}

Key-words: Junction vesico-urethral. Elastic fibers. Aging. 


\section{LISTA DE ILUSTRAÇÕES}

Figura 1. Fotomicrografia da JVU, coloração Verhoeff, grupo neonato .45

Figura 2. Fotomicrografia da JVU, coloração Verhoeff, grupo adulto 46

Figura 3. Fotomicrografia da JVU, coloração Verhoeff, grupo velho 47

Figura 4. Fotomicrografia da JVU, coloração Weigert, grupo neonato .48

Figura 5. Fotomicrografia da JVU, coloração Weigert, grupo adulto 49

Figura 6. Fotomicrografia da JVU, coloração Weigert, grupo velho 50

Figura 7. Fotomicrografia da JVU, coloração Weigert-Oxona, grupo neonato 51

Figura 8. Fotomicrografia da JVU, coloração Weigert-Oxona, grupo adulto 52

Figura 9. Fotomicrografia da JVU, coloração Weigert-Oxona, grupo velho 53

Figura 10. Eletromicrografia da JVU, grupo neonato, 30K 54

Figura 11. Eletromicrografia da JVU, grupo neonato, 100K 54

Figura 12. Eletromicrografia da JVU, grupo neonato, 43.120X 55

Figura 13. Eletromicrografia da JVU, grupo neonato, 43.120X ….................................... 55

Figura 14. Eletromicrografia da JVU, grupo neonato, 100K 56

Figura 15. Eletromicrografia da JVU, grupo neonato, 100K 56

Figura 16. Eletromicrografia da junção vésico-uretral, grupo neonato, 43.120X 57 
Figura 17. Eletromicrografia da JVU, grupo neonato, 43.120X

Figura 18. Eletromicrografia da JVU, grupo neonato, 100K 58

Figura 19. Eletromicrografia da JVU, grupo neonato, 100K 58

Figura 20. Eletromicrografia da JVU, grupo adulto, 100K 59

Figura 21. Eletromicrografia da JVU, grupo adulto, 100K 59

Figura 22. Eletromicrografia da JVU, grupo adulto, $40 \mathrm{~K}$ 60

Figura 23. Eletromicrografia da JVU, grupo adulto, 100K 60

Figura 24. Eletromicrografia da JVU, grupo adulto, 50K 61

Figura 25. Eletromicrografia da JVU, grupo adulto, 100K 61

Figura 26. Eletromicrografia da JVU, grupo adulto, 100K 62

Figura 27. Eletromicrografia da JVU, grupo adulto, 100K 62

Figura 28. Eletromicrografia da JVU, grupo velho, 40K 63

Figura 29. Eletromicrografia da JVU, grupo velho, 40K 63

Figura 30. Eletromicrografia da JVU, grupo velho, 50K 64

Figura 31. Eletromicrografia da JVU, grupo velho, 35K 64

Figura 32. Eletromicrografia da JVU, grupo velho, $75 \mathrm{~K}$ 65

Figura 33. Eletromicrografia da JVU, grupo velho, 100K 65 
Figura 34. Gráfico da Densidade Linear das fibras do sistema elástico, colorações, em relação à idade 68

Figura 35. Gráfico da LD das fibras do sistema elástico, tipificação das fibras elásticas, em

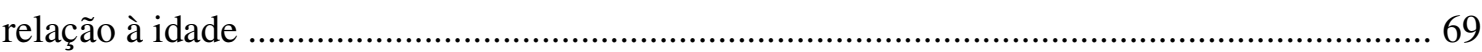

Figura 36. Curva de regressão quadrática das fibras do sistema elástico, colorações, em relação à idade 70

Figura 37. Curva de regressão quadrática das fibras do sistema elástico, tipificação das fibras elásticas, em relação à idade 70 


\section{LISTA DE ABREVIATURAS}

A - área total do sistema-teste

At - área total examinada em campos

$\mathrm{C}$ ou $\mathrm{CR}$ - número de intersecções das fibras elásticas com as retas paralelas do sistema teste

D $(\mu \mathrm{m})$ - distância entre as retas do sistema-teste

EL - elaunínicas

EM - elásticas maduras

F - fator de correção para amostras não homogêneas

FC - fibras colágenas

HD - número total de pontos do sistema teste

$\mathrm{HF}$ - número total de pontos do sistema teste sem estrutura tecidual

JVU - junção vésico-uretral

$\mathrm{L}(\mu \mathrm{m})$ - comprimento de fibras por unidade de volume

LD - densidade linear

$\mathrm{M}-$ molar

OX - oxitalânicas

PU - número total de pontos do sistema teste 


\section{SUMÁRIO}

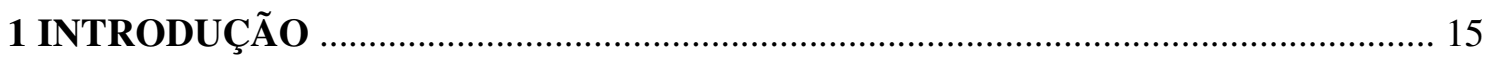

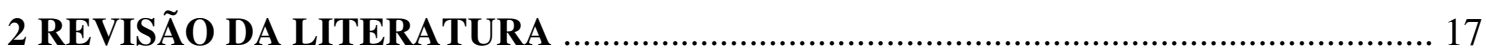

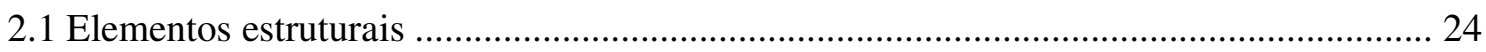

2.2 Sistema elástico - fibras elásticas maduras, elaunínicas

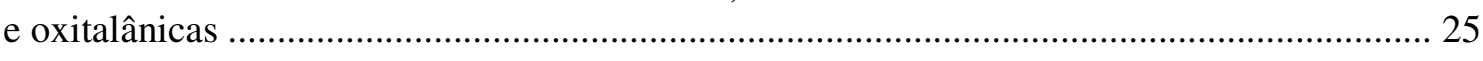

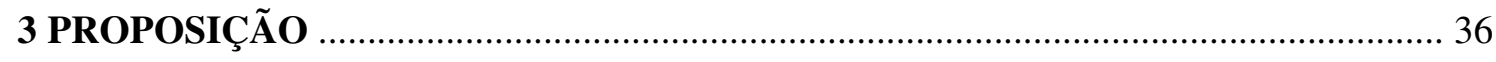

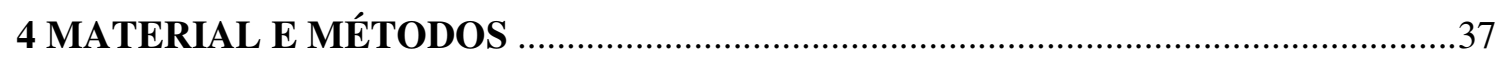

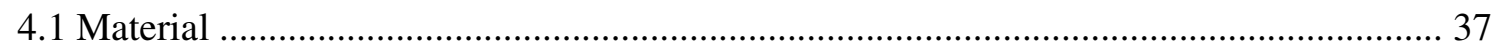

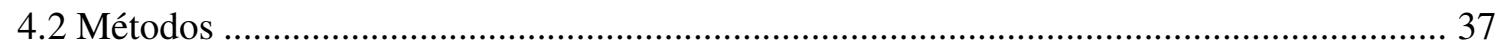

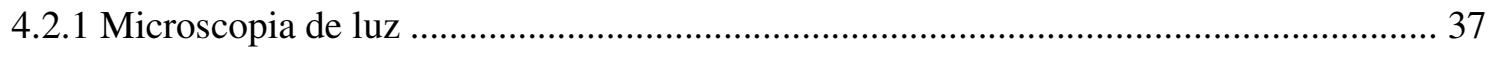

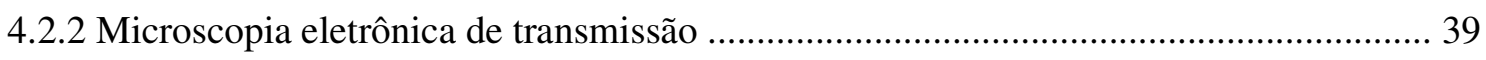

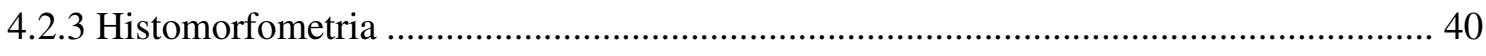

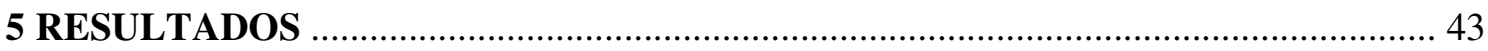

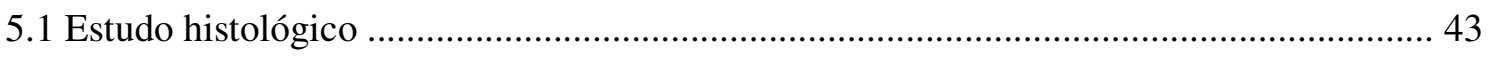

5.2 Estudo microscopia eletrônica de transmissão ............................................................. 43

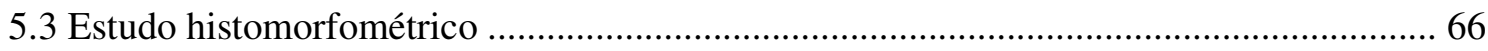

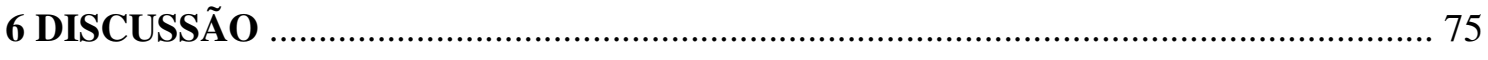

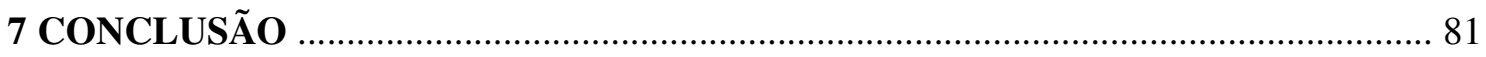

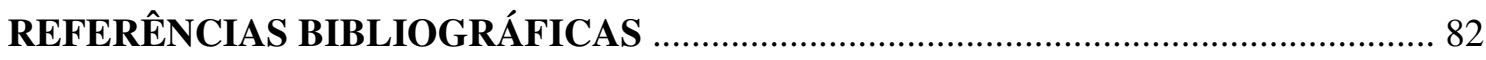

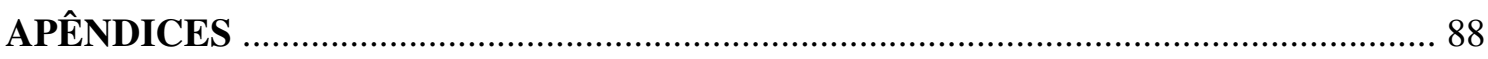




\section{INTRODUÇÀO}

A junção vésico-uretral (JVU) é um dos componentes do trígono da bexiga, que juntamente com o colo vesical possui relevante importância para fixação e posicionamento da bexiga urinária (DORSCHENER, 2002), pois as fibras musculares constituintes do trígono são compactas e possuem abundante componente fibroso dando suporte eficiente para sua ação funcional.

A JVU também controla o armazenamento e esvaziamento da urina (MENEZES, 2000), sendo que no momento que este ocorre, a camada muscular superficial da musculatura do trígono, já está em contração, para evitar o refluxo vésico-ureteral, agindo com as estruturas do colo para colaborar com seu afunilamento e abertura, facilitados pelo relaxamento dos diafragmas pélvico e urogenital (TANAGHO et al., 1968).

A continência urinária é mantida por meio de uma complexa relação que envolve estruturas do trato urinário inferior, sendo este dividido em bexiga e uretra associado ao colo vesical, De Lancey et al., 2004.

A bexiga urinária é um órgão muscular oco, constituído por uma camada serosa circundada por camadas musculares denominadas de músculo detrusor (DE LANCEY, 2004; GOSLING, 1979; HAURI, 1978; WEY, 2004) e uma camada mucosa de epitélio de transição. Segundo Levy et al. (1990), existem quatro camadas distintas na bexiga, como se segue, o urotélio, a lâmina própria, a submucosa e o músculo detrusor, a submucosa é dividida em uma camada superficial e uma profunda através de um feixe neurovascular. O músculo detrusor é formado com uma região central de fibras arranjadas circularmente entre camadas de feixes de fibras longitudinais, este acúmulo de tecido muscular permite a bexiga se expandir em todas as direções, conforme descrito por Hauri (1978) e Gosling (1979). 
As fibras do sistema elástico estão presentes em várias estruturas do nosso organismo (JOHNSON et al., 1982) e o arranjo destas fibras contribui para a arquitetura tecidual, pois promove uma ação passiva no tecido quando este é exposto à tensão mecânica, para que o mesmo volte à sua disposição original; juntamente com as fibras colágenas, as fibras elásticas são estruturas importantes para a manutenção da resistência normal tecidual (BARROS et al., 2002), assim o tecido fibroelástico, presente na junção vésico-uretral é considerado o principal fator na geração da pressão de fechamento da uretra e da JVU em repouso (AWAD et al., 1976). As fibras elásticas dispostas circularmente na JVU podem ser parcialmente responsáveis pela elasticidade e plasticidade da região, permitindo a sua expansão e recuo rápido, com o fluxo da urina. Sendo assim, as fibras elásticas presentes nesta região atuam juntamente com a musculatura lisa e controle nervoso, formando um conjunto importante para a manutenção da continência urinária (WOODBURNE,1961).

O sistema elástico foi estudado através da microscopia de luz (COTTA-PEREIRA et al., 1977; GAWLIK, 1965), e microscopia eletrônica de transmissão associada à técnica do ácido tânico (COTTA-PEREIRA et al., 1976; KAJIKAWA et al., 1975; SACCHETTI, 1996), onde foi possível evidenciar e tipificar os três tipos de fibras elásticas que compõem esse sistema.

Porém existem alguns pontos não esclarecidos nesta região, quanto ao sistema elástico e sua participação nos estados de continência/incontinência urinária, assim o presente trabalho tem por objetivo o estudo do sistema elástico da JVU, com qualificação e tipificação através de microscopia de luz e transmissão e quantificação através de estudo histomorfométrico em relação ao avanço da idade. 


\section{REVISÃO DA LITERATURA}

A junção vésico-uretral (JVU) é a região de transição da bexiga com a uretra; localizada no colo da bexiga, é marcada pelo óstio interno da uretra. O colo vesical, a parte mais inferior e fixa da bexiga, apresenta uma musculatura com comportamento diferenciado, pois as camadas musculares nessa região, são dispostas circularmente ao óstio interno da uretra, constituindo o esfíncter interno da uretra (WOODBURNE, 1961). Segundo Vernet (1968) o termo colo vesical é regional e funcional, não se referindo apenas a uma simples entidade anatômica, assim esta área é uma área da base da bexiga onde o lúmen uretral passa através de uma fina camada de músculo detrusor da base da bexiga circundado o trígono e o óstio interno da uretra. Gray et al. (1973), descrevem que no homem, o colo está assentado na base da próstata, com sua parede estando em continuidade direta com a glândula; na mulher o colo se relaciona com a fáscia pélvica que circunda a parte superior da uretra. Além disso, Netter et al. (1976) consideram que no homem, óstio interno da uretra encontra-se cerca de 1 a $2 \mathrm{~cm}$ posteriormente à margem inferior da sínfise púbica. Na mulher, a posição desse óstio é ligeiramente inferior, ao passo que no recém-nascido, pode situar-se ao nível da margem superior da sínfise púbica.

A JVU faz parte do trígono da bexiga, um triângulo aproximadamente eqüilátero definido, pelos dois óstios dos ureteres e pelo óstio interno da uretra (DORSCHENER et al., 2002; GARDNER et al., 1971). Dorschener at al. (2002) definiram o trígono vesical como uma região topográfica que auxilia na orientação da bexiga urinária.

Para Netter et al. (1976) o revestimento mucoso na região do trígono é anatômica e embriologicamente distinto da mucosa do resto da bexiga. Anatomicamente, a mucosa do trígono encontra-se fortemente aderida à camada muscular, de modo a parecer moldada por igual sobre a musculatura subjacente. Devido a este fator, mesmo quando a bexiga encontra- 
se vazia, a mucosa desta área não é pregueada como no restante do órgão, permanecendo lisa e plana. Com base na sua embriologia, o trígono representa uma área mesodérmica diferentemente das outras partes da bexiga e também a mucosa, que são de origem endodérmica.

Sob o aspecto histológico, a camada muscular da base da bexiga, na região do trígono, é facilmente distinguida da musculatura das demais partes do órgão, já que o músculo detrusor tem uma arquitetura muscular fascicular, quando comparado com os aspectos uniformes do trígono, sendo este estreitado logo abaixo do óstio da uretra e em seguida alarga-se e se espessa em direção da musculatura vesical e prostática (BASKIN et al., 2004).

O sistema muscular do trígono é formado por duas camadas, uma superficial e outra profunda. A mais superficial é originada da musculatura do ureter justa-vesical, sendo que, no homem estas fibras procedem ao longo da parede posterior da uretra prostática produzindo uma elevação mediana chamada de crista posterior mediana ou crista uretral, contínua para baixo em direção a musculatura do ducto ejaculatório. Apesar de não haver interconexão muscular entre o trígono superficial e o colo vesical, a passagem de fibras sobre o colo vesical influência em sua função, Tanagho et al. (1968). Além das fibras da camada média do detrusor que a bainha de Waldayer recebe no momento em que estas fibras passam através do hiato ureteral, a camada profunda do trígono, em direta continuação com esta bainha, faz conexões profundas com o músculo detrusor ao redor do colo vesical, Tanagho et al. (1963). Esta porção mais profunda do trígono adere firmemente à musculatura vesical e é formada pelo músculo esfíncter trigonal ou pelo músculo esfíncter vesical que circunda elipticamente o óstio interno da uretra e não se estende para a uretra. A musculatura que forma o trígono é considerada um sistema anelar, sendo que a circunferência dorsal é no trígono, onde está a bexiga e as bordas encontram-se sobre a musculatura interuretral, a circunferência ventral é em frente à uretra abaixo da camada média circular do músculo detrusor vesical, e 
caudalmente a musculatura do trígono se encerra sobre o colículo seminal dentro da próstata, no homem. Devido a este posicionamento, este sistema muscular anelar não circunda o óstio interno da uretra concentricamente, mas se molda como uma elipse (DIETRICH et al., 1994). As duas camadas do trígono são totalmente musculares e sua espessura é quase igual à espessura da parede da bexiga. As fibras musculares do trígono são mais compactas do que aquelas do detrusor, sendo ricas em seu elemento muscular tão quanto em seu componente fibroso, o qual dá ao trígono força, firmeza e fixação (TANAGHO et al., 1968). Funcionalmente, cada camada do trígono tem papel específico na função do colo vesical, como no ciclo de esvaziamento da urina, a camada superficial do trígono contrai alguns segundos antes da contração detrusora (TANAGHO et al., 1965), onde esta possui dois propósitos: 1.) ocluir o ureter intravesical para evitar refluxo durante o início da fase que marca o aumento da pressão intravesical causada pela ativa contração do detrusor; 2.) para deprimir o lábio posterior do colo vesical ajudando outros mecanismos para iniciar o afunilamento da saída da bexiga, simultaneamente o esfíncter estriado externo relaxa e o diafragma urogenital vai para baixo, resultando no afunilamento do colo vesical e uma progressiva queda na pressão de fechamento uretral. A contração do trígono superficial sozinho, sem o relaxamento do diafragma urogenital, é insuficiente para abrir o colo vesical ou conduzí-lo para o afunilamento. A camada profunda do trígono faz a parte do suporte do colo vesical quando a bexiga esta em plenitude, e a contração de suas fibras disparam a contração muscular de todo o músculo detrusor que inicia no colo vesical e se propaga para o resto da bexiga aumentando o afunilamento da saída do órgão direcionando o escoamento da urina (TANAGHO et al., 1968).

As camadas musculares, circular média e longitudinal externa, do músculo detrusor se encerram no óstio interno da uretra formando um anel ao redor do mesmo (DORSCHENER al., 1994). Segundo Gray (1946) e Netter et al. (1976), próximo à parte inferior da bexiga, em 
torno do óstio interno da uretra, as fibras musculares da camada circular média desta túnica agrupam-se em uma camada espessa e condensada formando o músculo esfíncter interno. Nele se distinguem um componente de abertura e outro de fechamento, um conjunto de fascículos de fibras musculares lisas unidas por tecido elástico, formando assim um sistema mioelástico. Este por sua vez, tem importante função na fisiologia normal e patológica da micção, sendo considerado por Tanagho et al. (1968), um mecanismo para a manutenção da continência urinária.

A função de contração da bexiga depende de um adequado suprimento de oxigênio e nutrientes oriundos do sangue, sendo sua arquitetura microvascular caracterizada por dois principais plexos vasculares (adventício-seroso e mucoso) e duas distintas cadeias capilares (muscular e subepitelial) podem ser distinguidos nas sucessivas camadas da parede da bexiga. Os vasos da bexiga, exceto os capilares, caracterizam-se por sua tortuosidade, oscilando em ondulações e espirais. Abundantes ramos das principais artérias e veias extras vesicais formadas no plexo adventícia-seroso apresentam um curso altamente tortuoso e com numerosas anastomoses, este plexo supre e drena a rede de capilares da muscular e também envia vasos longos e perpendiculares de 100-300 $\mu \mathrm{m}$ de diâmetro, perfurando esta e comunicando-se diretamente com o plexo mucoso. Este plexo, por sua vez, consiste de alguns capilares, finas artérias $(50-100 \mu \mathrm{m})$ e numerosas veias espessas $(80-250 \mu \mathrm{m})$, apresentando um aspecto tortuoso e freqüentes entrelaçamentos, formando uma distinta camada vascular paralela à superfície interna da bexiga e seguindo o perfil da prega mucosa. A muscular contém muitos ramos arteriais e venosos tortuosos, em sua maioria derivada do plexo adventícia-seroso e capilares irregulares de finos calibres $(8-12 \mu \mathrm{m})$. Em contraste, os capilares sub-epiteliais são extremamente densos, em forma de uma malha plana com diâmetros de 10-20 $\mu \mathrm{m}$, de contorno desigual com constrições e dilatações. Somente na área do trígono e ao redor do óstio interno da uretra, na JVU, eles são arranjados em uma cadeia 
frouxa de malhas alongadas e, especialmente na região posterior, possuem um diâmetro mais uniforme. Essa arquitetura vascular permite que os vasos sanguíneos se adaptem às mudanças que o órgão sofre durante seus ciclos de enchimento e esvaziamento, sem comprometer a vascularização sanguínea local (MIODONSKI et al., 1999).

O trato urinário inferior tem como função o armazenamento e a liberação periódica da urina, sendo que isto depende da atividade de duas unidades funcionais: 1.) um reservatório (bexiga urinária); 2.) uma saída, consistindo do colo vesical, uretra, músculos estriados uretrais (GROAT et al., 1997), musculatura do assoalho pélvico, ligamentos e controle neural (CANNON et al., 2004).

Como descrito por Menezes (2000) a JVU, têm por sua vez, função de controlar o armazenamento e o esvaziamento da urina e, em adultos normais o controle urinário pode ser subdividido em fases de enchimento da bexiga e armazenamento da urina, por isso para ocorrer um funcionamento normal desse processo, o trato urinário inferior requer capacidade para armazenar urina em uma baixa pressão, tão quanto capacidade para esvaziar completamente a bexiga voluntariamente com pouca resistência para a passagem da urina. Sob condições normais, aproximadamente $300 \mathrm{ml}$ de urina pode ser acumulada antes de um aumento significativo da pressão vesical que leva à urgência consciente da necessidade de ocorrer à micção e para ocorrer a continência urinária é necessário que a pressão intra-vesical permaneça abaixo da pressão intra-uretral, sabendo-se que aquela pressão depende do tônus do músculo detrusor, do volume da bexiga e da pressão intra-abdominal, já a pressão intrauretral está sob dependência da pressão intra-abdominal, tônus da musculatura lisa da uretra e do colo vesical, tônus da musculatura estriada uretral e da camada mucosa uretral, Williams et al. (1982).

O controle neural das funções do trato urinário inferior são governadas por um processo complexo que envolve o encéfalo, a medula espinal, a musculatura lisa da bexiga e a 
parte posterior da uretra, além da musculatura estriada do esfíncter externo (Menezes, 2000). Para Groat (1997) a dependência do controle nervoso central, distingue o trato urinário inferior de muitas outras estruturas viscerais (trato gastrintestinal e sistema cardiovascular), pois mantêm certo nível igual de função depois da eliminação de estímulos neurais centrais. O controle da função vésico-esfincteriana é adquirido a partir dos 2 anos de idade, no lactente a micção ocorre espontaneamente pelo reflexo medular quando a distensão vesical provoca um estímulo via aferente do arco reflexo sacral resultando em micção automática. Entre 1 e 2 anos, a aquisição da continência depende do aumento gradativo da capacidade vesical e maturação dos lobos frontal e parietal. O controle total urinário ocorre, em maioria, aos 4 anos e meio de idade, a partir daí, tanto a continência urinária como a micção, ambas são governadas por uma integração complexa entre sistema somático medular e parassimpático, por intermédio do nervo pudendo (S2-S4), do simpático pelo plexo nervoso hipogástrico (T11-L2) e pelos centros nervosos supramedulares (BADAWI, et al., 1974; BRADLEY et al., 1978; GROAT, 1997; TANAGHO, et al., 1969). O centro parassimpático sacral promove a principal excitação na bexiga, neurônios pré-ganglionares colinérgicos localizados na região intermédia lateral da coluna espinal sacral enviam axônios, via nervos pélvicos para células ganglionares no plexo pélvico e nas paredes da bexiga, onde receptores parassimpáticos estão localizados em toda a musculatura vesical e uretra proximal e os simpáticos no colo vesical, uretra proximal e corpo vesical. O músculo detrusor é inervado primariamente pelo sistema nervoso parassimpático e a base da bexiga, colo vesical e esfíncter muscular liso pelo sistema nervoso simpático (alfa-adrenérgico) como evidenciado por Resnick et al. (1985). O circuito reflexo que controla a micção consiste de quatro componentes básicos: neurônios espinais eferentes, interneurônios espinais, neurônios primários aferentes e neurônios cerebrais, que modulam as vias reflexas espinais (GROAT, 1997). Segundo Feneley et al. (1982) durante o enchimento da bexiga as contrações do detrusor são inibidas e durante o esvaziamento a 
contração detrusora é associada com o relaxamento do esfincter uretral até ocorrer o completo esvaziamento da bexiga. O relaxamento do detrusor é realizado pela inibição do tônus parassimpático através do sistema nervoso central, o fechamento dos esfincteres é mediado pelo aumento reflexo alfa-adrenérgico e atividade somática, por outro lado, a contração detrusora é mediada pelo sistema nervoso parassimpático, e o relaxamento dos esfincteres requerem a inibição de impulsos nervosos somáticos e simpáticos para a saída da urina. A mútua relação entre o detrusor e o escoamento da urina é coordenado pelo centro da micção na ponte, e os centros do sistema nervoso central, no córtex e diencéfalo, também permitem um reflexo contrátil de detrusor em resposta a distensão da bexiga.

Assim como ocorrem mudanças estruturais em todo o organismo com o envelhecimento, o mesmo também acontece com as estruturas do trato urinário inferior, Chun et al. (1988) observaram que em ratos velhos, o peso da bexiga urinária aumentou $20 \%$ enquanto sua complacência diminuiu, Susset (1983) através de evidências bioquímicas sugeriu mudanças significativas no tecido conjuntivo de bexigas urinárias de indivíduos idosos, onde o conteúdo colágeno aumentou em 30\%, sendo que algumas possibilidades colocam o detrusor ou a submucosa como locais onde ocorrem estes aumentos. Em bexigas urinárias de indivíduos idosos, Levy et al. (1990) descreveram a presença de aglomerações eletrodensas e fibras elásticas, ambas associadas com células musculares, assim como a presença de células musculares lisas fragmentadas.

Em alguns casos as funções do trato urinário inferior podem estar alteradas para estados patológicos, como em situações de aumento da pressão interna da bexiga acima da pressão que mantém a uretra ocluida, resultando em um processo patológico denominado de incontinência urinária, ou seja, uma perda involuntária de urina em que geralmente há uma deficiência ou ausência de atividade detrusora e/ ou eventos que a pressão uretral é sobre ativa ou incompetente, sendo assim estas alterações sempre resultarão em pressões intra-vesical e 
uretral alteradas (FENELEY et al., 1982). Alguns autores (BROCKLEHURST et al., 1968; WILLINGTON et al., 1969), consideram que a incontinência urinária não é uma conseqüência inevitável do aumento da idade, mas sim em alguns casos, conseqüência de estados patológicos, sem descartar que o envelhecimento pode afetar o trato urinário de várias maneiras. Resnick et al. (1985) descreve que no indivíduo idoso a capacidade da bexiga, a habilidade para diferir o esvaziamento, a complacência da bexiga e uretra, pressão de fechamento uretral, e a taxa de fluxo urinário são todos provavelmente reduzidos, por outro lado, o volume urinário residual pós-esvaziamento da bexiga e a prevalência para desinibir a contração do detrusor são aumentados, onde cada uma dessas mudanças predispõe para a incontinência, mas nenhuma sozinha irá desenvolvê-la ou antecipá-la. Para Jørgensen et al. (1993) o aparecimento destas condições está associado ao aumento da probabilidade de que uma pessoa idosa é submetida a patologias, problemas psicológicos e uso de fármacos, fazendo com que ocorra uma maior incidência de incontinência urinária no idoso, ao mesmo tempo, podem ocorrer alterações variáveis em relação à taxa de fluxo urinário com o aumento da idade, mesmo em indivíduos normais, Jørgensen et al. (1993). Tortora (2007) descreve que lesões à inervação que controla a bexiga urinária, perda da flexibilidade da bexiga com o envelhecimento, doença ou irritação da bexiga urinária e/ ou uretra, danos ao esfíncter externo da uretra e determinados medicamentos, podem levar à condição de incontinência urinária.

\subsection{Elementos Estruturais}

Dentre os elementos estruturais da junção vésico-uretral estão as fibras musculares lisas, fibras colágenas e fibras elásticas. Dass et al. (1999) em trabalho com imagens computadorizadas quantificaram as fibras elásticas em secções realizadas na base da bexiga, 
JVU e uretra de cobaias (machos e fêmeas) observando que há um aumento significante de fibras elásticas circularmente dispostas na JVU, em relação às outras duas regiões examinadas. Os autores relataram que esta disposição particular das fibras elásticas pode ser parcialmente responsável pela elasticidade e plasticidade da JVU, permitindo a sua expansão e recuo rápido com o fluxo da urina. Mencionaram ainda que as fibras elásticas presentes na JVU possam ser parcialmente responsáveis pela força oclusiva e passiva nesta região.

Para alguns pesquisadores, o tecido fibroelástico assumiu o papel de ser o principal fator na geração da pressão de fechamento da uretra e da JVU em repouso, onde Awad e Dawnie (1976) depois de eliminar os fatores neurais responsáveis pela pressão intrauretral observaram uma pressão residual. Esta descoberta foi confirmada por Bump et al. (1988) demonstrando que os elementos fibroelásticos apresentaram efeitos na pressão uretral com perfil equivalente ao mostrado pela camada vascular.

Gosling et al. (1983) sugeriram que as inúmeras fibras elásticas observadas por Lápides, 1958, nas junções vésico-uretrais de uretras humanas femininas, eram importantes no fornecimento de oclusões passivas para a luz da uretra. A presença de fibras elásticas na JVU e a relevância destas para manter a continência foram também descritas e comentadas por Woodburne (1961).

2.2 Sistema elástico - fibras elásticas maduras, elaunínicas e oxitalânicas

O sistema elástico é o principal componente da matriz extracelular que dá ao tecido conjuntivo resiliência, permitindo grande deformação e recuo passivo sem perda de energia, sendo estas propriedades importantes para a função de algumas estruturas como as artérias, as quais sofrem repetidas ações de extensão e recuo, pulmões, pele e outros tecidos conjuntivos dinâmicos, assim esta função elástica é complementar às fibrilas colágenas que concedem 
resistência à tração aos tecidos, Kielty et al. (2002). As fibras do sistema elástico compreendem elementos amorfos e fibrosos (GREENLEE et al., 1966) com aproximadamente 0,2 a $1,5 \mu \mathrm{m}$, podendo se ramificar e anastomosar (RICHARDS, $1902^{1}$ APUD USHIKI, 2002); (ROSS, 1973) para formar uma firme cadeia nos tecidos conjuntivos frouxos, e em tecidos elásticos densos as fibras elásticas se fundem para formar lâminas achatadas (RICHARDS et al., 1902 APUD USHIKI, 2002). Ross (1973) descreveu que as fibras elásticas são estruturas extensíveis podendo ser estiradas $1 / 3$ e meio do seu comprimento e quando relaxam retornam ao seu comprimento normal, sendo que estas fibras quando contraídas em sua estrutura se retorcem e se encurtam concedendo ao tecido onde está presente uma flexibilidade dinâmica.

Estudos sob microscopia de luz e eletrônica permitem distinguir no sistema elástico, três tipos de fibras - oxitalânicas, elaunínicas e elásticas maduras ou elásticas, com propriedades ultraestruturais diferentes (AVERY et al., 1980; CARVALHO et al., 1996; COTTA-PEREIRA et al., 1977; FULLMER et al., 1960; GAWLIK, 1965; GREENLEE et al., 1966; SACHETTI, 1996; SAKAY et al., 1986; SAWADA et al., 2006) sendo que esses três diferentes tipos de fibras pertencem a uma série contínua, em ordem cronológica, que estão ligadas ao fenômeno da elastogênese (BRADAMANTE et al., 1977; SAGE et al., 1979). Albert (1972) sugere que a forma prematura ou precursora da elastina é uma estrutura fibrilar, e mais tarde no desenvolvimento, a morfologia convencional do tecido elástico começa a se manifestar na forma de material amorfo embebido em uma massa fibrilar e como maturação progressiva do tecido elástico, a quantia de material amorfo aumenta e de material fibrilar diminui, sendo então esta maturação formada, quase que exclusivamente, por componente amorfo. Do mesmo modo, Farrenbach et al. (1966); Gawlik (1965) em estudo sobre a ultraestrutura do desenvolvimento das fibras elásticas, afirmam que o primeiro componente

\footnotetext{
${ }^{1}$ RICHARDS, A. N.; GIES, W. J. Chemical studies of elastin, mucoid, and other proteids in elastic tissue, with some notes on ligament extractives. The American Journal of Physiology, v. 7, p. 93-134, 1902.
} 
formado durante a elastogênese é a fibra oxitalânica, formada por microfibrilas sintetizadas e secretadas por fibroblastos no meio extra celular, onde essas microfibrilas estão dispostas em feixes paralelos indicando a direção e a forma da futura fibra elástica. Em seguida, pequena quantidade de substância amorfa, elastina, se adere a essas microfibrilas, formando o segundo componente do sistema elástico: a fibra elaunínica, com o acúmulo de maior quantidade de elastina entre as microfiblilas, a fibra se torna espessa e aparece o terceiro componente do sistema elástico: as fibras elásticas maduras, em que a presença dos três componentes do sistema elástico nos tecidos indica uma elastogênese completa. Em certos tecidos, de indivíduos adultos, feixes de microfibrilas desprovidos de material amorfo (fibras oxitalânicas) e feixes de microfibrilas entremeados com material amorfo (fibras elaunínicas) estão presentes, e mesmo no estado de completa maturação, essas fibras não atingem o desenvolvimento completo da fibra elástica. Estas observações mostram que nem todos os feixes de microfibrilas são destinados a servirem de molde para a deposição de elastina e conversão em fibras elásticas maduras. Conclui-se então que um feixe de microfibrilas pode ser um progenitor para a maturação completa (em tecidos fetais) ou uma entidade independente do tecido conjuntivo (fibra oxitalânica), como mencionado por Cotta-Pereira et al. (1976). Gawlik (1965) demonstra através de estudo em aortas fetais e de recém-nascidos humanos, que as fibras que surgem inicialmente são as oxitalânicas e após, estas adquirem características de elaunínicas e finalmente formam-se lâminas de fibras elásticas maduras assim, estas fibras representam etapas evolutivas da elastogênese. Cotta-Pereira et al. (1975) em estudo do componente elástico em pele humana, demonstrou que durante a elastogênese o componente fibrotubular aparece antes do material amorfo, sendo possível relacionar os fibrotúbulos observados na derme superficial com fibras elásticas jovens destituídas de elastina. Baseados em observações ultra-estruturais, os autores concluem, que as fibras superficiais da derme (oxitalânicas) possuem apenas constituição fibrotubular e as fibras 
elaunínicas têm características intermediárias entre as oxitalânicas e as elásticas maduras. Fullmer et al. (1960) propõem que o termo fibra oxitalânica seja usado para designar as fibras elásticas presentes em áreas, que na fase adulta não possuem as características da fibra elástica madura, e o termo fibra pré-elástica para aquelas que iriam adquirir características de fibra elástica madura.

As fibras oxitalânicas são constituídas por microfibras de 10 a 16 nm de espessura, agrupados paralelamente, com aproximadamente $150 \mathrm{~A}^{\circ}$ de diâmetro, sendo que, o componente amorfo e fibrotubular destas fibras são diferentes dos presentes nas fibras elásticas maduras (AVERY et al., 1980; CARVALHO et al., 1996). Sakay et al. (1986); Sawada et al. (2006) também descreveram que as fibras oxitalânicas são constituídas por feixes amplos de microfibrilas, os quais não estão associados a elastina, sendo constituídas por várias glicoproteínas, incluindo a fibrilina, e componente amilóide P. Estas fibras foram reconhecidas e individualizadas pela primeira vez, sob microscopia de luz, por Fullmer e Lillie (1958). Ao estudarem tecidos humanos, do rato, do camundongo, da cobaia e do macaco afirmaram que as fibras oxitalânicas são encontradas somente nas membranas periodontais, tendões, ligamentos, adventícia de vasos sanguíneos, bainhas de tecido conjuntivo dos anexos da pele, epineuro e perineuro, sugerindo uma distribuição restrita ao local onde o tecido conjuntivo é submetido à tensão. Goldfischer, et al. (1983) observaram microfibrilas (fibras oxitalânicas) em aortas, arranjadas em feixes retos ou curvos e anastomosados, servindo para limitar a membrana plasmática de algumas células murais. Alguns trabalhos inferem possíveis funções das fibras oxitalânicas como ancoragem, manutenção da elasticidade, guia para migração celular, estabilização de vasos sanguíneos e regularização do fluxo sanguíneo (BEERTSEN et al., 1974; EVERTS et al., 1998; FULLMER et al., 1974; SAKAI et al., 1986; SIMS et al., 1973, 1975; TAKAGI et al., 1989). Esses autores também citam que estas fibras podem ser evidenciadas pelos métodos de 
coloração da resorcina-fucsina e da aldeído-fucsina após prévia oxidação com oxona, e que as mesmas por apresentarem resistência à hidrólise ácida são denominadas de oxitalânicas e como evidenciado por Sculean et al. (1997) sem prévia oxidação, as fibras oxitalânicas não podem ser demonstradas através de nenhum método de coloração. Junqueira e Carneiro (1999) citam que sob o aspecto ultra-estrutural, as fibras oxitalânicas são constituídas exclusivamente de microfibrilas sem elastina.

As fibras elaunínicas foram, inicialmente, evidenciadas à microscopia de luz por Gawlik (1965) através da coloração resorcina-fucsina e aldeído-fucsina sem prévia oxidação. Cotta-Pereira et al. (1977) verificaram sob microscopia eletrônica de transmissão, que essas fibras apresentam-se formadas por feixes de microfibrilas dispersos em material amorfo constituído por elastina. Descrevem também, que as fibras elaunínicas são mais espessas que as oxitalânicas, com disposição tortuosa ou em espiral e seu diâmetro e comprimento variam com as características do tecido ao qual pertencem, refletindo sua adaptação funcional.

Segundo Junqueira e Carneiro (1999) as fibras elásticas maduras são constituídas por uma grande quantidade de elastina e uma proporção muito menor de microfibrilas, sendo a elastina uma glicoproteína estrutural. Greenlee et al. (1966) descreve que estas fibras contêm dois componentes morfológicos, onde se observa uma região central ampla "núcleo" circundada por uma fina camada de fibrilas, cada qual com $100 \mathrm{~A}^{\circ}$ de diâmetro aproximadamente. As fibras elásticas maduras podem ser evidenciadas à microscopia óptica após coloração com resorcina-fucsina e aldeído-fucsina e também pelo método da hematoxilina férrica que é exclusivo para estas fibras (VERHOEFF, 1908).

O sistema elástico, em trabalhos prévios, foi evidenciado através da microscopia de transmissão usando-se a técnica do ácido tânico. Kajikawa et al. (1975) utilizando esse ácido como corante dos preparos histológicos, relataram que o mesmo marca o componente amorfo das fibras elásticas intensamente, Souza et al. (1996) adicionaram ácido tânico $(0,1 \%)$ ao 
fixador (glutaraldeído 3\%), obtendo uma coloração de vários componentes do tecido conjuntivo de corações humanos, incluindo as fibras elásticas. De acordo com Cotta-Pereira et al. (1976) uma visualização uniforme e fiel das fibras elásticas é alcançada se o fixador (glutaraldeído) conter ácido tânico, onde haverá um aumento da densidade eletrônica da elastina e microfibrilas, sendo possível distinguir fibras elásticas maduras e elaunínicas, onde estas se apresentam formadas por porções de material amorfo circundado por feixes de microtúbulos e aquelas se apresentam espessadas e com componente amorfo mais compacto e abundante. Sacchetti (1996) em estudo do sistema elástico da cápsula esplênica, utilizou o método do ácido tânico $(0,25 \%)$ diluído em glutaraldeído (3\%) em tampão fosfato $0,1 \mathrm{M}$ (Ph 7,4) como fixador para microscopia de trasmissão, e descreveu que as fibras elásticas maduras apresentaram seu material amorfo fortemente eletrodenso circundado por um sistema de microfibrilas, as fibras elaunínicas com escassa substância amorfa dispersas em meio ao componente microfibrilar e por sua vez, fibras oxitalânicas representadas por pequenos feixes de microtúbulos.

Carvalho et al. (1996) descrevem que segundo Mander et al. (1985) e Uitto (1977), os vários tipos de fibras do sistema elástico também podem ser diferenciados por meio de sua composição química, e esta é distinta entre os tipos de fibras do sistema elástico, o que explica as diferentes reações aos métodos de coloração. Segundo Böck et al. (1984) os parâmetros usados para diferenciar fibras elaunínicas de elásticas maduras são baseados no diâmetro da fibra e variação nas distribuições de microfibrilas e elastina.

A arquitetura das fibras elásticas é altamente específica ao tecido onde está presente, refletindo funções específicas em diferentes tecidos como, por exemplo, devido ao seu arranjo nas paredes dos vasos sanguíneos, estas fibras concedem elasticidade e resiliência ao local; nos pulmões o sistema elástico está presente nas paredes dos vasos sanguíneos e ao longo de toda a árvore respiratória, auxiliando na expansão e recuo alveolar durante a respiração, já na 
pele formam uma cadeia contínua fornecendo elasticidade para todas as suas porções de derme para epiderme (KIELTY et al., 2002). As propriedades elásticas do sistema elástico estão relacionadas ao seu maior ou menor conteúdo de elastina (COTTA-PEREIRA et al., 1977), onde a diferença na distribuição das fibras elásticas maduras, elaunínicas e oxitalânicas nos tecidos, sugerem que há diferença na qualidade da elasticidade (ROSS et al., 1969), em que mesmo em regiões teciduais próximas a distribuição das fibras elásticas pode não ser homogênea, como observado por Chopard et al. 2000 nos três segmentos da artéria anterior cerebral no homem. Dependendo do tecido onde estão presentes, as fibrilas de elastina podem se apresentar individualmente ou em feixes, se estiverem em feixes podem formar fibras ou lâminas de elastina (USHIKI et al., 1991), esta organização da elastina em fibras ou lâminas aparentemente influenciam na resiliência tecidual quanto as suas propriedades mecânicas. As fibrilas de elastina e as microfibrilas presentes nas fibras oxitalânicas, elaunínicas e elásticas maduras do sistema elástico, formam em conjunto um sistema microfibrila-elastina, o qual representa o papel de um distribuidor uniforme das forças de tensão no tecido e mantenedor de resiliência se adaptando conforme a exigência tecidual, sendo que, neste sistema as microfibrilas estão usualmente presentes ao redor das fibras de elastina, estando arranjadas coincidentemente a elas, assim, quando as fibras de elastina são estiradas, as microfibrilas mudam de direção junto com a elastina em resposta a este estiramento. As microfibrilas podem também partir das fibras de elastina para formar feixes ou emaranhados nos tecidos onde estão presentes, Ushiki (2002). As fibras elásticas cedem facilmente mesmo a trações mínimas, porém retomam a sua forma inicial tão logo cessem as forças deformantes, ou seja, elas conferem a propriedade de recuo elástico para locais cuja habilidade para funcionar efetivamente exige extensibilidade reversível, sendo que a elastina constitui o primeiro componente de suporte de tensão e é responsável pelo restabelecimento do arranjo da forma tecidual após a deformação, como descrito por Buckwalter et al. (1976). As fibras oxitalânicas 
não se alongam sobre mecanismos de estresse/tensão (ROSS, 1973), e por isso essas fibras estão presentes onde o tecido é submetido ao stress como no periodonto (FULLMER et al., 1978), junção derme-epiderme (COTTA-PEREIRA et al., 1976), em que estas fibras previnem um superestiramento do tecido, onde as microfibrilas possuem função de ancoragem (GIBSON et al., 1987). As fibras elaunínicas, que contém feixes de microfibrilas e pouco material amorfo, possuem propriedades intermediárias entre as fibras elásticas maduras e oxitalânicas (COTTA-PEREIRA et al.,1984). Sawada et al. (2006) em estudo do ligamento periodontal na região molar de ratos, afirmou que as fibras elaunínicas presentes estavam em áreas mais expostas à tensão mecânica, sendo que o sistema elástico da área estudada tem papel fundamental na proteção e manutenção da integridade vascular durante a mastigação. Paniagua et al. (1983) em estudo do sistema elástico no ducto deferente, em humanos, observou que as fibras elásticas aparecem na lâmina própria da estrutura e formam duas camadas, uma interna com estrias paralelas e longas, as quais se interconectam por delicados ramos e penetram na prega epitelial, a outra camada é formada por uma malha irregular e é menos densa que a interna, sem limites definidos, podendo se misturar com as fibras elásticas da camada interna ou com a camada muscular, já na microscopia eletrônica foi observado grupos de microfibrilas localizados entre fibras colágenas da lâmina própria e nos espaços intercelulares da camada muscular, pouca massa de elastina também foram encontradas entre as microfibrilas, verificou-se também que as fibras elásticas no ducto deferente aparecem apenas na puberdade, quando esta estrutura se torna funcional, sugerindo o importante papel do sistema elástico no funcionamento desta estrutura, como também em outras estruturas tubulares do trato urinário, glândulas mamárias e ducto prostático, os quais contém muitas fibras elásticas. Gawlik (1965) afirma que, a ocorrência de elementos elásticos está restrita aos órgãos que estão sujeitos ao estiramento bi ou multi-direcional. Carvalho et al. (1997) reportam que o trabalho das microfibrilas é muito importante no fornecimento de 
complacência ao tecido durante a contração da musculatura lisa e restabelecimento elástico da morfologia após forças compressivas, sendo que isto não é somente resultado da extensibilidade resultante da associação elastina - microfibrilas, mas também da flexibilidade de rearranjo e organização. Costa et al. (2004) em estudo sobre hiperplasia prostática, relata que uma constante remodelação do componente elástico também ocorre devido a uma elevada variação da densidade volumétrica de tais fibras. Segundo Karlinsk et al. (1976) os elementos fibrosos (colágeno e elastina) dos tecidos conjuntivos têm função de preenchimento, enquanto o componente microfilamentoso representa um elemento capaz de sustentar as variações de distensão do tecido garantindo sua integridade.

Estudos experimentais têm sido realizados em vários tecidos com relação às modificações que ocorrem no sistema elástico com o envelhecimento, pois as fibras elásticas são designadas para manter a função elástica do tecido por toda a vida, entretanto várias enzimas são capazes de fazer a quebra das moléculas das fibras elásticas levando à perda de elasticidade devido a essas mudanças degradativas que ocorrem quando há o envelhecimento do tecido conjuntivo (ASHWORTH et al., $1999^{2}$ e KIELTY et al., 1994³ APUD KIELTY et al., 2002). Niewoehner, et al. (1977) verificou em pulmões humanos, que em idades avançadas o número total de fibras elásticas continuavam presentes, sendo que em média o calibre dessas fibras continuou aumentando com a idade, não excluindo a possibilidade de que ocorre nova síntese de fibras, em taxas iguais, as que são destruídas. Carvalho et al. (1996) relataram que, durante o processo de envelhecimento diversas alterações têm sido evidenciadas no sistema elástico em relação a sua morfologia, composição química e quantidade de fibras. Em estudo do sistema muscular no colo vesical, Rother et al. (1996) observaram que o volume das células muscular e das fibras diminui por volta de $2 \%$ a cada 10

\footnotetext{
${ }^{2}$ ASHWORTH, J. L.; KELLY, V.; ROCK, M. J. Regulation of fibrillin carboxy-terminal furin processing by Nglycosilation, and association of amino-and carboxy -terminal sequences. Journal of Cell Science, v. 112, p. 4163-4171, 1999.

3 KIELTY, C. M.; WOOLEY, D. E.; WHITTAKER, S. P. Catabolism of intact fibrillin microfibrils by neutrophil elastase, chymotripsin and tripsisn. FEBS Letters, v. 351, p. 85-89, 1994.
} 
anos. Souza et al. (1996) em estudo das fibras elásticas no coração humano, descreveram que há uma diferença na quantidade e estrutura destas fibras entre crianças, adultos e velhos, onde o comprimento das fibras por unidade de volume permanece constante da criança para o adulto e aumenta do adulto para o velho, demonstrando uma constante degradação de elastina ao longo da vida, para Sephel et al. (1986) e Uitto (1988) com o avanço da idade ocorrem um declínio nas taxas de biosíntese de elastina. Gogly et al. (1997) em estudo de pele e gengiva humana, observaram que com o envelhecimento as fibras oxitalânicas, presentes nessas estruturas, tornam-se irregulares e curtas, as fibras elaunínicas são fragmentadas e as fibras elásticas maduras aparecem dispersas, fragmentadas e espessadas. Na fáscia transversal do triângulo inguinal em humanos, observado por Rodrigues, Jr. et al. (1990) também foram evidenciadas fibras elásticas, sendo que, em pacientes jovens, os microfilamentos das fibras elásticas maduras, elaunínicas e oxitalânicas são mais distintos, onde este componente microfilamentoso diminui com a idade por volta dos 50 aos 60 anos e continua diminuindo com intensidade por volta dos 70 aos 80 anos de idade, evidenciando-se também um aumento na quantidade de material amorfo, onde este se apresentou fragmentado, mostrando assim, ultra estruturalmente, que com o aumento da idade há uma diminuição de fibras oxitalânicas e um aumento de fibras elásticas maduras. Sculean et al. (1997) em estudo do ligamento periodontal em macacos, revelou que as fibras oxitalânicas estavam presentes em ligamento periodontal recém-formado, atribuindo que estas fibras possuem um potencial de regeneração. Chopard et al. 1998 em avalaiação dos segmentos proximal e distal da artéria basilar, em homem, verificou em diferentes faixas etárias uma diminuição das fibras do sistema elástico, onde ocorreu perda de fibras oxitalânicas em indivíduos de 20-50 anos quando comparados com indivíduos de 0-1 ano de idade, as fibras elaunínicas diminuíram apenas após os 50 anos e com as elásticas maduras houve um decréscimo das mesmas na primeira (0-1 ano) e na segunda (20-50 anos) faixas etárias, permanecendo estável na terceira faixa etária (mais de 51 
anos). Barros et al. (2002) observaram em ligamentos interespinais, que com o envelhecimento, as fibras do sistema elástico mostraram-se, em sua maioria, curtas, espessadas, trançadas e agrupadas, e algumas fibras se apresentaram alongadas e finas, sendo que o grande número de fibras elásticas fragmentadas e degeneradas, presentes nos ligamentos com o aumento da idade, promovem uma perda da complacência normal do tecido, não obstante com as mudanças estruturais, revelou-se que com o envelhecimento houve uma indução no desaparecimento de fibras oxitalânicas, as quais são responsáveis pela resistência tecidual.

Paniagua et al. (1983) através de observações eletromicroscópicas de ductos deferentes, relatou que com o aumento da idade há um aumento da substância amorfa, que forma amplas massas estruturais contendo abundante inclusão eletrodensa e áreas de rarefação, enquanto que as microfibrilas tornam-se gradualmente menos numerosas, onde também há uma fragmentação e desorganização das fibras elásticas, sugerindo assim que com o envelhecimento há uma diminuição da síntese de glicoproteína estrutural (microfibrilas), conseqüentemente as fibras elásticas tornam-se mais susceptíveis à ação da elastase, ficando totalmente desintegradas em idades mais avançadas. Chopard et al. 2000 relataram que em dois segmentos da artéria cerebral anterior, no homem, houve aumento de fibras elásticas maduras, elaunínicas e oxitalânicas com o envelhecimento, enquanto que em um terceiro segmento desta artéria, as fibras mostraram-se diminuídas em seu contingente. 


\section{PROPOSIÇÃO}

Utilizando a microscopia de luz e eletrônica de transmissão, foi estudada a junção vésico-uretral de ratos em diferentes faixas etárias verificando a participação dos sistemas fibrosos elásticos nesta estrutura, objetivando:

1. Qualificação das fibras do sistema elástico através de microscopia de luz;

2. Tipificação ultraestrutural do sistema de fibras elásticas através de microscopia eletrônica de transmissão;

3. Quantificação do sistema de fibras elásticas através de estudo histomorfométrico. 


\title{
4 MATERIAL E MÉTODOS
}

\author{
4.1 Material
}

Para a realização dos experimentos foram utilizados 27 ratos Wistar (Rattus norvegicus), machos, obtidos do Biotério Central do Instituto de Ciências Biomédicas da Universidade de São Paulo, mantidos em condições controladas de temperatura $\left(21^{\circ} \mathrm{C}\right)$ e de iluminação (12 horas de luz / 12 horas de escuro), com ração balanceada ${ }^{4}$ e água a vontade, sem restrições nutricionais. Os animais foram divididos em 3 grupos distinguidos por diferentes faixas etárias, sendo 9 animais por grupo:

Grupo Neonato (21 dias);

Grupo Adulto (200 dias);

Grupo Velho (450 dias).

O material de estudo será obtido através da remoção da junção vésico-uretral contendo o colo vesical, orifícios uretéricos e uretra proximal.

\subsection{Métodos}

\subsubsection{Microscopia de luz:}

Para obtenção do material de estudo para a microscopia de $l u z^{5}$, foram utilizados 5 animais de cada grupo, onde estes foram anestesiados através de injeção intraperitoneal com o uso de coquetel anestésico ( $40 \%$ água destilada $+25 \%$ quetamina $+25 \%$ xilazina $+10 \%$

\footnotetext{
${ }^{4}$ Ração Nuvilab CR1/Nuvital

${ }^{5}$ Leica Wild MPS 52
} 
acepromazina) em que os batimentos cardíacos foram mantidos até a perfusão ${ }^{6}$ do animal. Para a perfusão foi realizada a abertura da cavidade torácica para exposição do coração, após foi introduzido no ventrículo esquerdo uma cânula metálica e o átrio direito foi aberto para fazer o escoamento do sangue e da solução salina, esta foi injetada através da bomba de perfusão e uma cânula metálica acoplada com o objetivo de lavar o sistema sanguíneo evitando a formação de coágulos, posteriormente ao uso da solução salina e com o mesmo método, foi utilizado uma solução de formaldeído a $10 \%$ para promover uma primeira fixação da estrutura almejada. Após o completo proceso de perfusão, a parede abdominal foi aberta através de laparatomia e iniciou-se a dissecção das estruturas até a visualização da bexiga urinária, ureteres e uretra proximal. Removemos o bloco bexiga urinária, ureteres intravesicais e uretra proximal, o qual foi dissecado até a obtenção da JVU, contendo também o óstio interno da uretra e óstios uretéricos com o auxílio de microscópio estereoscópico 7 . Após fixação, o material obtido foi lavado em água corrente por três minutos e ficou embebido em álcool $70 \%$ por 12 horas, sendo processado na seqüência através de desidratação em série crescente de álcoois (95\%I, 95\%II, absoluto I, II e III), então, seguiu-se com a diafanização das peças utilizando Xilol I, II e III. Após, as peças passaram por 3 banhos de parafina, de 30 minutos cada, foram incluídas em blocos de parafina de acordo com as técnicas convencionais. Os blocos preparados foram seccionados em micrótomo ${ }^{8}$ com obtenção de cortes transversais semi-seriados com $5 \mu \mathrm{m}$ de espessura. Estes cortes foram preparados em lâminas histológicas e corados pelos seguintes métodos:

- Hematoxilina férrica (Verhoeff, 1908): para evidenciação de fibras elásticas maduras;

\footnotetext{
${ }^{6}$ Bomba de Perfusão Masterflex Pump Controller

${ }^{7}$ Stemi SV6 Zeiss Germany

${ }^{8}$ Leica RM 2145
} 
- Resorcina-fucsina (Weigert, 1898): para evidenciação de fibras elásticas e elaunínicas;

- $\quad$ Resorcina-fucsina (Weigert, 1898) após oxidação com solução aquosa a 1\% de oxona: para evidenciação de fibras elásticas, elaunínicas e oxitalânicas.

\subsubsection{Microscopia Eletrônica de Transmissão:}

Para o estudo ao microscópio eletrônico de transmissão ${ }^{9,10}$ foram utilizados materiais obtidos de 4 animais de cada grupo, onde o anestésico e o método de perfusão utilizado foram os mesmos para a microscopia de luz, exceto o fixador, onde neste caso utilizamos glutaraldeído a 25\%. Após laparatomia e obtenção das peças (idem microscopia de luz), os segmentos selecionados contendo a junção vésico-uretral foram reduzidos utilizando uma navalha e fixados durante 3 horas a $4^{\circ} \mathrm{C}$ em solução de glutaraldeído a 2,5\% e ácido tânico a $0,25 \%$, em tampão fosfato $0,1 \mathrm{M}(\mathrm{pH} 7,4)$. As amostras receberam cuidadosa lavagem com tampão fosfato a 0,1M (pH 7,4) e seguiu-se a pós-fixação das mesmas em tetróxido de ósmio a $2 \%$ durante 2 horas a $4^{\circ} \mathrm{C}$. As peças foram lavadas em solução salina e colocadas em solução de uranila $0,5 \%$ por 12 horas em temperatura ambiente. Após este período o material em estudo foi novamente lavado em solução salina e iniciou-se o processo de desidratação em séries crescentes de álcoois $-70^{\circ}, 80^{\circ}, 95^{\circ}$ - banho de 15 minutos cada, $100^{\circ}$ - 4 banhos de 15 minutos cada, e dois banhos de óxido de propileno $99 \%$ por 15 minutos cada. Depois da passagem em óxido de propileno, as amostras foram colocadas em uma mistura de resina e óxido de propileno na proporção de 1:1. A infiltração foi feita agitando-se o material em rotação (1/2 r.p.m), em suporte com $45^{\circ}$ de inclinação em relação ao solo, acoplado a um eixo de motor elétrico, durante 4 horas. Após este período, foi trocada esta mistura por resina pura

\footnotetext{
${ }^{9}$ Leo 906 - Instituto Butantan, São Paulo

${ }^{10}$ Jeol Jem 1010 - Instituto de Ciências Biomédicas, Universidade de São Paulo, São Paulo
} 
e novamente o material foi colocado em rotação por mais 12 horas. Novamente a resina foi trocada por resina pura e ficou em estufa a $37^{\circ} \mathrm{C}$ por 1 hora; após as peças foram incluídas em resina spurr ${ }^{11}$, mantendo-se na estufa por 5 dias a $60^{\circ}$ C. Foram utilizados cortes semifinos de $400 \mu \mathrm{m}$ obtidos em ultra- micrótomo ${ }^{12}$, corando os cortes com azul de toluidina para localizar as estruturas em estudo. Depois de localizadas, foram feitos cortes ultra-finos em ultra-micrótomo ${ }^{13}$ coletados com uma tela de 200 mesh e constratados com acetato de uranila e citrato de chumbo. Então as amostras foram fotografadas através de microscópio eletrônico de transmissão, para análise das diferenças dos componentes ultraestruturais entre fibras oxitalânicas, elaunínicas e elásticas maduras dos grupos neonato, adulto e velho.

\subsubsection{Histomorfometria:}

O estudo histomorfométrico do sistema elástico foi realizado através do cálculo da densidade linear (LD). O comprimento das fibras do sistema elástico é obtido pela fórmula $\mathrm{L}=2 \mathrm{Q} \times \mathrm{EV}(\mathrm{L}=$ comprimento de fibras por unidade de volume, $\mathrm{Q}=$ número de intersecções de fibras elásticas em uma secção plana e EV é a unidade de volume).

A densidade linear (LD) dos sistemas fibrosos elásticos avalia o comprimento total das fibras elásticas no tecido. Esta é a base fundamental para a avaliação histomorfométrica aplicada a sistemas fibrosos (NIEWOEHNER e KLEINERMAN, 1977).

A estimativa para se obter a Densidade Linear $(\mathrm{LD})$ é dada pela fórmula $\mathrm{LD}=2 \mathrm{XC} / \mathrm{A}$, sendo A: área total examinada em campos; C: número de intersecções das fibras com as retas paralelas do sistema teste. Para se obter serão utilizadas as seguintes relações:

\section{$A t=L \times d \times p \times m$}

\footnotetext{
${ }^{11}$ Spurr Embedding Kit / Ladd, Burlington, Vermont

12 Sorvall MT2-B

${ }^{13}$ Leica Ultracut UCT
} 


\section{$\mathbf{f}=\mathbf{P u} / \mathbf{p} \times \mathbf{m}$}

$A=\operatorname{At} \mathbf{x} \mathbf{f}$

$\mathbf{A t}=$ área total do sistema-teste;

$\mathbf{A}$ = área total examinada em $\mathrm{m}$ campos;

$\mathbf{L}=$ comprimento do segmento de reta do sistema-teste;

D = distância entre as retas do sistema-teste;

$\mathbf{P}=$ número de pontos do sistema teste;

$\mathbf{M}=$ número de campos estudados;

$\mathbf{f}=$ fator de correção para amostras não-homogêneas;

$\mathbf{P i}=$ pontos incidentes da túnica média;

$\mathbf{P u}=$ número total de pontos do sistema teste;

$\mathbf{C}=$ número de intersecções das fibras elásticas com as retas paralelas do sistema-teste.

Foram estudados 50 campos, em cortes histológicos aleatórios, de cada animal nas três faixas etárias (neonato, adulto e velho) para cada coloração utilizada (Verhoeff, Weigert e Weigert-Oxona), através do uso de um sistema teste, onde as secções histológicas da junção vésico-uretral foram analisadas ao microscópio de luz com objetiva de luz de 100x em imersão ocular de compensação Kf $10 \times 18$, em gratículo de integração ${ }^{13}$ de 400 pontos (sistema teste), ${ }^{14}$ exibindo 20 linhas paralelas, sendo a densidade (D) entre as linhas de 4,94 $\mu \mathrm{m}$, entre os pontos de $5 \mu \mathrm{m}$ e a área total de $386250 \mu \mathrm{m}^{2}$.

As análises estatísticas dos valores da LD foram obtidos através da análise de variância (ANOVA) com um fator idade seguida de comparações múltiplas pelo método de Tukey. A suposição de homogeneidade de variâncias foi verificada e o nível de significância adotado foi $\mathrm{p}<0.05$. Os valores da densidade linear também foram expressos através de um modelo de regressão quadrática usando a seguinte equação: $\mathrm{LD}=\alpha+\beta \mathrm{x}$ idade $+\mathrm{c} \mathrm{x}$ idade ${ }^{2}$,

\footnotetext{
${ }^{14}$ Wild Leitz $6 \mathrm{MBH}$
} 
obtendo assim um coeficiente de correlação (r), que deve ser entre 1 e -1 , relacionando a LD em função da idade. 


\section{RESULTADOS}

\subsection{Estudo Histológico}

As análises de nossos resultados referentes ao estudo histológico mostram a presença dos três tipos de fibras do sistema elástico em todas as faixas etárias estudadas, estas estão distribuídas em toda a junção vésico-uretral, na camada muscular que está localizada logo abaixo da lâmina própria do epitélio. As fibras elásticas aparecem tanto na camada superficial como na camada profunda da muscular e também nas regiões onde circunda os óstios uretéricos e o óstio uretral. A orientação das fibras elásticas na JVU é longitudinal e oblíqua e às mesmas não estão arranjadas em lâminas ou feixes, aparecendo de forma dispersa na camada muscular da JVU. Dentre as colorações utilizadas, todas evidenciaram de forma satisfatória e específica às fibras do sistema elástico, ou seja, quanto à especificidade as colorações de Verhoeff (hematoxilina férrica) destacou as fibras elásticas maduras, de Weigert (resorcina-fucsina) as fibras elásticas maduras e elaunínicas e de Weigert-Oxona (resorcina-fucsina, com prévia oxidação) evidenciou as fibras elásticas maduras, elaunínicas e oxitalânicas.

As preparações histológicas que demonstram as fibras do sistema elástico na junção vésico-uretral, obtidos pelos métodos de coloração Verhoeff, Weigert e Weigert-Oxona, são mostradas nas figuras de 1 a 9.

\subsection{Estudo Microscopia Eletrônica de Transmissão}

Para a realização do estudo através da microscopia eletrônica de transmissão foram realizados cortes transversais na JVU, em que observamos a ultra-estrutura dos três tipos de 
fibras do sistema elástico, onde através da técnica do ácido tânico tipificamos as mesmas. A análise deste estudo, representado pelas figuras de 10 a 33, demonstra que as fibras elásticas maduras são formadas por componente material amorfo eletrodenso, compacto e abundante (elastina), as fibras elaunínicas por escasso material amorfo (elastina) e componente microtubular em maior quantidade e as oxitalânicas compostas apenas por componente microtubular formando feixes e dispostos paralelamente não estando associados a elastina. Essas fibras mostraram-se orientadas longitudinalmente, obliquamente e circularmente, formando um emaranhado, entre os espaços intercelulares da camada muscular e também entre os feixes de fibras colágenas. Verificamos que no grupo neonato ocorre uma transição de fibras oxitlânicas para elaunínicas; elaunínicas para maduras, caracterizando as etapas da elastogêne (Figuras 18 e 19), no grupo velho observamos a presença de fibras elásticas mauras irregulares e degradadas (Figuras 28 e 30). 

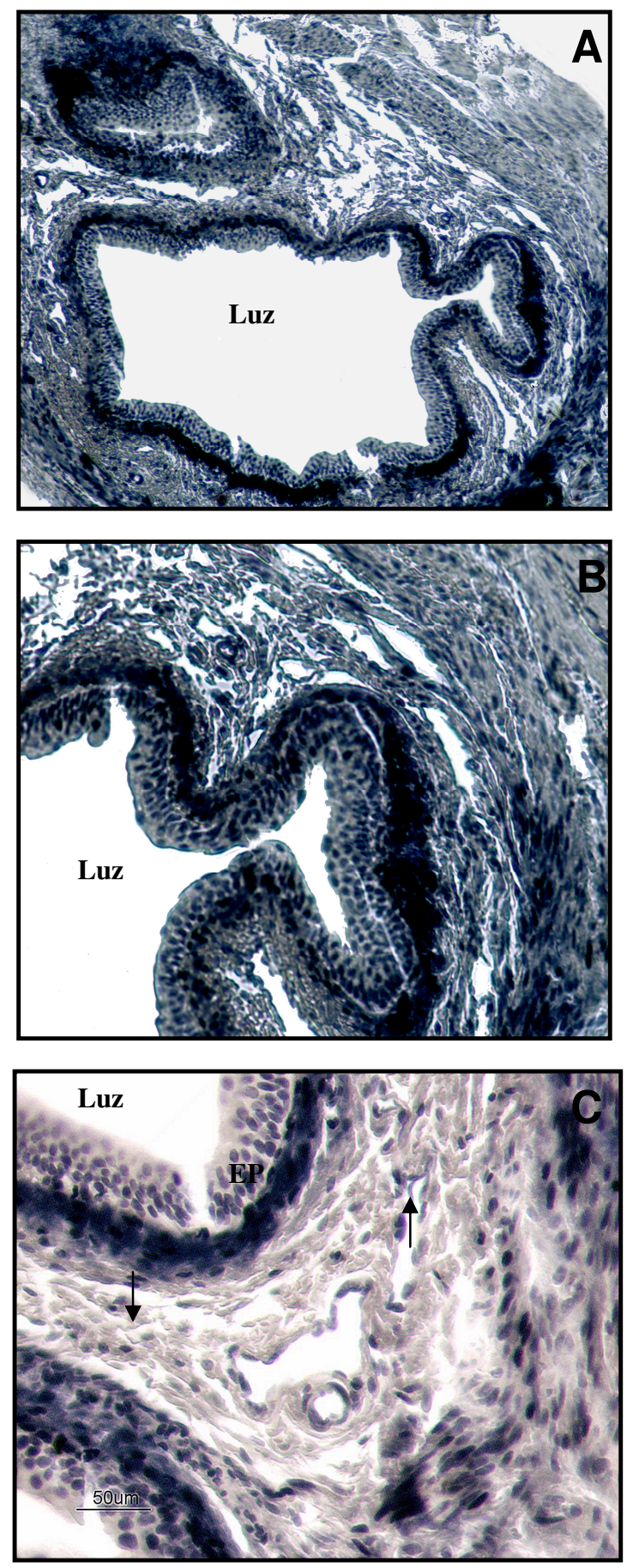

Figura 1 - Fotomicrografia da JVU, coloração Verhoeff, Grupo Neonato. A- 10x; B- 20x; C- 40x.

Notar fibras elásticas (setas), Epitélio (EP). 

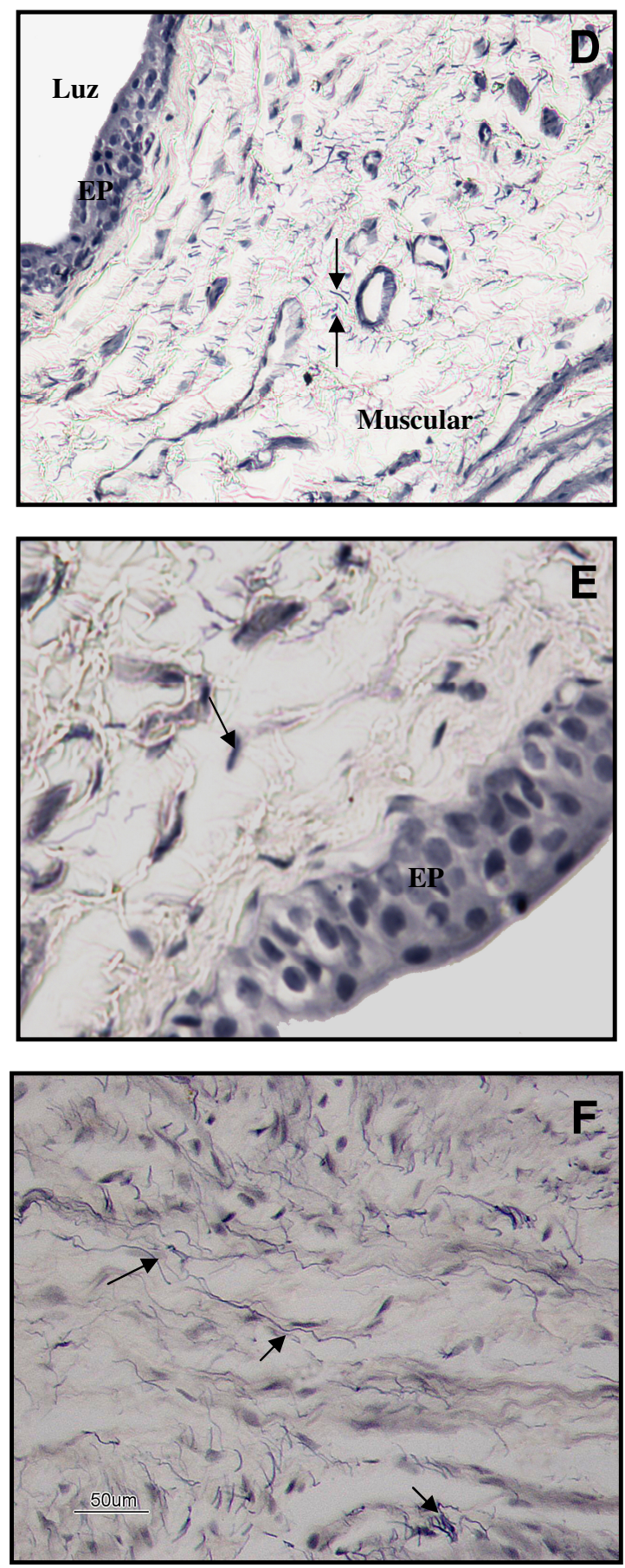

Figura 2 - Fotomicrografia da JVU, coloração Verhoeff, Grupo Adulto. D- 20x; E- 40x; F- 40x.

Notar fibras elásticas (setas). Epitélio (EP). 

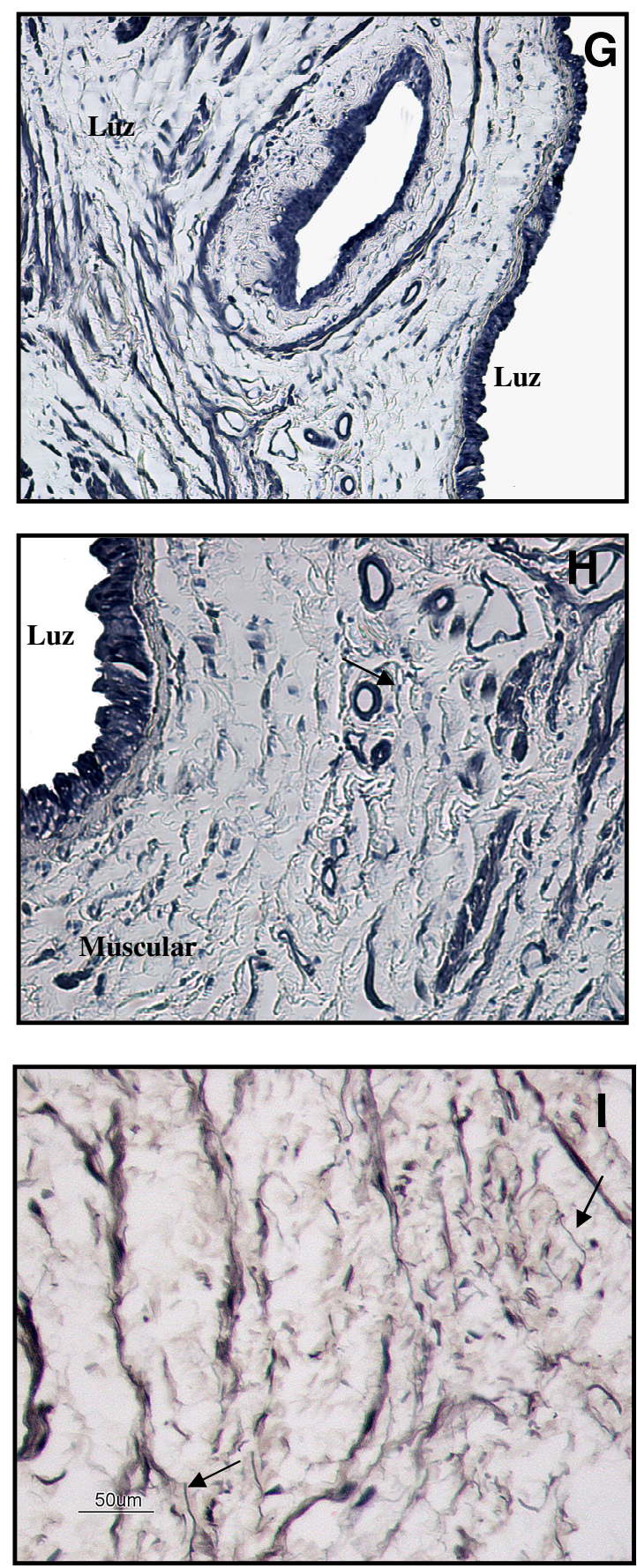

Figura 3 - Fotomicrografia da JVU, coloração Verhoeff, Grupo Velho. G- 10x; H- 20x; I- 40x.

Notar fibras elásticas (setas). 

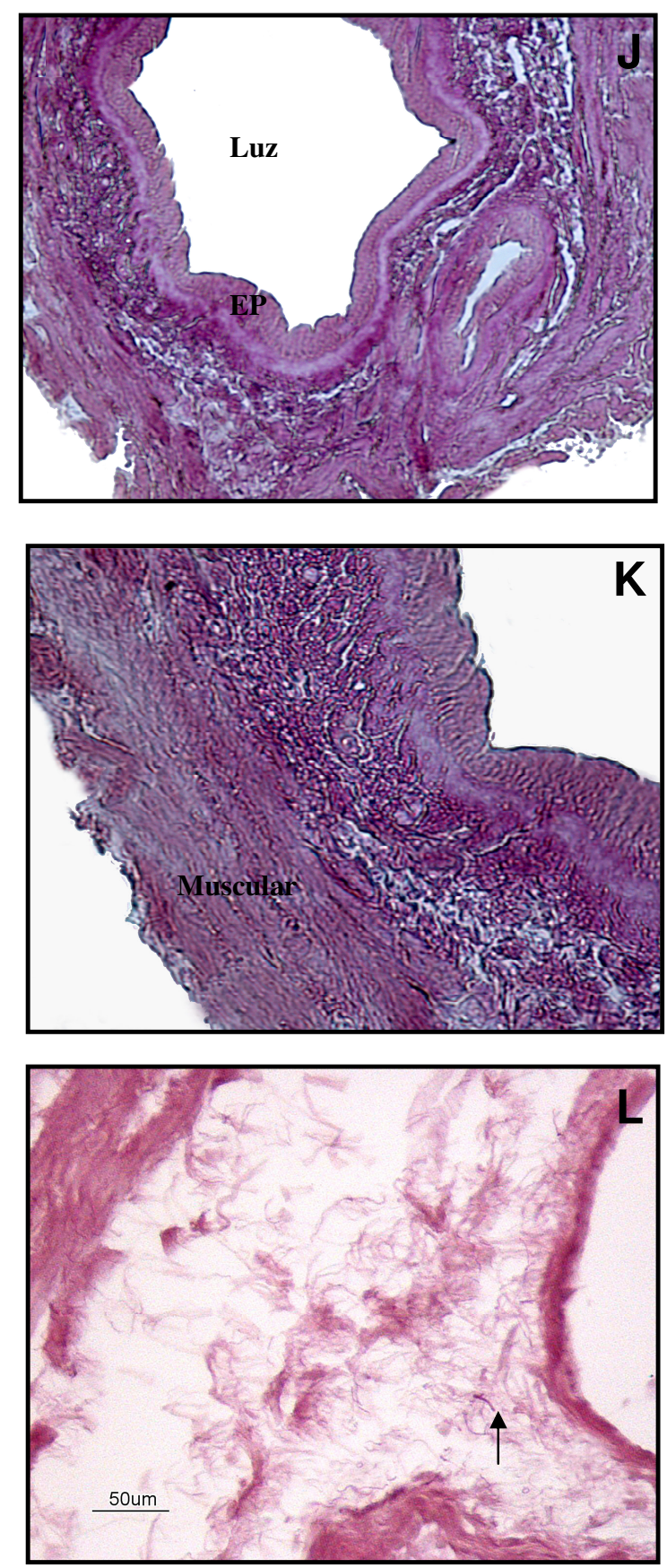

Figura 4 - Fotomicrografia da JVU, coloração Weigert, Grupo Neonato. J-20x; K- 20x; L- 40x.

Notar fibras elásticas (setas), Epitélio (EP) 

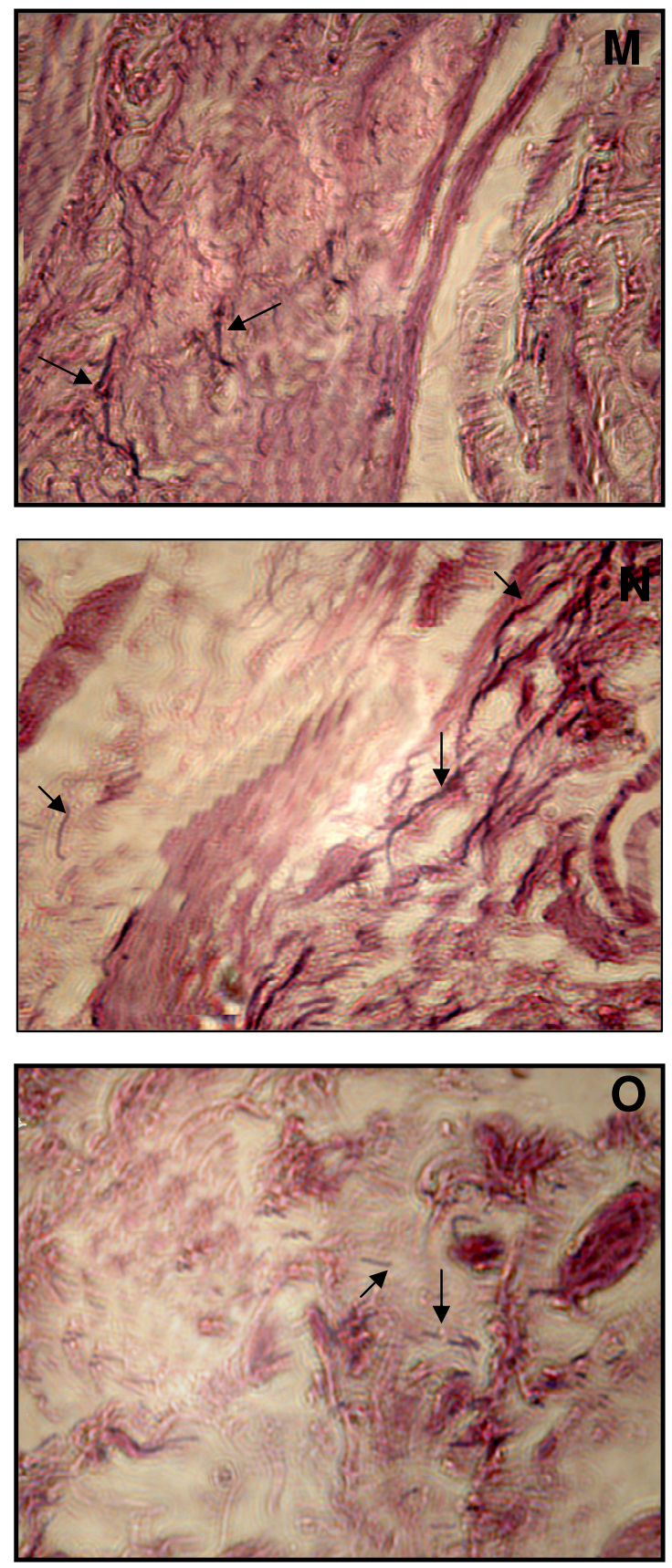

Figura 5 - Fotomicrografia da JVU, coloração Weigert, Grupo Adulto. M- 40x; N- 40x; O- 40x.

Notar fibras elásticas (setas). 

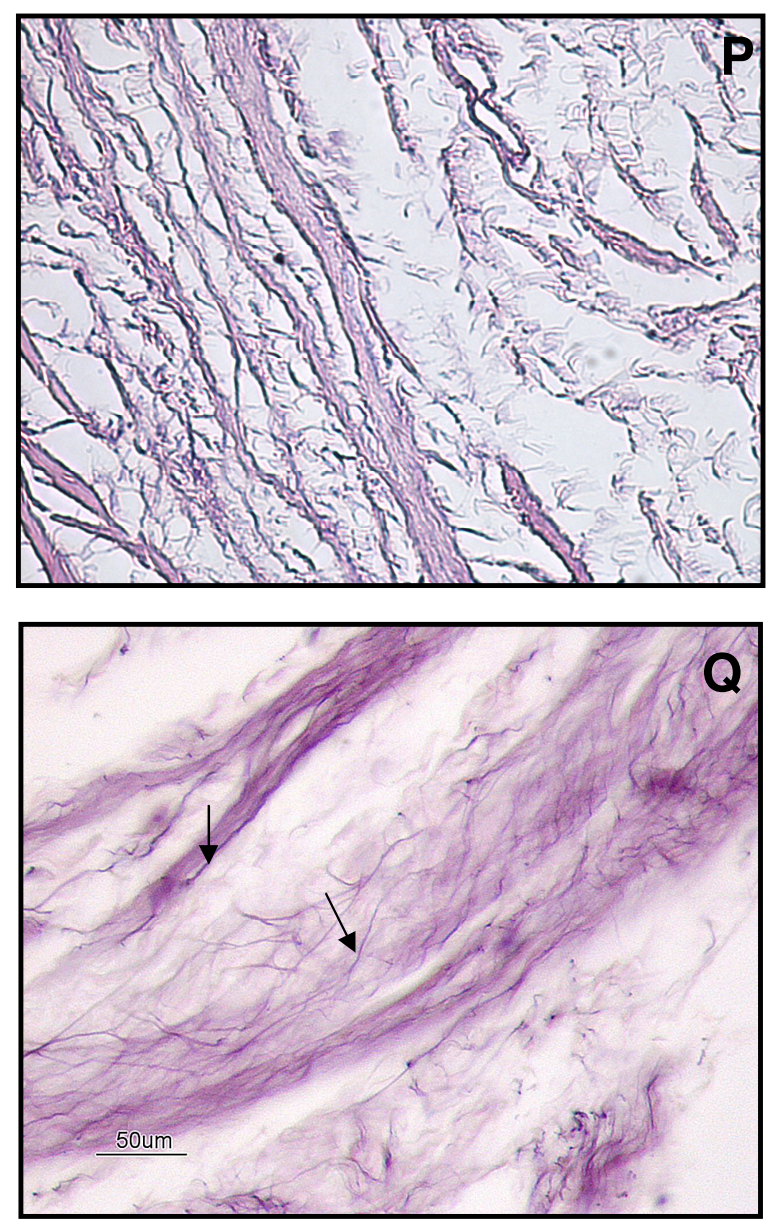

Figura 6 - Fotomicrografia da JVU, coloração Weigert, Grupo Velho. P- 20x; Q- 20x.

Notar fibras elásticas (setas). 

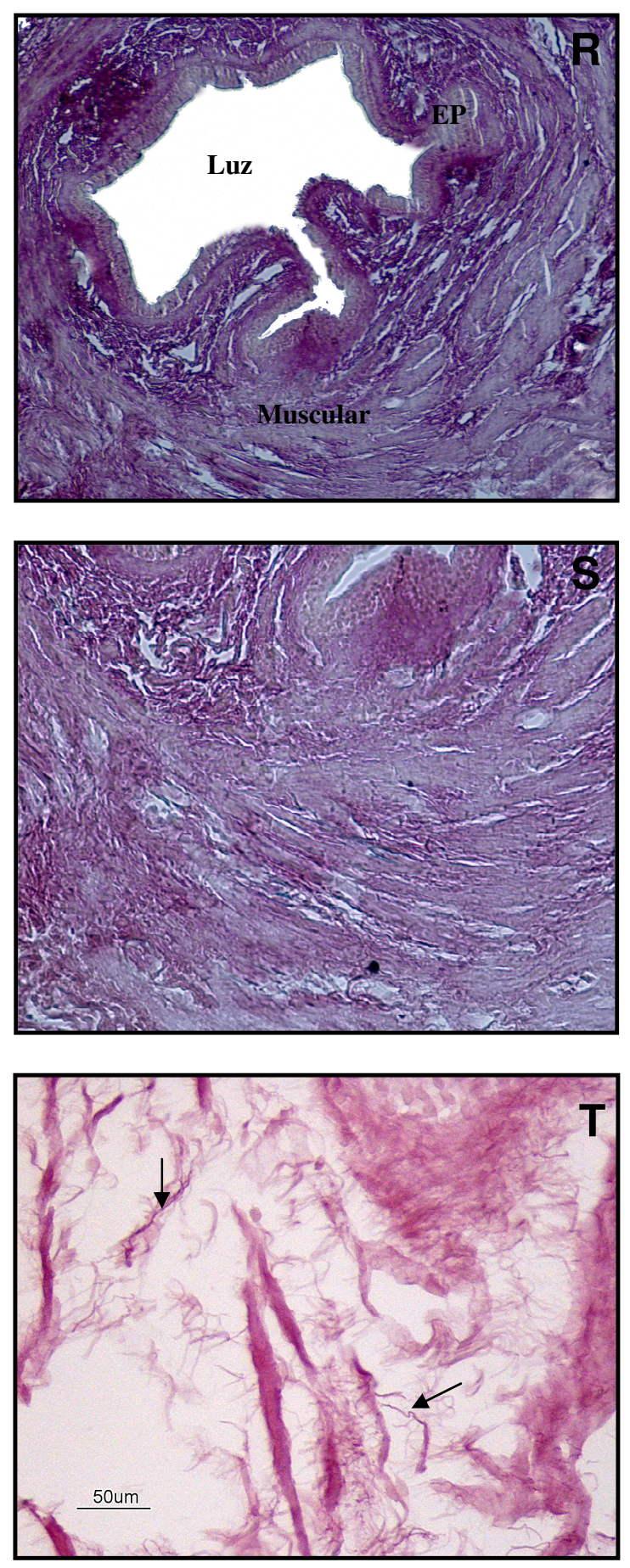

Figura 7 - Fotomicrografia da JVU, coloração Weigert-Oxona,Grupo Neonato.

R- 10x; S- 20x; T- 40x.

Notar fibras elásticas (setas), Epitélio (EP). 

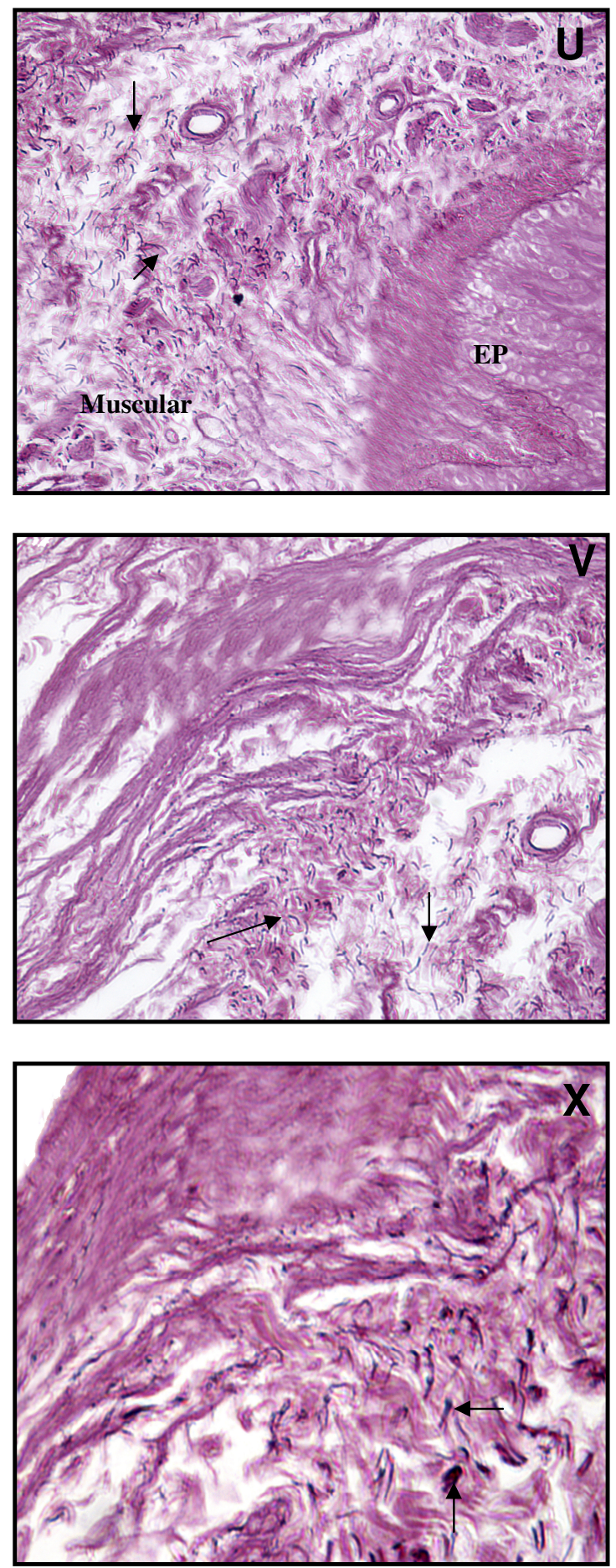

Figura 8 - Fotomicrografia da JVU, coloração Weigert-Oxona,Grupo Adulto.

U- 20x; V- 20x; X- 40x.

Notar fibras elásticas (setas), Epitélio (EP). 

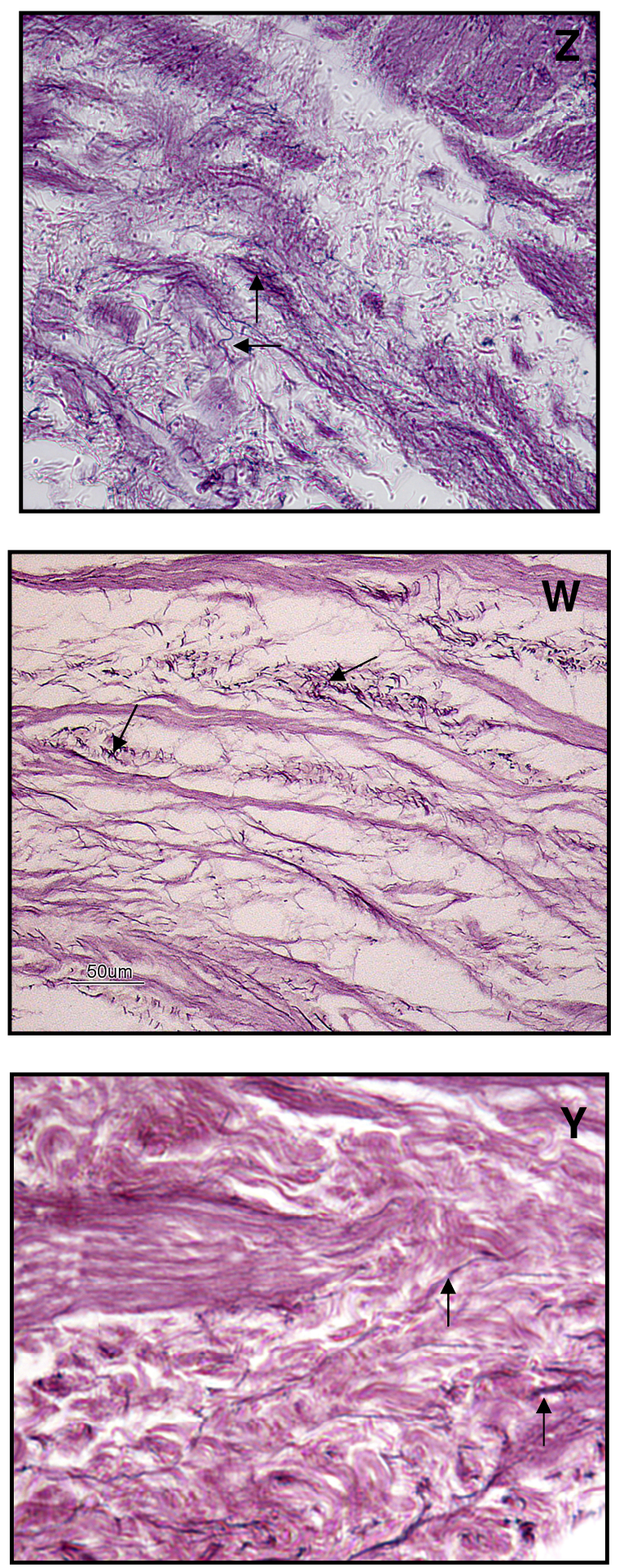

Figura 9 - Fotomicrografia da JVU, coloração Weigert-Oxona,Grupo Velho.

Z- 20x; W- 20x; Y- 40x.

Notar fibras elásticas (setas). 


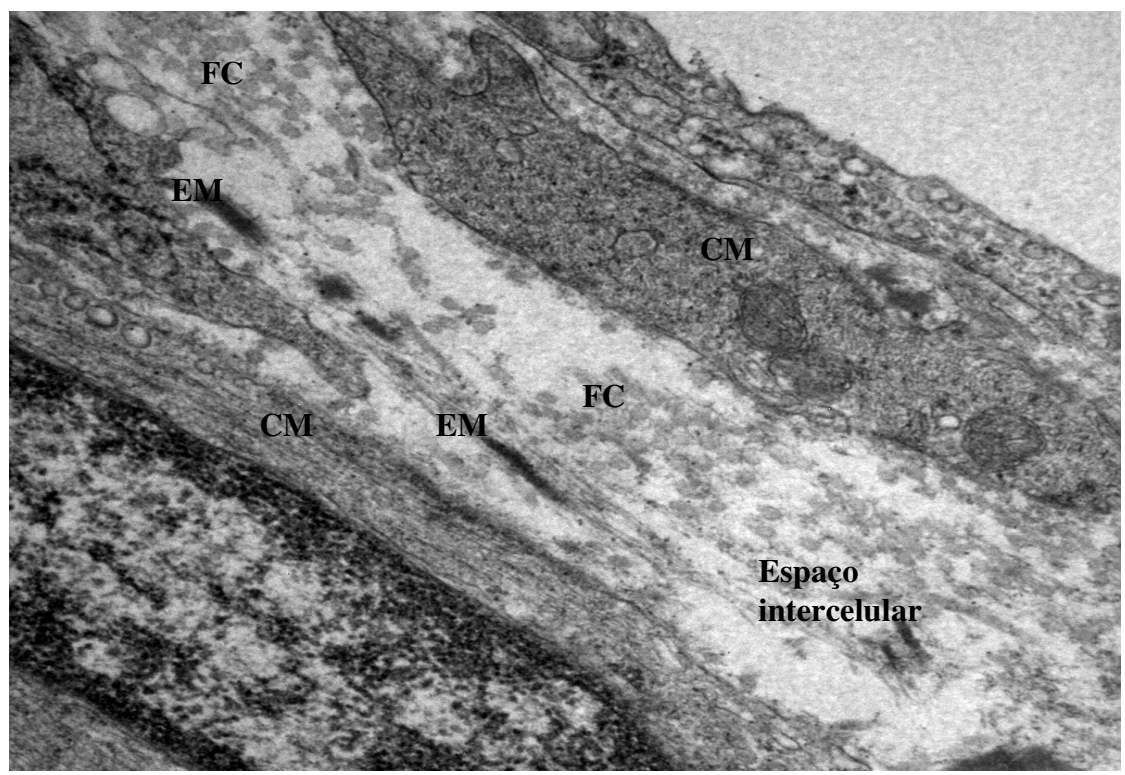

Figura 10 - Eletromicrografia da JVU de rato Wistar neonato (21 dias). Notar fibras elásticas maduras (EM), fibras colágenas (FC) e célula muscular $(\mathrm{CM})$. (30K)

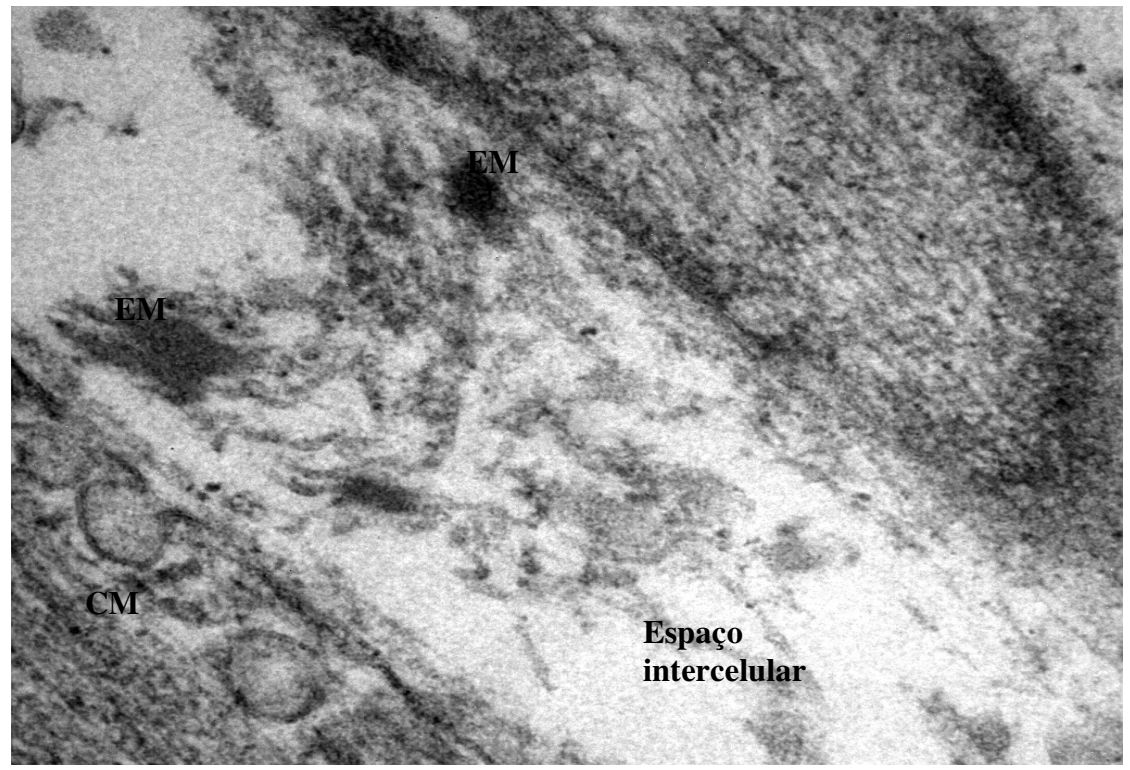

Figura 11 - Eletromicrografia da JVU de rato Wistar neonato (21 dias).

Notar fibras elásticas maduras (EM) e célula muscular (CM). (100K) 


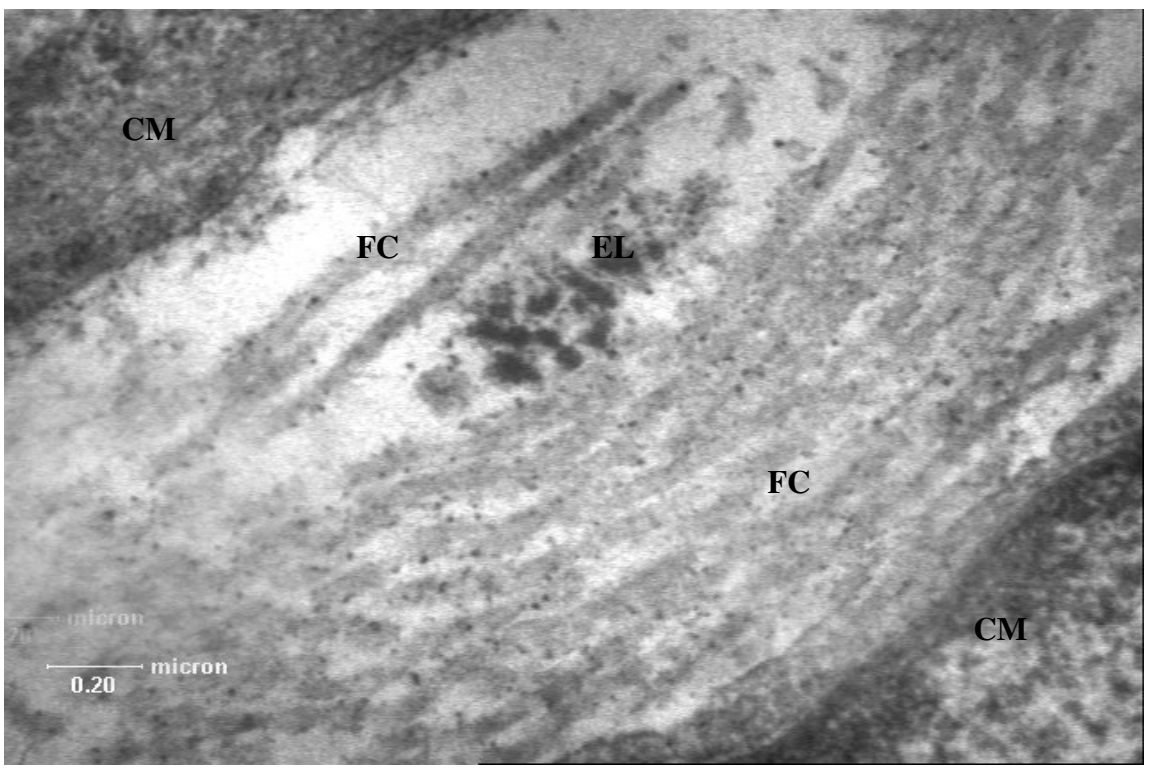

Figura 12 - Eletromicrografia da JVU de rato Wistar neonato (21 dias). Notar fibra elaunínica (EL), fibras colágenas (FC) e célula muscular (CM) (43.120X).

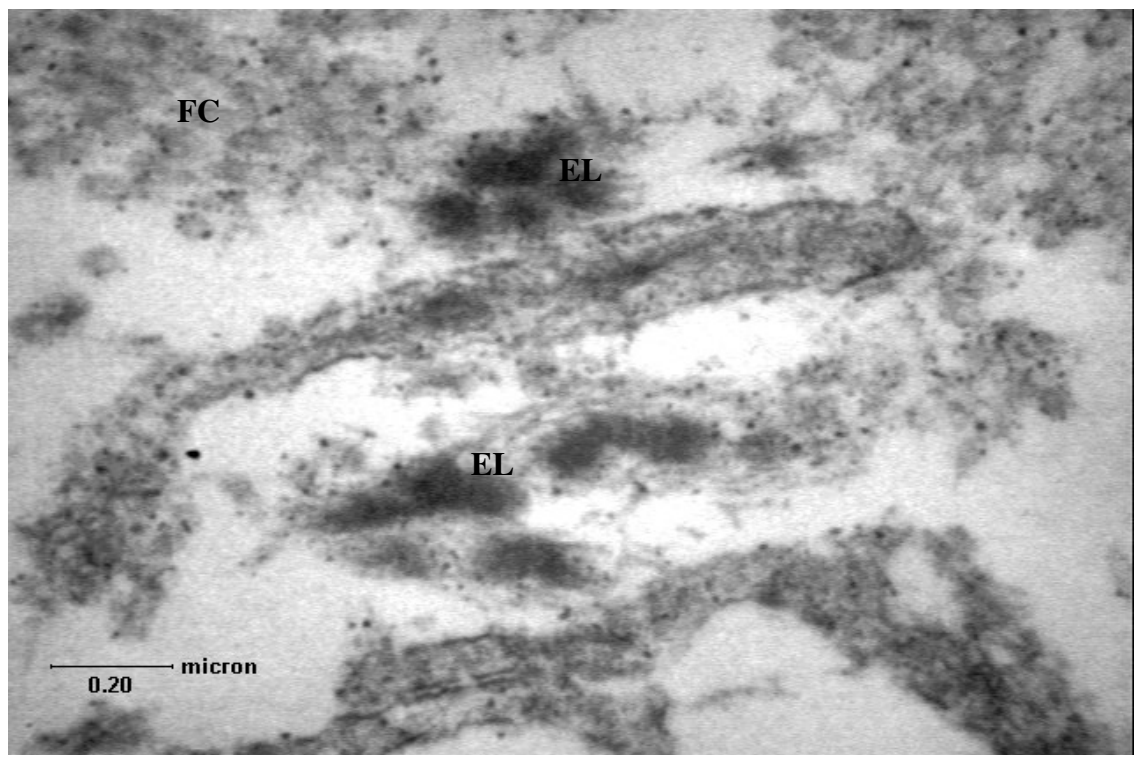

Figura 13 - Eletromicrografia da JVU de rato Wistar neonato (21 dias). Notar fibras elaunínicas (EL) e fibras colágenas (FC). (43.120x) 


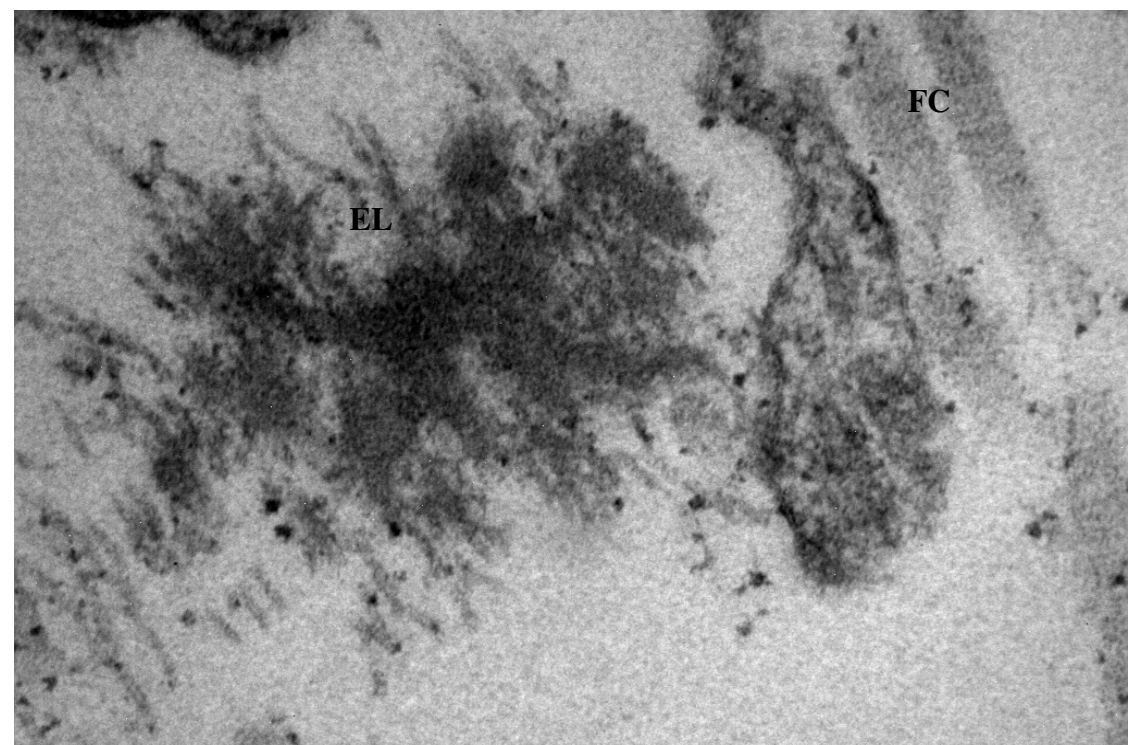

Figura 14 - Eletromicrografia da JVU de rato Wistar neonato (21 dias). Notar fibra elaunínica (EL), fibras colágenas (FC). (100K)

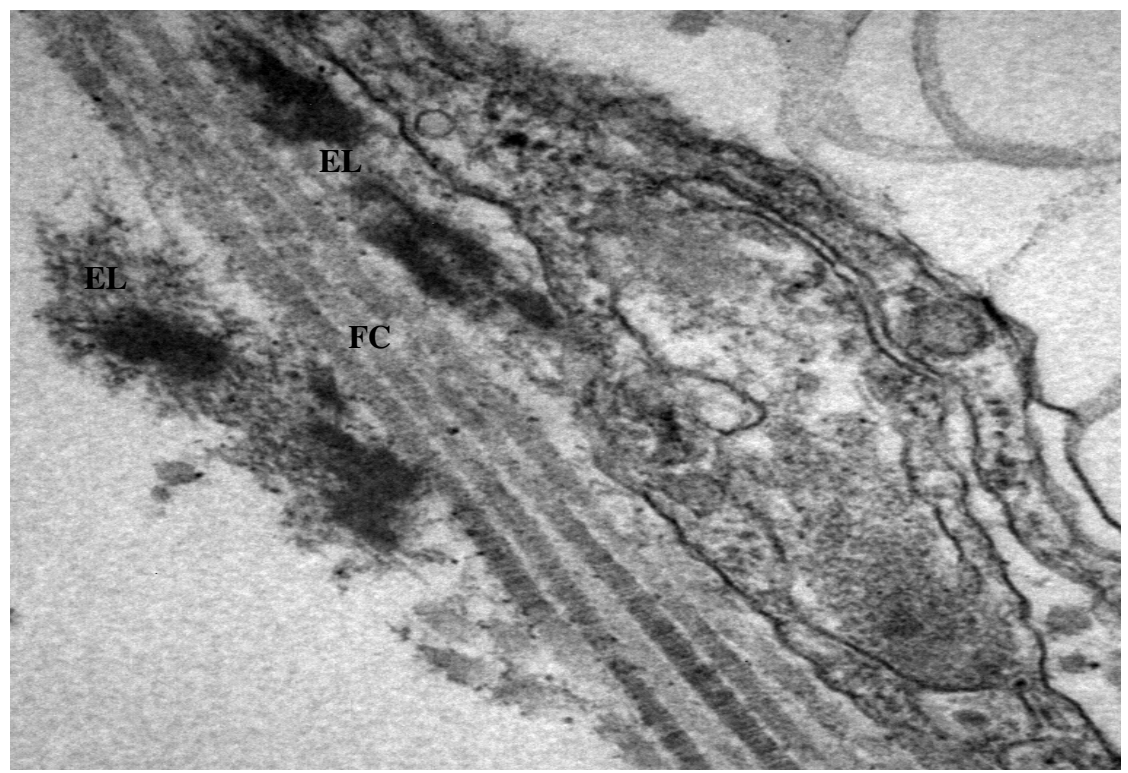

Figura 15 - Eletromicrografia da JVU de rato Wistar neonato (21 dias). Notar fibras elaunínicas (EL) e colágenas (FC). (100K) 


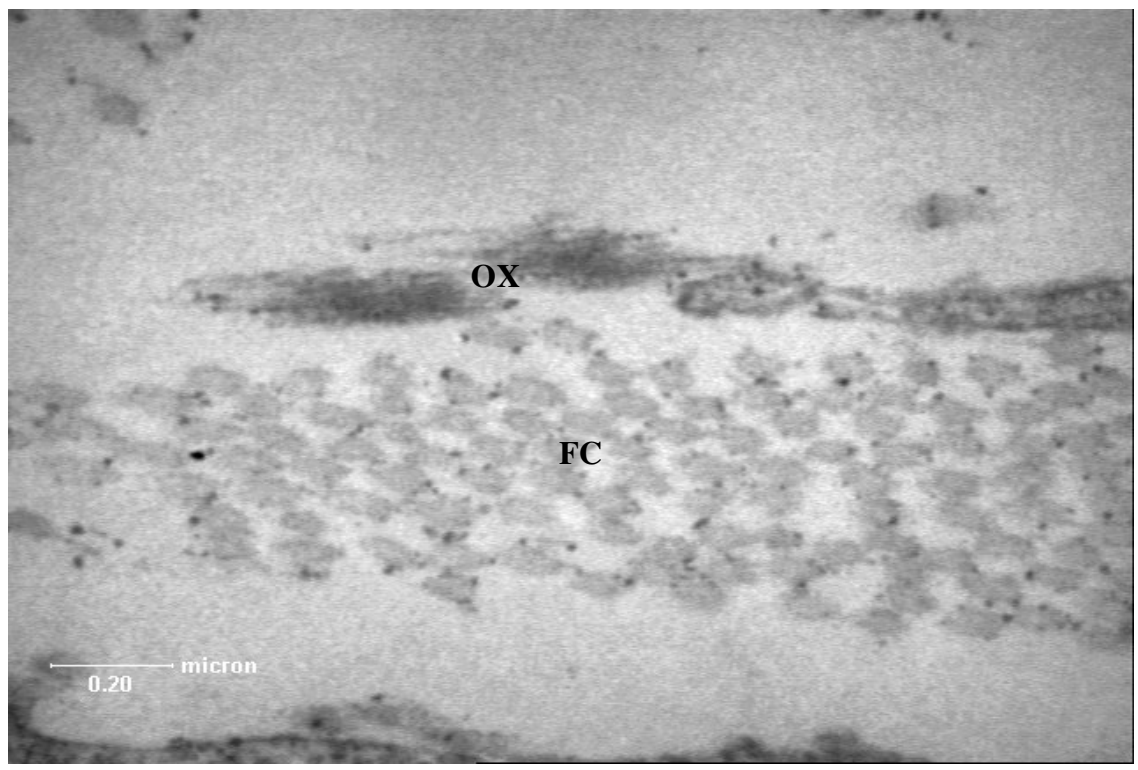

Figura 16 - Eletromicrografia da JVU de rato Wistar neonato (21 dias). Notar fibras oxitalânicas (OX), e fibras colágenas (FC). (43.120X).

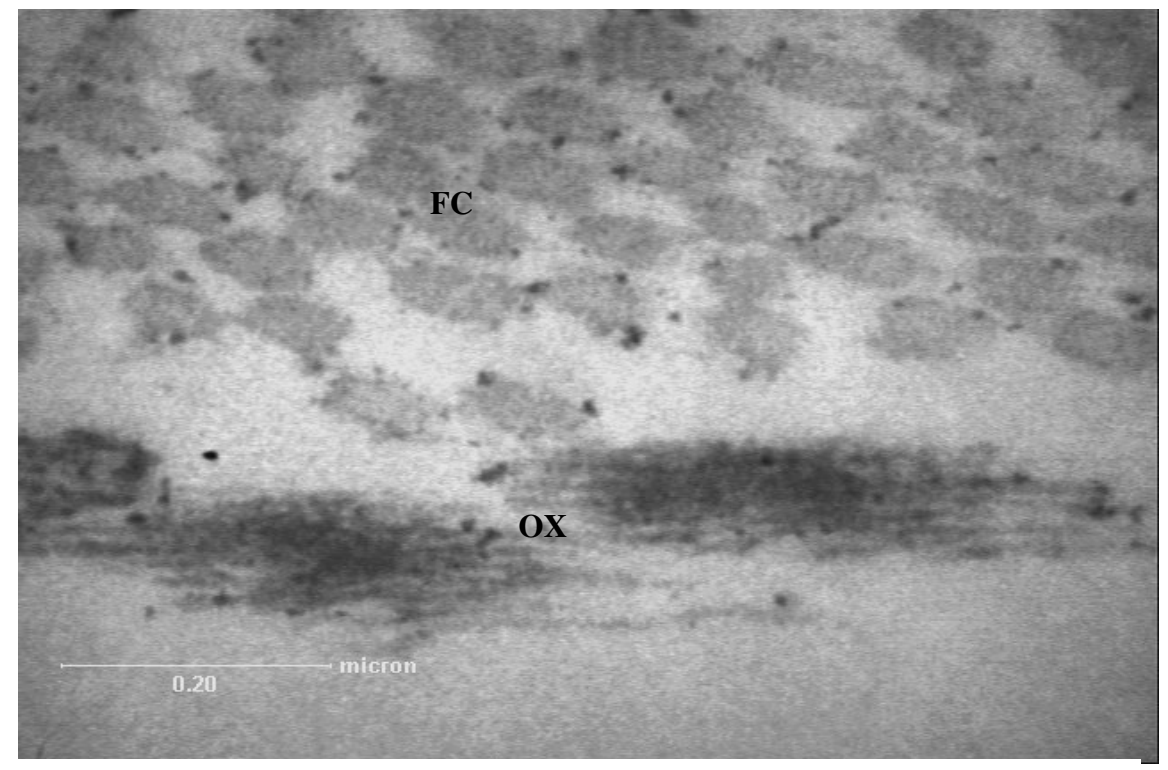

Figura 17 - Eletromicrografia da JVU de rato Wistar neonato (21 dias). Notar fibras oxitalânicas (OX), e fibras colágenas (FC). (43.120X). 


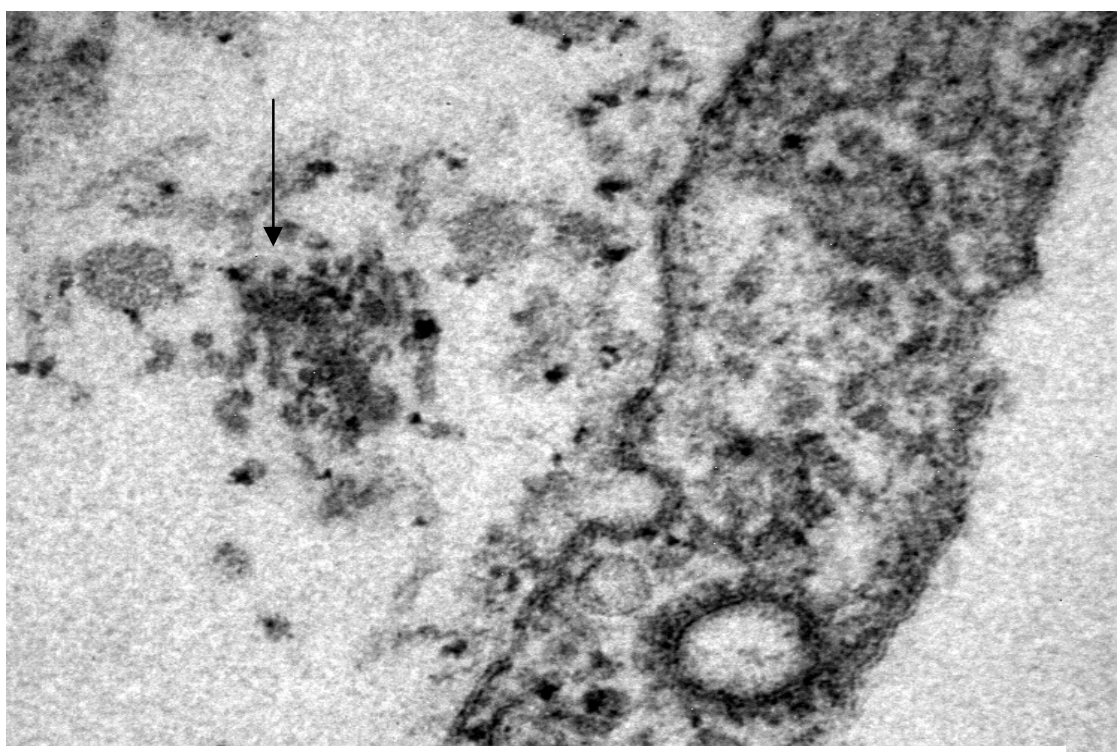

Figura 18 - Eletromicrografia da JVU de rato Wistar neonato (21 dias). Transição de fibra oxitalânica para elaunínica (seta). $(100 \mathrm{~K})$

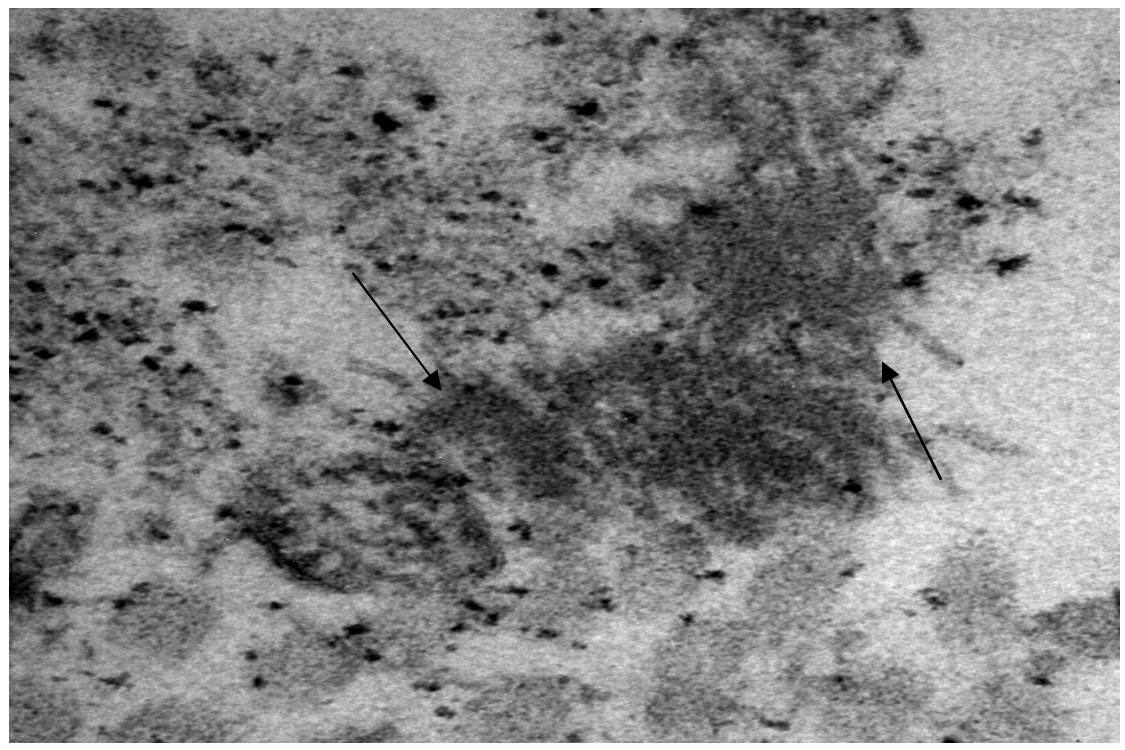

Figura 19 - Eletromicrografia da JVU de rato Wistar neonato (21 dias). Transição de fibra elaunínica para elástica madura. (100K) 


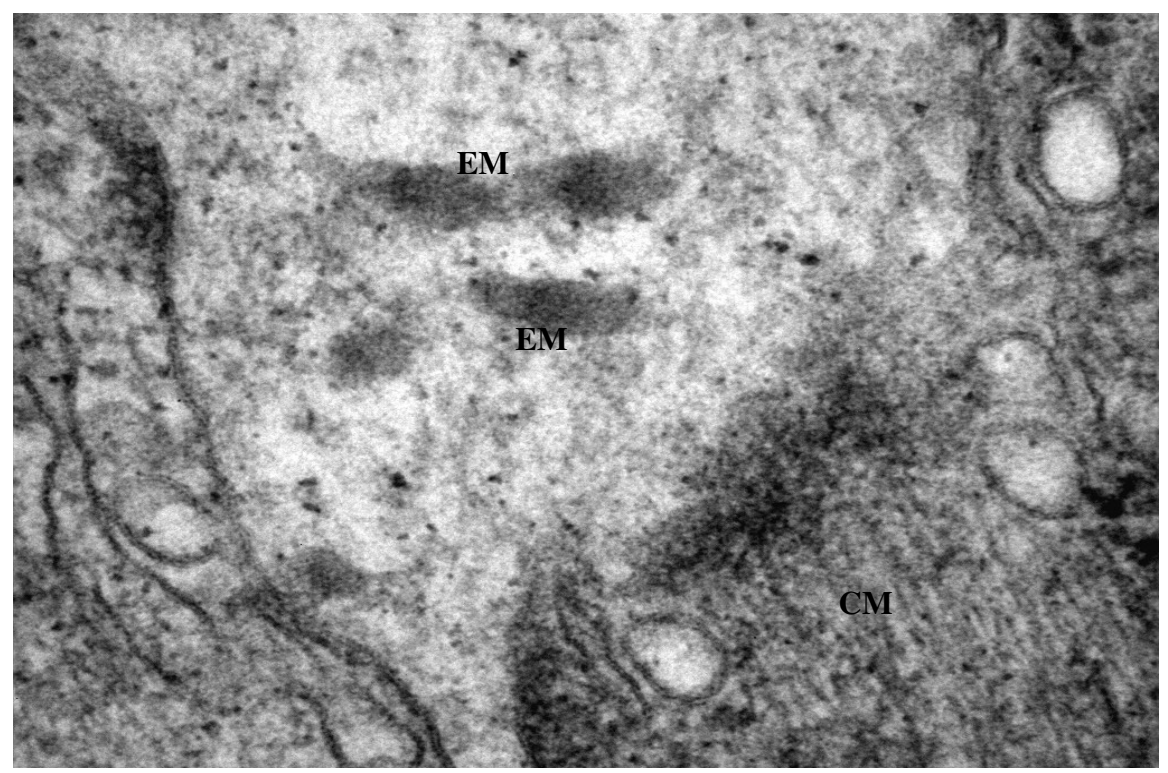

Figura 20 - Eletromicrografia da JVU de rato Wistar adulto (200 dias). Notar fibras elásticas maduras (EM), e célula muscular (CM). $(100 \mathrm{~K})$.

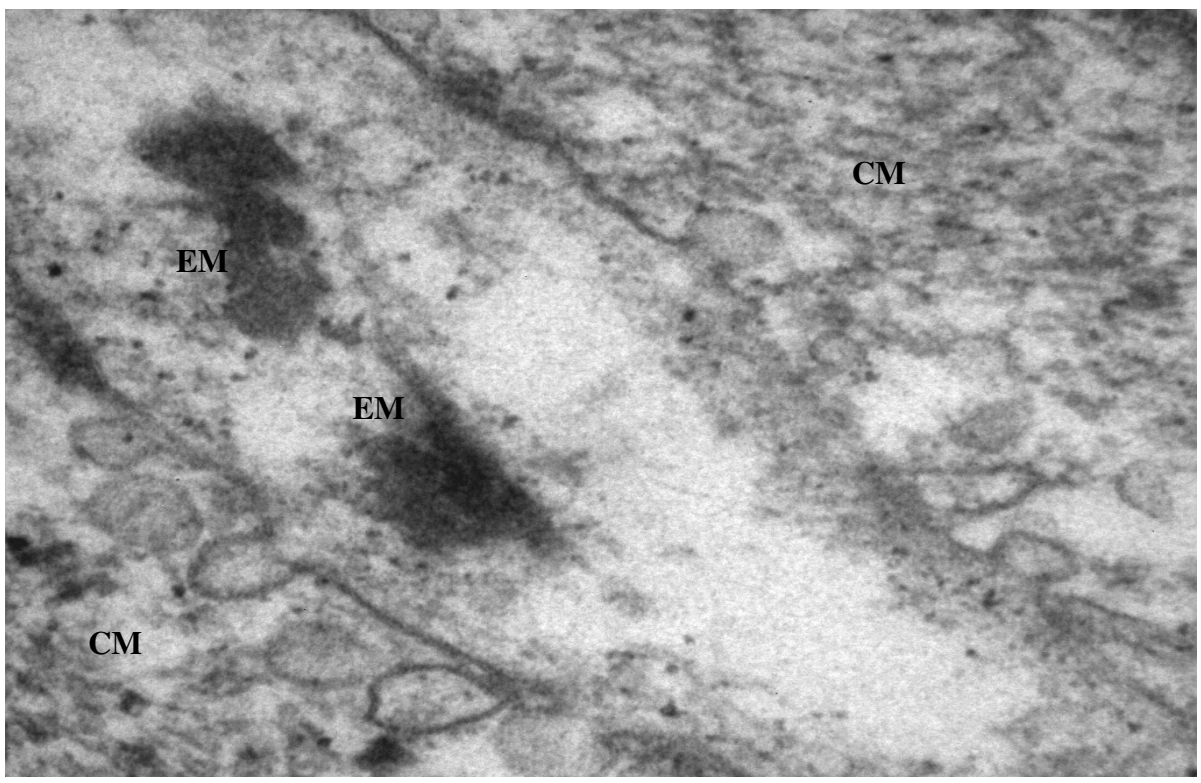

Figura 21 - Eletromicrografia da JVU de rato Wistar adulto (200 dias). Notar fibras eláticas maduras (EM), e célula muscular (CM). $(100 \mathrm{~K})$. 


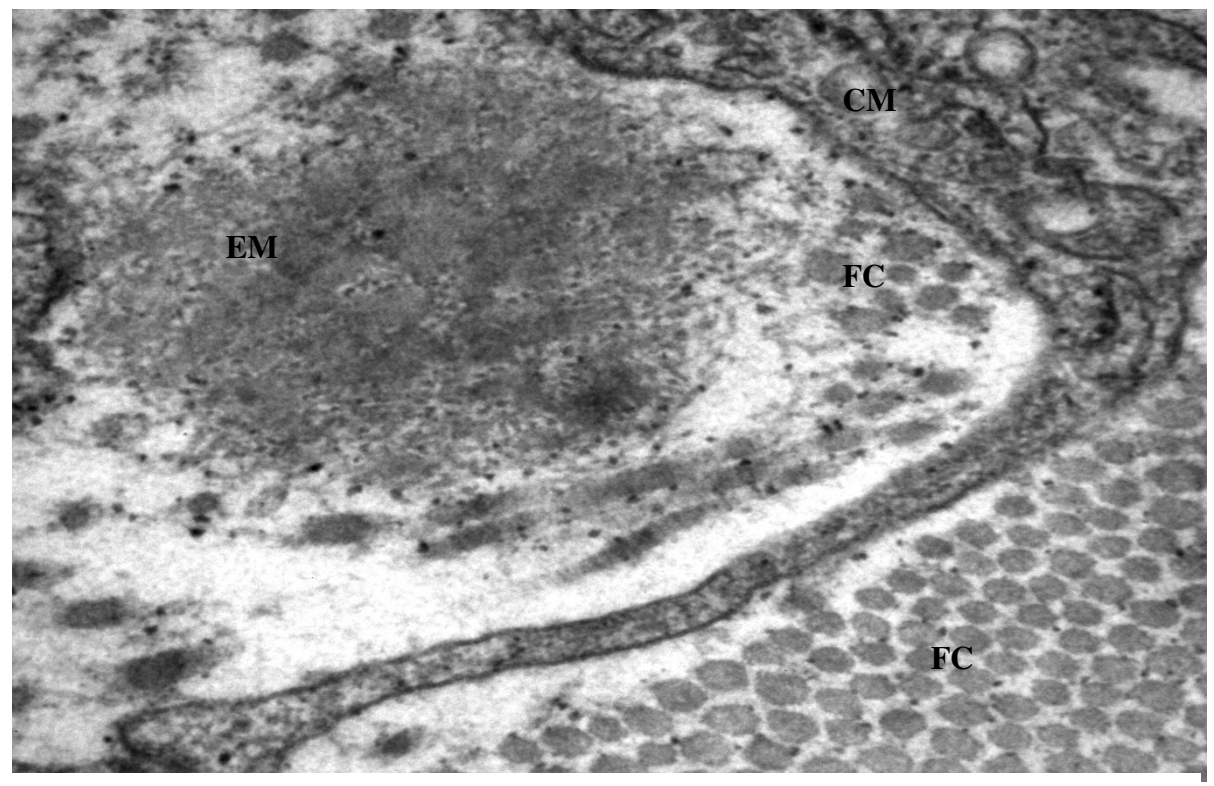

Figura 22 - Eletromicrografia da JVU de rato Wistar adulto (200 dias). Notar fibra elática madura (EM), fibras colágenas (FC) e célula muscular (CM). (40 K).

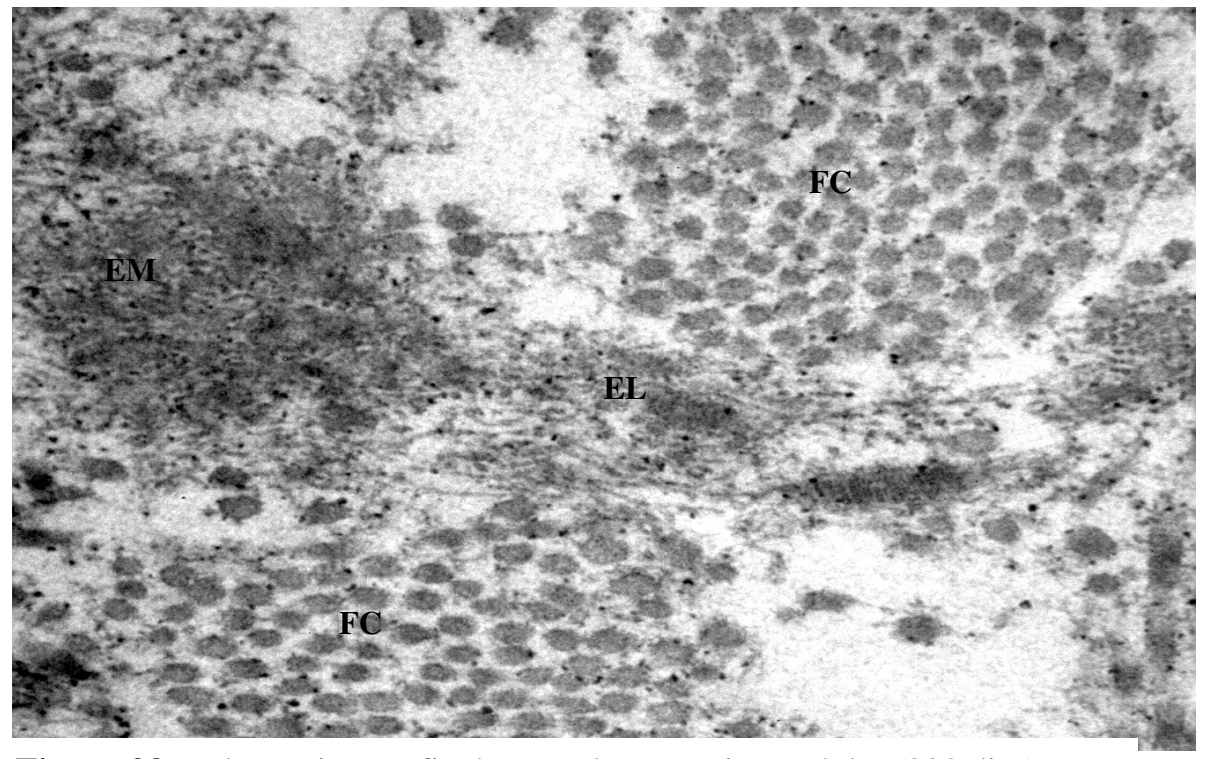

Figura 23 - Eletromicrografia da JVU de rato Wistar adulto (200 dias). Notar fibras eláticas maduras (EM) elaunínicas (EL) e fibras colágenas (FC). (100 K). 


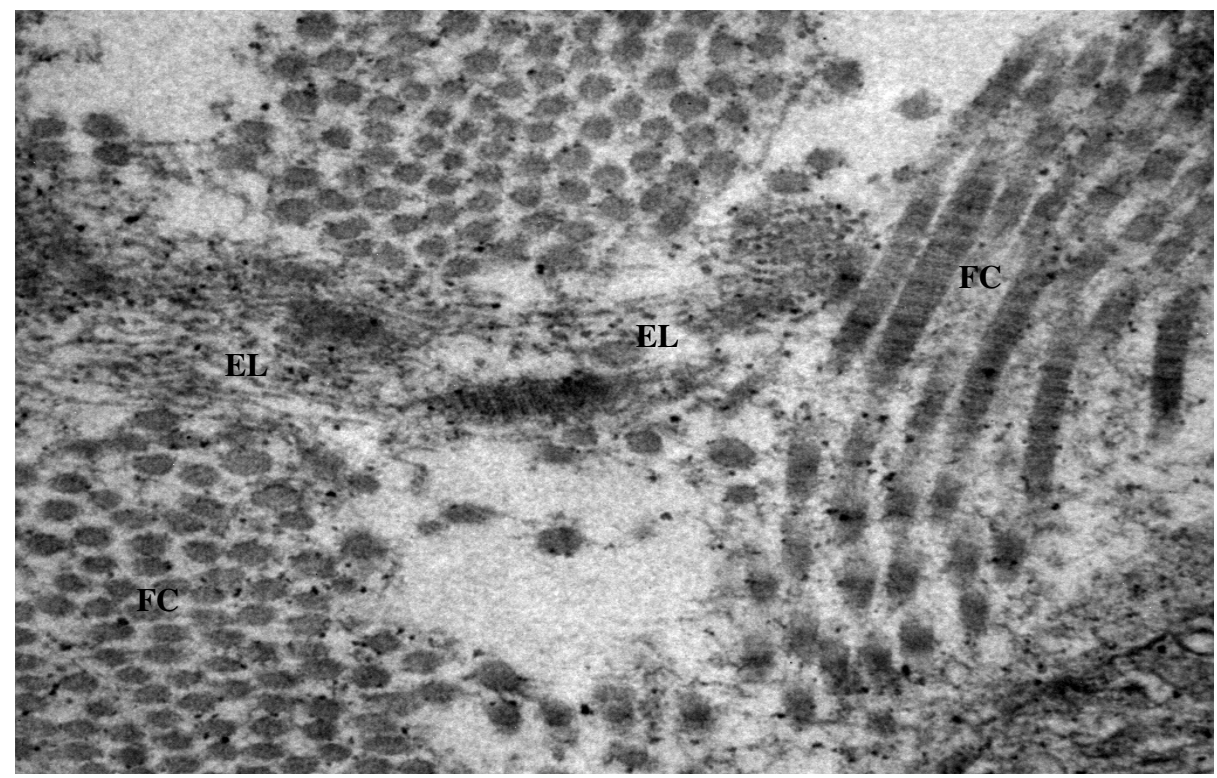

Figura 24 - Eletromicrografia da JVU de rato Wistar adulto (200 dias). Notar fibras elaunínicas (EL) e fibras colágenas (FC). (50K)

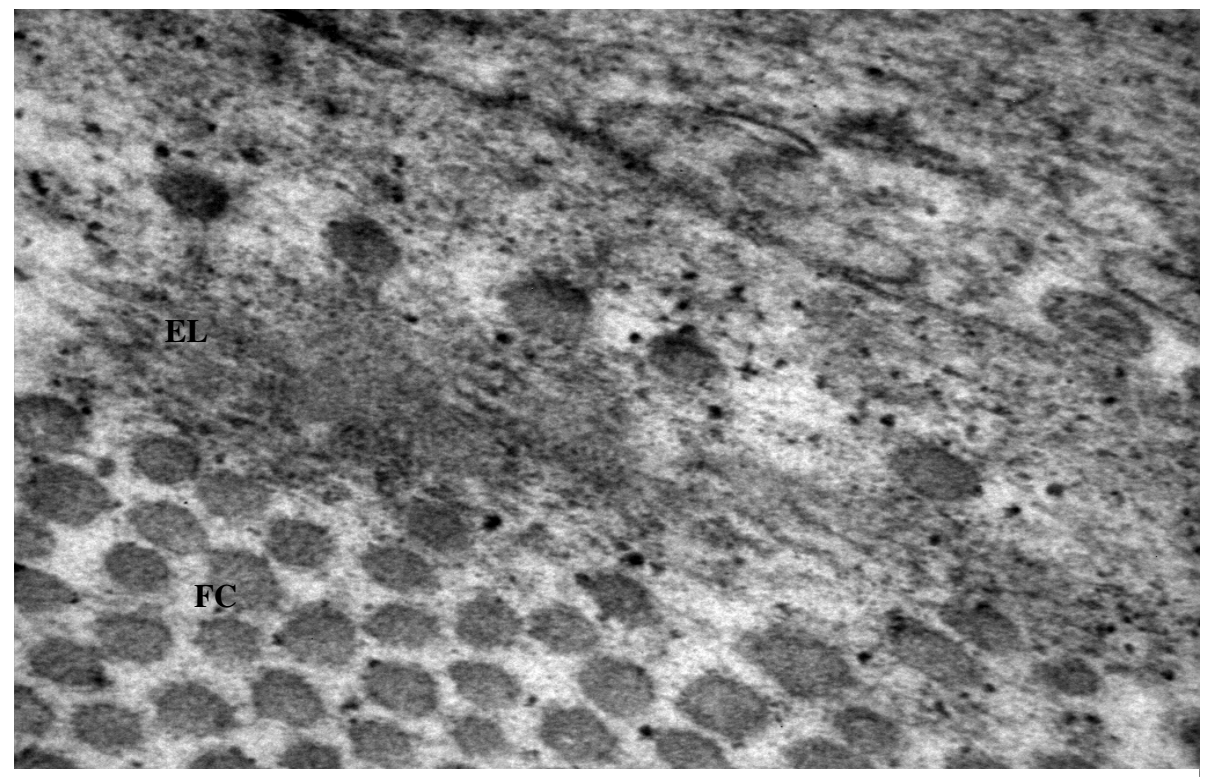

Figura 25 - Eletromicrografia da JVU de rato Wistar adulto (200 dias). Notar fibra elaunínica (EL) e fibras colágenas (FC). (100K) 


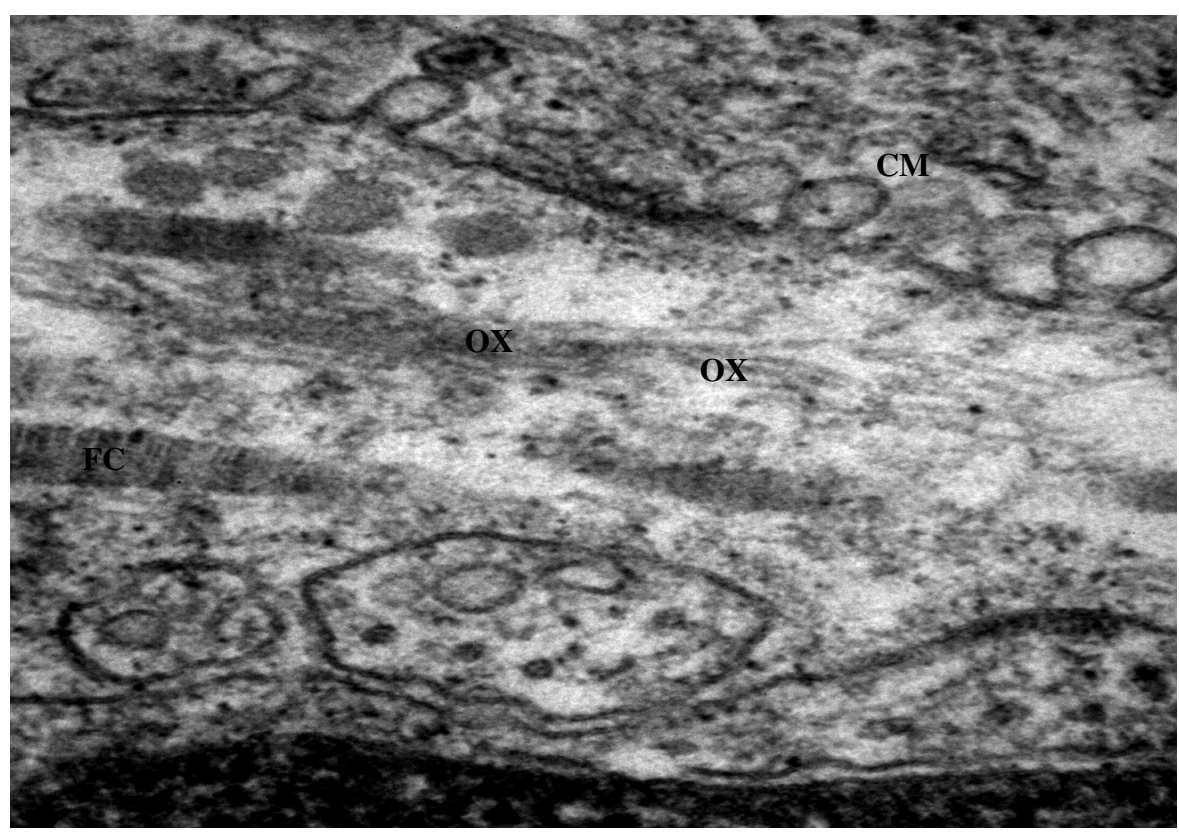

Figura 26 - Eletromicrografia da JVU de rato Wistar adulto (200 dias). Notar fibras oxitalânicas (OX), fibras colágenas (FC) e célula muscular (CM). (100K)

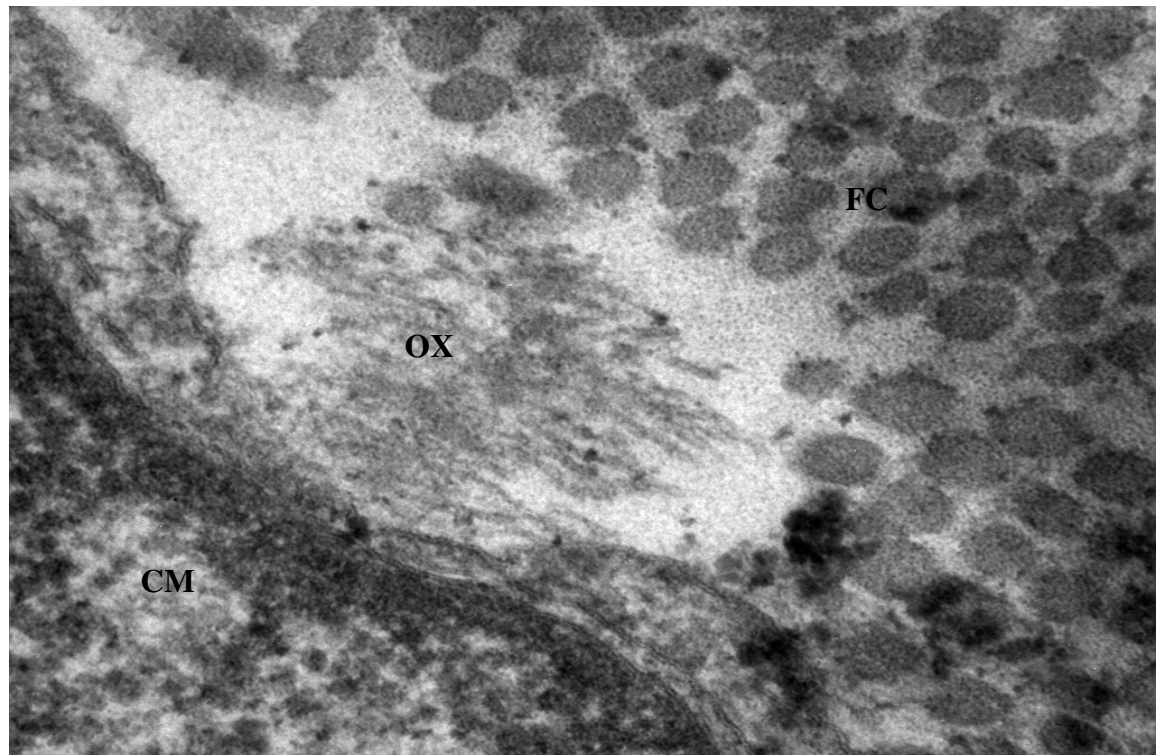

Figura 27 - Eletromicrografia da JVU de rato Wistar adulto (200 dias). Notar fibras oxitalânicas (OX), fibras colágenas (FC) e célula muscular (CM). (100K) 


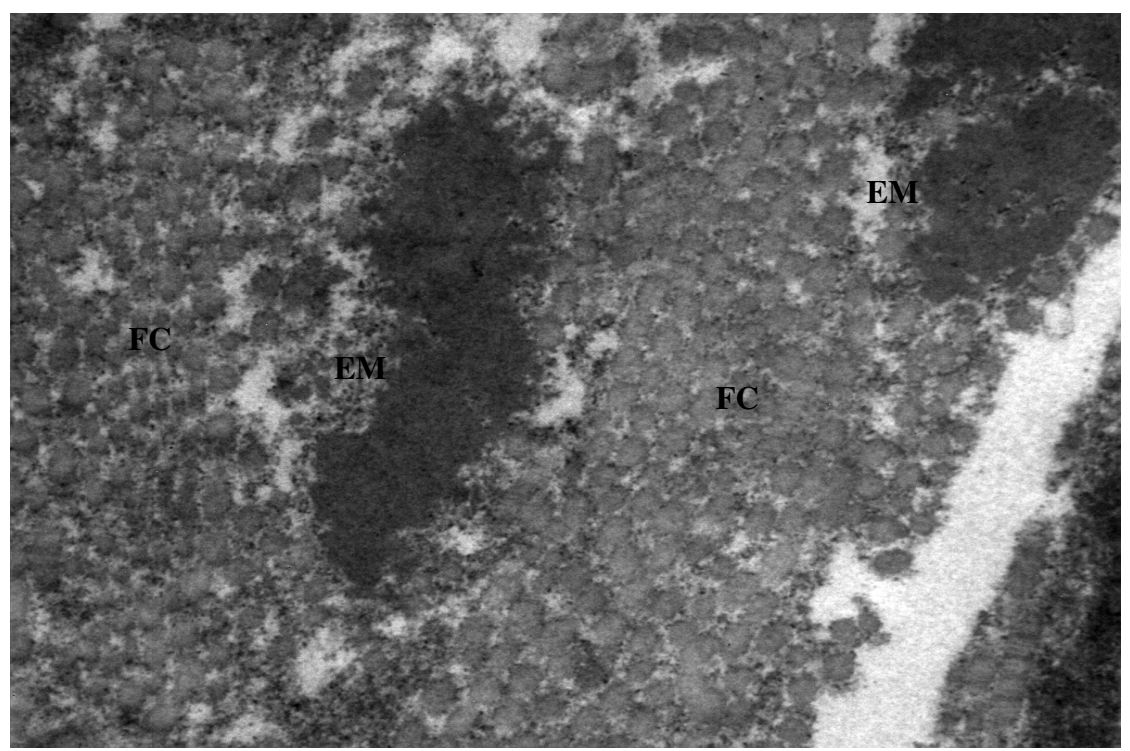

Figura 28 - Eletromicrografia da JVU de rato Wistar velho (450 dias). Notar fibra elástica madura (EM) e fibras colágenas (FC). $(40 \mathrm{~K})$

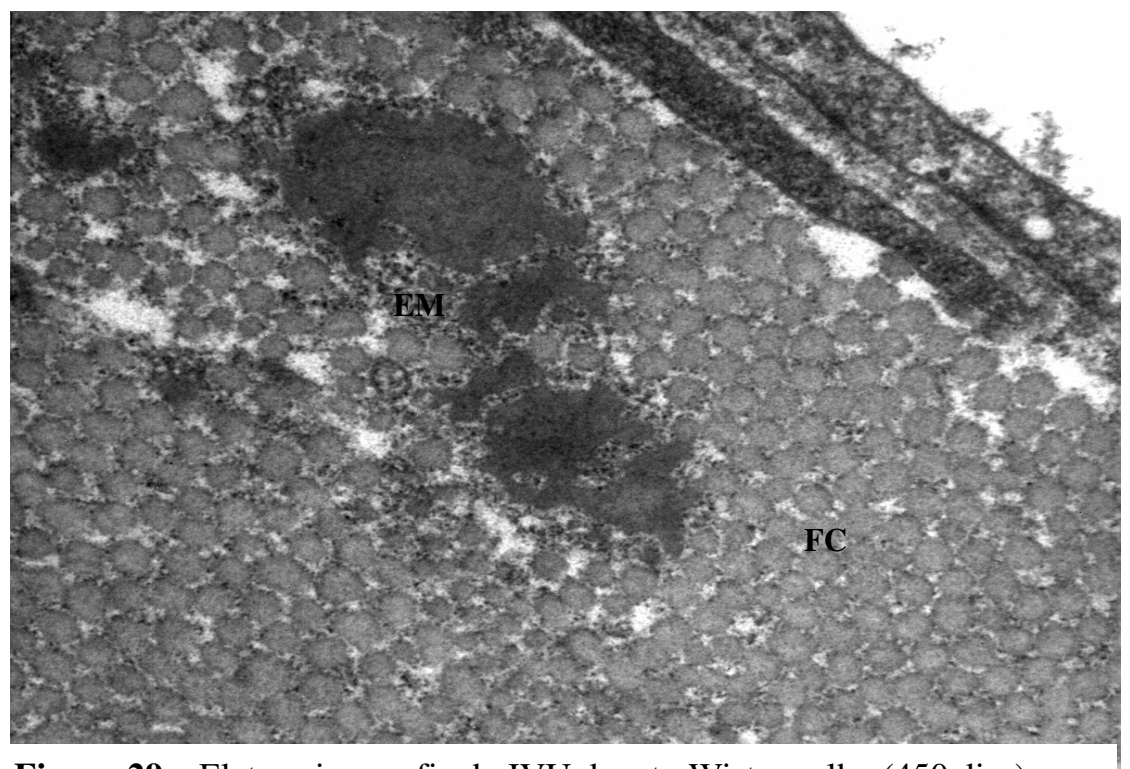

Figura 29 - Eletromicrografia da JVU de rato Wistar velho (450 dias). Notar fibras elásticas maduras (EM) e fibras colágenas (FC). $(50 \mathrm{~K})$ 


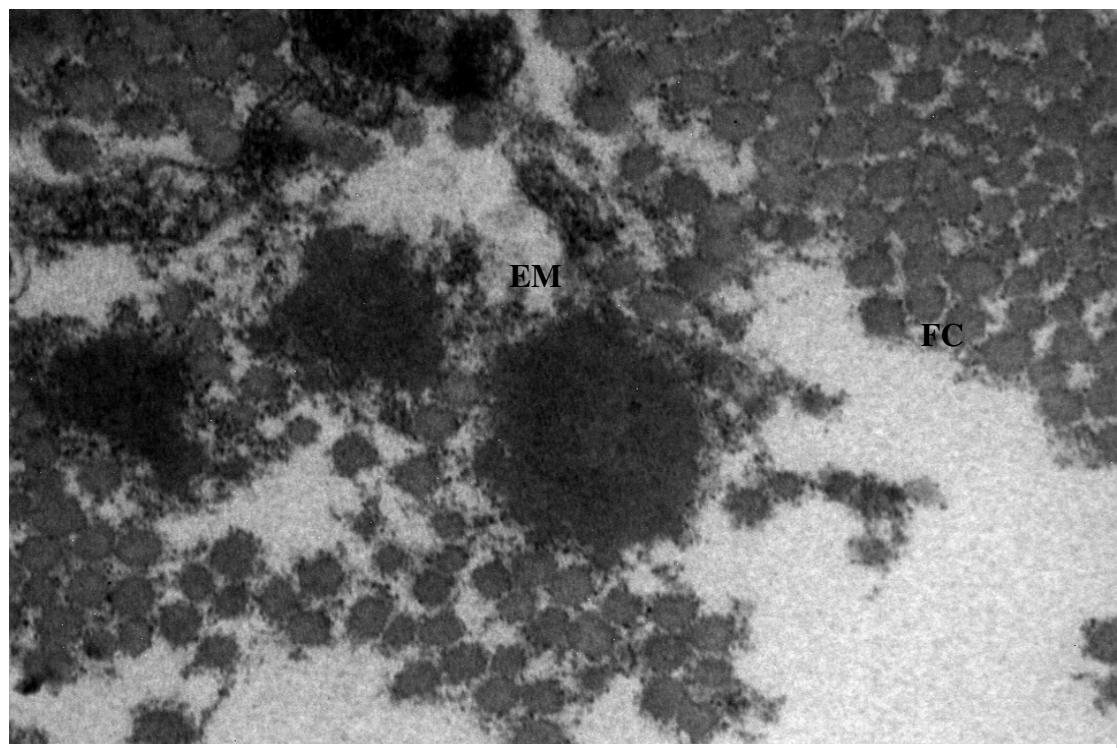

Figura 30 - Eletromicrografia da JVU de rato Wistar velho (450 dias). Notar fibras elasticas (EL) e fibras colágenas (FC). (50K)

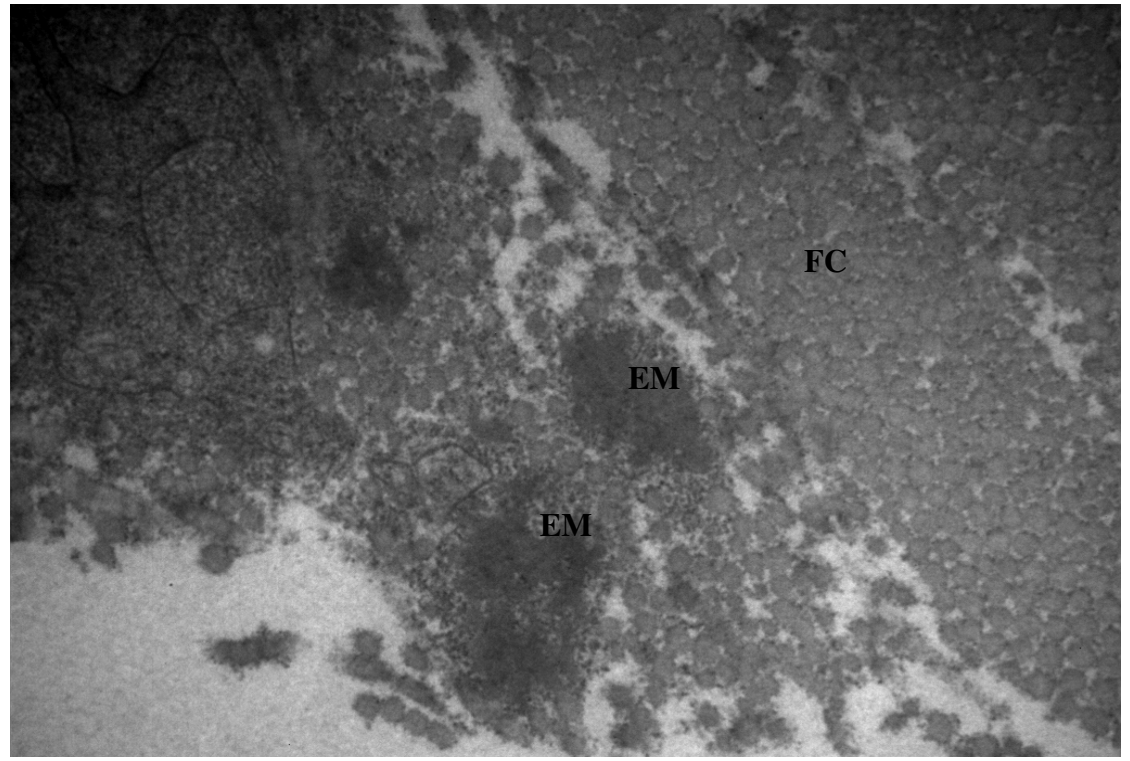

Figura 31 - Eletromicrografia da JVU de rato Wistar velho (450 dias). Notar fibras elástica madura (EM), elaunínicas (EL) e fibras colágenas (FC). (35K) 


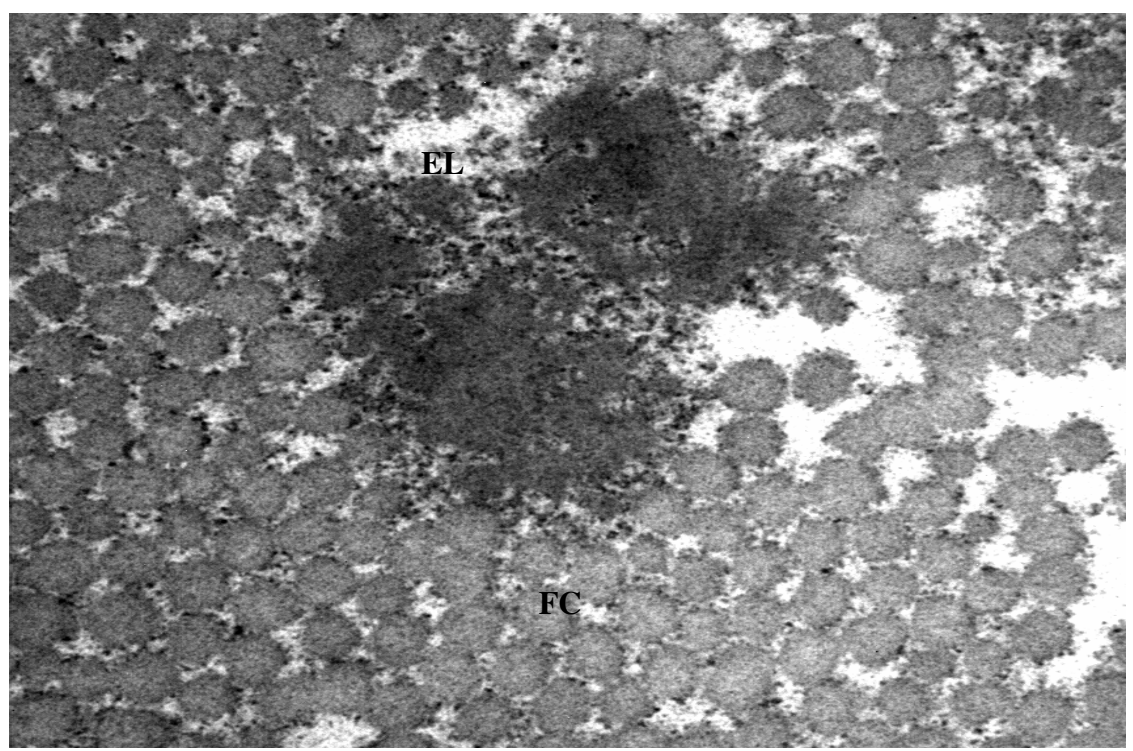

Figura 32 - Eletromicrografia da JVU de rato Wistar velho (450 dias). Notar fibras elaunínicas (EL) e colágenas (FC). (75K)

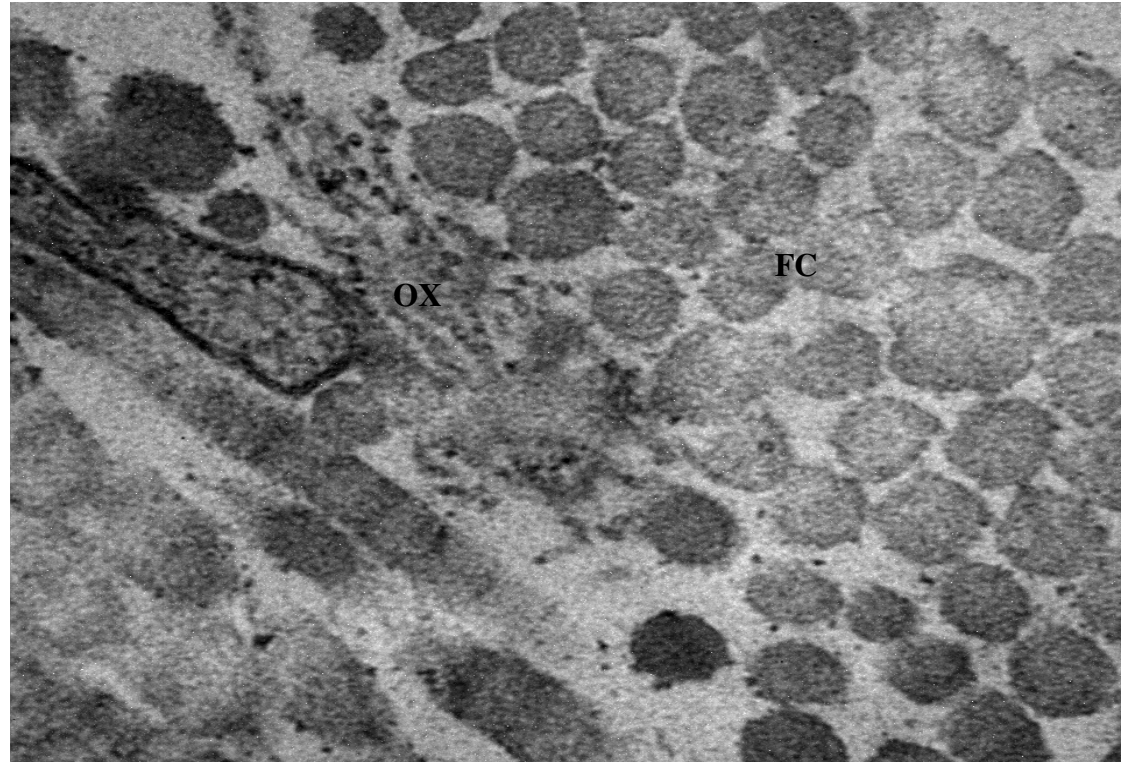

Figura 33 - Eletromicrografia da JVU de rato Wistar velho (450 dias). Notar fibras oxitlânicas (OX), fibras colágenas (FC). (100K) 


\subsection{Estudo Histomorfométrico}

Para a realização deste estudo utilizou-se de relações matemáticas entre a densidade linear e as idades dos animais em dois aspectos, primeiramente em relação aos métodos de coloração empregados e posteriormente para cada tipo de fibra presente na região estudada, resultando em comparações entre os grupos. Na figura 34, foi observada a densidade linear das fibras do sistema elástico em relação à idade (neonatos, adultos e velhos) nos três métodos de colorações usados (Verhoeff, Weigert e Weigert-Oxona). Quando observado os métodos de Verhoeff, que evidência as fibras elásticas maduras, Weigert, fibras elásticas maduras e elaunínicas e Weigert-Oxona, fibras elásticas maduras, elaunínicas e oxitalânicas, temos que a LD das fibras elásticas coradas por esses métodos, respectivamente, aumentam do grupo neonato (21 dias) para o grupo adulto (200 dias) e por outro lado, diminui com o envelhecimento, ou seja, do grupo adulto (200 dias) para o grupo velho (450 dias) $(\mathrm{p}<0,05)$, sendo que não houve relação significativa dos valores da LD entre os grupos neonato (21 dias) e velho (450 dias). Os valores das densidades lineares, de cada coloração estão dispostos nas tabelas 1,2 e 3 . Na figura 35 , foi analisada a LD de cada tipo de fibra que compõe o sistema elástico (elásticas maduras, elaunínicas e oxitalânicas) quanto à idade através das seguintes relações: $\mathrm{LD}$ Verhoeff $=$ LD fibras elásticas maduras; LD Weigert - LD Verhoeff = LD Elaunínicas; LD Weigert-Oxona - LD Elaunínicas - LD Verhoeff = LD Oxitalânicas, temos que as fibras elásticas maduras aumentam dos animais do grupo neonato (21 dias) para aqueles do grupo adulto (200 dias) $(\mathrm{p}<0,05)$ e diminui sua LD do grupo adulto (200 dias) para o velho (450 dias), não mostrando significância da LD entre os grupos neonato (21 dias) e velho (450 dias). As fibras elaunínicas em relação à sua $L D$, não demonstraram diferenças significativas entre os grupos neonato, adulto e velho. Por sua vez, a LD das fibras oxitalânicas diminuiu com o aumento da idade, dos animais adultos (200 dias) para os velhos 
(450 dias), não revelando valores significativos entre o grupo neonato (21 dias) com os grupos adulto (200 dias) e velho (450 dias).

Em análise às regressões quadráticas, observamos que a LD das fibras elásticas coradas pelos métodos Verhoeff, Weigert e Weigert-Oxona aumenta do grupo neonato (21 dias) para o grupo adulto (200 dias) e, deste grupo para o grupo velho (450 dias) há uma diminuição desta LD associado ao envelhecimento do animal (Figura 36). Quando observamos as fibras do sistema elástico, cada uma em separado vemos que a LD das fibras elásticas maduras e oxitalânicas, esta corada com o método de Verhoeff e aquela pelo método de Weigert, aumenta do grupo neonato (21 dias) para o grupo adulto (200 dias) e diminui do adulto para o velho (450 dias), entretando a LD das fibras elaunínicas (coradas com Weigert) aumenta com o aumento da idade de 21 dias para 450 dias, ou seja, no animal velho estas fibras estão com os valores de sua densidade linear aumentados (Figura 37). As médias da densidade linear da junção vésico-uretral de cada faixa etária das fibras elásticas do sistema elástico, tanto quanto às colorações como a tipificação, estão representadas nas tabelas 4 e 5 , respectivamente. 


\section{Densidade Linear Sistema Elástico - JVU (colorações)}

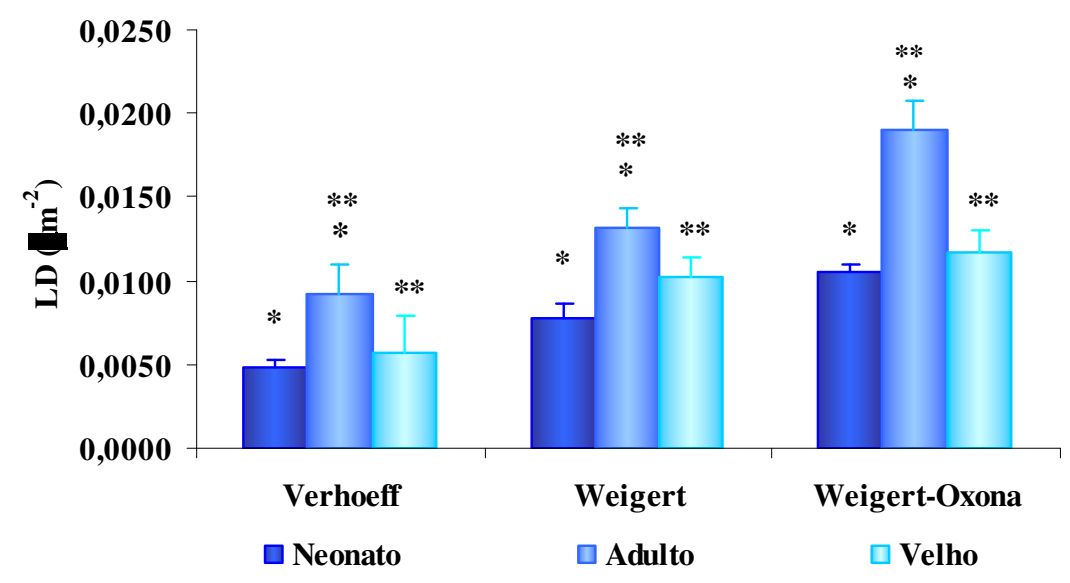

Figura 34 - Gráfico da LD das fibras do sistema elástico, de cada coloração, em relação à idade. Aumento da LD das fibras do sistema elástico do grupo neonato 21dias) para o grupo adulto* (200 dias) nas colorações Verhoeff, Weigert e Weigert-Oxona $(\mathrm{p}<0,05)$; Diminuição da LD das fibras do sistema elástico do grupo adulto (200 dias) para o grupo velho** (450 dias) nas colorações Verhoeff, Weigert e Weigert-Oxona $(\mathrm{p}<0,05)$. 


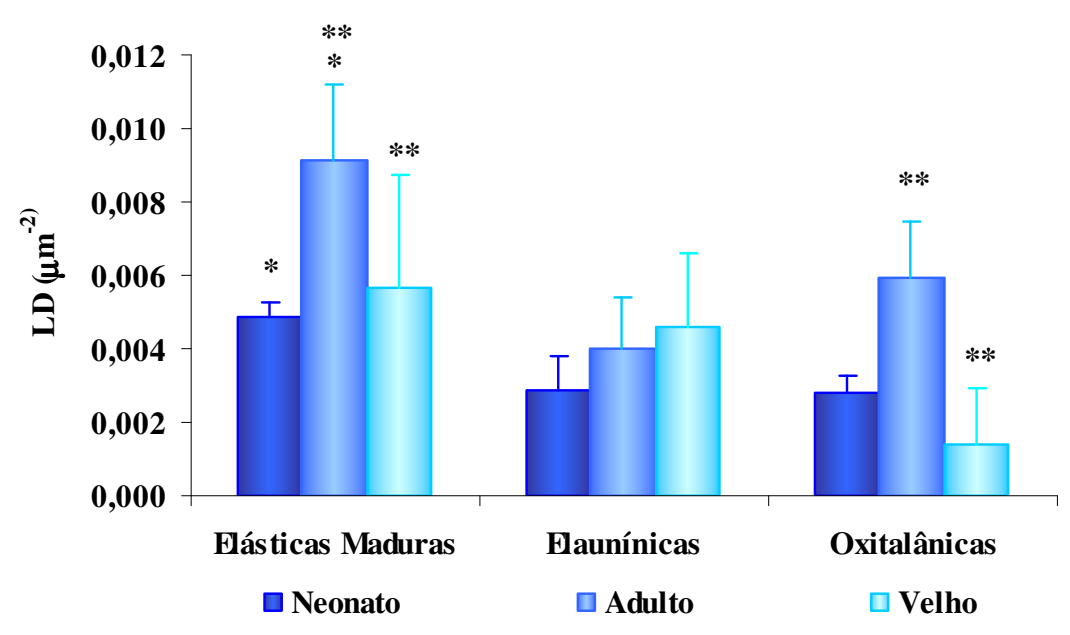

Figura 35 - Gráfico da LD, com tipificação das fibras do sistema elástico, em relação à idade. Aumento da LD das fibras elásticas maduras do grupo adulto (200 dias) para o grupo neonato* (21 dias) $(\mathrm{p}<0,05)$. Diminuição da LD das fibras elásticas maduras e das fibras oxitalânicas do grupo adulto (200 dias) para o grupo velho** (450 dias) $(\mathrm{p}<0,05)$. 


\section{Densidade Linear Sistema Elástico - JVU (colorações)}

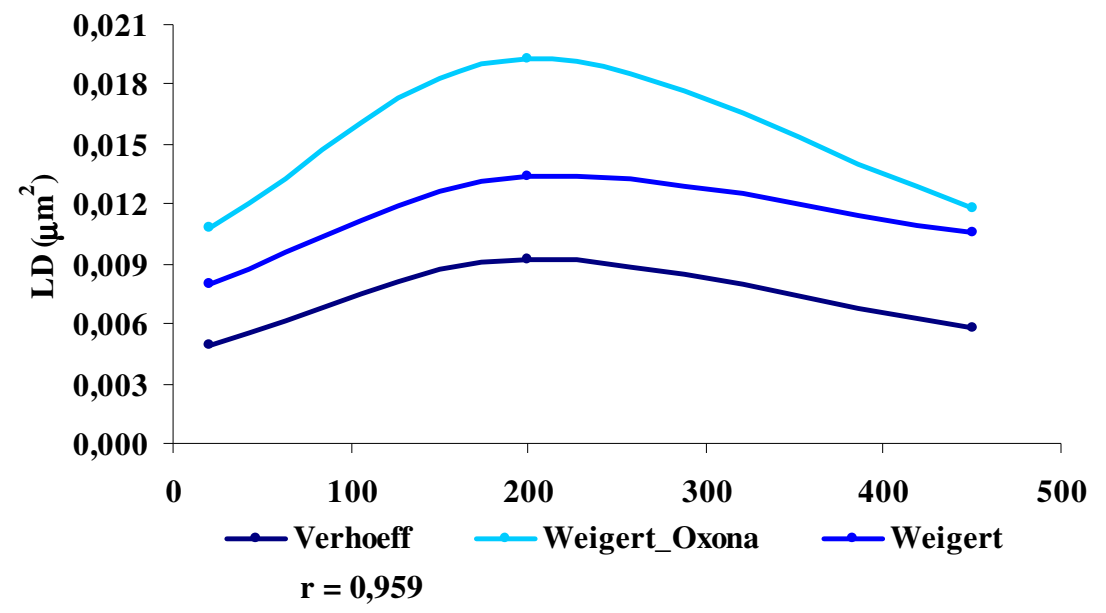

Figura 36 - Curva de regressão quadrática dos valores da LD das fibras do sistema elástico, para cada coloração, em relação à idade.

\section{Densidade Linear Fibras Elásticas - JVU}

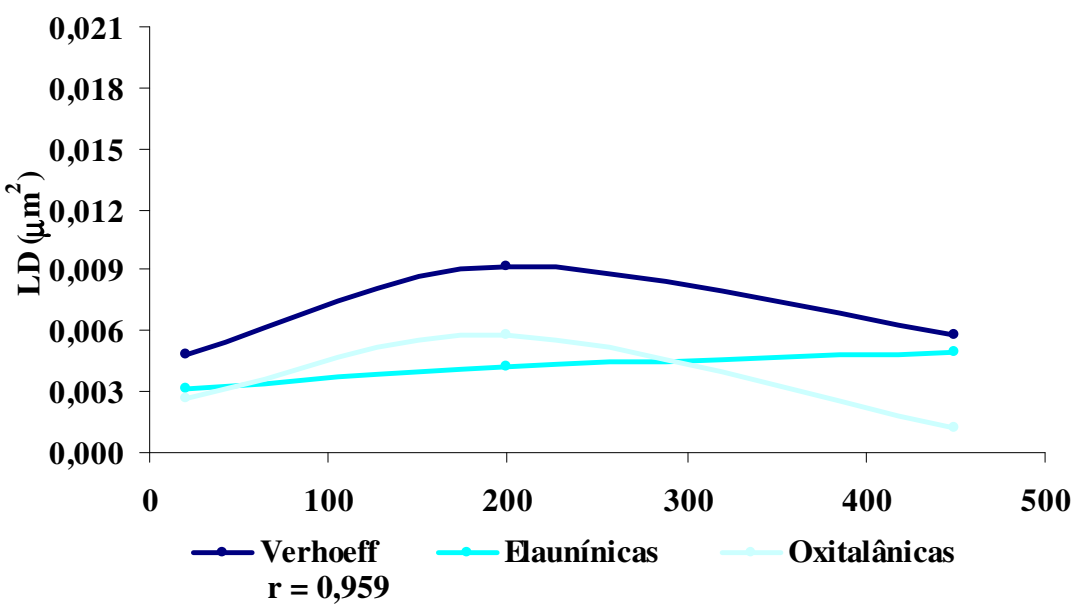

Figura 37 - Curva de regressão quadrática da LD, com tipificação das fibras do sistema elástico, em relação à idade. 
Tabela 1 - Valores das Densidades Lineares de Cada Animal em Cada Faixa Etária na Coloração de Verhoeff.

\begin{tabular}{c|c|c|c|c|c|c|c}
\hline PU & CR & DIAS & $\begin{array}{c}\mathbf{f}= \\
\text { PU/PT }\end{array}$ & AT & $\begin{array}{c}\mathbf{A}=\mathbf{A T ~ x} \\
\mathbf{F}\end{array}$ & $\begin{array}{c}\mathbf{C}= \\
\mathbf{C R X 2}\end{array}$ & $\begin{array}{c}\mathbf{L D}= \\
\mathbf{2 X C / A}\end{array}$ \\
\hline 17.538 & 421 & 21 & 0,8769 & 386250 & 338702,62 & 842 & 0,0049719 \\
\hline 18.369 & 435 & 21 & 0,91845 & 386250 & 354751,31 & 870 & 0,0049048 \\
\hline 18.279 & 443 & 21 & 0,91395 & 386250 & 353013,18 & 886 & 0,0050196 \\
\hline 17.356 & 346 & 21 & 0,8678 & 386250 & 335187,75 & 692 & 0,004129 \\
\hline 17.917 & 446 & 21 & 0,89585 & 386250 & 346022,06 & 892 & 0,0051557 \\
\hline 17.832 & 845 & 200 & 0,8916 & 386250 & 344380,5 & 1.690 & 0,0098147 \\
\hline 17.739 & 686 & 200 & 0,88695 & 386250 & 342584,43 & 1.372 & 0,0080097 \\
\hline 17.755 & 777 & 200 & 0,88775 & 386250 & 342893,43 & 1.554 & 0,009064 \\
\hline 18.049 & 750 & 200 & 0,90245 & 386250 & 348571,31 & 1.500 & 0,0086065 \\
\hline 17.541 & 862 & 200 & 0,87705 & 386250 & 338760,56 & 1.736 & 0,0102491 \\
\hline 16.675 & 461 & 450 & 0,83375 & 386250 & 322035,93 & 922 & 0,005726 \\
\hline 17.298 & 498 & 450 & 0,8649 & 386250 & 334067,62 & 996 & 0,0059628 \\
\hline 17.263 & 449 & 450 & 0,86315 & 386250 & 333391,68 & 898 & 0,005387 \\
\hline 17.708 & 530 & 450 & 0,8854 & 386250 & 341985,75 & 1.060 & 0,006199 \\
\hline 16.906 & 421 & 450 & 0,8453 & 386250 & 326497,12 & 842 & 0,0051577 \\
\hline
\end{tabular}


Tabela 2 - Valores das Densidades Lineares de Cada Animal em Cada Faixa Etária na Coloração de Weigert.

\begin{tabular}{c|c|c|c|c|c|c|c}
\hline PU & CR & DIAS & $\begin{array}{c}\mathbf{f =} \\
\text { PU/PT }\end{array}$ & AT & $\begin{array}{c}\text { A = AT X } \\
\text { F }\end{array}$ & $\begin{array}{c}\mathbf{C}= \\
\text { CRX2 }\end{array}$ & $\begin{array}{c}\text { LD }= \\
\text { 2XC/A }\end{array}$ \\
\hline 17.559 & 889 & 21 & 0,87795 & 386250 & 339108,18 & 1.778 & 0,0104863 \\
\hline 17.327 & 614 & 21 & 0,86635 & 386250 & 334627,68 & 1.228 & 0,0073395 \\
\hline 17.116 & 485 & 21 & 0,8558 & 386250 & 330552,75 & 970 & 0,0058689 \\
\hline 18.062 & 751 & 21 & 0,9031 & 386250 & 348822,37 & 1.502 & 0,0086118 \\
\hline 17.919 & 544 & 21 & 0,89595 & 386250 & 346060,68 & 1.088 & 0,0062879 \\
\hline 18.113 & 1.006 & 200 & 0,90565 & 386250 & 349807,31 & 2.012 & 0,0115034 \\
\hline 17.648 & 1.123 & 200 & 0,8824 & 386250 & 340827 & 2.246 & 0,0131797 \\
\hline 17.659 & 1.076 & 200 & 0,88295 & 386250 & 341039,43 & 2.152 & 0,0126202 \\
\hline 18.202 & 1.179 & 200 & 0,9101 & 386250 & 351526,12 & 2.358 & 0,0134157 \\
\hline 17.950 & 1.290 & 200 & 0,8975 & 386250 & 346659,37 & 2.580 & 0,0148849 \\
\hline 17.443 & 904 & 450 & 0,87215 & 386250 & 336867,93 & 1.808 & 0,0107341 \\
\hline 17.782 & 1.051 & 450 & 0,8891 & 386250 & 343414,87 & 2.102 & 0,0122417 \\
\hline 17.363 & 927 & 450 & 0,86815 & 386250 & 335322,93 & 1.854 & 0,0110580 \\
\hline 17.875 & 837 & 450 & 0,89375 & 386250 & 345210,93 & 1.674 & 0,0096984 \\
\hline 17.701 & 661 & 450 & 0,88505 & 386250 & 341850,56 & 1.322 & 0,0077343 \\
\hline
\end{tabular}


Tabela 3 - Valores das Densidades Lineares de Cada Animal em Cada Faixa Etária na Coloração de Weigert.

\begin{tabular}{c|c|c|c|c|c|c|c}
\hline PU & CR & DIAS & $\begin{array}{c}\mathbf{f}= \\
\text { PU/PT }\end{array}$ & AT & $\begin{array}{c}\text { A }=\text { AT X } \\
\mathbf{F}\end{array}$ & $\begin{array}{c}\mathbf{C}= \\
\mathbf{C R X 2}\end{array}$ & $\begin{array}{c}\text { LD }= \\
\text { 2XC/A }\end{array}$ \\
\hline 16.995 & 1.002 & 21 & 0,84975 & 386250 & 328215,93 & 2.004 & 0,0122114 \\
\hline 17.820 & 902 & 21 & 0,891 & 386250 & 344148,75 & 1.804 & 0,0104838 \\
\hline 18.019 & 1.118 & 21 & 0,9009 & 386250 & 347991,93 & 2.236 & 0,0128508 \\
\hline 18.408 & 651 & 21 & 0,9204 & 386250 & 355504,5 & 1.302 & 0,0073248 \\
\hline 17.896 & 854 & 21 & 0,8948 & 386250 & 345616,5 & 1.708 & 0,0098837 \\
\hline 17.685 & 1.640 & 200 & 0,88425 & 386250 & 341541,56 & 3.280 & 0,0192070 \\
\hline 18.209 & 1.789 & 200 & 0,91045 & 386250 & 351661,31 & 3.578 & 0,0203491 \\
\hline 18.052 & 1.594 & 200 & 0,9026 & 386250 & 348629,25 & 3.188 & 0,0182887 \\
\hline 18.104 & 1.742 & 200 & 0,9052 & 386250 & 349633,5 & 3.484 & 0,0199294 \\
\hline 18.292 & 1.544 & 200 & 0,9146 & 386250 & 353264,25 & 3.088 & 0,0174826 \\
\hline 17.564 & 844 & 450 & 0,8782 & 386250 & 339204,75 & 1.688 & 0,0099526 \\
\hline 17.370 & 1.111 & 450 & 0,8685 & 386250 & 335458,12 & 2.222 & 0,0132475 \\
\hline 17.370 & 1.040 & 450 & 0,8685 & 386250 & 335458,12 & 2.080 & 0,0124009 \\
\hline 18.640 & 1.073 & 450 & 0,932 & 386250 & 359985 & 2.146 & 0,0119227 \\
\hline 17.674 & 939 & 450 & 0,8837 & 386250 & 341329,12 & 1.878 & 0,011004 \\
\hline
\end{tabular}


Tabela 4 - Valores Médios da Densidade Linear das Fibras do Sistema Elástico da JVU (Colorações)

\begin{tabular}{c|c|c|c}
\hline Grupo & Verhoeff & Weigert & Weigert-Oxona \\
\hline Neonato & 0,004836 & 0,007719 & 0,010535 \\
\hline Adulto & 0,009146 & 0,013120 & 0,019052 \\
\hline Velho & 0,005687 & 0,010293 & 0,011706 \\
\hline
\end{tabular}

Tabela 5 - Valores Médios da Densidade Linear das Fibras do Sistema Elástico da JVU

\begin{tabular}{c|c|c|c}
\hline Grupo & Elástica Madura & Elaunínica & Oxitalânica \\
\hline Neonato & 0,004836 & 0,002883 & 0,002816 \\
\hline Adulto & 0,009146 & 0,003974 & 0,005932 \\
\hline Velho & 0,005687 & 0,004607 & 0,001412 \\
\hline
\end{tabular}




\section{DISCUSSÃO}

O sistema de fibras elásticas,tem sido evidenciado em vários tecidos como na aorta (GAWLIK, 1965; GOLDFISCHE et al., 1983), pele (COTTA-PEREIRA et al., 1975), periodonto (FULLMER e LILIE, 1958; FULLMER, 1978; SAWADAculean et al., 2006, SCULEAN et al., 1997), ducto deferente (PANIAGUA et al., 1983), cápsula esplênica (SACHETTI, 1996), musculatura lisa (CARVALHO et al., 1997), coração (SOUZA et al., 1996), junção vésico-uretral (AWAD et al., 1976; DASS et al., 1999; LÁPIDES, 1958), uretra (BUMP et al., 1988), próstata (KARLINSKI et al., 1976), fáscia transversal iguinal (RODRIGUES, Jr. et al., 1990), pulmão (NIEWOEHNER et al., 1994), colo vesical (ROTHER et al., 1996), neste estudo também confirmamos a distribuição das fibras do sistema elástico na junção vésico-uretral concordando com os achados de Lápides (1958); Awad et al. (1976) e Dass et al. (1999) referentes à mesma estrutura.

Trabalhos prévios como de Beertesen et al. (1974); Cotta-Perira et al., 1977; Everts et al. (1998) ; Fullmer et al., (1974) Gawlik (1965); Sakai et al., 1986; Sims et al. (1973, 1975); Takagi et al. (1989) relataram que as fibras que compõem o sistema elástico são evidenciadas, na microscopia de luz, pelos métodos de coloração hematoxilina férrica (Verhoeff), resorcinafucsina (Weigert) e resorcina-fucsina com prévia oxidação (Weigert-Oxona), corando fibras elásticas maduras, fibras elásticas maduras e elaunínicas, fibras elásticas maduras, elaunínicas e oxitalânicas, respectivamente. Em nosso trabalho, também foi possível identificar e tipificar o sistema elástico, através da microscopia de luz com o uso dessas colorações específicas, em que foi possível realizar a evidenciação das fibras elásticas maduras, elaunínicas e oxitalânicas na JVU, sendo assim observamos que essas fibras estão localizadas em toda a camada muscular da JVU não estando organizadas em feixes, cadeias ou lâminas como 
aquelas encontradas na pele (KIELTY et al., 2002), ducto deferente (PANIAGUA et al., 1983).

A tipificação ultra-estrutural, das fibras do sistema elástico, através da microscopia eletrônica de transmissão e uso da técnica do ácido tânico foi estudada por alguns autores, onde se preconizou que o uso do ácido tânico marca o componente amorfo das fibras elásticas intensamente (KAJIKAWA et al., 1975) e uma vizualização uniforme e fiel das fibras elásticas é alcançada se o fixador (glutaraldeído) conter ácido tânico, havendo um aumento da densidade eletrônica da elastina e microfibrilas (COTTA-PEREIRA et al., 1976), em nossa pesquisa concordamos com os autores que ocorre uma melhor marcação da elastina e das microfibrilas presentes na composição ultra-estrutural das fibras do sistema elástico através da utilização do ácido tânico associado ao fixador glutaraldeído, onde também conseguimos evidenciar cada tipo de fibra elástica em relação às diferenças que estas apresentam quanto a sua ultra-estrutura, em que as fibras elásticas maduras apresentaram um material amorfo fortemente eletrodenso, compacto e abundante, composto por elastina apenas, concordando com os achados de Kajikawa et al. (1975); Cotta-Pereira et al. (1976); Souza et al. (1996) e Sachetti (1996) as fibras elaunínicas, por sua vez, caracterizaram-se ultra-estruturalmente por serem constituídas por escasso material amorfo disperso em meio ao componente microfibrilas, assim como evidenciado previamente por Cotta-Pereia et al. $(1976,1977)$; Sachetti (1996), já as fibras oxitalânicas estão representadas por feixes de microtúbulos dispostos paralelamente, confirmando os achados de Avery et al. (1980), Carvalho et al. (1996); Sachetti (1996). Verificamos também que as fibras elásticas da JVU encontram-se nos espaços intercelulares da camada muscular e entre os feixes de fibras colágenas, apresentando assim, a mesma localização das fibras elásticas do ducto deferente como relatado previamente por Paniagua et al. (1983) em estudo eletro-microscópico desta estrutura. 
Alguns autores colocam que o arranjo das fibras do sistema elástico nos tecidos se refletem nas funções que elas deveram desempenhar, sejam de suporte, elasticidade, resiliência, complacência, expansão ou recuo elástico (CARVALHO et al., 1997; COTTAPEREIRA et al., 1977, KIELTY et al., 2002, ROSS et al, 1969; USHIKIK et al., 1991, 2002), visto que em nosso estudo observamos grande quantidade dos três tipos de fibras elásticas na JVU estando dispersas em toda a musculatura, assim associando este achado com sua função e principalmente a do óstio interno da uretra, de elasticidade, plasticidade, expansão e recuo rápido com o fluxo da urina, evidenciamos então que o sistema elástico da JVU está presente em toda a muscular e em várias direções para desempenhar a elasticidade, fornecimento de pressão de fechamento do local em repouso, e principalmente a propriedade de recuo elástico sem haver deformação da estrutura após a passagem da urina, complementando desta forma a ação muscular e lhe dando suporte, exercendo sobre a JVU não apenas uma, mas várias funções, confirmando os achados de Awad et al. (1976); Bump et al. (1988); Dass et al. (1999); Gosling et al. (1983); Woodburne (1961) tornando a JVU em um tecido com flexibilidade dinâmica e de extensibilidade reversível. Sabemos também que cada tipo de fibra elástica desempenha uma função, sendo esta determinada pela quantidade de elastina e microtúbulos, onde a elastina é responsável pela elasticidade e recuo elástico (ROSS et al., 1969) e os microtúbulos por fornecer complacência durante a contração da musculatura lisa, ancoragem e flexibilidade de rearranjo estrutural, prevenindo um super-estiramento tecidual (CARVALHO et al., 1997), através disso determinamos que as fibras oxitalânicas na JVU estão presentes por ser esta região submetida a constante tensão, reforçando esta definição clássica das funções dos microtúbulos nos tecidos, como relatado pelos autores. Por outro lado, as fibras elásticas maduras (elastina), tornam-se responsáveis pela elasticidade e recuo elástico da JVU e por sua vez, as fibras elaunínicas assume função intermediária entre as oxitalânicas e as elásticas maduras fornecendo adaptação funcional à JVU, conforme descrito 
previamente por Cotta-Pereira et al. $(1977,1984)$ em estudo na pele, assim a função de uma fibra elástica complementa a ação da outra e forma na JVU um sistema microfibrila-elastina, como já descrito por Ushiki (2002) funcionando como um distribuidor uniforme das forças de tensão no tecido, mantenedor da resiliência tecidual e adaptação do local para o fluxo urinário.

Vários estudos, ao longo dos anos, relatam algumas alterações do sistema elástico em relação ao envelhecimento do tecido, em nossos achados com relação ao sistema elástico presente na JVU de ratos Wistar e o avanço da idade destes animais observamos que a densidade linear das fibras elásticas é diferente entre os animais neonatos, adultos e velhos, concordando com os achados de Souza et al. (1996) em coração humano, em que a o comprimento das fibras elásticas por unidade de volume estava diferente para crianças, adultos e idosos e com Carvalho et al. (1997) que relataram que durante o processo de envelhecimento ocorrem alterações nas fibras do sistema elástico. Quanto à densidade linear de cada tipo de fibra do sistema elástico da JVU, obtemos que a densidade linear das fibras elásticas maduras aumentou do neonato para o adulto, mas diminui do adulto para o velho complementando os achados de Sephel et al. (1986) e Uitto (1998) que afirmam que com o avanço da idade ocorre um declínio nas taxas de biossíntese de elastina, afirmando que na JVU ocorre o processo inverso que no ducto deferente, em que Paniagua et al. (1983) verificou que há um aumento de elastina com relação ao avanço da idade, exceto com relação às fibras oxitalânicas, que nesta estrutura está menos numerosa, assim como na JVU, onde a densidade linear destas fibras também diminui nos animais velhos, ocorrendo também o mesmo com os achados de Rodrigues, Jr. et al. (1990) em estudo da fáscia transversa inguinal, que com o aumento da idade há uma diminuição de fibras oxitalânicas e um aumento de fibras elásticas maduras e concordando com Barros et al. (2002) que com o envelhecimento há uma indução no desaparecimento das fibras oxitalânicas. As fibras elaunínicas, em nosso estudo, 
foi o único tipo de fibra da JVU que apresentou sua densidade linear aumentando tanto do animal neonato para o adulto, como deste para o velho, ou seja, com o envelhecimento. Conseqüentemente se há uma diferença nas densidades lineares das fibras elásticas, então também teremos uma mudança nas funções da JVU com o envelhecimento, funções estas relacionadas apenas com o sistema elástico, portanto se a densidade linear das fibras elásticas maduras diminui com o envelhecimento, subtende-se que através da diminuição das fibras elásticas maduras, há proporcionalmente uma queda na quantidade de elastina na JVU. Segundo Cotta-Pereira et al. (1977) as propriedades elásticas e a propriedade de recuo elástico são determinadas pela presença de elastina, assim se há uma diminuição de fibras elásticas maduras temos uma diminuição na capacidade de recuo elástico da região estudada com o processo de envelhecimento. Com relação às fibras oxitalânicas que estão presentes em tecidos submetidos à tensão (FULLMER e LILLIE, 1958) e com funções de ancoragem e manutenção da elasticidade (SIMS et al., 1973), a JVU terá uma diminuição destas funções em animais velhos, visto que em nosso trabalho a densidade linear das fibras oxitalânicas está diminuída nestes animais. Quanto às fibras elaunínicas nossos resultados apontaram um aumento da densidade linear destas fibras que são formadas por microtúbulos e elastina (COTTA-PEREIRA et al., 1977), estando relacionadas também à ancoragem, então no envelhecimento, como estas fibras possuem características intermediárias entre as fibras elásticas maduras e oxitalânicas (COTTA-PEREIRA et al., 1984), elas irão manter, no animal velho, a resitência à tensão e a plasticidade da JVU, alguma elasticidade e propriedade de recuo elástico, sendo estas funções provavelmente diminuídas, mas não ausentes.

No nosso entendimento as alterações do sistema elástico que ocorrem nos animais velhos, estão associados ao processo natural de envelhecimento, e certamente com a diminuição da tonicidade muscular, tornaram o esfincter fisiológico mais permeável, favorecendo processos progressivos de incontinência urinária, sendo que sozinhas, as fibras 
elásticas não são responsáveis por este estado patológico, pois estudos evidenciaram que a incontinência urinária ocorre por problemas urodinâmicos como deficiência ou ausência da atividade detrusora, pressão uretral sobre ativa ou incompetente levando a alterações pressóricas intra-vesicais indesejáveis (FENELEY et al., 1982), patologias sistêmicas e psicológicas e uso de alguns fármacos (RESNICK et al., 1985).

A ação esfinctérica e a manutenção pressórica dependem não só da morfologia da JVU, mas também da parede uretral, que funcionam associadas ao diafragma pélvico, que suporta o colo vesical direta ou indiretamente.

Acreditamos que na JVU a distribuição das fibras elásticas é homogênea existindo um sistema mioelástico formado pelo sistema elástico juntamente com a muscular e as fibras colágenas presentes, onde os achados de microscopia eletrônica de transmissão revelaram qualitativamente, um aumento no contingente do conteúdo colágeno nos animais velhos. Assim, se transferirmos os achados nos animais para o homem, hipoteticamente, podemos supor que o sistema elástico na JVU serve como suporte compensatório da camada muscular do trígono por ela apresentar mais alterações funcionais no processo de envelhecimento e também ser um alvo propício para patologias e intervenções cirúrgicas, sendo que através do aumento das fibras elaunínicas, provavelmente há um remodelamento do sistema elástico durante o envelhecimento natural da junção vésico-uretral, bem como de todo o trato urinário inferior, devido a isto atribuímos ao sistema elástico na JVU uma responsabilidade indireta de manutenção da continência urinária independente da faixa etária que o espécime se encontra. 


\section{CONCLUSÕES}

No presente trabalho concluímos que:

- Nas três faixas etárias estudadas, estão presentes todos os tipos de fibras do sistema elástico;

- As diferenças ultra-estruturais das fibras elásticas na JVU podem ser distinguidas através da técnica do ácido tânico associado ao glutaraldeído nas preparações das peças para a microscopia eletrônica de transmissão, em que as fibras elásticas maduras possuem um componente amorfo eletrodenso e compacto, as elaunínicas um componente microtubular mais abundadnte que o componete anorfo e as oxitalânicas formadas exclusivamente por microtúbulos;

- As fibras elásticas maduras e as oxitalânicas apresentaram seu comprimento total diminuídos com o avanço da idade, enquanto que as fibras elaunínicas tiveram seu comprimento aumentado com o envelhecimento;

- O sistema elástico da JVU não é um componente que determina o aparecimento da incontinência urinária no processo fisiológico de envelhecimento;

- O sistema elástico na região é indiretamente responsável pela continência urinária, em todas as faixas etárias estudadas e no animal velho atua como suporte para a musculatura lisa do local que provavelmente tem alterações mais relevantes com o avanço da idade do que o próprio sistema elástico. 


\section{REFERÊNCIAS BIBLIOGRÁFICAS*}

ALBERT, E. N. Developing elastic tissue. An electron microscopic study. The American Journal of Pathology, v. 69, p. 89-102, 1972.

AVERY, J. K.; SIMMONS, T. A. Electron dense staining affinities of mouse oxytalan and elastic fibers. Journal of Oral Pathology, v. 9, p. 183-188, 1980.

BADWAY, A.; SCHENCK, E. A. A new theory of the innervation of bladder musculature: III Inervation of the vesico-urethral junction and external sphincter. The Journal of Urology, v. 111, p. 613, 1974.

BARROS, E. M. K. P.; RODRIGUES, C. J.; RODRIGUES, N. R. Aging of the elastic and collagen fibers in the human cervical interspinous ligaments. The Spine Journal, v. 2, p. 57$62,2002$.

BASKIN, S. L.; YUCEL, S. An anatomical description of the male and female urethral sphincter complex. The Journal of Urology, v. 171, n. 5, p. 1891, 2004.

BEERTESEN, W.; EVERTS, V.; VAN DE HOOF, A. Fine structure of fibroblasts in the periodontal ligament of the rat incisor and their posible role in the tooth eruption. Archives of Oral Biology, v. 19, p. 1087-1098, 1974.

BÖCK, P.; STOCKINGER, L. Light and electron microscopic identification of elastic, elaunin and oxytalan fibers in human tracheal and bronchial mucosa. Acta Anatomica, v. 170, p. 145-153, 1984.

BRADAMANTE, Z.; SVAJGER, A. Pré-elastic (oxytalan) fibres in the developing elastic cartilage of the external ear of the rat. Journal of Anatomy, v. 123, p. 735-743, 1977.

BRADLEY, W. F. Innervation of the male urinary bladder. The Urologic Clinics of North America, v. 5, p. 279, 1978.

BUCKWALTER, J. A.; COOPER, R. R.; MAYNARD, J. A. Elastic fibers in human intervertebral discs. The Journal of Bone \& Joint Surgery, v. 58, p. 73, 1976.

CANNON, T. W.; DAMASER, M. Pathophysiology of the lower urinary tract: continence and incontinence. Clinical Obstetrics and Gynecology, v. 47, n. 1, p. 28, 2004.

CARVALHO, H. F.; LINE, S. R. P. Basement membrane associated changes in the rat ventral prostate following castration. Cell Biology International, v. 20, p. 809-819, 1997.

CHOPARD, R. P.; LUCAS, G. A.; GERHARD, R.; LOURENÇO, M. G. A. Histomorphological study in age related changes in the elastic fiber system of the basilar artery Journal of Anatatomy and Embryology, v. 103, n. 4, p. 157-75, 1998.

\footnotetext{
* De acordo com:

ASSOCIAÇÃO BRASILEIRA DE NORMAS E TÉCNICAS. NBR 6023: Informação e documentação: referências: elaboração. Rio de Janeiro, 2002.
} 
CHOPARD, R. P.; GERHARD, R. Histomorphometrical study of the elastic fiber system in the anterior cerebral artery of man. Arq. Neuropsiquiatr., v. 58, n.4, p. 1040-1046, 2000.

CORTIVO, R.; PAGANO, F.; PASSERINI, G. Elastin and collagen in the normal and obstructer urinary bladder. British Journal of Urology, n. 53, p. 134, 1981.

COSTACURTA, L. Anatomia médico-cirúrgica da pelve humana. São Paulo: Atheneu, 1982. p. 23-33.

COSTA, W. S.; CARVALHO, M. A.; BABINSKI, M. A. Volumetric density of elastic and reticular fibers in transition zone of controls and patients with benign prostatic hyperplasia. Adult Urology, v. 64, n. 4, p. 693-697, 2004.

COTTA-PEREIRA, G.; RODRIGO, F. G.; BITTENCOURT-SAMPAIO, S. Oxytalan, elaunin and elastic fibers in the human skin. The Journal of Investigative Dermatology, v. 113, p. $15,1975$.

COTTA-PEREIRA, G.; RODRIGO, F. G.; DAVID-FERREIRA, J. F. The use of tannic acidglutaraldehide in the study of elastic and elastic-related fibers. Stain Technology, v. 51, n. 1, p. 7-11, 1976.

COTTA-PEREIRA, G.; RODRIGO, F. G.; FERREIRA, D. The elastic system fibers. Advances in Experimental Medicine and Biology, v. 79, p. 19-30, 1977.

COTTA-PEREIRA, G.; DEL-CLARO, L. M.; MONTES, G. S. Distribution of elastic system fibers in hyaline and fibrous cartilages of the rat. Acta Anatomica, v. 119, p. 80-85, 1984.

CHUN, A. L.; WALLACE, L. J.; GERALD, M. C. Effect of age on in vivo urinary bladder function in the rat. The Journal of Urology, v. 139, p. 625, 1988.

DASS, N.; MCMURRAY, G.; BRADING, A. F. Elastic fibers in the vesicourethral junction and urethra of the guinea pig: quantification with computerized image analyses. Journal of Anatomy, v. 195, p. 447-53, 1999.

DIETRICH, F.; DORSCHNER, W.; STOLZENBURG, J. - U. A new theory of micturition and urinary continence based on histomorphological studies. 2. The musculus sphincter vesicae: continence or sexual function. Urologia Internationalis, v. 52, p. 155-157, 1994.

DORSCHNER, W.; STOLZENBURG, J. - U.; POSTENJAK, M. Sphincteric musculature of female canine urethra in comparasion to woman including $3 \mathrm{D}$ reconstruction. Cells, Tissues, Organs, v. 170, n. 2-3, p. 153, 2002.

DORSCHNER, W.; STOLZENBURG, J. - U.; LEUTERT, G. A new theory of micturition and urinary continence based on histomorphological studies. 1. The musculus detrusor vesicae: occlusive function or support of micturition? Urologia Internationalis, v. 52, p. 6263, 1994. 
EVERTS, V.; NIEHOF, A.; JANSEN, D.; BEERTESEN, W. Type VI collagen is associated with microfibrils and oxytalan fibers in the extracellular matrix of periodontm, mesenterium and periosteum. Journal of Periodontology Research, v. 33, p. 125, 1998.

EWALT, D. H.; HOWARD, P. S.; BLYTH, B. Is lamina propria matrix responsible for normal bladder compliance? Journal of Urology, v. 148, p. 544-549, 1992.

FAHRENBACH, W. H.; SANDBERG, L. B.; CLEARY, E. G. Ultraestructural studies on early elastogenesis. Anatomical Record, v. 155, p. 563-576, 1966.

FENELEY, R. C. L.; THOMAS, D. G.; BLANNIN, J. P. Urinary incontinence. Journal of the Royal College of Physicians of London, v. 16, n. 2, p. 89-93, 1982.

FILHO, E. T. C.; CARVALHO, C. A. F.; SOUZA, R. R. Modificações das fibras do sistema elástico no envelhecimento. Revista da Associação Médica Brasileira, v. 42, n. 1, p. 25-30, 1996.

FILHO, E. T. C.; CARVALHO, C. A. F.; SOUZA, R. R. Age-related changes in elastic fibers of human heart. Gerontology, v. 42, p. 211-217, 1996.

FULLMER, H. M. The oxytalan fiber: a previously undescribed connective tissue fiber. Journal of Histochemistry and Cytochemistry, v. 6, n. 6, p. 425-430, 1958.

FULLMER, H. M. A comparative histochemical study of elastic, pre-elastic and oxytalan connective tissues fibers. Journal of Histochemistry and Cytochemistry, v. 8, p. 290-295, 1960 .

GARDNER, E.; GRAY, J. D. Estudo regional do corpo humano. 3. ed. Rio de Janeiro: Guanabara Koogan, 1971. cap. 42, p. 482-83.

GAWLIK, Z. Morphological and morphochemical properties of the elastic system in the motor organ of the man. Folia Histochemica et Cytochemica, v. 3, p. 233-251, 1965.

GIBSON, M. A.; CLEARY, E. G. The immunohistochemical localization of microfibrilassociated glycoprotein in elastic and nonelastic tissues. Immunology and Cell Biology, v. 65, p. 345-356, 1987.

GILPIN, S.A.; GILPIN, C. J.; DIXON, J. S. The effect of age on the autonomic innervation of the urinary bladder. British Journal of Urology, v. 58, p. 378-381, 1986.

GOGLY, B.; GODEAU, G.; GILBERT, S.; Morphometric analysis of collagen and elastic fibers in normal skin and gingival in relation to age. Clinical Oral Investigation, v. 1, p. 147$152,1997$.

GOLDFISCHER, S.; SCHWARTZ, E.; BLUMENFELD, O. O. Ultrastructure an staining properties of aortic microfibrils (oxytalan). The Journal of Histochemistry and Cytochemistry, v. 31, n. 3, p. 382-390, 1983.

GOSLING, J. The structure of the bladder and urethra in relation to function. The Urologic Clinics of North America, v. 44, p.31-8, 1979. 
GRAY, H. Tratado de anatomia humana. 24. ed. Rio de Janeiro: Editora Guanabara, 1946 p. 1453.

GREENLEE, T. K.; ROSS, R.; HARTMAN, J. L. The fine structure of elastic fibers. The Journal of Cell Biology, v. 30, p. 59-71, 1966.

GROAT, C. W. A neurologic basis for the overactive bladder. Urology, v. 50, n. 6A, p. 3639; 44, 1997.

GUYTON, A. C.; HALL, J. E. Tratado de fisiologia médica. 10. ed. Rio de Janeiro: Guanabara Koogan, 2002. p. 218.

HARVI, D. Post-prostatectomy incontinence. Urological Research, v. 6, p. 493-6, 1978.

JOHNSON, E. F.; CHETTY, K.; MOORE, I. M. The distribuition and arrangement of elastic fibers in the intervertebral discs of the adult human. The Journal of Anatomy, v. 135, n. 2, p. 301-304, 1982.

JØRGENSEN, J. B.; JENSEN, K. M. -E.; MOGENSEN, P. Longitudinal observations on normal and abnormal voiding in men over the age of 50 years. British Journal of Urology, $\mathrm{v}$. 72, p. 413-420, 1993.

JUNQUEIRA, L. C.; CARNEIRO, J. Histologia Básica, 9. ed. Rio de Janeiro: Guanabara Koogan, 1999. p. 78-80.

KAJIKAWA, K.; YAMAGUCHI, T.; KATSUDA, S.; MIWA, A. An improved electron stain for elastic fibers using tannic acid. Journal of Electron Microscopy, v. 24, n. 4, p. 287-288, 1975.

KARLINSKY, J. B.; SNIDER, G. L.; FRANZBLAU, C. In vitro effects of elastase and collagenase on mechanical properties of hamster lungs. The American. Review of Respiratory Disease, v. 113, p. 769-777,1976.

KIELTY, C. M.; SHERRATT, M. J.; SHUTTLEWORTH, C. A. Elastic fibers. Journal of Cell Science, v. 115, p. 2.817-2.828, 2002.

LEVI, B. J.; WIGHT, T. N. Structural changes in the aging submucosa: new morphologic criteria for the evaluation of the unstable human bladder. Journal of Urology, v. 144, p. 1044-1055, 1990.

MADERSBACHER, S.; PYCHA, A.; SCHATZL, G. The aging lower urinary tract: a comparative urodynamic study of men and women. Urology, v.51, n.2, p. 206-212, 1998.

MENESES, P. R. Atualização em nefrologia pediátrica: distúrbios funcionais da micção na infância. J. Bras. Nefrol., v. 22, n. 2, p. 95-102, 2000.

MIODÓNSKI, J. A.; LITWIN, A. J. Microvascular architeture of the human urinary bladder wall: A corrosion casting study. The Anatomical Record, v. 254, p. 375 - 381, 1999. 
NETTER, F. H.; SHAPTER, R. K. Ilustrações médicas: rins, ureteres e bexiga. Rio de Janeiro: Guanabara Koogan, 1976. v. 6, p. 20 - 2.

NIEWOEHNER, D. E.; KLEINERMAN, J. Morphometric study of elastic fibers in normal and emphysematous human lungs. American Review of Respiratory Disease, v. 115, p. 15$21,1977$.

PANIAGUA, R.; REGADERA, J.; NISTAL, M. Elastic fibers of the human ductus deferens. Journal of Anatomy, v. 137, n. 3, p. 467-476, 1983.

RESNICK, M. D.; YALLA, S. V. Management of urinary incontinence in the elderly. The New England Journal of Medicine, v. 26, Sept., p. 800-805, 1985.

RODRIGUES JR., A. J.; TOLOSA, E. M. C.; CARVALHO, C. A. F. Electron microscopy study on the elastic and elastic related fibres in the human fascia transversalis at different ages. Gegenbaurs Morphologisches Jahrbuch, v. 136, n. 6, p. 645-652, 1990.

ROSS, R.; BORNSTEIN, P. The elastic fiber: I. The separation and partial characterization of its macromolecular components. The Journal of Cell Biology, v. 40, p. 366-381, 1969.

ROSS, R. The elastic fiber: a review. Journal of Histochemica et Cytochemica, v. 21, p. 199-208, 1973.

ROTHER, P.; LÖFFLER, S.; DORSCHENER, W.; REIBIGER, I.; BENGS, T. Anatomic basis of micturition and urinary continence - muscle systems in urinary bladder neck during ageing. Surgical Radiologic Anatomy, v. 18, p. 173-177, 1996.

SACCHETTI, J. C. L. Estudo histomorfométrico e ultraestrutural dos componentes fibrosos elásticos da cápsula esplênica. 1996. 75 f. Dissertação (Mestrado) - Instituto de Ciências Biomédicas, Universidade de São Paulo, São Paulo, 1996.

SAGE, H.; GRAY, W. R. Studies on the evolution of elastin: I. Phylogenetic distribution, Comparative Biochemistry and Physiology, v. 64, p. 313-327, 1979.

SAKAY, L. Y.; KEENE, D. R.; ENGVALL, E. Fibrillin, a new 350-kD glycoprotein, is a component of extracellular microfibrils. The Journal of Cell Biology, v. 103, p. 2509, 1986.

SAWADA, T.; SUGAWARA, Y.; ASAI, T. Immunohistochemical characterization of elastic system fibers in rat molar periodontal ligament. Journal of Histochemistry \& Cytochemistry, v. 54, n. 10, p. 1095-1103, 2006.

SCULEAN, A.; KARRING, T.; THEILADE, J. The regeneration potential of oxytalan fibers: An experimental study in the monkey. Journal of Clinical Periodontology, v. 24, p. 932936, 1997.

SEPHEL, G. C.; DAVIDSON, J. M. Elastin production in human skin fibroblast culture and its decline with age. Journal Investigative Dermatology, v. 86, p. 279-285,1986.

SUSSET, J. G.; SERVOT-VIGUIER, D.; LAMY, F. Collagen in 155 human bladders. Investigative Urology, n. 16, p. 204, 1978. 
SUZUKI, K. Distribuição das fibras elásticas, elaunínicas e oxitalânicas no ligamento vocal em diferentes idades. 131 f. Dissertação (Doutorado) - Instituto de Ciências Biomédicas, Universidade de São Paulo, São Paulo, 1984.

TANAGHO, E. A.; PUGH, R. C. B. The anatomy and function of the ureterovesical junction. British Journal of Urology, v.35, p. 151-165, 1963.

TANAGHO, E. A.; HUTCH, J. A.; MEYERS, F. H. Primary vesicoureteral reflux: experimental study of its etiology. Journal of Urology, v. 93, p. 165-176, 1965.

TANAGHO, E. A.; MEYERS, F. H.; SMITH, D. R. The trigone: anatomical and physiological considerations, 2. In relation to the bladder neck. The Journal of Urology, v. 100, p. 633-639, 1968a.

TANAGHO, E. A.; SMITH, D. R. Mechanism of urinary continence: 1- Embryologic, anatomic and pathologic considerations. The Journal of Urology, v. 100, p. 640-646, 1968b.

TANAGHO, E. A.; MEYERS, F. H.; SMITH, D. R. Uretrhal resistance: Its components and implications. II. Striated muscle component. Investigative Urology, v. 7, p. 195, 1969.

TORTORA, G. J. Princípios de anatomia humana. 10. ed. Rio de Janeiro: Guanabara Koogan, 2007. p.

UITTO, J.; FAZIO, M. J.; OLSEN, D. R. Molecular mechanisms of cutaneous aging: ageassociated connective tissue alterations in the dermis. Journal Investigative Dermatology, v. 90, p. 643, 1988.

USHIKI, T.; MURAKUMO, M. Scanning electron microscopic studies of tissue elastin components exposed by a KOII-Collagenase or simple $\mathrm{KOH}$ digestion method. Archives of Histology and Cytology, v. 54, p. 427-436, 1991.

USHIKI, T. Collagen fibers, reticular fibers and elastic fibers: A comprehensive understanding from a morphological viewpoint. Archives of Histology and Cytology, v. 65, n. 2, p. 109-126,2002.

VERNET, G. S. Morphology and function of the vesicoprostato-urethral musculature.Trevizo: Edizioni Canova, 1968.

WEI, J. T.; DE LANCEY, J. O. L. Functional anatomy of the pelvis floor and lower urinary tract. Clinical Obstetrics and Gynecology, v.47, n. 1, p. 13, 2004.

WILLIAMS, M. E.; PANNILL, F. C. Urinary incontinence in the elderly. Annais of Internal Medicine, v. 97, p. 895-907, 1982.

WOODBURNE, R. T. The sphincter mechanism of the urinary bladder and the urethra. The Anatomical Records, v. 141, p. 11-20, 1961. 
APÊNDICES 


\section{APÊNDICE A - COLORAÇÃO VERHOEFF}

Animal: $1 \quad$ Grupo: Neonato

\begin{tabular}{|c|c|c|c|c|c|c|c|c|c|c|c|c|c|c|}
\hline Campos & $\mathbf{1}$ & $\mathbf{2}$ & $\mathbf{3}$ & $\mathbf{4}$ & $\mathbf{5}$ & $\mathbf{6}$ & $\mathbf{7}$ & $\mathbf{8}$ & $\mathbf{9}$ & $\mathbf{1 0}$ & $\mathbf{1 1}$ & $\mathbf{1 2}$ & $\mathbf{1 3}$ & $\mathbf{1 4}$ \\
\hline HF & 25 & 63 & 42 & 71 & 88 & 33 & 22 & 42 & 45 & 27 & 48 & 70 & 59 & 28 \\
\hline HD & 375 & 337 & 358 & 329 & 312 & 367 & 378 & 358 & 355 & 373 & 352 & 330 & 341 & 372 \\
\hline Contagem & 5 & 9 & 9 & 8 & 14 & 9 & 5 & 10 & 9 & 8 & 6 & 5 & 8 & 11 \\
\hline
\end{tabular}

\begin{tabular}{|c|c|c|c|c|c|c|c|c|c|c|c|c|c|c|}
\hline Campos & $\mathbf{1 5}$ & $\mathbf{1 6}$ & $\mathbf{1 7}$ & $\mathbf{1 8}$ & $\mathbf{1 9}$ & $\mathbf{2 0}$ & $\mathbf{2 1}$ & $\mathbf{2 2}$ & $\mathbf{2 3}$ & $\mathbf{2 4}$ & $\mathbf{2 5}$ & $\mathbf{2 6}$ & $\mathbf{2 7}$ & $\mathbf{2 8}$ \\
\hline HF & 75 & 14 & 68 & 71 & 54 & 70 & 40 & 100 & 35 & 54 & 51 & 124 & 124 & 70 \\
\hline HD & 325 & 386 & 332 & 329 & 346 & 330 & 360 & 300 & 365 & 346 & 349 & 276 & 276 & 330 \\
\hline Contagem & 17 & 6 & 6 & 5 & 12 & 9 & 6 & 6 & 8 & 7 & 8 & 11 & 7 & 15 \\
\hline
\end{tabular}

\begin{tabular}{|c|c|c|c|c|c|c|c|c|c|c|c|c|c|c|}
\hline Campos & $\mathbf{2 9}$ & $\mathbf{3 0}$ & $\mathbf{3 1}$ & $\mathbf{3 2}$ & $\mathbf{3 3}$ & $\mathbf{3 4}$ & $\mathbf{3 5}$ & $\mathbf{3 6}$ & $\mathbf{3 7}$ & $\mathbf{3 8}$ & $\mathbf{3 9}$ & $\mathbf{4 0}$ & $\mathbf{4 1}$ & $\mathbf{4 2}$ \\
\hline HF & 33 & 29 & 39 & 19 & 30 & 52 & 60 & 29 & 34 & 37 & 37 & 22 & 19 & 38 \\
\hline HD & 367 & 371 & 361 & 381 & 370 & 348 & 340 & 371 & 366 & 363 & 363 & 378 & 381 & 362 \\
\hline Contagem & 7 & 8 & 6 & 4 & 11 & 13 & 10 & 16 & 7 & 6 & 5 & 6 & 3 & 5 \\
\hline
\end{tabular}

\begin{tabular}{|c|c|c|c|c|c|c|c|c|c|}
\hline Campos & $\mathbf{4 3}$ & $\mathbf{4 4}$ & $\mathbf{4 5}$ & $\mathbf{4 6}$ & $\mathbf{4 7}$ & $\mathbf{4 8}$ & $\mathbf{4 9}$ & $\mathbf{5 0}$ & Soma \\
\hline HF & 29 & 52 & 58 & 35 & 58 & 54 & 30 & 55 & 2.462 \\
\hline HD & 371 & 348 & 342 & 365 & 342 & 346 & 370 & 345 & 17538 \\
\hline Contagem & 4 & 8 & 8 & 10 & 13 & 13 & 10 & 9 & 421 \\
\hline
\end{tabular}


Animal: 2 Grupo: Neonato

\begin{tabular}{|c|c|c|c|c|c|c|c|c|c|c|c|c|c|c|}
\hline Campos & $\mathbf{1}$ & $\mathbf{2}$ & $\mathbf{3}$ & $\mathbf{4}$ & $\mathbf{5}$ & $\mathbf{6}$ & $\mathbf{7}$ & $\mathbf{8}$ & $\mathbf{9}$ & $\mathbf{1 0}$ & $\mathbf{1 1}$ & $\mathbf{1 2}$ & $\mathbf{1 3}$ & $\mathbf{1 4}$ \\
\hline HF & 19 & 21 & 11 & 19 & 4 & 10 & 79 & 8 & 19 & 22 & 17 & 31 & 47 & 18 \\
\hline HD & 381 & 379 & 389 & 381 & 396 & 390 & 321 & 392 & 381 & 378 & 383 & 369 & 353 & 382 \\
\hline Contagem & 12 & 7 & 15 & 8 & 10 & 6 & 4 & 7 & 9 & 12 & 9 & 6 & 4 & 11 \\
\hline
\end{tabular}

\begin{tabular}{|c|c|c|c|c|c|c|c|c|c|c|c|c|c|c|}
\hline Campos & $\mathbf{1 5}$ & $\mathbf{1 6}$ & $\mathbf{1 7}$ & $\mathbf{1 8}$ & $\mathbf{1 9}$ & $\mathbf{2 0}$ & $\mathbf{2 1}$ & $\mathbf{2 2}$ & $\mathbf{2 3}$ & $\mathbf{2 4}$ & $\mathbf{2 5}$ & $\mathbf{2 6}$ & $\mathbf{2 7}$ & $\mathbf{2 8}$ \\
\hline HF & 39 & 24 & 12 & 19 & 44 & 9 & 110 & 59 & 27 & 20 & 9 & 67 & 22 & 54 \\
\hline HD & 361 & 376 & 388 & 381 & 356 & 391 & 290 & 341 & 373 & 380 & 391 & 333 & 378 & 346 \\
\hline Contagem & 6 & 10 & 15 & 12 & 3 & 2 & 5 & 6 & 6 & 14 & 8 & 10 & 11 & 6 \\
\hline
\end{tabular}

\begin{tabular}{|c|c|c|c|c|c|c|c|c|c|c|c|c|c|c|}
\hline Campos & $\mathbf{2 9}$ & $\mathbf{3 0}$ & $\mathbf{3 1}$ & $\mathbf{3 2}$ & $\mathbf{3 3}$ & $\mathbf{3 4}$ & $\mathbf{3 5}$ & $\mathbf{3 6}$ & $\mathbf{3 7}$ & $\mathbf{3 8}$ & $\mathbf{3 9}$ & $\mathbf{4 0}$ & $\mathbf{4 1}$ & $\mathbf{4 2}$ \\
\hline HF & 7 & 18 & 15 & 35 & 23 & 46 & 19 & 57 & 47 & 50 & 57 & 9 & 13 & 34 \\
\hline HD & 393 & 382 & 385 & 365 & 377 & 354 & 381 & 343 & 353 & 350 & 343 & 391 & 387 & 366 \\
\hline Contagem & 12 & 6 & 12 & 13 & 6 & 10 & 4 & 6 & 8 & 14 & 10 & 7 & 11 & 6 \\
\hline
\end{tabular}

\begin{tabular}{|c|c|c|c|c|c|c|c|c|c|}
\hline Campos & $\mathbf{4 3}$ & $\mathbf{4 4}$ & $\mathbf{4 5}$ & $\mathbf{4 6}$ & $\mathbf{4 7}$ & $\mathbf{4 8}$ & $\mathbf{4 9}$ & $\mathbf{5 0}$ & Soma \\
\hline HF & 44 & 73 & 87 & 43 & 23 & 41 & 41 & 9 & 1.631 \\
\hline HD & 356 & 327 & 313 & 357 & 377 & 359 & 359 & 391 & 18.369 \\
\hline Contagem & 13 & 9 & 8 & 9 & 9 & 11 & 10 & 7 & 435 \\
\hline
\end{tabular}


Animal: 3

Grupo: Neonato

\begin{tabular}{|c|c|c|c|c|c|c|c|c|c|c|c|c|c|c|}
\hline Campos & $\mathbf{1}$ & $\mathbf{2}$ & $\mathbf{3}$ & $\mathbf{4}$ & $\mathbf{5}$ & $\mathbf{6}$ & $\mathbf{7}$ & $\mathbf{8}$ & $\mathbf{9}$ & $\mathbf{1 0}$ & $\mathbf{1 1}$ & $\mathbf{1 2}$ & $\mathbf{1 3}$ & $\mathbf{1 4}$ \\
\hline HF & 49 & 19 & 60 & 27 & 4 & 24 & 35 & 25 & 48 & 19 & 102 & 44 & 30 & 24 \\
\hline HD & 351 & 381 & 340 & 373 & 396 & 376 & 365 & 375 & 352 & 381 & 298 & 356 & 370 & 376 \\
\hline Contagem & 4 & 7 & 6 & 9 & 11 & 9 & 9 & 9 & 6 & 4 & 6 & 7 & 4 & 10 \\
\hline
\end{tabular}

\begin{tabular}{|c|c|c|c|c|c|c|c|c|c|c|c|c|c|c|}
\hline Campos & $\mathbf{1 5}$ & $\mathbf{1 6}$ & $\mathbf{1 7}$ & $\mathbf{1 8}$ & $\mathbf{1 9}$ & $\mathbf{2 0}$ & $\mathbf{2 1}$ & $\mathbf{2 2}$ & $\mathbf{2 3}$ & $\mathbf{2 4}$ & $\mathbf{2 5}$ & $\mathbf{2 6}$ & $\mathbf{2 7}$ & $\mathbf{2 8}$ \\
\hline HF & 53 & 22 & 46 & 26 & 53 & 17 & 32 & 37 & 37 & 30 & 45 & 21 & 32 & 7 \\
\hline HD & 347 & 378 & 354 & 374 & 347 & 383 & 368 & 363 & 363 & 370 & 355 & 379 & 368 & 393 \\
\hline Contagem & 5 & 11 & 14 & 9 & 8 & 6 & 10 & 9 & 17 & 9 & 18 & 6 & 10 & 3 \\
\hline
\end{tabular}

\begin{tabular}{|c|c|c|c|c|c|c|c|c|c|c|c|c|c|c|}
\hline Campos & $\mathbf{2 9}$ & $\mathbf{3 0}$ & $\mathbf{3 1}$ & $\mathbf{3 2}$ & $\mathbf{3 3}$ & $\mathbf{3 4}$ & $\mathbf{3 5}$ & $\mathbf{3 6}$ & $\mathbf{3 7}$ & $\mathbf{3 8}$ & $\mathbf{3 9}$ & $\mathbf{4 0}$ & $\mathbf{4 1}$ & $\mathbf{4 2}$ \\
\hline HF & 47 & 36 & 9 & 17 & 25 & 18 & 32 & 22 & 45 & 12 & 8 & 56 & 56 & 78 \\
\hline HD & 353 & 364 & 391 & 383 & 375 & 382 & 368 & 378 & 355 & 388 & 392 & 344 & 344 & 322 \\
\hline Contagem & 17 & 13 & 12 & 13 & 18 & 6 & 7 & 7 & 9 & 11 & 5 & 20 & 7 & 10 \\
\hline
\end{tabular}

\begin{tabular}{|c|c|c|c|c|c|c|c|c|c|}
\hline Campos & $\mathbf{4 3}$ & $\mathbf{4 4}$ & $\mathbf{4 5}$ & $\mathbf{4 6}$ & $\mathbf{4 7}$ & $\mathbf{4 8}$ & $\mathbf{4 9}$ & $\mathbf{5 0}$ & Soma \\
\hline HF & 23 & 53 & 33 & 10 & 37 & 44 & 63 & 27 & 1.721 \\
\hline HD & 377 & 347 & 367 & 390 & 363 & 356 & 337 & 373 & 18.279 \\
\hline Contagem & 6 & 6 & 10 & 5 & 5 & 6 & 8 & 6 & 443 \\
\hline
\end{tabular}


Animal: $4 \quad$ Grupo: Neonato

\begin{tabular}{|c|c|c|c|c|c|c|c|c|c|c|c|c|c|c|}
\hline Campos & $\mathbf{1}$ & $\mathbf{2}$ & $\mathbf{3}$ & $\mathbf{4}$ & $\mathbf{5}$ & $\mathbf{6}$ & $\mathbf{7}$ & $\mathbf{8}$ & $\mathbf{9}$ & $\mathbf{1 0}$ & $\mathbf{1 1}$ & $\mathbf{1 2}$ & $\mathbf{1 3}$ & $\mathbf{1 4}$ \\
\hline HF & 29 & 50 & 46 & 42 & 67 & 60 & 12 & 35 & 50 & 127 & 70 & 27 & 55 & 15 \\
\hline HD & 371 & 350 & 354 & 358 & 333 & 340 & 388 & 365 & 350 & 273 & 330 & 373 & 345 & 385 \\
\hline Contagem & 4 & 3 & 6 & 3 & 5 & 7 & 6 & 13 & 15 & 8 & 5 & 12 & 5 & 15 \\
\hline
\end{tabular}

\begin{tabular}{|c|c|c|c|c|c|c|c|c|c|c|c|c|c|c|}
\hline Campos & $\mathbf{1 5}$ & $\mathbf{1 6}$ & $\mathbf{1 7}$ & $\mathbf{1 8}$ & $\mathbf{1 9}$ & $\mathbf{2 0}$ & $\mathbf{2 1}$ & $\mathbf{2 2}$ & $\mathbf{2 3}$ & $\mathbf{2 4}$ & $\mathbf{2 5}$ & $\mathbf{2 6}$ & $\mathbf{2 7}$ & $\mathbf{2 8}$ \\
\hline HF & 23 & 28 & 84 & 92 & 62 & 71 & 67 & 58 & 70 & 80 & 41 & 56 & 46 & 63 \\
\hline HD & 377 & 372 & 316 & 308 & 338 & 329 & 333 & 342 & 330 & 320 & 359 & 344 & 354 & 337 \\
\hline Contagem & 7 & 5 & 5 & 6 & 5 & 8 & 10 & 4 & 8 & 11 & 6 & 12 & 6 & 5 \\
\hline
\end{tabular}

\begin{tabular}{|c|c|c|c|c|c|c|c|c|c|c|c|c|c|c|}
\hline Campos & $\mathbf{2 9}$ & $\mathbf{3 0}$ & $\mathbf{3 1}$ & $\mathbf{3 2}$ & $\mathbf{3 3}$ & $\mathbf{3 4}$ & $\mathbf{3 5}$ & $\mathbf{3 6}$ & $\mathbf{3 7}$ & $\mathbf{3 8}$ & $\mathbf{3 9}$ & $\mathbf{4 0}$ & $\mathbf{4 1}$ & $\mathbf{4 2}$ \\
\hline HF & 79 & 13 & 117 & 52 & 39 & 20 & 37 & 20 & 68 & 54 & 63 & 65 & 73 & 34 \\
\hline HD & 321 & 387 & 283 & 348 & 361 & 380 & 363 & 380 & 332 & 346 & 337 & 335 & 327 & 366 \\
\hline Contagem & 8 & 9 & 12 & 8 & 4 & 10 & 7 & 5 & 4 & 5 & 3 & 4 & 3 & 5 \\
\hline
\end{tabular}

\begin{tabular}{|c|c|c|c|c|c|c|c|c|c|}
\hline Campos & $\mathbf{4 3}$ & $\mathbf{4 4}$ & $\mathbf{4 5}$ & $\mathbf{4 6}$ & $\mathbf{4 7}$ & $\mathbf{4 8}$ & $\mathbf{4 9}$ & $\mathbf{5 0}$ & Soma \\
\hline HF & 95 & 48 & 46 & 18 & 33 & 20 & 64 & 60 & 2.644 \\
\hline HD & 305 & 352 & 354 & 382 & 367 & 380 & 336 & 340 & 17.356 \\
\hline Contagem & 4 & 7 & 8 & 8 & 8 & 7 & 7 & 5 & 346 \\
\hline
\end{tabular}


Animal: 5 Grupo: Neonato

\begin{tabular}{|c|c|c|c|c|c|c|c|c|c|c|c|c|c|c|}
\hline Campos & $\mathbf{1}$ & $\mathbf{2}$ & $\mathbf{3}$ & $\mathbf{4}$ & $\mathbf{5}$ & $\mathbf{6}$ & $\mathbf{7}$ & $\mathbf{8}$ & $\mathbf{9}$ & $\mathbf{1 0}$ & $\mathbf{1 1}$ & $\mathbf{1 2}$ & $\mathbf{1 3}$ & $\mathbf{1 4}$ \\
\hline HF & 32 & 19 & 26 & 27 & 118 & 137 & 9 & 108 & 25 & 25 & 50 & 40 & 27 & 41 \\
\hline HD & 368 & 381 & 374 & 373 & 282 & 263 & 391 & 292 & 375 & 375 & 350 & 360 & 373 & 359 \\
\hline Contagem & 9 & 10 & 8 & 6 & 5 & 3 & 8 & 8 & 5 & 8 & 6 & 3 & 6 & 9 \\
\hline
\end{tabular}

\begin{tabular}{|c|c|c|c|c|c|c|c|c|c|c|c|c|c|c|}
\hline Campos & $\mathbf{1 5}$ & $\mathbf{1 6}$ & $\mathbf{1 7}$ & $\mathbf{1 8}$ & $\mathbf{1 9}$ & $\mathbf{2 0}$ & $\mathbf{2 1}$ & $\mathbf{2 2}$ & $\mathbf{2 3}$ & $\mathbf{2 4}$ & $\mathbf{2 5}$ & $\mathbf{2 6}$ & $\mathbf{2 7}$ & $\mathbf{2 8}$ \\
\hline HF & 69 & 48 & 41 & 31 & 62 & 45 & 25 & 30 & 58 & 27 & 35 & 17 & 21 & 42 \\
\hline HD & 331 & 352 & 359 & 369 & 338 & 355 & 375 & 370 & 342 & 373 & 365 & 383 & 379 & 358 \\
\hline Contagem & 6 & 5 & 4 & 4 & 9 & 10 & 3 & 4 & 7 & 15 & 16 & 10 & 7 & 4 \\
\hline
\end{tabular}

\begin{tabular}{|c|c|c|c|c|c|c|c|c|c|c|c|c|c|c|}
\hline Campos & $\mathbf{2 9}$ & $\mathbf{3 0}$ & $\mathbf{3 1}$ & $\mathbf{3 2}$ & $\mathbf{3 3}$ & $\mathbf{3 4}$ & $\mathbf{3 5}$ & $\mathbf{3 6}$ & $\mathbf{3 7}$ & $\mathbf{3 8}$ & $\mathbf{3 9}$ & $\mathbf{4 0}$ & $\mathbf{4 1}$ & $\mathbf{4 2}$ \\
\hline HF & 28 & 14 & 45 & 13 & 30 & 10 & -- & 49 & 122 & 28 & 45 & 36 & 60 & 22 \\
\hline HD & 372 & 386 & 355 & 387 & 370 & 390 & 400 & 351 & 278 & 372 & 355 & 364 & 340 & 378 \\
\hline Contagem & 7 & 5 & 9 & 9 & 10 & 11 & 18 & 8 & 12 & 12 & 11 & 12 & 13 & 13 \\
\hline
\end{tabular}

\begin{tabular}{|c|c|c|c|c|c|c|c|c|c|}
\hline Campos & $\mathbf{4 3}$ & $\mathbf{4 4}$ & $\mathbf{4 5}$ & $\mathbf{4 6}$ & $\mathbf{4 7}$ & $\mathbf{4 8}$ & $\mathbf{4 9}$ & $\mathbf{5 0}$ & Soma \\
\hline HF & 18 & 43 & 90 & 69 & 72 & 30 & 14 & 10 & 2.083 \\
\hline HD & 382 & 357 & 310 & 331 & 328 & 370 & 386 & 390 & 17.917 \\
\hline Contagem & 11 & 8 & 11 & 16 & 15 & 5 & 8 & 14 & 446 \\
\hline
\end{tabular}


Animal: $1 \quad$ Grupo: Adulto

\begin{tabular}{|c|c|c|c|c|c|c|c|c|c|c|c|c|c|c|}
\hline Campos & $\mathbf{1}$ & $\mathbf{2}$ & $\mathbf{3}$ & $\mathbf{4}$ & $\mathbf{5}$ & $\mathbf{6}$ & $\mathbf{7}$ & $\mathbf{8}$ & $\mathbf{9}$ & $\mathbf{1 0}$ & $\mathbf{1 1}$ & $\mathbf{1 2}$ & $\mathbf{1 3}$ & $\mathbf{1 4}$ \\
\hline HF & 56 & 158 & 36 & 90 & 32 & 48 & 38 & 74 & 21 & 134 & 29 & 51 & 38 & 9 \\
\hline HD & 344 & 242 & 364 & 310 & 368 & 352 & 362 & 326 & 379 & 266 & 371 & 349 & 362 & 391 \\
\hline Contagem & 13 & 13 & 23 & 25 & 16 & 9 & 7 & 9 & 18 & 15 & 18 & 25 & 10 & 20 \\
\hline
\end{tabular}

\begin{tabular}{|c|c|c|c|c|c|c|c|c|c|c|c|c|c|c|}
\hline Campos & $\mathbf{1 5}$ & $\mathbf{1 6}$ & $\mathbf{1 7}$ & $\mathbf{1 8}$ & $\mathbf{1 9}$ & $\mathbf{2 0}$ & $\mathbf{2 1}$ & $\mathbf{2 2}$ & $\mathbf{2 3}$ & $\mathbf{2 4}$ & $\mathbf{2 5}$ & $\mathbf{2 6}$ & $\mathbf{2 7}$ & $\mathbf{2 8}$ \\
\hline HF & 41 & 43 & 5 & 82 & 10 & 16 & 60 & 44 & 28 & 22 & 19 & 43 & 32 & 25 \\
\hline HD & 359 & 357 & 395 & 318 & 390 & 384 & 340 & 356 & 372 & 378 & 381 & 357 & 368 & 375 \\
\hline Contagem & 19 & 19 & 42 & 16 & 13 & 17 & 10 & 14 & 36 & 27 & 31 & 6 & 11 & 15 \\
\hline
\end{tabular}

\begin{tabular}{|c|c|c|c|c|c|c|c|c|c|c|c|c|c|c|}
\hline Campos & $\mathbf{2 9}$ & $\mathbf{3 0}$ & $\mathbf{3 1}$ & $\mathbf{3 2}$ & $\mathbf{3 3}$ & $\mathbf{3 4}$ & $\mathbf{3 5}$ & $\mathbf{3 6}$ & $\mathbf{3 7}$ & $\mathbf{3 8}$ & $\mathbf{3 9}$ & $\mathbf{4 0}$ & $\mathbf{4 1}$ & $\mathbf{4 2}$ \\
\hline HF & 24 & 21 & 38 & 27 & 106 & 24 & 14 & 44 & 15 & 54 & 23 & 39 & 21 & 22 \\
\hline HD & 376 & 379 & 362 & 373 & 294 & 376 & 386 & 356 & 385 & 346 & 377 & 361 & 379 & 378 \\
\hline Contagem & 11 & 5 & 40 & 19 & 17 & 36 & 14 & 9 & 13 & 5 & 12 & 13 & 14 & 20 \\
\hline
\end{tabular}

\begin{tabular}{|c|c|c|c|c|c|c|c|c|c|}
\hline Campos & $\mathbf{4 3}$ & $\mathbf{4 4}$ & $\mathbf{4 5}$ & $\mathbf{4 6}$ & $\mathbf{4 7}$ & $\mathbf{4 8}$ & $\mathbf{4 9}$ & $\mathbf{5 0}$ & Soma \\
\hline HF & 29 & 76 & 46 & 50 & 53 & 38 & 40 & 80 & 2.168 \\
\hline HD & 371 & 324 & 354 & 350 & 347 & 362 & 360 & 320 & 17.832 \\
\hline Contagem & 31 & 13 & 14 & 15 & 13 & 8 & 12 & 14 & 845 \\
\hline
\end{tabular}


Animal: 2 Grupo: Adulto

\begin{tabular}{|c|c|c|c|c|c|c|c|c|c|c|c|c|c|c|}
\hline Campos & $\mathbf{1}$ & $\mathbf{2}$ & $\mathbf{3}$ & $\mathbf{4}$ & $\mathbf{5}$ & $\mathbf{6}$ & $\mathbf{7}$ & $\mathbf{8}$ & $\mathbf{9}$ & $\mathbf{1 0}$ & $\mathbf{1 1}$ & $\mathbf{1 2}$ & $\mathbf{1 3}$ & $\mathbf{1 4}$ \\
\hline HF & 118 & 35 & 40 & 108 & 67 & 65 & 31 & 69 & 100 & 65 & 32 & 30 & 9 & 36 \\
\hline HD & 282 & 365 & 360 & 292 & 333 & 335 & 369 & 331 & 300 & 335 & 368 & 370 & 391 & 364 \\
\hline Contagem & 10 & 10 & 17 & 15 & 14 & 14 & 24 & 25 & 11 & 23 & 12 & 7 & 8 & 16 \\
\hline
\end{tabular}

\begin{tabular}{|c|c|c|c|c|c|c|c|c|c|c|c|c|c|c|}
\hline Campos & $\mathbf{1 5}$ & $\mathbf{1 6}$ & $\mathbf{1 7}$ & $\mathbf{1 8}$ & $\mathbf{1 9}$ & $\mathbf{2 0}$ & $\mathbf{2 1}$ & $\mathbf{2 2}$ & $\mathbf{2 3}$ & $\mathbf{2 4}$ & $\mathbf{2 5}$ & $\mathbf{2 6}$ & $\mathbf{2 7}$ & $\mathbf{2 8}$ \\
\hline HF & 23 & 39 & 42 & 76 & 38 & 41 & 42 & 131 & 44 & 133 & 32 & 59 & 35 & 61 \\
\hline HD & 377 & 361 & 358 & 324 & 362 & 359 & 358 & 269 & 356 & 267 & 368 & 341 & 365 & 339 \\
\hline Contagem & 6 & 10 & 6 & 9 & 12 & 15 & 19 & 12 & 12 & 11 & 8 & 11 & 9 & 14 \\
\hline
\end{tabular}

\begin{tabular}{|c|c|c|c|c|c|c|c|c|c|c|c|c|c|c|}
\hline Campos & $\mathbf{2 9}$ & $\mathbf{3 0}$ & $\mathbf{3 1}$ & $\mathbf{3 2}$ & $\mathbf{3 3}$ & $\mathbf{3 4}$ & $\mathbf{3 5}$ & $\mathbf{3 6}$ & $\mathbf{3 7}$ & $\mathbf{3 8}$ & $\mathbf{3 9}$ & $\mathbf{4 0}$ & $\mathbf{4 1}$ & $\mathbf{4 2}$ \\
\hline HF & 25 & 19 & 10 & 54 & 27 & 85 & 23 & 17 & 17 & 16 & 31 & 38 & 10 & 20 \\
\hline HD & 375 & 381 & 390 & 346 & 373 & 315 & 377 & 383 & 383 & 384 & 369 & 362 & 390 & 380 \\
\hline Contagem & 18 & 19 & 14 & 16 & 14 & 13 & 12 & 15 & 15 & 19 & 17 & 22 & 13 & 17 \\
\hline
\end{tabular}

\begin{tabular}{|c|c|c|c|c|c|c|c|c|c|}
\hline Campos & $\mathbf{4 3}$ & $\mathbf{4 4}$ & $\mathbf{4 5}$ & $\mathbf{4 6}$ & $\mathbf{4 7}$ & $\mathbf{4 8}$ & $\mathbf{4 9}$ & $\mathbf{5 0}$ & Soma \\
\hline HF & 11 & 43 & 32 & 32 & 46 & 69 & 20 & 15 & 2.261 \\
\hline HD & 389 & 357 & 368 & 368 & 354 & 331 & 380 & 385 & 17.739 \\
\hline Contagem & 13 & 13 & 11 & 14 & 19 & 11 & 8 & 13 & 686 \\
\hline
\end{tabular}


Animal: 3 Grupo: Adulto

\begin{tabular}{|c|c|c|c|c|c|c|c|c|c|c|c|c|c|c|}
\hline Campos & $\mathbf{1}$ & $\mathbf{2}$ & $\mathbf{3}$ & $\mathbf{4}$ & $\mathbf{5}$ & $\mathbf{6}$ & $\mathbf{7}$ & $\mathbf{8}$ & $\mathbf{9}$ & $\mathbf{1 0}$ & $\mathbf{1 1}$ & $\mathbf{1 2}$ & $\mathbf{1 3}$ & $\mathbf{1 4}$ \\
\hline HF & 141 & 76 & 20 & 18 & 177 & 90 & 114 & 49 & 52 & 71 & 37 & 73 & 25 & 29 \\
\hline HD & 259 & 324 & 380 & 382 & 223 & 310 & 286 & 351 & 348 & 329 & 363 & 327 & 375 & 371 \\
\hline Contagem & 19 & 28 & 34 & 27 & 24 & 17 & 15 & 22 & 18 & 26 & 9 & 7 & 11 & 17 \\
\hline
\end{tabular}

\begin{tabular}{|c|c|c|c|c|c|c|c|c|c|c|c|c|c|c|}
\hline Campos & $\mathbf{1 5}$ & $\mathbf{1 6}$ & $\mathbf{1 7}$ & $\mathbf{1 8}$ & $\mathbf{1 9}$ & $\mathbf{2 0}$ & $\mathbf{2 1}$ & $\mathbf{2 2}$ & $\mathbf{2 3}$ & $\mathbf{2 4}$ & $\mathbf{2 5}$ & $\mathbf{2 6}$ & $\mathbf{2 7}$ & $\mathbf{2 8}$ \\
\hline HF & 38 & 12 & 14 & 42 & 31 & 19 & 58 & 18 & 36 & 35 & 27 & 41 & 38 & 43 \\
\hline HD & 362 & 388 & 386 & 358 & 369 & 381 & 342 & 382 & 364 & 365 & 373 & 359 & 362 & 357 \\
\hline Contagem & 9 & 23 & 16 & 11 & 16 & 12 & 16 & 18 & 21 & 15 & 14 & 7 & 15 & 16 \\
\hline
\end{tabular}

\begin{tabular}{|c|c|c|c|c|c|c|c|c|c|c|c|c|c|c|}
\hline Campos & $\mathbf{2 9}$ & $\mathbf{3 0}$ & $\mathbf{3 1}$ & $\mathbf{3 2}$ & $\mathbf{3 3}$ & $\mathbf{3 4}$ & $\mathbf{3 5}$ & $\mathbf{3 6}$ & $\mathbf{3 7}$ & $\mathbf{3 8}$ & $\mathbf{3 9}$ & $\mathbf{4 0}$ & $\mathbf{4 1}$ & $\mathbf{4 2}$ \\
\hline HF & 34 & 49 & 104 & 33 & 43 & 18 & 28 & 19 & 32 & 27 & 30 & 54 & 39 & 28 \\
\hline HD & 366 & 351 & 296 & 367 & 357 & 382 & 372 & 381 & 368 & 373 & 370 & 346 & 361 & 372 \\
\hline Contagem & 11 & 19 & 14 & 19 & 18 & 7 & 15 & 9 & 11 & 11 & 13 & 15 & 17 & 13 \\
\hline
\end{tabular}

\begin{tabular}{|c|c|c|c|c|c|c|c|c|c|}
\hline Campos & $\mathbf{4 3}$ & $\mathbf{4 4}$ & $\mathbf{4 5}$ & $\mathbf{4 6}$ & $\mathbf{4 7}$ & $\mathbf{4 8}$ & $\mathbf{4 9}$ & $\mathbf{5 0}$ & Soma \\
\hline HF & 25 & 38 & 17 & 8 & 74 & 19 & 65 & 37 & 2.245 \\
\hline HD & 375 & 362 & 383 & 392 & 326 & 381 & 335 & 363 & 17.755 \\
\hline Contagem & 15 & 17 & 8 & 7 & 15 & 15 & 13 & 9 & 777 \\
\hline
\end{tabular}


Animal: 4 Grupo: Adulto

\begin{tabular}{|c|c|c|c|c|c|c|c|c|c|c|c|c|c|c|}
\hline Campos & $\mathbf{1}$ & $\mathbf{2}$ & $\mathbf{3}$ & $\mathbf{4}$ & $\mathbf{5}$ & $\mathbf{6}$ & $\mathbf{7}$ & $\mathbf{8}$ & $\mathbf{9}$ & $\mathbf{1 0}$ & $\mathbf{1 1}$ & $\mathbf{1 2}$ & $\mathbf{1 3}$ & $\mathbf{1 4}$ \\
\hline HF & 18 & 41 & 41 & 5 & 48 & 62 & 10 & 7 & 34 & 70 & 15 & 41 & 62 & 17 \\
\hline HD & 382 & 359 & 359 & 395 & 352 & 338 & 390 & 393 & 366 & 330 & 385 & 359 & 338 & 383 \\
\hline Contagem & 37 & 16 & 13 & 23 & 9 & 4 & 30 & 21 & 48 & 28 & 22 & 16 & 14 & 14 \\
\hline
\end{tabular}

\begin{tabular}{|c|c|c|c|c|c|c|c|c|c|c|c|c|c|c|}
\hline Campos & $\mathbf{1 5}$ & $\mathbf{1 6}$ & $\mathbf{1 7}$ & $\mathbf{1 8}$ & $\mathbf{1 9}$ & $\mathbf{2 0}$ & $\mathbf{2 1}$ & $\mathbf{2 2}$ & $\mathbf{2 3}$ & $\mathbf{2 4}$ & $\mathbf{2 5}$ & $\mathbf{2 6}$ & $\mathbf{2 7}$ & $\mathbf{2 8}$ \\
\hline HF & 37 & 25 & 22 & 61 & 28 & 17 & 10 & 7 & 61 & 36 & 44 & 85 & 55 & 34 \\
\hline HD & 363 & 375 & 378 & 339 & 372 & 383 & 390 & 393 & 339 & 364 & 356 & 315 & 345 & 366 \\
\hline Contagem & 14 & 19 & 9 & 15 & 11 & 13 & 14 & 15 & 11 & 15 & 15 & 7 & 8 & 20 \\
\hline
\end{tabular}

\begin{tabular}{|c|c|c|c|c|c|c|c|c|c|c|c|c|c|c|}
\hline Campos & $\mathbf{2 9}$ & $\mathbf{3 0}$ & $\mathbf{3 1}$ & $\mathbf{3 2}$ & $\mathbf{3 3}$ & $\mathbf{3 4}$ & $\mathbf{3 5}$ & $\mathbf{3 6}$ & $\mathbf{3 7}$ & $\mathbf{3 8}$ & $\mathbf{3 9}$ & $\mathbf{4 0}$ & $\mathbf{4 1}$ & $\mathbf{4 2}$ \\
\hline HF & 9 & 27 & 16 & 27 & 31 & 25 & 32 & 57 & 23 & 31 & 25 & 35 & 43 & 100 \\
\hline HD & 391 & 373 & 384 & 373 & 369 & 375 & 368 & 343 & 377 & 369 & 375 & 365 & 357 & 300 \\
\hline Contagem & 32 & 14 & 23 & 9 & 12 & 9 & 11 & 22 & 18 & 9 & 6 & 11 & 12 & 8 \\
\hline
\end{tabular}

\begin{tabular}{|c|c|c|c|c|c|c|c|c|c|}
\hline Campos & $\mathbf{4 3}$ & $\mathbf{4 4}$ & $\mathbf{4 5}$ & $\mathbf{4 6}$ & $\mathbf{4 7}$ & $\mathbf{4 8}$ & $\mathbf{4 9}$ & $\mathbf{5 0}$ & Soma \\
\hline HF & 83 & 46 & 27 & 122 & 28 & 39 & 89 & 43 & 1.951 \\
\hline HD & 317 & 354 & 373 & 278 & 372 & 361 & 311 & 357 & 18.049 \\
\hline Contagem & 8 & 5 & 9 & 13 & 7 & 9 & 13 & 9 & 750 \\
\hline
\end{tabular}


Animal: 5 Grupo: Adulto

\begin{tabular}{|c|c|c|c|c|c|c|c|c|c|c|c|c|c|c|}
\hline Campos & $\mathbf{1}$ & $\mathbf{2}$ & $\mathbf{3}$ & $\mathbf{4}$ & $\mathbf{5}$ & $\mathbf{6}$ & $\mathbf{7}$ & $\mathbf{8}$ & $\mathbf{9}$ & $\mathbf{1 0}$ & $\mathbf{1 1}$ & $\mathbf{1 2}$ & $\mathbf{1 3}$ & $\mathbf{1 4}$ \\
\hline HF & 106 & 80 & 68 & 44 & 67 & 69 & 64 & 72 & 79 & 88 & 49 & 114 & 111 & 47 \\
\hline HD & 294 & 320 & 332 & 356 & 333 & 331 & 336 & 328 & 321 & 312 & 351 & 286 & 289 & 353 \\
\hline Contagem & 21 & 19 & 18 & 24 & 8 & 13 & 25 & 14 & 9 & 22 & 17 & 25 & 16 & 27 \\
\hline
\end{tabular}

\begin{tabular}{|c|c|c|c|c|c|c|c|c|c|c|c|c|c|c|}
\hline Campos & $\mathbf{1 5}$ & $\mathbf{1 6}$ & $\mathbf{1 7}$ & $\mathbf{1 8}$ & $\mathbf{1 9}$ & $\mathbf{2 0}$ & $\mathbf{2 1}$ & $\mathbf{2 2}$ & $\mathbf{2 3}$ & $\mathbf{2 4}$ & $\mathbf{2 5}$ & $\mathbf{2 6}$ & $\mathbf{2 7}$ & $\mathbf{2 8}$ \\
\hline HF & 62 & 24 & 8 & 80 & 5 & 67 & 68 & 30 & 9 & 40 & 42 & 13 & 10 & 32 \\
\hline HD & 338 & 376 & 392 & 320 & 395 & 333 & 332 & 370 & 391 & 360 & 358 & 387 & 390 & 368 \\
\hline Contagem & 22 & 21 & 12 & 21 & 11 & 14 & 14 & 14 & 29 & 33 & 22 & 17 & 11 & 23 \\
\hline
\end{tabular}

\begin{tabular}{|c|c|c|c|c|c|c|c|c|c|c|c|c|c|c|}
\hline Campos & $\mathbf{2 9}$ & $\mathbf{3 0}$ & $\mathbf{3 1}$ & $\mathbf{3 2}$ & $\mathbf{3 3}$ & $\mathbf{3 4}$ & $\mathbf{3 5}$ & $\mathbf{3 6}$ & $\mathbf{3 7}$ & $\mathbf{3 8}$ & $\mathbf{3 9}$ & $\mathbf{4 0}$ & $\mathbf{4 1}$ & $\mathbf{4 2}$ \\
\hline HF & 27 & 35 & 110 & 75 & 65 & 53 & 50 & 14 & 17 & 83 & 35 & 39 & 25 & 22 \\
\hline HD & 373 & 365 & 290 & 325 & 335 & 347 & 350 & 386 & 383 & 317 & 365 & 361 & 375 & 378 \\
\hline Contagem & 26 & 16 & 7 & 12 & 17 & 14 & 19 & 13 & 17 & 11 & 11 & 30 & 22 & 15 \\
\hline
\end{tabular}

\begin{tabular}{|c|c|c|c|c|c|c|c|c|c|}
\hline Campos & $\mathbf{4 3}$ & $\mathbf{4 4}$ & $\mathbf{4 5}$ & $\mathbf{4 6}$ & $\mathbf{4 7}$ & $\mathbf{4 8}$ & $\mathbf{4 9}$ & $\mathbf{5 0}$ & Soma \\
\hline HF & 20 & 29 & 43 & 48 & 25 & 30 & 32 & 35 & 2.460 \\
\hline HD & 380 & 371 & 357 & 352 & 375 & 370 & 368 & 365 & 17.540 \\
\hline Contagem & 10 & 31 & 17 & 15 & 13 & 16 & 13 & 11 & 868 \\
\hline
\end{tabular}


Animal: $1 \quad$ Grupo: Velho

\begin{tabular}{|c|c|c|c|c|c|c|c|c|c|c|c|c|c|c|}
\hline Campos & $\mathbf{1}$ & $\mathbf{2}$ & $\mathbf{3}$ & $\mathbf{4}$ & $\mathbf{5}$ & $\mathbf{6}$ & $\mathbf{7}$ & $\mathbf{8}$ & $\mathbf{9}$ & $\mathbf{1 0}$ & $\mathbf{1 1}$ & $\mathbf{1 2}$ & $\mathbf{1 3}$ & $\mathbf{1 4}$ \\
\hline HF & 82 & 150 & 65 & 175 & 74 & 132 & 87 & 127 & 133 & 115 & 32 & 45 & 60 & 57 \\
\hline HD & 318 & 250 & 335 & 225 & 326 & 268 & 313 & 273 & 267 & 285 & 368 & 355 & 340 & 343 \\
\hline Contagem & 9 & 6 & 8 & 10 & 8 & 16 & 11 & 3 & 6 & 13 & 11 & 5 & 11 & 6 \\
\hline
\end{tabular}

\begin{tabular}{|c|c|c|c|c|c|c|c|c|c|c|c|c|c|c|}
\hline Campos & $\mathbf{1 5}$ & $\mathbf{1 6}$ & $\mathbf{1 7}$ & $\mathbf{1 8}$ & $\mathbf{1 9}$ & $\mathbf{2 0}$ & $\mathbf{2 1}$ & $\mathbf{2 2}$ & $\mathbf{2 3}$ & $\mathbf{2 4}$ & $\mathbf{2 5}$ & $\mathbf{2 6}$ & $\mathbf{2 7}$ & $\mathbf{2 8}$ \\
\hline HF & 60 & 35 & 38 & 41 & 115 & 52 & 48 & 54 & 30 & 32 & 112 & 80 & 20 & 20 \\
\hline HD & 340 & 365 & 362 & 359 & 285 & 348 & 352 & 346 & 370 & 368 & 288 & 320 & 380 & 380 \\
\hline Contagem & 8 & 5 & 7 & 12 & 10 & 3 & 5 & 12 & 7 & 11 & 9 & 12 & 11 & 10 \\
\hline
\end{tabular}

\begin{tabular}{|c|c|c|c|c|c|c|c|c|c|c|c|c|c|c|}
\hline Campos & $\mathbf{2 9}$ & $\mathbf{3 0}$ & $\mathbf{3 1}$ & $\mathbf{3 2}$ & $\mathbf{3 3}$ & $\mathbf{3 4}$ & $\mathbf{3 5}$ & $\mathbf{3 6}$ & $\mathbf{3 7}$ & $\mathbf{3 8}$ & $\mathbf{3 9}$ & $\mathbf{4 0}$ & $\mathbf{4 1}$ & $\mathbf{4 2}$ \\
\hline HF & 78 & 80 & 35 & 56 & 87 & 28 & 59 & 28 & 32 & 72 & 62 & 102 & 89 & 29 \\
\hline HD & 322 & 320 & 365 & 344 & 313 & 372 & 341 & 372 & 368 & 328 & 338 & 298 & 311 & 371 \\
\hline Contagem & 6 & 9 & 14 & 12 & 11 & 14 & 8 & 4 & 7 & 12 & 12 & 11 & 9 & 7 \\
\hline
\end{tabular}

\begin{tabular}{|c|c|c|c|c|c|c|c|c|c|}
\hline Campos & $\mathbf{4 3}$ & $\mathbf{4 4}$ & $\mathbf{4 5}$ & $\mathbf{4 6}$ & $\mathbf{4 7}$ & $\mathbf{4 8}$ & $\mathbf{4 9}$ & $\mathbf{5 0}$ & Soma \\
\hline HF & 90 & 51 & 35 & 76 & 21 & 17 & 46 & 35 & 3.279 \\
\hline HD & 310 & 349 & 365 & 324 & 379 & 383 & 354 & 365 & 16.721 \\
\hline Contagem & 7 & 5 & 10 & 10 & 9 & 13 & 17 & 9 & 461 \\
\hline
\end{tabular}


Animal: 2 Grupo: Velho

\begin{tabular}{|c|c|c|c|c|c|c|c|c|c|c|c|c|c|c|}
\hline Campos & $\mathbf{1}$ & $\mathbf{2}$ & $\mathbf{3}$ & $\mathbf{4}$ & $\mathbf{5}$ & $\mathbf{6}$ & $\mathbf{7}$ & $\mathbf{8}$ & $\mathbf{9}$ & $\mathbf{1 0}$ & $\mathbf{1 1}$ & $\mathbf{1 2}$ & $\mathbf{1 3}$ & $\mathbf{1 4}$ \\
\hline HF & 26 & 42 & 87 & 122 & 102 & 78 & 140 & 122 & 72 & 267 & 18 & 49 & 76 & 21 \\
\hline HD & 374 & 358 & 313 & 278 & 298 & 322 & 260 & 278 & 328 & 133 & 382 & 351 & 324 & 379 \\
\hline Contagem & 5 & 15 & 5 & 7 & 3 & 5 & 7 & 9 & 9 & 8 & 8 & 13 & 8 & 11 \\
\hline
\end{tabular}

\begin{tabular}{|c|c|c|c|c|c|c|c|c|c|c|c|c|c|c|}
\hline Campos & $\mathbf{1 5}$ & $\mathbf{1 6}$ & $\mathbf{1 7}$ & $\mathbf{1 8}$ & $\mathbf{1 9}$ & $\mathbf{2 0}$ & $\mathbf{2 1}$ & $\mathbf{2 2}$ & $\mathbf{2 3}$ & $\mathbf{2 4}$ & $\mathbf{2 5}$ & $\mathbf{2 6}$ & $\mathbf{2 7}$ & $\mathbf{2 8}$ \\
\hline HF & 44 & 47 & 48 & 32 & 35 & 10 & 40 & 96 & 29 & 21 & 44 & 65 & 51 & 82 \\
\hline HD & 356 & 353 & 352 & 368 & 365 & 390 & 360 & 304 & 371 & 379 & 356 & 335 & 349 & 318 \\
\hline Contagem & 11 & 9 & 10 & 9 & 10 & 7 & 9 & 14 & 10 & 9 & 9 & 11 & 4 & 8 \\
\hline
\end{tabular}

\begin{tabular}{|c|c|c|c|c|c|c|c|c|c|c|c|c|c|c|}
\hline Campos & $\mathbf{2 9}$ & $\mathbf{3 0}$ & $\mathbf{3 1}$ & $\mathbf{3 2}$ & $\mathbf{3 3}$ & $\mathbf{3 4}$ & $\mathbf{3 5}$ & $\mathbf{3 6}$ & $\mathbf{3 7}$ & $\mathbf{3 8}$ & $\mathbf{3 9}$ & $\mathbf{4 0}$ & $\mathbf{4 1}$ & $\mathbf{4 2}$ \\
\hline HF & 85 & 18 & 47 & 51 & 28 & 60 & 21 & 43 & 15 & 44 & 25 & 14 & 22 & 56 \\
\hline HD & 315 & 382 & 353 & 349 & 372 & 340 & 379 & 357 & 385 & 356 & 375 & 386 & 378 & 344 \\
\hline Contagem & 8 & 3 & 5 & 11 & 7 & 17 & 8 & 13 & 14 & 13 & 9 & 7 & 8 & 15 \\
\hline
\end{tabular}

\begin{tabular}{|c|c|c|c|c|c|c|c|c|c|}
\hline Campos & $\mathbf{4 3}$ & $\mathbf{4 4}$ & $\mathbf{4 5}$ & $\mathbf{4 6}$ & $\mathbf{4 7}$ & $\mathbf{4 8}$ & $\mathbf{4 9}$ & $\mathbf{5 0}$ & Soma \\
\hline HF & 64 & 38 & 25 & 35 & 36 & 39 & 30 & 40 & 2.702 \\
\hline HD & 336 & 362 & 375 & 365 & 364 & 361 & 370 & 360 & 17.298 \\
\hline Contagem & 13 & 11 & 12 & 23 & 16 & 13 & 12 & 17 & 498 \\
\hline
\end{tabular}


Animal: $3 \quad$ Grupo: Velho

\begin{tabular}{|c|c|c|c|c|c|c|c|c|c|c|c|c|c|c|}
\hline Campos & $\mathbf{1}$ & $\mathbf{2}$ & $\mathbf{3}$ & $\mathbf{4}$ & $\mathbf{5}$ & $\mathbf{6}$ & $\mathbf{7}$ & $\mathbf{8}$ & $\mathbf{9}$ & $\mathbf{1 0}$ & $\mathbf{1 1}$ & $\mathbf{1 2}$ & $\mathbf{1 3}$ & $\mathbf{1 4}$ \\
\hline HF & 46 & 30 & 53 & 73 & 166 & 103 & 181 & 211 & 100 & 48 & 45 & 49 & 11 & 88 \\
\hline HD & 354 & 370 & 347 & 327 & 234 & 297 & 219 & 189 & 300 & 352 & 355 & 351 & 389 & 312 \\
\hline Contagem & 6 & 8 & 14 & 9 & 6 & 10 & 7 & 10 & 6 & 6 & 5 & 9 & 12 & 14 \\
\hline
\end{tabular}

\begin{tabular}{|c|c|c|c|c|c|c|c|c|c|c|c|c|c|c|}
\hline Campos & $\mathbf{1 5}$ & $\mathbf{1 6}$ & $\mathbf{1 7}$ & $\mathbf{1 8}$ & $\mathbf{1 9}$ & $\mathbf{2 0}$ & $\mathbf{2 1}$ & $\mathbf{2 2}$ & $\mathbf{2 3}$ & $\mathbf{2 4}$ & $\mathbf{2 5}$ & $\mathbf{2 6}$ & $\mathbf{2 7}$ & $\mathbf{2 8}$ \\
\hline HF & 16 & 41 & 38 & 32 & 36 & 44 & 70 & 94 & 95 & 32 & 51 & 23 & 45 & 39 \\
\hline HD & 384 & 359 & 362 & 368 & 364 & 356 & 330 & 306 & 305 & 368 & 349 & 377 & 355 & 361 \\
\hline Contagem & 4 & 10 & 8 & 15 & 7 & 11 & 13 & 9 & 7 & 10 & 5 & 9 & 10 & 14 \\
\hline
\end{tabular}

\begin{tabular}{|c|c|c|c|c|c|c|c|c|c|c|c|c|c|c|}
\hline Campos & $\mathbf{2 9}$ & $\mathbf{3 0}$ & $\mathbf{3 1}$ & $\mathbf{3 2}$ & $\mathbf{3 3}$ & $\mathbf{3 4}$ & $\mathbf{3 5}$ & $\mathbf{3 6}$ & $\mathbf{3 7}$ & $\mathbf{3 8}$ & $\mathbf{3 9}$ & $\mathbf{4 0}$ & $\mathbf{4 1}$ & $\mathbf{4 2}$ \\
\hline HF & 26 & 64 & 16 & 14 & 71 & 35 & 58 & 31 & 16 & 28 & 44 & 44 & 117 & 24 \\
\hline HD & 374 & 336 & 384 & 386 & 329 & 365 & 342 & 369 & 384 & 372 & 356 & 356 & 283 & 376 \\
\hline Contagem & 9 & 7 & 12 & 11 & 13 & 5 & 7 & 5 & 7 & 8 & 10 & 11 & 6 & 8 \\
\hline
\end{tabular}

\begin{tabular}{|c|c|c|c|c|c|c|c|c|c|}
\hline Campos & $\mathbf{4 3}$ & $\mathbf{4 4}$ & $\mathbf{4 5}$ & $\mathbf{4 6}$ & $\mathbf{4 7}$ & $\mathbf{4 8}$ & $\mathbf{4 9}$ & $\mathbf{5 0}$ & Soma \\
\hline HF & 37 & 27 & 69 & 52 & 15 & 23 & 16 & 50 & 2.737 \\
\hline HD & 363 & 373 & 331 & 348 & 385 & 377 & 384 & 350 & 17.263 \\
\hline Contagem & 7 & 8 & 6 & 9 & 5 & 9 & 8 & 14 & 449 \\
\hline
\end{tabular}


Animal: 4 Grupo: Velho

\begin{tabular}{|c|c|c|c|c|c|c|c|c|c|c|c|c|c|c|}
\hline Campos & $\mathbf{1}$ & $\mathbf{2}$ & $\mathbf{3}$ & $\mathbf{4}$ & $\mathbf{5}$ & $\mathbf{6}$ & $\mathbf{7}$ & $\mathbf{8}$ & $\mathbf{9}$ & $\mathbf{1 0}$ & $\mathbf{1 1}$ & $\mathbf{1 2}$ & $\mathbf{1 3}$ & $\mathbf{1 4}$ \\
\hline HF & 68 & 47 & 34 & 22 & 101 & 98 & 144 & 145 & 144 & 49 & 82 & 33 & 49 & 35 \\
\hline HD & 332 & 353 & 366 & 378 & 299 & 302 & 256 & 255 & 256 & 351 & 318 & 367 & 351 & 365 \\
\hline Contagem & 13 & 10 & 9 & 6 & 7 & 17 & 5 & 8 & 14 & 19 & 8 & 9 & 10 & 10 \\
\hline
\end{tabular}

\begin{tabular}{|c|c|c|c|c|c|c|c|c|c|c|c|c|c|c|}
\hline Campos & $\mathbf{1 5}$ & $\mathbf{1 6}$ & $\mathbf{1 7}$ & $\mathbf{1 8}$ & $\mathbf{1 9}$ & $\mathbf{2 0}$ & $\mathbf{2 1}$ & $\mathbf{2 2}$ & $\mathbf{2 3}$ & $\mathbf{2 4}$ & $\mathbf{2 5}$ & $\mathbf{2 6}$ & $\mathbf{2 7}$ & $\mathbf{2 8}$ \\
\hline HF & 34 & 48 & 33 & 20 & 60 & 9 & 22 & 45 & 50 & 37 & 38 & 27 & 72 & 17 \\
\hline HD & 366 & 352 & 367 & 380 & 340 & 391 & 378 & 355 & 350 & 363 & 362 & 373 & 328 & 383 \\
\hline Contagem & 7 & 13 & 7 & 9 & 11 & 13 & 7 & 6 & 6 & 5 & 11 & 11 & 14 & 14 \\
\hline
\end{tabular}

\begin{tabular}{|c|c|c|c|c|c|c|c|c|c|c|c|c|c|c|}
\hline Campos & $\mathbf{2 9}$ & $\mathbf{3 0}$ & $\mathbf{3 1}$ & $\mathbf{3 2}$ & $\mathbf{3 3}$ & $\mathbf{3 4}$ & $\mathbf{3 5}$ & $\mathbf{3 6}$ & $\mathbf{3 7}$ & $\mathbf{3 8}$ & $\mathbf{3 9}$ & $\mathbf{4 0}$ & $\mathbf{4 1}$ & $\mathbf{4 2}$ \\
\hline HF & 12 & 29 & 28 & 16 & 33 & 41 & 26 & 47 & 49 & 37 & 36 & 58 & 55 & 45 \\
\hline HD & 388 & 371 & 372 & 384 & 367 & 359 & 374 & 353 & 351 & 363 & 364 & 342 & 345 & 355 \\
\hline Contagem & 19 & 12 & 10 & 12 & 8 & 7 & 11 & 10 & 13 & 11 & 12 & 20 & 12 & 17 \\
\hline
\end{tabular}

\begin{tabular}{|c|c|c|c|c|c|c|c|c|c|}
\hline Campos & $\mathbf{4 3}$ & $\mathbf{4 4}$ & $\mathbf{4 5}$ & $\mathbf{4 6}$ & $\mathbf{4 7}$ & $\mathbf{4 8}$ & $\mathbf{4 9}$ & $\mathbf{5 0}$ & Soma \\
\hline HF & 43 & 21 & 40 & 50 & 15 & 12 & 21 & 15 & 2.292 \\
\hline HD & 357 & 379 & 360 & 350 & 385 & 388 & 379 & 385 & 17.708 \\
\hline Contagem & 5 & 11 & 13 & 16 & 9 & 7 & 8 & 8 & 530 \\
\hline
\end{tabular}


Animal: 5 Grupo: Velho

\begin{tabular}{|c|c|c|c|c|c|c|c|c|c|c|c|c|c|c|}
\hline Campos & $\mathbf{1}$ & $\mathbf{2}$ & $\mathbf{3}$ & $\mathbf{4}$ & $\mathbf{5}$ & $\mathbf{6}$ & $\mathbf{7}$ & $\mathbf{8}$ & $\mathbf{9}$ & $\mathbf{1 0}$ & $\mathbf{1 1}$ & $\mathbf{1 2}$ & $\mathbf{1 3}$ & $\mathbf{1 4}$ \\
\hline HF & 141 & 96 & 104 & 127 & 214 & 139 & 75 & 186 & 175 & 14 & 40 & 57 & 47 & 33 \\
\hline HD & 259 & 304 & 296 & 273 & 186 & 261 & 325 & 214 & 225 & 386 & 360 & 343 & 353 & 367 \\
\hline Contagem & 14 & 13 & 5 & 10 & 9 & 12 & 10 & 14 & 9 & 7 & 8 & 5 & 10 & 9 \\
\hline
\end{tabular}

\begin{tabular}{|c|c|c|c|c|c|c|c|c|c|c|c|c|c|c|}
\hline Campos & $\mathbf{1 5}$ & $\mathbf{1 6}$ & $\mathbf{1 7}$ & $\mathbf{1 8}$ & $\mathbf{1 9}$ & $\mathbf{2 0}$ & $\mathbf{2 1}$ & $\mathbf{2 2}$ & $\mathbf{2 3}$ & $\mathbf{2 4}$ & $\mathbf{2 5}$ & $\mathbf{2 6}$ & $\mathbf{2 7}$ & $\mathbf{2 8}$ \\
\hline HF & 113 & 75 & 15 & 36 & 9 & 60 & 15 & 43 & 16 & 55 & 39 & 52 & 77 & 16 \\
\hline HD & 287 & 325 & 385 & 364 & 391 & 340 & 385 & 357 & 384 & 345 & 361 & 348 & 323 & 384 \\
\hline Contagem & 5 & 7 & 5 & 4 & 6 & 6 & 8 & 5 & 6 & 7 & 7 & 11 & 5 & 3 \\
\hline
\end{tabular}

\begin{tabular}{|c|c|c|c|c|c|c|c|c|c|c|c|c|c|c|}
\hline Campos & $\mathbf{2 9}$ & $\mathbf{3 0}$ & $\mathbf{3 1}$ & $\mathbf{3 2}$ & $\mathbf{3 3}$ & $\mathbf{3 4}$ & $\mathbf{3 5}$ & $\mathbf{3 6}$ & $\mathbf{3 7}$ & $\mathbf{3 8}$ & $\mathbf{3 9}$ & $\mathbf{4 0}$ & $\mathbf{4 1}$ & $\mathbf{4 2}$ \\
\hline HF & 27 & 43 & 25 & 55 & 36 & 57 & 100 & 30 & 38 & 67 & 31 & 28 & 21 & 63 \\
\hline HD & 373 & 357 & 375 & 345 & 364 & 343 & 300 & 370 & 362 & 333 & 369 & 372 & 379 & 337 \\
\hline Contagem & 11 & 4 & 4 & 6 & 4 & 7 & 6 & 4 & 4 & 9 & 7 & 5 & 9 & 6 \\
\hline
\end{tabular}

\begin{tabular}{|c|c|c|c|c|c|c|c|c|c|}
\hline Campos & $\mathbf{4 3}$ & $\mathbf{4 4}$ & $\mathbf{4 5}$ & $\mathbf{4 6}$ & $\mathbf{4 7}$ & $\mathbf{4 8}$ & $\mathbf{4 9}$ & $\mathbf{5 0}$ & Soma \\
\hline HF & 43 & 36 & 49 & 58 & 62 & 6 & 82 & 68 & 3.094 \\
\hline HD & 357 & 364 & 351 & 342 & 338 & 394 & 318 & 332 & 16.906 \\
\hline Contagem & 8 & 6 & 7 & 7 & 9 & 9 & 5 & 10 & 421 \\
\hline
\end{tabular}




\section{PLANILHA - COLORAÇÃO VERHOEFF}

\begin{tabular}{|c|c|c|c|c|c|c|c||}
\hline PU & CR & DIAS & $\begin{array}{c}\mathrm{f}= \\
\mathrm{PU} / \mathrm{PT}\end{array}$ & AT & $\begin{array}{c}\text { A }=\text { AT X } \\
\mathrm{F}\end{array}$ & $\begin{array}{c}\mathrm{C}= \\
\mathrm{CRX} 2\end{array}$ & $\begin{array}{c}\text { LD }= \\
\text { 2XC/A }\end{array}$ \\
\hline 17.538 & 421 & 21 & 0,8769 & 386250 & 338702,62 & 842 & 0,0049719 \\
\hline 18.369 & 435 & 21 & 0,91845 & 386250 & 354751,31 & 870 & 0,0049048 \\
\hline 18.279 & 443 & 21 & 0,91395 & 386250 & 353013,18 & 886 & 0,0050196 \\
\hline 17.356 & 346 & 21 & 0,8678 & 386250 & 335187,75 & 692 & 0,004129 \\
\hline 17.917 & 446 & 21 & 0,89585 & 386250 & 346022,06 & 892 & 0,0051557 \\
\hline 17.832 & 845 & 200 & 0,8916 & 386250 & 344380,5 & 1.690 & 0,0098147 \\
\hline 17.739 & 686 & 200 & 0,88695 & 386250 & 342584,43 & 1.372 & 0,0080097 \\
\hline 17.755 & 777 & 200 & 0,88775 & 386250 & 342893,43 & 1.554 & 0,009064 \\
\hline 18.049 & 750 & 200 & 0,90245 & 386250 & 348571,31 & 1.500 & 0,0086065 \\
\hline 17.541 & 862 & 200 & 0,87705 & 386250 & 338760,56 & 1.736 & 0,0102491 \\
\hline 16.675 & 461 & 450 & 0,83375 & 386250 & 322035,93 & 922 & 0,005726 \\
\hline 17.298 & 498 & 450 & 0,8649 & 386250 & 334067,62 & 996 & 0,0059628 \\
\hline 17.263 & 449 & 450 & 0,86315 & 386250 & 333391,68 & 898 & 0,005387 \\
\hline 17.708 & 530 & 450 & 0,8854 & 386250 & 341985,75 & 1.060 & 0,006199 \\
\hline 16.906 & 421 & 450 & 0,8453 & 386250 & 326497,12 & 842 & 0,0051577 \\
\hline
\end{tabular}




\section{APÊNDICE B - COLORAÇÃO WEIGERT}

Animal: $1 \quad$ Grupo: Neonato

\begin{tabular}{|c|c|c|c|c|c|c|c|c|c|c|c|c|c|c|}
\hline Campos & $\mathbf{1}$ & $\mathbf{2}$ & $\mathbf{3}$ & $\mathbf{4}$ & $\mathbf{5}$ & $\mathbf{6}$ & $\mathbf{7}$ & $\mathbf{8}$ & $\mathbf{9}$ & $\mathbf{1 0}$ & $\mathbf{1 1}$ & $\mathbf{1 2}$ & $\mathbf{1 3}$ & $\mathbf{1 4}$ \\
\hline HF & 22 & 10 & 134 & 10 & 23 & 35 & 55 & 28 & 31 & 12 & 57 & 20 & 106 & 31 \\
\hline HD & 378 & 390 & 266 & 390 & 377 & 365 & 345 & 372 & 369 & 388 & 343 & 380 & 294 & 369 \\
\hline Contagem & 12 & 26 & 11 & 18 & 8 & 13 & 17 & 18 & 27 & 20 & 20 & 19 & 15 & 6 \\
\hline
\end{tabular}

\begin{tabular}{|c|c|c|c|c|c|c|c|c|c|c|c|c|c|c|}
\hline Campos & $\mathbf{1 5}$ & $\mathbf{1 6}$ & $\mathbf{1 7}$ & $\mathbf{1 8}$ & $\mathbf{1 9}$ & $\mathbf{2 0}$ & $\mathbf{2 1}$ & $\mathbf{2 2}$ & $\mathbf{2 3}$ & $\mathbf{2 4}$ & $\mathbf{2 5}$ & $\mathbf{2 6}$ & $\mathbf{2 7}$ & $\mathbf{2 8}$ \\
\hline HF & 56 & 42 & 88 & 77 & 27 & 34 & 33 & 108 & 93 & 40 & 45 & 82 & 47 & 33 \\
\hline HD & 344 & 358 & 312 & 323 & 373 & 366 & 367 & 292 & 307 & 360 & 355 & 318 & 353 & 367 \\
\hline Contagem & 20 & 16 & 9 & 32 & 26 & 18 & 16 & 22 & 27 & 20 & 17 & 12 & 24 & 11 \\
\hline
\end{tabular}

\begin{tabular}{|c|c|c|c|c|c|c|c|c|c|c|c|c|c|c|}
\hline Campos & $\mathbf{2 9}$ & $\mathbf{3 0}$ & $\mathbf{3 1}$ & $\mathbf{3 2}$ & $\mathbf{3 3}$ & $\mathbf{3 4}$ & $\mathbf{3 5}$ & $\mathbf{3 6}$ & $\mathbf{3 7}$ & $\mathbf{3 8}$ & $\mathbf{3 9}$ & $\mathbf{4 0}$ & $\mathbf{4 1}$ & $\mathbf{4 2}$ \\
\hline HF & 89 & 46 & 36 & 44 & 20 & 21 & 28 & 99 & 113 & 67 & 55 & 44 & 51 & 23 \\
\hline HD & 311 & 354 & 364 & 356 & 380 & 379 & 372 & 301 & 287 & 333 & 345 & 356 & 349 & 377 \\
\hline Contagem & 15 & 20 & 13 & 13 & 19 & 21 & 29 & 9 & 10 & 9 & 20 & 9 & 33 & 24 \\
\hline
\end{tabular}

\begin{tabular}{|c|c|c|c|c|c|c|c|c|c|}
\hline Campos & $\mathbf{4 3}$ & $\mathbf{4 4}$ & $\mathbf{4 5}$ & $\mathbf{4 6}$ & $\mathbf{4 7}$ & $\mathbf{4 8}$ & $\mathbf{4 9}$ & $\mathbf{5 0}$ & Soma \\
\hline HF & 30 & 15 & 58 & 25 & 36 & 62 & 34 & 66 & 2.441 \\
\hline HD & 370 & 385 & 342 & 375 & 334 & 338 & 366 & 334 & 17.559 \\
\hline Contagem & 20 & 16 & 11 & 18 & 29 & 28 & 12 & 11 & 889 \\
\hline
\end{tabular}


Animal: 2 Grupo: Neonato

\begin{tabular}{|c|c|c|c|c|c|c|c|c|c|c|c|c|c|c|}
\hline Campos & $\mathbf{1}$ & $\mathbf{2}$ & $\mathbf{3}$ & $\mathbf{4}$ & $\mathbf{5}$ & $\mathbf{6}$ & $\mathbf{7}$ & $\mathbf{8}$ & $\mathbf{9}$ & $\mathbf{1 0}$ & $\mathbf{1 1}$ & $\mathbf{1 2}$ & $\mathbf{1 3}$ & $\mathbf{1 4}$ \\
\hline HF & 14 & 12 & 38 & 18 & 5 & 72 & 100 & 51 & 22 & 59 & 53 & 28 & 10 & 76 \\
\hline HD & 386 & 388 & 362 & 382 & 395 & 328 & 300 & 349 & 378 & 341 & 347 & 372 & 390 & 324 \\
\hline Contagem & 6 & 12 & 10 & 12 & 14 & 14 & 21 & 16 & 8 & 7 & 8 & 11 & 10 & 13 \\
\hline
\end{tabular}

\begin{tabular}{|c|c|c|c|c|c|c|c|c|c|c|c|c|c|c|}
\hline Campos & $\mathbf{1 5}$ & $\mathbf{1 6}$ & $\mathbf{1 7}$ & $\mathbf{1 8}$ & $\mathbf{1 9}$ & $\mathbf{2 0}$ & $\mathbf{2 1}$ & $\mathbf{2 2}$ & $\mathbf{2 3}$ & $\mathbf{2 4}$ & $\mathbf{2 5}$ & $\mathbf{2 6}$ & $\mathbf{2 7}$ & $\mathbf{2 8}$ \\
\hline HF & 19 & 41 & 121 & 93 & 45 & 30 & 65 & 38 & 184 & 108 & 57 & 76 & 63 & 99 \\
\hline HD & 381 & 359 & 279 & 307 & 355 & 370 & 335 & 362 & 216 & 292 & 343 & 324 & 337 & 301 \\
\hline Contagem & 10 & 16 & 8 & 10 & 13 & 14 & 13 & 11 & 11 & 11 & 14 & 14 & 24 & 10 \\
\hline
\end{tabular}

\begin{tabular}{|c|c|c|c|c|c|c|c|c|c|c|c|c|c|c|}
\hline Campos & $\mathbf{2 9}$ & $\mathbf{3 0}$ & $\mathbf{3 1}$ & $\mathbf{3 2}$ & $\mathbf{3 3}$ & $\mathbf{3 4}$ & $\mathbf{3 5}$ & $\mathbf{3 6}$ & $\mathbf{3 7}$ & $\mathbf{3 8}$ & $\mathbf{3 9}$ & $\mathbf{4 0}$ & $\mathbf{4 1}$ & $\mathbf{4 2}$ \\
\hline HF & 96 & 68 & 90 & 45 & 31 & 80 & 36 & 13 & 42 & 36 & 83 & 33 & 35 & 5 \\
\hline HD & 304 & 332 & 310 & 355 & 369 & 320 & 364 & 387 & 358 & 364 & 317 & 367 & 365 & 395 \\
\hline Contagem & 28 & 20 & 20 & 4 & 7 & 8 & 10 & 22 & 15 & 10 & 14 & 8 & 5 & 9 \\
\hline
\end{tabular}

\begin{tabular}{|c|c|c|c|c|c|c|c|c|c|}
\hline Campos & $\mathbf{4 3}$ & $\mathbf{4 4}$ & $\mathbf{4 5}$ & $\mathbf{4 6}$ & $\mathbf{4 7}$ & $\mathbf{4 8}$ & $\mathbf{4 9}$ & $\mathbf{5 0}$ & Soma \\
\hline HF & 11 & 85 & 19 & 62 & 61 & 77 & 25 & 43 & 2.673 \\
\hline HD & 389 & 315 & 381 & 338 & 339 & 323 & 375 & 357 & 17.327 \\
\hline Contagem & 11 & 6 & 12 & 13 & 12 & 10 & 14 & 16 & 614 \\
\hline
\end{tabular}


Animal: $3 \quad$ Grupo: Neonato

\begin{tabular}{|c|c|c|c|c|c|c|c|c|c|c|c|c|c|c|}
\hline Campos & $\mathbf{1}$ & $\mathbf{2}$ & $\mathbf{3}$ & $\mathbf{4}$ & $\mathbf{5}$ & $\mathbf{6}$ & $\mathbf{7}$ & $\mathbf{8}$ & $\mathbf{9}$ & $\mathbf{1 0}$ & $\mathbf{1 1}$ & $\mathbf{1 2}$ & $\mathbf{1 3}$ & $\mathbf{1 4}$ \\
\hline HF & 37 & 22 & 54 & 46 & 95 & 97 & 70 & 38 & 34 & 19 & 39 & 16 & 120 & 32 \\
\hline HD & 363 & 378 & 346 & 354 & 305 & 303 & 330 & 362 & 366 & 381 & 361 & 384 & 280 & 368 \\
\hline Contagem & 17 & 27 & 12 & 7 & 15 & 17 & 5 & 6 & 10 & 10 & 5 & 7 & 9 & 12 \\
\hline
\end{tabular}

\begin{tabular}{|c|c|c|c|c|c|c|c|c|c|c|c|c|c|c|}
\hline Campos & $\mathbf{1 5}$ & $\mathbf{1 6}$ & $\mathbf{1 7}$ & $\mathbf{1 8}$ & $\mathbf{1 9}$ & $\mathbf{2 0}$ & $\mathbf{2 1}$ & $\mathbf{2 2}$ & $\mathbf{2 3}$ & $\mathbf{2 4}$ & $\mathbf{2 5}$ & $\mathbf{2 6}$ & $\mathbf{2 7}$ & $\mathbf{2 8}$ \\
\hline HF & 61 & 66 & 56 & 74 & 45 & 92 & 76 & 81 & 58 & 87 & 116 & 97 & 56 & 64 \\
\hline HD & 339 & 334 & 344 & 326 & 355 & 308 & 324 & 319 & 342 & 313 & 284 & 303 & 344 & 336 \\
\hline Contagem & 6 & 9 & 11 & 7 & 5 & 7 & 7 & 12 & 8 & 10 & 7 & 10 & 8 & 12 \\
\hline
\end{tabular}

\begin{tabular}{|c|c|c|c|c|c|c|c|c|c|c|c|c|c|c|}
\hline Campos & $\mathbf{2 9}$ & $\mathbf{3 0}$ & $\mathbf{3 1}$ & $\mathbf{3 2}$ & $\mathbf{3 3}$ & $\mathbf{3 4}$ & $\mathbf{3 5}$ & $\mathbf{3 6}$ & $\mathbf{3 7}$ & $\mathbf{3 8}$ & $\mathbf{3 9}$ & $\mathbf{4 0}$ & $\mathbf{4 1}$ & $\mathbf{4 2}$ \\
\hline HF & 86 & 57 & 34 & 37 & 105 & 80 & 35 & 35 & 32 & 90 & 35 & 65 & 28 & 82 \\
\hline HD & 314 & 343 & 366 & 363 & 295 & 320 & 365 & 365 & 368 & 310 & 365 & 335 & 372 & 318 \\
\hline Contagem & 5 & 9 & 6 & 10 & 10 & 9 & 12 & 8 & 10 & 7 & 3 & 11 & 13 & 7 \\
\hline
\end{tabular}

\begin{tabular}{|c|c|c|c|c|c|c|c|c|c|}
\hline Campos & $\mathbf{4 3}$ & $\mathbf{4 4}$ & $\mathbf{4 5}$ & $\mathbf{4 6}$ & $\mathbf{4 7}$ & $\mathbf{4 8}$ & $\mathbf{4 9}$ & $\mathbf{5 0}$ & Soma \\
\hline HF & 19 & 90 & 63 & 30 & 56 & 37 & 16 & 24 & 2.884 \\
\hline HD & 381 & 310 & 337 & 370 & 344 & 363 & 384 & 376 & 17.116 \\
\hline Contagem & 6 & 11 & 16 & 7 & 16 & 9 & 9 & 13 & 485 \\
\hline
\end{tabular}


Animal: 4 Grupo: Neonato

\begin{tabular}{|c|c|c|c|c|c|c|c|c|c|c|c|c|c|c|}
\hline Campos & $\mathbf{1}$ & $\mathbf{2}$ & $\mathbf{3}$ & $\mathbf{4}$ & $\mathbf{5}$ & $\mathbf{6}$ & $\mathbf{7}$ & $\mathbf{8}$ & $\mathbf{9}$ & $\mathbf{1 0}$ & $\mathbf{1 1}$ & $\mathbf{1 2}$ & $\mathbf{1 3}$ & $\mathbf{1 4}$ \\
\hline HF & 3 & 14 & 32 & 122 & 23 & 22 & 37 & 38 & 72 & 25 & 62 & 32 & 13 & 113 \\
\hline HD & 397 & 386 & 368 & 278 & 377 & 378 & 363 & 362 & 328 & 375 & 338 & 368 & 387 & 287 \\
\hline Contagem & 8 & 4 & 13 & 11 & 33 & 19 & 20 & 13 & 25 & 15 & 12 & 14 & 16 & 27 \\
\hline
\end{tabular}

\begin{tabular}{|c|c|c|c|c|c|c|c|c|c|c|c|c|c|c|}
\hline Campos & $\mathbf{1 5}$ & $\mathbf{1 6}$ & $\mathbf{1 7}$ & $\mathbf{1 8}$ & $\mathbf{1 9}$ & $\mathbf{2 0}$ & $\mathbf{2 1}$ & $\mathbf{2 2}$ & $\mathbf{2 3}$ & $\mathbf{2 4}$ & $\mathbf{2 5}$ & $\mathbf{2 6}$ & $\mathbf{2 7}$ & $\mathbf{2 8}$ \\
\hline HF & 17 & 20 & 15 & 12 & 19 & 23 & 12 & 30 & 145 & 4 & 40 & 12 & 42 & 32 \\
\hline HD & 383 & 380 & 385 & 388 & 381 & 377 & 388 & 370 & 255 & 396 & 360 & 388 & 358 & 368 \\
\hline Contagem & 17 & 12 & 12 & 22 & 17 & 9 & 20 & 16 & 14 & 12 & 12 & 17 & 49 & 26 \\
\hline
\end{tabular}

\begin{tabular}{|c|c|c|c|c|c|c|c|c|c|c|c|c|c|c|}
\hline Campos & $\mathbf{2 9}$ & $\mathbf{3 0}$ & $\mathbf{3 1}$ & $\mathbf{3 2}$ & $\mathbf{3 3}$ & $\mathbf{3 4}$ & $\mathbf{3 5}$ & $\mathbf{3 6}$ & $\mathbf{3 7}$ & $\mathbf{3 8}$ & $\mathbf{3 9}$ & $\mathbf{4 0}$ & $\mathbf{4 1}$ & $\mathbf{4 2}$ \\
\hline HF & 47 & 55 & 12 & 113 & 32 & 22 & 21 & 76 & 43 & 11 & 23 & 35 & 19 & 47 \\
\hline HD & 353 & 345 & 388 & 287 & 368 & 378 & 379 & 324 & 357 & 389 & 377 & 365 & 381 & 353 \\
\hline Contagem & 24 & 25 & 20 & 10 & 16 & 10 & 12 & 12 & 13 & 16 & 4 & 12 & 9 & 18 \\
\hline
\end{tabular}

\begin{tabular}{|c|c|c|c|c|c|c|c|c|c|}
\hline Campos & $\mathbf{4 3}$ & $\mathbf{4 4}$ & $\mathbf{4 5}$ & $\mathbf{4 6}$ & $\mathbf{4 7}$ & $\mathbf{4 8}$ & $\mathbf{4 9}$ & $\mathbf{5 0}$ & Soma \\
\hline HF & 55 & 27 & 14 & 63 & 11 & 47 & 24 & 110 & 1.938 \\
\hline HD & 345 & 373 & 386 & 337 & 389 & 353 & 376 & 290 & 18.062 \\
\hline Contagem & 6 & 6 & 13 & 11 & 10 & 4 & 7 & 8 & 751 \\
\hline
\end{tabular}


Animal: 5 Grupo: Neonato

\begin{tabular}{|c|c|c|c|c|c|c|c|c|c|c|c|c|c|c|}
\hline Campos & $\mathbf{1}$ & $\mathbf{2}$ & $\mathbf{3}$ & $\mathbf{4}$ & $\mathbf{5}$ & $\mathbf{6}$ & $\mathbf{7}$ & $\mathbf{8}$ & $\mathbf{9}$ & $\mathbf{1 0}$ & $\mathbf{1 1}$ & $\mathbf{1 2}$ & $\mathbf{1 3}$ & $\mathbf{1 4}$ \\
\hline HF & 18 & 33 & 4 & 41 & 17 & 77 & 56 & 15 & 69 & 122 & 33 & 87 & 34 & 12 \\
\hline HD & 382 & 367 & 396 & 359 & 383 & 323 & 344 & 385 & 331 & 278 & 367 & 313 & 366 & 388 \\
\hline Contagem & 21 & 17 & 9 & 9 & 15 & 6 & 3 & 19 & 22 & 12 & 16 & 18 & 6 & 8 \\
\hline
\end{tabular}

\begin{tabular}{|c|c|c|c|c|c|c|c|c|c|c|c|c|c|c|}
\hline Campos & $\mathbf{1 5}$ & $\mathbf{1 6}$ & $\mathbf{1 7}$ & $\mathbf{1 8}$ & $\mathbf{1 9}$ & $\mathbf{2 0}$ & $\mathbf{2 1}$ & $\mathbf{2 2}$ & $\mathbf{2 3}$ & $\mathbf{2 4}$ & $\mathbf{2 5}$ & $\mathbf{2 6}$ & $\mathbf{2 7}$ & $\mathbf{2 8}$ \\
\hline HF & 91 & 22 & 24 & 22 & 23 & 36 & 53 & 39 & 19 & 53 & 22 & 22 & 39 & 83 \\
\hline HD & 309 & 378 & 376 & 378 & 377 & 364 & 347 & 361 & 381 & 347 & 378 & 378 & 361 & 317 \\
\hline Contagem & 5 & 5 & 15 & 12 & 7 & 14 & 14 & 15 & 10 & 15 & 7 & 9 & 13 & 6 \\
\hline
\end{tabular}

\begin{tabular}{|c|c|c|c|c|c|c|c|c|c|c|c|c|c|c|}
\hline Campos & $\mathbf{2 9}$ & $\mathbf{3 0}$ & $\mathbf{3 1}$ & $\mathbf{3 2}$ & $\mathbf{3 3}$ & $\mathbf{3 4}$ & $\mathbf{3 5}$ & $\mathbf{3 6}$ & $\mathbf{3 7}$ & $\mathbf{3 8}$ & $\mathbf{3 9}$ & $\mathbf{4 0}$ & $\mathbf{4 1}$ & $\mathbf{4 2}$ \\
\hline HF & 64 & 16 & 30 & 20 & 15 & 63 & 17 & 35 & 45 & 67 & 11 & 38 & 46 & 49 \\
\hline HD & 336 & 384 & 370 & 380 & 385 & 337 & 383 & 365 & 355 & 333 & 389 & 362 & 354 & 351 \\
\hline Contagem & 7 & 13 & 4 & 7 & 11 & 13 & 14 & 11 & 10 & 9 & 6 & 11 & 12 & 10 \\
\hline
\end{tabular}

\begin{tabular}{|c|c|c|c|c|c|c|c|c|c|}
\hline Campos & $\mathbf{4 3}$ & $\mathbf{4 4}$ & $\mathbf{4 5}$ & $\mathbf{4 6}$ & $\mathbf{4 7}$ & $\mathbf{4 8}$ & $\mathbf{4 9}$ & $\mathbf{5 0}$ & Soma \\
\hline HF & 74 & 41 & 14 & 16 & 29 & 81 & 112 & 32 & 2.081 \\
\hline HD & 326 & 359 & 386 & 384 & 371 & 319 & 288 & 368 & 17.919 \\
\hline Contagem & 8 & 10 & 5 & 14 & 9 & 11 & 10 & 11 & 544 \\
\hline
\end{tabular}


Animal: $1 \quad$ Grupo: Adulto

\begin{tabular}{|c|c|c|c|c|c|c|c|c|c|c|c|c|c|c|}
\hline Campos & $\mathbf{1}$ & $\mathbf{2}$ & $\mathbf{3}$ & $\mathbf{4}$ & $\mathbf{5}$ & $\mathbf{6}$ & $\mathbf{7}$ & $\mathbf{8}$ & $\mathbf{9}$ & $\mathbf{1 0}$ & $\mathbf{1 1}$ & $\mathbf{1 2}$ & $\mathbf{1 3}$ & $\mathbf{1 4}$ \\
\hline HF & 26 & -- & 122 & 50 & 31 & 51 & 11 & 50 & 134 & 30 & 43 & 55 & 41 & 26 \\
\hline HD & 374 & 400 & 278 & 350 & 369 & 349 & 389 & 350 & 266 & 370 & 357 & 345 & 359 & 374 \\
\hline Contagem & 20 & 36 & 46 & 38 & 29 & 29 & 24 & 31 & 18 & 29 & 7 & 24 & 24 & 24 \\
\hline
\end{tabular}

\begin{tabular}{|c|c|c|c|c|c|c|c|c|c|c|c|c|c|c|}
\hline Campos & $\mathbf{1 5}$ & $\mathbf{1 6}$ & $\mathbf{1 7}$ & $\mathbf{1 8}$ & $\mathbf{1 9}$ & $\mathbf{2 0}$ & $\mathbf{2 1}$ & $\mathbf{2 2}$ & $\mathbf{2 3}$ & $\mathbf{2 4}$ & $\mathbf{2 5}$ & $\mathbf{2 6}$ & $\mathbf{2 7}$ & $\mathbf{2 8}$ \\
\hline HF & 37 & 23 & 35 & 90 & 39 & 39 & 42 & 18 & 24 & 57 & 38 & 68 & 38 & 27 \\
\hline HD & 363 & 377 & 365 & 310 & 361 & 361 & 358 & 382 & 376 & 343 & 362 & 332 & 362 & 373 \\
\hline Contagem & 12 & 21 & 14 & 13 & 32 & 9 & 15 & 38 & 36 & 10 & 16 & 10 & 21 & 16 \\
\hline
\end{tabular}

\begin{tabular}{|c|c|c|c|c|c|c|c|c|c|c|c|c|c|c|}
\hline Campos & $\mathbf{2 9}$ & $\mathbf{3 0}$ & $\mathbf{3 1}$ & $\mathbf{3 2}$ & $\mathbf{3 3}$ & $\mathbf{3 4}$ & $\mathbf{3 5}$ & $\mathbf{3 6}$ & $\mathbf{3 7}$ & $\mathbf{3 8}$ & $\mathbf{3 9}$ & $\mathbf{4 0}$ & $\mathbf{4 1}$ & $\mathbf{4 2}$ \\
\hline HF & 33 & 23 & 49 & 88 & 55 & 7 & 24 & 36 & 27 & 18 & 43 & 34 & 20 & 32 \\
\hline HD & 367 & 377 & 351 & 312 & 345 & 393 & 376 & 364 & 373 & 382 & 357 & 366 & 380 & 368 \\
\hline Contagem & 11 & 25 & 16 & 13 & 10 & 14 & 25 & 13 & 12 & 16 & 16 & 12 & 26 & 19 \\
\hline
\end{tabular}

\begin{tabular}{|c|c|c|c|c|c|c|c|c|c|}
\hline Campos & $\mathbf{4 3}$ & $\mathbf{4 4}$ & $\mathbf{4 5}$ & $\mathbf{4 6}$ & $\mathbf{4 7}$ & $\mathbf{4 8}$ & $\mathbf{4 9}$ & $\mathbf{5 0}$ & Soma \\
\hline HF & 15 & 17 & 18 & 9 & 24 & 19 & 25 & 26 & 1.887 \\
\hline HD & 385 & 383 & 382 & 391 & 376 & 381 & 375 & 374 & 18.113 \\
\hline Contagem & 14 & 21 & 19 & 17 & 21 & 19 & 15 & 10 & 1.006 \\
\hline
\end{tabular}


Animal: 2 Grupo: Adulto

\begin{tabular}{|c|c|c|c|c|c|c|c|c|c|c|c|c|c|c|}
\hline Campos & $\mathbf{1}$ & $\mathbf{2}$ & $\mathbf{3}$ & $\mathbf{4}$ & $\mathbf{5}$ & $\mathbf{6}$ & $\mathbf{7}$ & $\mathbf{8}$ & $\mathbf{9}$ & $\mathbf{1 0}$ & $\mathbf{1 1}$ & $\mathbf{1 2}$ & $\mathbf{1 3}$ & $\mathbf{1 4}$ \\
\hline HF & 67 & 104 & 74 & 26 & 79 & 135 & 49 & 13 & 75 & 83 & 64 & 13 & 31 & 18 \\
\hline HD & 333 & 296 & 326 & 374 & 321 & 265 & 351 & 387 & 325 & 317 & 336 & 387 & 369 & 382 \\
\hline Contagem & 26 & 23 & 25 & 34 & 32 & 22 & 17 & 25 & 26 & 19 & 22 & 18 & 17 & 18 \\
\hline
\end{tabular}

\begin{tabular}{|c|c|c|c|c|c|c|c|c|c|c|c|c|c|c|}
\hline Campos & $\mathbf{1 5}$ & $\mathbf{1 6}$ & $\mathbf{1 7}$ & $\mathbf{1 8}$ & $\mathbf{1 9}$ & $\mathbf{2 0}$ & $\mathbf{2 1}$ & $\mathbf{2 2}$ & $\mathbf{2 3}$ & $\mathbf{2 4}$ & $\mathbf{2 5}$ & $\mathbf{2 6}$ & $\mathbf{2 7}$ & $\mathbf{2 8}$ \\
\hline HF & 44 & 9 & 10 & 22 & 54 & 39 & 77 & 19 & 25 & 13 & 19 & 57 & 56 & 52 \\
\hline HD & 356 & 391 & 390 & 378 & 346 & 361 & 323 & 381 & 375 & 387 & 381 & 343 & 344 & 348 \\
\hline Contagem & 15 & 21 & 23 & 25 & 27 & 23 & 22 & 29 & 15 & 16 & 18 & 22 & 26 & 15 \\
\hline
\end{tabular}

\begin{tabular}{|c|c|c|c|c|c|c|c|c|c|c|c|c|c|c|}
\hline Campos & $\mathbf{2 9}$ & $\mathbf{3 0}$ & $\mathbf{3 1}$ & $\mathbf{3 2}$ & $\mathbf{3 3}$ & $\mathbf{3 4}$ & $\mathbf{3 5}$ & $\mathbf{3 6}$ & $\mathbf{3 7}$ & $\mathbf{3 8}$ & $\mathbf{3 9}$ & $\mathbf{4 0}$ & $\mathbf{4 1}$ & $\mathbf{4 2}$ \\
\hline HF & 56 & 92 & 54 & 24 & 72 & 17 & 42 & 15 & 30 & 52 & 77 & 72 & 69 & 57 \\
\hline HD & 344 & 308 & 346 & 376 & 328 & 383 & 358 & 385 & 370 & 348 & 323 & 328 & 331 & 343 \\
\hline Contagem & 18 & 20 & 23 & 29 & 20 & 15 & 25 & 25 & 31 & 31 & 23 & 20 & 19 & 22 \\
\hline
\end{tabular}

\begin{tabular}{|c|l|l|l|l|l|l|l|l|l|}
\hline Campos & $\mathbf{4 3}$ & $\mathbf{4 4}$ & $\mathbf{4 5}$ & $\mathbf{4 6}$ & $\mathbf{4 7}$ & $\mathbf{4 8}$ & $\mathbf{4 9}$ & $\mathbf{5 0}$ & Soma \\
\hline HF & 61 & 55 & 26 & 30 & 19 & 42 & 32 & 31 & 2352 \\
\hline HD & 339 & 345 & 374 & 370 & 381 & 358 & 368 & 369 & 17648 \\
\hline Contagem & 19 & 19 & 31 & 29 & 21 & 23 & 16 & 23 & 1123 \\
\hline
\end{tabular}


Animal: 3 Grupo: Adulto

\begin{tabular}{|c|c|c|c|c|c|c|c|c|c|c|c|c|c|c|}
\hline Campos & $\mathbf{1}$ & $\mathbf{2}$ & $\mathbf{3}$ & $\mathbf{4}$ & $\mathbf{5}$ & $\mathbf{6}$ & $\mathbf{7}$ & $\mathbf{8}$ & $\mathbf{9}$ & $\mathbf{1 0}$ & $\mathbf{1 1}$ & $\mathbf{1 2}$ & $\mathbf{1 3}$ & $\mathbf{1 4}$ \\
\hline HF & 60 & 62 & 33 & 36 & 100 & 104 & 37 & 64 & 55 & 50 & 39 & 70 & 43 & 22 \\
\hline HD & 340 & 338 & 367 & 364 & 300 & 296 & 363 & 336 & 345 & 350 & 361 & 330 & 357 & 378 \\
\hline Contagem & 40 & 46 & 70 & 56 & 24 & 19 & 38 & 27 & 24 & 19 & 20 & 21 & 25 & 28 \\
\hline
\end{tabular}

\begin{tabular}{|c|c|c|c|c|c|c|c|c|c|c|c|c|c|c|}
\hline Campos & $\mathbf{1 5}$ & $\mathbf{1 6}$ & $\mathbf{1 7}$ & $\mathbf{1 8}$ & $\mathbf{1 9}$ & $\mathbf{2 0}$ & $\mathbf{2 1}$ & $\mathbf{2 2}$ & $\mathbf{2 3}$ & $\mathbf{2 4}$ & $\mathbf{2 5}$ & $\mathbf{2 6}$ & $\mathbf{2 7}$ & $\mathbf{2 8}$ \\
\hline HF & 44 & 33 & 60 & 46 & 33 & 52 & 22 & 23 & 33 & 40 & 30 & 44 & 17 & 32 \\
\hline HD & 356 & 367 & 340 & 354 & 367 & 348 & 378 & 377 & 367 & 360 & 370 & 356 & 383 & 368 \\
\hline Contagem & 23 & 14 & 14 & 14 & 15 & 11 & 17 & 33 & 17 & 12 & 18 & 21 & 19 & 12 \\
\hline
\end{tabular}

\begin{tabular}{|c|c|c|c|c|c|c|c|c|c|c|c|c|c|c|}
\hline Campos & $\mathbf{2 9}$ & $\mathbf{3 0}$ & $\mathbf{3 1}$ & $\mathbf{3 2}$ & $\mathbf{3 3}$ & $\mathbf{3 4}$ & $\mathbf{3 5}$ & $\mathbf{3 6}$ & $\mathbf{3 7}$ & $\mathbf{3 8}$ & $\mathbf{3 9}$ & $\mathbf{4 0}$ & $\mathbf{4 1}$ & $\mathbf{4 2}$ \\
\hline HF & 11 & 23 & 38 & 37 & 37 & 25 & 55 & 61 & 80 & 68 & 33 & 64 & 13 & 60 \\
\hline HD & 389 & 377 & 362 & 363 & 363 & 375 & 345 & 339 & 320 & 332 & 367 & 336 & 387 & 340 \\
\hline Contagem & 17 & 16 & 30 & 19 & 17 & 17 & 12 & 18 & 15 & 14 & 24 & 19 & 23 & 11 \\
\hline
\end{tabular}

\begin{tabular}{|c|c|c|c|c|c|c|c|c|c|}
\hline Campos & $\mathbf{4 3}$ & $\mathbf{4 4}$ & $\mathbf{4 5}$ & $\mathbf{4 6}$ & $\mathbf{4 7}$ & $\mathbf{4 8}$ & $\mathbf{4 9}$ & $\mathbf{5 0}$ & Soma \\
\hline HF & 158 & 89 & 9 & 44 & 40 & 34 & 37 & 41 & 2.341 \\
\hline HD & 242 & 311 & 391 & 356 & 360 & 366 & 363 & 359 & 17.659 \\
\hline Contagem & 16 & 15 & 14 & 16 & 14 & 16 & 17 & 19 & 1.076 \\
\hline
\end{tabular}


Animal: 4 Grupo: Adulto

\begin{tabular}{|c|c|c|c|c|c|c|c|c|c|c|c|c|c|c|}
\hline Campos & $\mathbf{1}$ & $\mathbf{2}$ & $\mathbf{3}$ & $\mathbf{4}$ & $\mathbf{5}$ & $\mathbf{6}$ & $\mathbf{7}$ & $\mathbf{8}$ & $\mathbf{9}$ & $\mathbf{1 0}$ & $\mathbf{1 1}$ & $\mathbf{1 2}$ & $\mathbf{1 3}$ & $\mathbf{1 4}$ \\
\hline HF & 33 & 27 & 40 & 32 & 43 & 97 & 39 & 47 & 54 & 62 & 31 & 65 & 96 & 50 \\
\hline HD & 367 & 373 & 360 & 368 & 357 & 303 & 361 & 353 & 346 & 338 & 369 & 335 & 304 & 350 \\
\hline Contagem & 36 & 37 & 47 & 60 & 29 & 16 & 32 & 30 & 35 & 33 & 30 & 26 & 29 & 22 \\
\hline
\end{tabular}

\begin{tabular}{|c|c|c|c|c|c|c|c|c|c|c|c|c|c|c|}
\hline Campos & $\mathbf{1 5}$ & $\mathbf{1 6}$ & $\mathbf{1 7}$ & $\mathbf{1 8}$ & $\mathbf{1 9}$ & $\mathbf{2 0}$ & $\mathbf{2 1}$ & $\mathbf{2 2}$ & $\mathbf{2 3}$ & $\mathbf{2 4}$ & $\mathbf{2 5}$ & $\mathbf{2 6}$ & $\mathbf{2 7}$ & $\mathbf{2 8}$ \\
\hline HF & 15 & 92 & 23 & 15 & 4 & 7 & 17 & 42 & 64 & 32 & 46 & 17 & 12 & 51 \\
\hline HD & 385 & 308 & 377 & 385 & 396 & 393 & 383 & 358 & 336 & 368 & 354 & 383 & 388 & 349 \\
\hline Contagem & 13 & 29 & 15 & 16 & 11 & 9 & 20 & 20 & 28 & 18 & 24 & 17 & 24 & 21 \\
\hline
\end{tabular}

\begin{tabular}{|c|c|c|c|c|c|c|c|c|c|c|c|c|c|c|}
\hline Campos & $\mathbf{2 9}$ & $\mathbf{3 0}$ & $\mathbf{3 1}$ & $\mathbf{3 2}$ & $\mathbf{3 3}$ & $\mathbf{3 4}$ & $\mathbf{3 5}$ & $\mathbf{3 6}$ & $\mathbf{3 7}$ & $\mathbf{3 8}$ & $\mathbf{3 9}$ & $\mathbf{4 0}$ & $\mathbf{4 1}$ & $\mathbf{4 2}$ \\
\hline HF & 37 & 17 & 19 & 15 & 32 & 31 & 23 & 35 & 24 & 22 & 46 & 16 & 52 & 106 \\
\hline HD & 363 & 383 & 381 & 385 & 368 & 369 & 377 & 365 & 376 & 378 & 354 & 384 & 348 & 294 \\
\hline Contagem & 21 & 24 & 22 & 20 & 20 & 23 & 29 & 17 & 16 & 30 & 23 & 19 & 14 & 6 \\
\hline
\end{tabular}

\begin{tabular}{|c|c|c|c|c|c|c|c|c|c|}
\hline Campos & $\mathbf{4 3}$ & $\mathbf{4 4}$ & $\mathbf{4 5}$ & $\mathbf{4 6}$ & $\mathbf{4 7}$ & $\mathbf{4 8}$ & $\mathbf{4 9}$ & $\mathbf{5 0}$ & Soma \\
\hline HF & 19 & 22 & 21 & 22 & 21 & 24 & 23 & 18 & 1.798 \\
\hline HD & 381 & 378 & 379 & 378 & 379 & 376 & 377 & 382 & 18.202 \\
\hline Contagem & 26 & 18 & 24 & 20 & 18 & 15 & 24 & 23 & 1.179 \\
\hline
\end{tabular}


Animal: 5 Grupo: Adulto

\begin{tabular}{|c|c|c|c|c|c|c|c|c|c|c|c|c|c|c|}
\hline Campos & $\mathbf{1}$ & $\mathbf{2}$ & $\mathbf{3}$ & $\mathbf{4}$ & $\mathbf{5}$ & $\mathbf{6}$ & $\mathbf{7}$ & $\mathbf{8}$ & $\mathbf{9}$ & $\mathbf{1 0}$ & $\mathbf{1 1}$ & $\mathbf{1 2}$ & $\mathbf{1 3}$ & $\mathbf{1 4}$ \\
\hline HF & 92 & 86 & 71 & 34 & 102 & 13 & 40 & 34 & 19 & 34 & 63 & 89 & 7 & 14 \\
\hline HD & 308 & 314 & 329 & 366 & 298 & 387 & 360 & 366 & 381 & 366 & 337 & 311 & 393 & 386 \\
\hline Contagem & 24 & 19 & 30 & 33 & 30 & 43 & 36 & 20 & 41 & 42 & 17 & 20 & 25 & 27 \\
\hline
\end{tabular}

\begin{tabular}{|c|c|c|c|c|c|c|c|c|c|c|c|c|c|c|}
\hline Campos & $\mathbf{1 5}$ & $\mathbf{1 6}$ & $\mathbf{1 7}$ & $\mathbf{1 8}$ & $\mathbf{1 9}$ & $\mathbf{2 0}$ & $\mathbf{2 1}$ & $\mathbf{2 2}$ & $\mathbf{2 3}$ & $\mathbf{2 4}$ & $\mathbf{2 5}$ & $\mathbf{2 6}$ & $\mathbf{2 7}$ & $\mathbf{2 8}$ \\
\hline HF & 14 & 14 & 44 & 19 & 102 & 31 & 17 & 83 & 38 & 97 & 33 & 32 & 35 & 25 \\
\hline HD & 386 & 386 & 356 & 381 & 298 & 369 & 383 & 317 & 362 & 303 & 367 & 368 & 365 & 375 \\
\hline Contagem & 19 & 35 & 27 & 32 & 25 & 32 & 17 & 18 & 23 & 11 & 16 & 23 & 15 & 23 \\
\hline
\end{tabular}

\begin{tabular}{|c|c|c|c|c|c|c|c|c|c|c|c|c|c|c|}
\hline Campos & $\mathbf{2 9}$ & $\mathbf{3 0}$ & $\mathbf{3 1}$ & $\mathbf{3 2}$ & $\mathbf{3 3}$ & $\mathbf{3 4}$ & $\mathbf{3 5}$ & $\mathbf{3 6}$ & $\mathbf{3 7}$ & $\mathbf{3 8}$ & $\mathbf{3 9}$ & $\mathbf{4 0}$ & $\mathbf{4 1}$ & $\mathbf{4 2}$ \\
\hline HF & 21 & 32 & 44 & 24 & 30 & 30 & 38 & 45 & 30 & 114 & 14 & 5 & 35 & 48 \\
\hline HD & 379 & 368 & 356 & 376 & 370 & 370 & 362 & 355 & 370 & 286 & 386 & 395 & 365 & 352 \\
\hline Contagem & 13 & 24 & 27 & 40 & 29 & 40 & 16 & 30 & 31 & 22 & 33 & 28 & 23 & 22 \\
\hline
\end{tabular}

\begin{tabular}{|c|c|c|c|c|c|c|c|c|c|}
\hline Campos & $\mathbf{4 3}$ & $\mathbf{4 4}$ & $\mathbf{4 5}$ & $\mathbf{4 6}$ & $\mathbf{4 7}$ & $\mathbf{4 8}$ & $\mathbf{4 9}$ & $\mathbf{5 0}$ & Soma \\
\hline HF & 20 & 30 & 21 & 36 & 22 & 20 & 29 & 80 & 2.050 \\
\hline HD & 380 & 370 & 379 & 364 & 378 & 380 & 371 & 320 & 17.950 \\
\hline Contagem & 48 & 31 & 18 & 9 & 15 & 19 & 33 & 16 & 1.290 \\
\hline
\end{tabular}


Animal: $1 \quad$ Grupo: Velho

\begin{tabular}{|c|c|c|c|c|c|c|c|c|c|c|c|c|c|c|}
\hline Campos & $\mathbf{1}$ & $\mathbf{2}$ & $\mathbf{3}$ & $\mathbf{4}$ & $\mathbf{5}$ & $\mathbf{6}$ & $\mathbf{7}$ & $\mathbf{8}$ & $\mathbf{9}$ & $\mathbf{1 0}$ & $\mathbf{1 1}$ & $\mathbf{1 2}$ & $\mathbf{1 3}$ & $\mathbf{1 4}$ \\
\hline HF & 89 & 59 & 20 & 70 & 181 & 59 & 31 & 29 & 108 & 79 & 50 & 49 & 55 & 64 \\
\hline HD & 311 & 341 & 380 & 330 & 219 & 341 & 369 & 371 & 292 & 321 & 350 & 351 & 345 & 336 \\
\hline Contagem & 40 & 25 & 18 & 24 & 23 & 35 & 27 & 29 & 27 & 22 & 24 & 15 & 11 & 12 \\
\hline
\end{tabular}

\begin{tabular}{|c|c|c|c|c|c|c|c|c|c|c|c|c|c|c|}
\hline Campos & $\mathbf{1 5}$ & $\mathbf{1 6}$ & $\mathbf{1 7}$ & $\mathbf{1 8}$ & $\mathbf{1 9}$ & $\mathbf{2 0}$ & $\mathbf{2 1}$ & $\mathbf{2 2}$ & $\mathbf{2 3}$ & $\mathbf{2 4}$ & $\mathbf{2 5}$ & $\mathbf{2 6}$ & $\mathbf{2 7}$ & $\mathbf{2 8}$ \\
\hline HF & 23 & 41 & 36 & 19 & 154 & 58 & 38 & 60 & 55 & 31 & 95 & 69 & 58 & 30 \\
\hline HD & 377 & 359 & 364 & 381 & 246 & 342 & 362 & 340 & 345 & 369 & 305 & 331 & 342 & 370 \\
\hline Contagem & 15 & 16 & 10 & 12 & 12 & 11 & 10 & 18 & 25 & 22 & 20 & 26 & 18 & 22 \\
\hline
\end{tabular}

\begin{tabular}{|c|c|c|c|c|c|c|c|c|c|c|c|c|c|c|}
\hline Campos & $\mathbf{2 9}$ & $\mathbf{3 0}$ & $\mathbf{3 1}$ & $\mathbf{3 2}$ & $\mathbf{3 3}$ & $\mathbf{3 4}$ & $\mathbf{3 5}$ & $\mathbf{3 6}$ & $\mathbf{3 7}$ & $\mathbf{3 8}$ & $\mathbf{3 9}$ & $\mathbf{4 0}$ & $\mathbf{4 1}$ & $\mathbf{4 2}$ \\
\hline HF & 65 & 19 & 28 & 69 & 41 & 64 & 33 & 25 & 48 & 25 & 55 & 11 & 49 & 22 \\
\hline HD & 335 & 381 & 372 & 331 & 359 & 336 & 367 & 375 & 352 & 375 & 345 & 389 & 351 & 378 \\
\hline Contagem & 26 & 19 & 16 & 16 & 14 & 16 & 20 & 34 & 20 & 18 & 8 & 9 & 8 & 16 \\
\hline
\end{tabular}

\begin{tabular}{|c|c|c|c|c|c|c|c|c|c|}
\hline Campos & $\mathbf{4 3}$ & $\mathbf{4 4}$ & $\mathbf{4 5}$ & $\mathbf{4 6}$ & $\mathbf{4 7}$ & $\mathbf{4 8}$ & $\mathbf{4 9}$ & $\mathbf{5 0}$ & Soma \\
\hline HF & 14 & 41 & 40 & 77 & 28 & 38 & 37 & 18 & 2.557 \\
\hline HD & 386 & 359 & 360 & 323 & 372 & 362 & 363 & 382 & 17.443 \\
\hline Contagem & 20 & 10 & 14 & 9 & 11 & 11 & 9 & 11 & 904 \\
\hline
\end{tabular}


Animal: 2 Grupo: Velho

\begin{tabular}{|c|c|c|c|c|c|c|c|c|c|c|c|c|c|c|}
\hline Campos & $\mathbf{1}$ & $\mathbf{2}$ & $\mathbf{3}$ & $\mathbf{4}$ & $\mathbf{5}$ & $\mathbf{6}$ & $\mathbf{7}$ & $\mathbf{8}$ & $\mathbf{9}$ & $\mathbf{1 0}$ & $\mathbf{1 1}$ & $\mathbf{1 2}$ & $\mathbf{1 3}$ & $\mathbf{1 4}$ \\
\hline HF & 104 & 126 & 53 & 124 & -- & 73 & 43 & 129 & 49 & 75 & 47 & 9 & 105 & 31 \\
\hline HD & 296 & 274 & 347 & 276 & 400 & 327 & 357 & 271 & 351 & 325 & 353 & 391 & 295 & 369 \\
\hline Contagem & 18 & 31 & 29 & 19 & 50 & 32 & 26 & 22 & 33 & 35 & 14 & 22 & 15 & 18 \\
\hline
\end{tabular}

\begin{tabular}{|c|c|c|c|c|c|c|c|c|c|c|c|c|c|c|}
\hline Campos & $\mathbf{1 5}$ & $\mathbf{1 6}$ & $\mathbf{1 7}$ & $\mathbf{1 8}$ & $\mathbf{1 9}$ & $\mathbf{2 0}$ & $\mathbf{2 1}$ & $\mathbf{2 2}$ & $\mathbf{2 3}$ & $\mathbf{2 4}$ & $\mathbf{2 5}$ & $\mathbf{2 6}$ & $\mathbf{2 7}$ & $\mathbf{2 8}$ \\
\hline HF & 44 & 36 & 58 & 26 & 12 & 47 & 17 & 33 & 26 & 14 & 42 & 25 & 21 & 33 \\
\hline HD & 356 & 364 & 342 & 374 & 388 & 353 & 383 & 367 & 374 & 386 & 358 & 375 & 379 & 367 \\
\hline Contagem & 17 & 23 & 21 & 19 & 16 & 16 & 22 & 21 & 20 & 17 & 20 & 18 & 23 & 21 \\
\hline
\end{tabular}

\begin{tabular}{|c|c|c|c|c|c|c|c|c|c|c|c|c|c|c|}
\hline Campos & $\mathbf{2 9}$ & $\mathbf{3 0}$ & $\mathbf{3 1}$ & $\mathbf{3 2}$ & $\mathbf{3 3}$ & $\mathbf{3 4}$ & $\mathbf{3 5}$ & $\mathbf{3 6}$ & $\mathbf{3 7}$ & $\mathbf{3 8}$ & $\mathbf{3 9}$ & $\mathbf{4 0}$ & $\mathbf{4 1}$ & $\mathbf{4 2}$ \\
\hline HF & 50 & 44 & 21 & 17 & 50 & 40 & 39 & 17 & 64 & 30 & 34 & 12 & 8 & 15 \\
\hline HD & 350 & 356 & 379 & 383 & 350 & 360 & 361 & 383 & 336 & 370 & 366 & 388 & 392 & 385 \\
\hline Contagem & 17 & 29 & 23 & 11 & 23 & 18 & 20 & 8 & 14 & 26 & 21 & 20 & 26 & 14 \\
\hline
\end{tabular}

\begin{tabular}{|c|c|c|c|c|c|c|c|c|c|}
\hline Campos & $\mathbf{4 3}$ & $\mathbf{4 4}$ & $\mathbf{4 5}$ & $\mathbf{4 6}$ & $\mathbf{4 7}$ & $\mathbf{4 8}$ & $\mathbf{4 9}$ & $\mathbf{5 0}$ & Soma \\
\hline HF & 26 & 27 & 28 & 25 & 39 & 95 & 84 & 51 & 2.218 \\
\hline HD & 374 & 373 & 372 & 375 & 361 & 305 & 316 & 349 & 17.782 \\
\hline Contagem & 19 & 23 & 15 & 12 & 18 & 28 & 14 & 14 & 1.051 \\
\hline
\end{tabular}


Animal: $3 \quad$ Grupo: Velho

\begin{tabular}{|c|c|c|c|c|c|c|c|c|c|c|c|c|c|c|}
\hline Campos & $\mathbf{1}$ & $\mathbf{2}$ & $\mathbf{3}$ & $\mathbf{4}$ & $\mathbf{5}$ & $\mathbf{6}$ & $\mathbf{7}$ & $\mathbf{8}$ & $\mathbf{9}$ & $\mathbf{1 0}$ & $\mathbf{1 1}$ & $\mathbf{1 2}$ & $\mathbf{1 3}$ & $\mathbf{1 4}$ \\
\hline HF & 116 & 95 & 100 & 84 & 73 & 41 & 39 & 26 & 66 & 127 & 33 & 36 & 47 & 43 \\
\hline HD & 284 & 305 & 300 & 316 & 327 & 359 & 361 & 374 & 334 & 273 & 367 & 364 & 353 & 357 \\
\hline Contagem & 38 & 29 & 29 & 23 & 28 & 41 & 19 & 23 & 38 & 20 & 23 & 18 & 18 & 30 \\
\hline
\end{tabular}

\begin{tabular}{|c|c|c|c|c|c|c|c|c|c|c|c|c|c|c|}
\hline Campos & $\mathbf{1 5}$ & $\mathbf{1 6}$ & $\mathbf{1 7}$ & $\mathbf{1 8}$ & $\mathbf{1 9}$ & $\mathbf{2 0}$ & $\mathbf{2 1}$ & $\mathbf{2 2}$ & $\mathbf{2 3}$ & $\mathbf{2 4}$ & $\mathbf{2 5}$ & $\mathbf{2 6}$ & $\mathbf{2 7}$ & $\mathbf{2 8}$ \\
\hline HF & 40 & 33 & 20 & 61 & 34 & 44 & 32 & 47 & 29 & 17 & 70 & 80 & 30 & 35 \\
\hline HD & 360 & 367 & 380 & 339 & 366 & 356 & 368 & 353 & 371 & 383 & 330 & 320 & 370 & 365 \\
\hline Contagem & 19 & 12 & 19 & 5 & 15 & 8 & 14 & 10 & 15 & 16 & 25 & 13 & 15 & 16 \\
\hline
\end{tabular}

\begin{tabular}{|c|c|c|c|c|c|c|c|c|c|c|c|c|c|c|}
\hline Campos & $\mathbf{2 9}$ & $\mathbf{3 0}$ & $\mathbf{3 1}$ & $\mathbf{3 2}$ & $\mathbf{3 3}$ & $\mathbf{3 4}$ & $\mathbf{3 5}$ & $\mathbf{3 6}$ & $\mathbf{3 7}$ & $\mathbf{3 8}$ & $\mathbf{3 9}$ & $\mathbf{4 0}$ & $\mathbf{4 1}$ & $\mathbf{4 2}$ \\
\hline HF & 50 & 31 & 46 & 38 & 46 & 71 & 77 & 62 & 98 & 32 & 93 & 61 & 50 & 26 \\
\hline HD & 350 & 369 & 354 & 362 & 354 & 329 & 323 & 338 & 302 & 368 & 307 & 339 & 350 & 374 \\
\hline Contagem & 11 & 12 & 15 & 18 & 23 & 23 & 13 & 15 & 11 & 12 & 17 & 27 & 22 & 18 \\
\hline
\end{tabular}

\begin{tabular}{|c|c|c|c|c|c|c|c|c|c|}
\hline Campos & $\mathbf{4 3}$ & $\mathbf{4 4}$ & $\mathbf{4 5}$ & $\mathbf{4 6}$ & $\mathbf{4 7}$ & $\mathbf{4 8}$ & $\mathbf{4 9}$ & $\mathbf{5 0}$ & Soma \\
\hline HF & 76 & 26 & 40 & 61 & 41 & 26 & 28 & 60 & 2.637 \\
\hline HD & 324 & 374 & 360 & 339 & 359 & 374 & 372 & 340 & 17.363 \\
\hline Contagem & 13 & 19 & 17 & 18 & 7 & 13 & 18 & 6 & 927 \\
\hline
\end{tabular}


Animal: 4 Grupo: Velho

\begin{tabular}{|c|c|c|c|c|c|c|c|c|c|c|c|c|c|c|}
\hline Campos & $\mathbf{1}$ & $\mathbf{2}$ & $\mathbf{3}$ & $\mathbf{4}$ & $\mathbf{5}$ & $\mathbf{6}$ & $\mathbf{7}$ & $\mathbf{8}$ & $\mathbf{9}$ & $\mathbf{1 0}$ & $\mathbf{1 1}$ & $\mathbf{1 2}$ & $\mathbf{1 3}$ & $\mathbf{1 4}$ \\
\hline HF & 36 & 27 & 79 & 43 & 21 & 29 & 75 & 11 & 17 & 31 & 67 & 65 & 59 & 59 \\
\hline HD & 364 & 373 & 321 & 357 & 379 & 371 & 325 & 389 & 383 & 369 & 333 & 335 & 341 & 341 \\
\hline Contagem & 42 & 36 & 22 & 30 & 28 & 23 & 20 & 10 & 25 & 47 & 11 & 16 & 15 & 12 \\
\hline
\end{tabular}

\begin{tabular}{|c|c|c|c|c|c|c|c|c|c|c|c|c|c|c|}
\hline Campos & $\mathbf{1 5}$ & $\mathbf{1 6}$ & $\mathbf{1 7}$ & $\mathbf{1 8}$ & $\mathbf{1 9}$ & $\mathbf{2 0}$ & $\mathbf{2 1}$ & $\mathbf{2 2}$ & $\mathbf{2 3}$ & $\mathbf{2 4}$ & $\mathbf{2 5}$ & $\mathbf{2 6}$ & $\mathbf{2 7}$ & $\mathbf{2 8}$ \\
\hline HF & 30 & 40 & 36 & 38 & 22 & 28 & 27 & 17 & 58 & 12 & 9 & 18 & 67 & 68 \\
\hline HD & 370 & 360 & 364 & 362 & 378 & 372 & 373 & 383 & 342 & 388 & 391 & 382 & 333 & 332 \\
\hline Contagem & 8 & 9 & 9 & 9 & 16 & 12 & 10 & 18 & 18 & 13 & 8 & 16 & 9 & 10 \\
\hline
\end{tabular}

\begin{tabular}{|c|c|c|c|c|c|c|c|c|c|c|c|c|c|c|}
\hline Campos & $\mathbf{2 9}$ & $\mathbf{3 0}$ & $\mathbf{3 1}$ & $\mathbf{3 2}$ & $\mathbf{3 3}$ & $\mathbf{3 4}$ & $\mathbf{3 5}$ & $\mathbf{3 6}$ & $\mathbf{3 7}$ & $\mathbf{3 8}$ & $\mathbf{3 9}$ & $\mathbf{4 0}$ & $\mathbf{4 1}$ & $\mathbf{4 2}$ \\
\hline HF & 59 & 50 & 33 & 28 & 44 & 56 & 56 & 122 & 42 & 41 & 36 & 90 & 43 & 43 \\
\hline HD & 341 & 350 & 367 & 372 & 356 & 344 & 344 & 278 & 358 & 359 & 364 & 310 & 357 & 357 \\
\hline Contagem & 12 & 17 & 16 & 19 & 16 & 19 & 15 & 17 & 14 & 11 & 13 & 5 & 10 & 23 \\
\hline
\end{tabular}

\begin{tabular}{|c|c|c|c|c|c|c|c|c|c|}
\hline Campos & $\mathbf{4 3}$ & $\mathbf{4 4}$ & $\mathbf{4 5}$ & $\mathbf{4 6}$ & $\mathbf{4 7}$ & $\mathbf{4 8}$ & $\mathbf{4 9}$ & $\mathbf{5 0}$ & Soma \\
\hline HF & 33 & 27 & 63 & 45 & 24 & 27 & 12 & 62 & 2.125 \\
\hline HD & 367 & 373 & 337 & 355 & 376 & 373 & 388 & 338 & 17.875 \\
\hline Contagem & 16 & 13 & 12 & 13 & 19 & 24 & 15 & 16 & 837 \\
\hline
\end{tabular}


Animal: 5 Grupo: Velho

\begin{tabular}{|c|c|c|c|c|c|c|c|c|c|c|c|c|c|c|}
\hline Campos & $\mathbf{1}$ & $\mathbf{2}$ & $\mathbf{3}$ & $\mathbf{4}$ & $\mathbf{5}$ & $\mathbf{6}$ & $\mathbf{7}$ & $\mathbf{8}$ & $\mathbf{9}$ & $\mathbf{1 0}$ & $\mathbf{1 1}$ & $\mathbf{1 2}$ & $\mathbf{1 3}$ & $\mathbf{1 4}$ \\
\hline HF & 33 & 20 & 64 & 41 & 82 & 160 & 58 & 38 & 36 & 31 & 34 & 38 & 19 & 26 \\
\hline HD & 367 & 380 & 336 & 359 & 318 & 240 & 342 & 362 & 364 & 369 & 366 & 362 & 381 & 374 \\
\hline Contagem & 16 & 10 & 18 & 8 & 29 & 21 & 15 & 19 & 28 & 10 & 10 & 18 & 9 & 8 \\
\hline
\end{tabular}

\begin{tabular}{|c|c|c|c|c|c|c|c|c|c|c|c|c|c|c|}
\hline Campos & $\mathbf{1 5}$ & $\mathbf{1 6}$ & $\mathbf{1 7}$ & $\mathbf{1 8}$ & $\mathbf{1 9}$ & $\mathbf{2 0}$ & $\mathbf{2 1}$ & $\mathbf{2 2}$ & $\mathbf{2 3}$ & $\mathbf{2 4}$ & $\mathbf{2 5}$ & $\mathbf{2 6}$ & $\mathbf{2 7}$ & $\mathbf{2 8}$ \\
\hline HF & 36 & 41 & 62 & 43 & 30 & 84 & 128 & 88 & 30 & 38 & 43 & 43 & 17 & 48 \\
\hline HD & 364 & 359 & 338 & 357 & 370 & 316 & 272 & 312 & 370 & 362 & 357 & 357 & 383 & 352 \\
\hline Contagem & 15 & 12 & 12 & 17 & 6 & 6 & 10 & 8 & 9 & 13 & 11 & 11 & 16 & 13 \\
\hline
\end{tabular}

\begin{tabular}{|c|c|c|c|c|c|c|c|c|c|c|c|c|c|c|}
\hline Campos & $\mathbf{2 9}$ & $\mathbf{3 0}$ & $\mathbf{3 1}$ & $\mathbf{3 2}$ & $\mathbf{3 3}$ & $\mathbf{3 4}$ & $\mathbf{3 5}$ & $\mathbf{3 6}$ & $\mathbf{3 7}$ & $\mathbf{3 8}$ & $\mathbf{3 9}$ & $\mathbf{4 0}$ & $\mathbf{4 1}$ & $\mathbf{4 2}$ \\
\hline HF & 24 & 27 & 84 & 79 & 48 & 25 & 45 & 29 & 48 & 70 & 35 & 35 & 25 & 28 \\
\hline HD & 376 & 373 & 316 & 321 & 352 & 375 & 355 & 371 & 352 & 330 & 365 & 365 & 375 & 372 \\
\hline Contagem & 10 & 16 & 14 & 14 & 10 & 8 & 8 & 9 & 13 & 18 & 12 & 7 & 15 & 16 \\
\hline
\end{tabular}

\begin{tabular}{|c|c|c|c|c|c|c|c|c|c|}
\hline Campos & $\mathbf{4 3}$ & $\mathbf{4 4}$ & $\mathbf{4 5}$ & $\mathbf{4 6}$ & $\mathbf{4 7}$ & $\mathbf{4 8}$ & $\mathbf{4 9}$ & $\mathbf{5 0}$ & Soma \\
\hline HF & 25 & 34 & 24 & 41 & 30 & 24 & 50 & 58 & 2.299 \\
\hline HD & 375 & 366 & 376 & 359 & 370 & 376 & 350 & 342 & 17.701 \\
\hline Contagem & 12 & 15 & 15 & 9 & 15 & 16 & 16 & 15 & 661 \\
\hline
\end{tabular}




\section{PLANILHA - COLORAÇÃO WEIGERT}

\begin{tabular}{|c|c|c|c|c|c|c|c||}
\hline PU & CR & DIAS & $\begin{array}{c}\mathrm{f}= \\
\mathrm{PU} / \mathrm{PT}\end{array}$ & AT & $\begin{array}{c}\text { A }=\text { AT X } \\
\mathrm{F}\end{array}$ & $\begin{array}{c}\mathrm{C}= \\
\mathrm{CRX} 2\end{array}$ & $\begin{array}{c}\text { LD }= \\
\text { 2XC/A }\end{array}$ \\
\hline 17.559 & 889 & 21 & 0,87795 & 386250 & 339108,18 & 1.778 & 0,0104863 \\
\hline 17.327 & 614 & 21 & 0,86635 & 386250 & 334627,68 & 1.228 & 0,0073395 \\
\hline 17.116 & 485 & 21 & 0,8558 & 386250 & 330552,75 & 970 & 0,0058689 \\
\hline 18.062 & 751 & 21 & 0,9031 & 386250 & 348822,37 & 1.502 & 0,0086118 \\
\hline 17.919 & 544 & 21 & 0,89595 & 386250 & 346060,68 & 1.088 & 0,0062879 \\
\hline 18.113 & 1.006 & 200 & 0,90565 & 386250 & 349807,31 & 2.012 & 0,0115034 \\
\hline 17.648 & 1.123 & 200 & 0,8824 & 386250 & 340827 & 2.246 & 0,0131797 \\
\hline 17.659 & 1.076 & 200 & 0,88295 & 386250 & 341039,43 & 2.152 & 0,0126202 \\
\hline 18.202 & 1.179 & 200 & 0,9101 & 386250 & 351526,12 & 2.358 & 0,0134157 \\
\hline 17.950 & 1.290 & 200 & 0,8975 & 386250 & 346659,37 & 2.580 & 0,0148849 \\
\hline 17.443 & 904 & 450 & 0,87215 & 386250 & 336867,93 & 1.808 & 0,0107341 \\
\hline 17.782 & 1.051 & 450 & 0,8891 & 386250 & 343414,87 & 2.102 & 0,0122417 \\
\hline 17.363 & 927 & 450 & 0,86815 & 386250 & 335322,93 & 1.854 & 0,0110580 \\
\hline 17.875 & 837 & 450 & 0,89375 & 386250 & 345210,93 & 1.674 & 0,0096984 \\
\hline 17.701 & 661 & 450 & 0,88505 & 386250 & 341850,56 & 1.322 & 0,0077343 \\
\hline
\end{tabular}




\section{APÊNDICE C - COLORAÇÃO WEIGERT -OXONA}

Animal: $1 \quad$ Grupo: Neonato

\begin{tabular}{|c|c|c|c|c|c|c|c|c|c|c|c|c|c|c|}
\hline Campos & $\mathbf{1}$ & $\mathbf{2}$ & $\mathbf{3}$ & $\mathbf{4}$ & $\mathbf{5}$ & $\mathbf{6}$ & $\mathbf{7}$ & $\mathbf{8}$ & $\mathbf{9}$ & $\mathbf{1 0}$ & $\mathbf{1 1}$ & $\mathbf{1 2}$ & $\mathbf{1 3}$ & $\mathbf{1 4}$ \\
\hline HF & 80 & 137 & 35 & 51 & 127 & 85 & 123 & 41 & 96 & 92 & 69 & 141 & 61 & 70 \\
\hline HD & 320 & 263 & 365 & 349 & 273 & 315 & 277 & 359 & 304 & 308 & 331 & 259 & 339 & 330 \\
\hline Contagem & 17 & 14 & 23 & 10 & 22 & 10 & 32 & 25 & 9 & 15 & 19 & 23 & 24 & 20 \\
\hline
\end{tabular}

\begin{tabular}{|c|c|c|c|c|c|c|c|c|c|c|c|c|c|c|}
\hline Campos & $\mathbf{1 5}$ & $\mathbf{1 6}$ & $\mathbf{1 7}$ & $\mathbf{1 8}$ & $\mathbf{1 9}$ & $\mathbf{2 0}$ & $\mathbf{2 1}$ & $\mathbf{2 2}$ & $\mathbf{2 3}$ & $\mathbf{2 4}$ & $\mathbf{2 5}$ & $\mathbf{2 6}$ & $\mathbf{2 7}$ & $\mathbf{2 8}$ \\
\hline HF & 21 & 102 & 58 & 17 & 129 & 32 & 13 & 45 & 40 & 79 & 47 & 63 & 53 & 24 \\
\hline HD & 379 & 298 & 342 & 383 & 271 & 368 & 387 & 355 & 360 & 321 & 353 & 337 & 347 & 376 \\
\hline Contagem & 19 & 19 & 28 & 15 & 14 & 13 & 27 & 13 & 18 & 27 & 19 & 16 & 22 & 9 \\
\hline
\end{tabular}

\begin{tabular}{|c|c|c|c|c|c|c|c|c|c|c|c|c|c|c|}
\hline Campos & $\mathbf{2 9}$ & $\mathbf{3 0}$ & $\mathbf{3 1}$ & $\mathbf{3 2}$ & $\mathbf{3 3}$ & $\mathbf{3 4}$ & $\mathbf{3 5}$ & $\mathbf{3 6}$ & $\mathbf{3 7}$ & $\mathbf{3 8}$ & $\mathbf{3 9}$ & $\mathbf{4 0}$ & $\mathbf{4 1}$ & $\mathbf{4 2}$ \\
\hline HF & 39 & 52 & 24 & 41 & 31 & 29 & 40 & 36 & 54 & 32 & 72 & 48 & 22 & 23 \\
\hline HD & 361 & 348 & 376 & 359 & 369 & 371 & 360 & 364 & 346 & 368 & 328 & 352 & 378 & 377 \\
\hline Contagem & 36 & 31 & 30 & 19 & 26 & 10 & 15 & 24 & 24 & 20 & 21 & 13 & 22 & 29 \\
\hline
\end{tabular}

\begin{tabular}{|c|c|c|c|c|c|c|c|c|c|}
\hline Campos & $\mathbf{4 3}$ & $\mathbf{4 4}$ & $\mathbf{4 5}$ & $\mathbf{4 6}$ & $\mathbf{4 7}$ & $\mathbf{4 8}$ & $\mathbf{4 9}$ & $\mathbf{5 0}$ & Soma \\
\hline HF & 54 & 69 & 53 & 49 & 25 & 72 & 30 & 179 & 3.005 \\
\hline HD & 346 & 331 & 347 & 351 & 375 & 328 & 370 & 221 & 16.995 \\
\hline Contagem & 22 & 15 & 36 & 27 & 26 & 10 & 13 & 11 & 1.002 \\
\hline
\end{tabular}


Animal: 2 Grupo: Neonato

\begin{tabular}{|c|c|c|c|c|c|c|c|c|c|c|c|c|c|c|}
\hline Campos & $\mathbf{1}$ & $\mathbf{2}$ & $\mathbf{3}$ & $\mathbf{4}$ & $\mathbf{5}$ & $\mathbf{6}$ & $\mathbf{7}$ & $\mathbf{8}$ & $\mathbf{9}$ & $\mathbf{1 0}$ & $\mathbf{1 1}$ & $\mathbf{1 2}$ & $\mathbf{1 3}$ & $\mathbf{1 4}$ \\
\hline HF & 58 & 29 & 56 & 66 & 55 & 124 & 15 & 20 & 13 & 20 & 82 & 19 & 58 & 37 \\
\hline HD & 342 & 371 & 344 & 334 & 345 & 270 & 385 & 380 & 387 & 380 & 318 & 381 & 342 & 363 \\
\hline Contagem & 5 & 12 & 5 & 15 & 24 & 20 & 26 & 24 & 19 & 19 & 18 & 14 & 20 & 24 \\
\hline
\end{tabular}

\begin{tabular}{|c|c|c|c|c|c|c|c|c|c|c|c|c|c|c|}
\hline Campos & $\mathbf{1 5}$ & $\mathbf{1 6}$ & $\mathbf{1 7}$ & $\mathbf{1 8}$ & $\mathbf{1 9}$ & $\mathbf{2 0}$ & $\mathbf{2 1}$ & $\mathbf{2 2}$ & $\mathbf{2 3}$ & $\mathbf{2 4}$ & $\mathbf{2 5}$ & $\mathbf{2 6}$ & $\mathbf{2 7}$ & $\mathbf{2 8}$ \\
\hline HF & 40 & 20 & 57 & 58 & 54 & 42 & 33 & 49 & 28 & 48 & 40 & 62 & 31 & 26 \\
\hline HD & 360 & 380 & 343 & 342 & 346 & 358 & 367 & 351 & 372 & 352 & 360 & 338 & 369 & 374 \\
\hline Contagem & 20 & 42 & 23 & 31 & 28 & 27 & 37 & 25 & 26 & 15 & 24 & 12 & 25 & 20 \\
\hline
\end{tabular}

\begin{tabular}{|c|c|c|c|c|c|c|c|c|c|c|c|c|c|c|}
\hline Campos & $\mathbf{2 9}$ & $\mathbf{3 0}$ & $\mathbf{3 1}$ & $\mathbf{3 2}$ & $\mathbf{3 3}$ & $\mathbf{3 4}$ & $\mathbf{3 5}$ & $\mathbf{3 6}$ & $\mathbf{3 7}$ & $\mathbf{3 8}$ & $\mathbf{3 9}$ & $\mathbf{4 0}$ & $\mathbf{4 1}$ & $\mathbf{4 2}$ \\
\hline HF & 32 & 55 & 43 & 16 & 17 & 81 & 40 & 40 & 40 & 30 & 14 & 23 & 35 & 61 \\
\hline HD & 368 & 345 & 357 & 384 & 383 & 319 & 360 & 360 & 360 & 370 & 386 & 377 & 365 & 339 \\
\hline Contagem & 12 & 16 & 26 & 12 & 12 & 10 & 15 & 15 & 22 & 10 & 9 & 18 & 8 & 24 \\
\hline
\end{tabular}

\begin{tabular}{|c|c|c|c|c|c|c|c|c|c|}
\hline Campos & $\mathbf{4 3}$ & $\mathbf{4 4}$ & $\mathbf{4 5}$ & $\mathbf{4 6}$ & $\mathbf{4 7}$ & $\mathbf{4 8}$ & $\mathbf{4 9}$ & $\mathbf{5 0}$ & Soma \\
\hline HF & 35 & 30 & 36 & 82 & 28 & 25 & 23 & 154 & 2.180 \\
\hline HD & 365 & 370 & 364 & 318 & 372 & 375 & 377 & 246 & 17.820 \\
\hline Contagem & 11 & 10 & 6 & 9 & 11 & 17 & 22 & 13 & 902 \\
\hline
\end{tabular}


Animal: $3 \quad$ Grupo: Neonato

\begin{tabular}{|c|c|c|c|c|c|c|c|c|c|c|c|c|c|c|}
\hline Campos & $\mathbf{1}$ & $\mathbf{2}$ & $\mathbf{3}$ & $\mathbf{4}$ & $\mathbf{5}$ & $\mathbf{6}$ & $\mathbf{7}$ & $\mathbf{8}$ & $\mathbf{9}$ & $\mathbf{1 0}$ & $\mathbf{1 1}$ & $\mathbf{1 2}$ & $\mathbf{1 3}$ & $\mathbf{1 4}$ \\
\hline HF & 25 & 18 & 48 & 4 & 21 & 16 & 85 & 31 & 46 & 20 & 47 & 37 & 16 & 74 \\
\hline HD & 375 & 382 & 352 & 396 & 379 & 384 & 315 & 369 & 354 & 380 & 353 & 363 & 384 & 326 \\
\hline Contagem & 32 & 10 & 25 & 15 & 12 & 27 & 19 & 15 & 8 & 14 & 36 & 17 & 30 & 18 \\
\hline
\end{tabular}

\begin{tabular}{|c|c|c|c|c|c|c|c|c|c|c|c|c|c|c|}
\hline Campos & $\mathbf{1 5}$ & $\mathbf{1 6}$ & $\mathbf{1 7}$ & $\mathbf{1 8}$ & $\mathbf{1 9}$ & $\mathbf{2 0}$ & $\mathbf{2 1}$ & $\mathbf{2 2}$ & $\mathbf{2 3}$ & $\mathbf{2 4}$ & $\mathbf{2 5}$ & $\mathbf{2 6}$ & $\mathbf{2 7}$ & $\mathbf{2 8}$ \\
\hline HF & 82 & 28 & 183 & 102 & 17 & 17 & 37 & 85 & 34 & 32 & 48 & 34 & 24 & 18 \\
\hline HD & 318 & 372 & 217 & 298 & 383 & 383 & 363 & 315 & 366 & 368 & 352 & 366 & 376 & 382 \\
\hline Contagem & 16 & 18 & 23 & 13 & 16 & 17 & 49 & 18 & 35 & 25 & 35 & 32 & 17 & 15 \\
\hline
\end{tabular}

\begin{tabular}{|c|c|c|c|c|c|c|c|c|c|c|c|c|c|c|}
\hline Campos & $\mathbf{2 9}$ & $\mathbf{3 0}$ & $\mathbf{3 1}$ & $\mathbf{3 2}$ & $\mathbf{3 3}$ & $\mathbf{3 4}$ & $\mathbf{3 5}$ & $\mathbf{3 6}$ & $\mathbf{3 7}$ & $\mathbf{3 8}$ & $\mathbf{3 9}$ & $\mathbf{4 0}$ & $\mathbf{4 1}$ & $\mathbf{4 2}$ \\
\hline HF & 111 & 14 & 63 & 43 & 24 & 44 & 28 & 13 & 12 & 61 & 13 & 10 & 32 & 15 \\
\hline HD & 289 & 286 & 337 & 357 & 376 & 356 & 372 & 387 & 388 & 339 & 387 & 390 & 368 & 385 \\
\hline Contagem & 9 & 13 & 15 & 32 & 43 & 46 & 53 & 15 & 18 & 20 & 18 & 8 & 28 & 21 \\
\hline
\end{tabular}

\begin{tabular}{|c|c|c|c|c|c|c|c|c|c|}
\hline Campos & $\mathbf{4 3}$ & $\mathbf{4 4}$ & $\mathbf{4 5}$ & $\mathbf{4 6}$ & $\mathbf{4 7}$ & $\mathbf{4 8}$ & $\mathbf{4 9}$ & $\mathbf{5 0}$ & Soma \\
\hline HF & 15 & 44 & 38 & 64 & 42 & 24 & 19 & 23 & 1.981 \\
\hline HD & 385 & 356 & 362 & 336 & 358 & 376 & 381 & 377 & 18.019 \\
\hline Contagem & 22 & 17 & 22 & 23 & 27 & 29 & 24 & 8 & 1.118 \\
\hline
\end{tabular}


Animal: 4 Grupo: Neonato

\begin{tabular}{|c|c|c|c|c|c|c|c|c|c|c|c|c|c|c|}
\hline Campos & $\mathbf{1}$ & $\mathbf{2}$ & $\mathbf{3}$ & $\mathbf{4}$ & $\mathbf{5}$ & $\mathbf{6}$ & $\mathbf{7}$ & $\mathbf{8}$ & $\mathbf{9}$ & $\mathbf{1 0}$ & $\mathbf{1 1}$ & $\mathbf{1 2}$ & $\mathbf{1 3}$ & $\mathbf{1 4}$ \\
\hline HF & 32 & 20 & 33 & 70 & 11 & 21 & 43 & 7 & 8 & 10 & 26 & 71 & 94 & 73 \\
\hline HD & 368 & 380 & 367 & 330 & 389 & 379 & 357 & 393 & 392 & 390 & 374 & 329 & 306 & 327 \\
\hline Contagem & 23 & 16 & 21 & 8 & 16 & 18 & 13 & 15 & 15 & 6 & 10 & 19 & 14 & 11 \\
\hline
\end{tabular}

\begin{tabular}{|c|c|c|c|c|c|c|c|c|c|c|c|c|c|c|}
\hline Campos & $\mathbf{1 5}$ & $\mathbf{1 6}$ & $\mathbf{1 7}$ & $\mathbf{1 8}$ & $\mathbf{1 9}$ & $\mathbf{2 0}$ & $\mathbf{2 1}$ & $\mathbf{2 2}$ & $\mathbf{2 3}$ & $\mathbf{2 4}$ & $\mathbf{2 5}$ & $\mathbf{2 6}$ & $\mathbf{2 7}$ & $\mathbf{2 8}$ \\
\hline HF & 68 & 10 & 34 & 33 & 104 & 11 & 22 & 87 & 16 & 53 & 16 & 32 & 18 & 5 \\
\hline HD & 332 & 390 & 366 & 367 & 296 & 389 & 378 & 313 & 384 & 347 & 384 & 368 & 382 & 395 \\
\hline Contagem & 6 & 13 & 6 & 14 & 14 & 12 & 13 & 26 & 22 & 6 & 6 & 7 & 18 & 8 \\
\hline
\end{tabular}

\begin{tabular}{|c|c|c|c|c|c|c|c|c|c|c|c|c|c|c|}
\hline Campos & $\mathbf{2 9}$ & $\mathbf{3 0}$ & $\mathbf{3 1}$ & $\mathbf{3 2}$ & $\mathbf{3 3}$ & $\mathbf{3 4}$ & $\mathbf{3 5}$ & $\mathbf{3 6}$ & $\mathbf{3 7}$ & $\mathbf{3 8}$ & $\mathbf{3 9}$ & $\mathbf{4 0}$ & $\mathbf{4 1}$ & $\mathbf{4 2}$ \\
\hline HF & 98 & 14 & 15 & 10 & 13 & 63 & 9 & 11 & 11 & 8 & 28 & 53 & 26 & 17 \\
\hline HD & 302 & 386 & 385 & 390 & 387 & 337 & 391 & 389 & 389 & 392 & 372 & 347 & 374 & 383 \\
\hline Contagem & 12 & 8 & 32 & 21 & 25 & 9 & 15 & 13 & 3 & 6 & 11 & 14 & 14 & 20 \\
\hline
\end{tabular}

\begin{tabular}{|c|c|c|c|c|c|c|c|c|c|}
\hline Campos & $\mathbf{4 3}$ & $\mathbf{4 4}$ & $\mathbf{4 5}$ & $\mathbf{4 6}$ & $\mathbf{4 7}$ & $\mathbf{4 8}$ & $\mathbf{4 9}$ & $\mathbf{5 0}$ & Soma \\
\hline HF & 23 & 57 & 28 & 12 & 10 & 19 & 21 & 18 & 1.592 \\
\hline HD & 377 & 343 & 372 & 388 & 390 & 381 & 379 & 382 & 18.408 \\
\hline Contagem & 12 & 10 & 6 & 6 & 19 & 5 & 5 & 9 & 651 \\
\hline
\end{tabular}


Animal: 5 Grupo: Neonato

\begin{tabular}{|c|c|c|c|c|c|c|c|c|c|c|c|c|c|c|}
\hline Campos & $\mathbf{1}$ & $\mathbf{2}$ & $\mathbf{3}$ & $\mathbf{4}$ & $\mathbf{5}$ & $\mathbf{6}$ & $\mathbf{7}$ & $\mathbf{8}$ & $\mathbf{9}$ & $\mathbf{1 0}$ & $\mathbf{1 1}$ & $\mathbf{1 2}$ & $\mathbf{1 3}$ & $\mathbf{1 4}$ \\
\hline HF & 92 & 150 & 150 & 90 & 130 & 38 & 47 & 83 & 38 & 16 & 53 & 23 & 43 & 26 \\
\hline HD & 308 & 250 & 250 & 310 & 270 & 362 & 353 & 317 & 362 & 384 & 347 & 377 & 357 & 374 \\
\hline Contagem & 11 & 12 & 3 & 13 & 9 & 10 & 23 & 5 & 21 & 38 & 28 & 8 & 27 & 16 \\
\hline
\end{tabular}

\begin{tabular}{|c|c|c|c|c|c|c|c|c|c|c|c|c|c|c|}
\hline Campos & $\mathbf{1 5}$ & $\mathbf{1 6}$ & $\mathbf{1 7}$ & $\mathbf{1 8}$ & $\mathbf{1 9}$ & $\mathbf{2 0}$ & $\mathbf{2 1}$ & $\mathbf{2 2}$ & $\mathbf{2 3}$ & $\mathbf{2 4}$ & $\mathbf{2 5}$ & $\mathbf{2 6}$ & $\mathbf{2 7}$ & $\mathbf{2 8}$ \\
\hline HF & 12 & 31 & 10 & 29 & 20 & 32 & 14 & 62 & 6 & 38 & 10 & 90 & 80 & 45 \\
\hline HD & 388 & 369 & 390 & 371 & 380 & 368 & 386 & 338 & 394 & 362 & 390 & 310 & 320 & 355 \\
\hline Contagem & 32 & 21 & 28 & 27 & 36 & 24 & 41 & 11 & 15 & 8 & 8 & 17 & 41 & 24 \\
\hline
\end{tabular}

\begin{tabular}{|c|c|c|c|c|c|c|c|c|c|c|c|c|c|c|}
\hline Campos & $\mathbf{2 9}$ & $\mathbf{3 0}$ & $\mathbf{3 1}$ & $\mathbf{3 2}$ & $\mathbf{3 3}$ & $\mathbf{3 4}$ & $\mathbf{3 5}$ & $\mathbf{3 6}$ & $\mathbf{3 7}$ & $\mathbf{3 8}$ & $\mathbf{3 9}$ & $\mathbf{4 0}$ & $\mathbf{4 1}$ & $\mathbf{4 2}$ \\
\hline HF & 96 & 19 & 20 & 19 & 24 & 16 & 22 & 24 & 35 & 16 & 29 & 96 & 24 & 14 \\
\hline HD & 304 & 381 & 380 & 381 & 376 & 384 & 378 & 376 & 365 & 384 & 371 & 304 & 376 & 386 \\
\hline Contagem & 19 & 19 & 20 & 19 & 24 & 10 & 20 & 6 & 15 & 6 & 13 & 7 & 11 & 6 \\
\hline
\end{tabular}

\begin{tabular}{|c|c|c|c|c|c|c|c|c|c|}
\hline Campos & $\mathbf{4 3}$ & $\mathbf{4 4}$ & $\mathbf{4 5}$ & $\mathbf{4 6}$ & $\mathbf{4 7}$ & $\mathbf{4 8}$ & $\mathbf{4 9}$ & $\mathbf{5 0}$ & Soma \\
\hline HF & 24 & 17 & 20 & 23 & 40 & 24 & 27 & 17 & 2.104 \\
\hline HD & 376 & 383 & 380 & 377 & 360 & 376 & 373 & 383 & 17.896 \\
\hline Contagem & 19 & 15 & 8 & 12 & 18 & 12 & 5 & 13 & 854 \\
\hline
\end{tabular}


Animal: $1 \quad$ Grupo: Adulto

\begin{tabular}{|c|c|c|c|c|c|c|c|c|c|c|c|c|c|c|}
\hline Campos & $\mathbf{1}$ & $\mathbf{2}$ & $\mathbf{3}$ & $\mathbf{4}$ & $\mathbf{5}$ & $\mathbf{6}$ & $\mathbf{7}$ & $\mathbf{8}$ & $\mathbf{9}$ & $\mathbf{1 0}$ & $\mathbf{1 1}$ & $\mathbf{1 2}$ & $\mathbf{1 3}$ & $\mathbf{1 4}$ \\
\hline HF & 42 & 24 & 61 & 56 & 42 & 35 & 53 & 31 & 11 & 59 & 70 & 30 & 23 & 105 \\
\hline HD & 358 & 376 & 339 & 344 & 358 & 365 & 347 & 369 & 389 & 341 & 330 & 370 & 377 & 295 \\
\hline Contagem & 42 & 36 & 24 & 56 & 39 & 52 & 35 & 33 & 56 & 20 & 36 & 37 & 23 & 27 \\
\hline
\end{tabular}

\begin{tabular}{|c|c|c|c|c|c|c|c|c|c|c|c|c|c|c|}
\hline Campos & $\mathbf{1 5}$ & $\mathbf{1 6}$ & $\mathbf{1 7}$ & $\mathbf{1 8}$ & $\mathbf{1 9}$ & $\mathbf{2 0}$ & $\mathbf{2 1}$ & $\mathbf{2 2}$ & $\mathbf{2 3}$ & $\mathbf{2 4}$ & $\mathbf{2 5}$ & $\mathbf{2 6}$ & $\mathbf{2 7}$ & $\mathbf{2 8}$ \\
\hline HF & 74 & 45 & 26 & 36 & 29 & 20 & 67 & 58 & 38 & 94 & 37 & 48 & 97 & 45 \\
\hline HD & 326 & 355 & 374 & 364 & 371 & 380 & 333 & 342 & 362 & 306 & 363 & 352 & 303 & 355 \\
\hline Contagem & 19 & 32 & 62 & 24 & 25 & 29 & 25 & 46 & 24 & 15 & 15 & 38 & 27 & 23 \\
\hline
\end{tabular}

\begin{tabular}{|c|c|c|c|c|c|c|c|c|c|c|c|c|c|c|}
\hline Campos & $\mathbf{2 9}$ & $\mathbf{3 0}$ & $\mathbf{3 1}$ & $\mathbf{3 2}$ & $\mathbf{3 3}$ & $\mathbf{3 4}$ & $\mathbf{3 5}$ & $\mathbf{3 6}$ & $\mathbf{3 7}$ & $\mathbf{3 8}$ & $\mathbf{3 9}$ & $\mathbf{4 0}$ & $\mathbf{4 1}$ & $\mathbf{4 2}$ \\
\hline HF & 47 & 23 & 38 & 21 & 32 & 33 & 57 & 52 & 56 & 37 & 25 & 47 & 39 & 83 \\
\hline HD & 353 & 377 & 362 & 379 & 368 & 367 & 343 & 348 & 344 & 363 & 375 & 353 & 361 & 317 \\
\hline Contagem & 15 & 13 & 37 & 46 & 36 & 40 & 47 & 23 & 19 & 61 & 15 & 24 & 55 & 36 \\
\hline
\end{tabular}

\begin{tabular}{|c|c|c|c|c|c|c|c|c|c|}
\hline Campos & $\mathbf{4 3}$ & $\mathbf{4 4}$ & $\mathbf{4 5}$ & $\mathbf{4 6}$ & $\mathbf{4 7}$ & $\mathbf{4 8}$ & $\mathbf{4 9}$ & $\mathbf{5 0}$ & Soma \\
\hline HF & 39 & 92 & 21 & 19 & 39 & 76 & 56 & 27 & 2.315 \\
\hline HD & 361 & 308 & 379 & 381 & 361 & 324 & 344 & 373 & 17.685 \\
\hline Contagem & 39 & 50 & 39 & 35 & 14 & 14 & 24 & 38 & 1.640 \\
\hline
\end{tabular}


Animal: 2 Grupo: Adulto

\begin{tabular}{|c|c|c|c|c|c|c|c|c|c|c|c|c|c|c|}
\hline Campos & $\mathbf{1}$ & $\mathbf{2}$ & $\mathbf{3}$ & $\mathbf{4}$ & $\mathbf{5}$ & $\mathbf{6}$ & $\mathbf{7}$ & $\mathbf{8}$ & $\mathbf{9}$ & $\mathbf{1 0}$ & $\mathbf{1 1}$ & $\mathbf{1 2}$ & $\mathbf{1 3}$ & $\mathbf{1 4}$ \\
\hline HF & 41 & 63 & 49 & 12 & 23 & 48 & 31 & 39 & 56 & 55 & 34 & 37 & 30 & 27 \\
\hline HD & 359 & 337 & 351 & 388 & 377 & 352 & 369 & 361 & 344 & 345 & 366 & 363 & 370 & 373 \\
\hline Contagem & 28 & 17 & 13 & 25 & 58 & 44 & 40 & 38 & 43 & 36 & 33 & 34 & 35 & 36 \\
\hline
\end{tabular}

\begin{tabular}{|c|c|c|c|c|c|c|c|c|c|c|c|c|c|c|}
\hline Campos & $\mathbf{1 5}$ & $\mathbf{1 6}$ & $\mathbf{1 7}$ & $\mathbf{1 8}$ & $\mathbf{1 9}$ & $\mathbf{2 0}$ & $\mathbf{2 1}$ & $\mathbf{2 2}$ & $\mathbf{2 3}$ & $\mathbf{2 4}$ & $\mathbf{2 5}$ & $\mathbf{2 6}$ & $\mathbf{2 7}$ & $\mathbf{2 8}$ \\
\hline HF & 22 & 18 & 8 & 68 & 39 & 44 & 54 & 90 & 22 & 37 & 40 & 20 & 33 & 18 \\
\hline HD & 378 & 382 & 392 & 332 & 361 & 356 & 346 & 310 & 378 & 363 & 360 & 380 & 367 & 382 \\
\hline Contagem & 46 & 50 & 55 & 28 & 37 & 48 & 44 & 10 & 49 & 51 & 45 & 50 & 50 & 41 \\
\hline
\end{tabular}

\begin{tabular}{|c|c|c|c|c|c|c|c|c|c|c|c|c|c|c|}
\hline Campos & $\mathbf{2 9}$ & $\mathbf{3 0}$ & $\mathbf{3 1}$ & $\mathbf{3 2}$ & $\mathbf{3 3}$ & $\mathbf{3 4}$ & $\mathbf{3 5}$ & $\mathbf{3 6}$ & $\mathbf{3 7}$ & $\mathbf{3 8}$ & $\mathbf{3 9}$ & $\mathbf{4 0}$ & $\mathbf{4 1}$ & $\mathbf{4 2}$ \\
\hline HF & 24 & 14 & 36 & 33 & 14 & 10 & 11 & 24 & 10 & 9 & 53 & 42 & 11 & 47 \\
\hline HD & 376 & 386 & 364 & 367 & 386 & 390 & 389 & 376 & 390 & 391 & 347 & 358 & 389 & 353 \\
\hline Contagem & 34 & 62 & 56 & 38 & 60 & 20 & 18 & 35 & 28 & 29 & 16 & 16 & 22 & 23 \\
\hline
\end{tabular}

\begin{tabular}{|c|c|c|c|c|c|c|c|c|c|}
\hline Campos & $\mathbf{4 3}$ & $\mathbf{4 4}$ & $\mathbf{4 5}$ & $\mathbf{4 6}$ & $\mathbf{4 7}$ & $\mathbf{4 8}$ & $\mathbf{4 9}$ & $\mathbf{5 0}$ & Soma \\
\hline HF & 11 & 23 & 118 & 47 & 30 & 26 & 23 & 117 & 1.791 \\
\hline HD & 389 & 377 & 282 & 353 & 370 & 374 & 377 & 283 & 18.209 \\
\hline Contagem & 46 & 38 & 28 & 36 & 21 & 28 & 40 & 20 & 1.789 \\
\hline
\end{tabular}


Animal: 3 Grupo: Adulto

\begin{tabular}{|c|c|c|c|c|c|c|c|c|c|c|c|c|c|c|}
\hline Campos & $\mathbf{1}$ & $\mathbf{2}$ & $\mathbf{3}$ & $\mathbf{4}$ & $\mathbf{5}$ & $\mathbf{6}$ & $\mathbf{7}$ & $\mathbf{8}$ & $\mathbf{9}$ & $\mathbf{1 0}$ & $\mathbf{1 1}$ & $\mathbf{1 2}$ & $\mathbf{1 3}$ & $\mathbf{1 4}$ \\
\hline HF & 33 & 27 & 33 & 20 & 63 & 23 & 35 & 45 & 32 & 55 & 42 & 43 & 30 & 36 \\
\hline HD & 367 & 373 & 367 & 380 & 337 & 377 & 365 & 355 & 368 & 345 & 358 & 357 & 370 & 364 \\
\hline Contagem & 28 & 28 & 42 & 38 & 45 & 37 & 32 & 44 & 46 & 30 & 26 & 25 & 25 & 22 \\
\hline
\end{tabular}

\begin{tabular}{|c|c|c|c|c|c|c|c|c|c|c|c|c|c|c|}
\hline Campos & $\mathbf{1 5}$ & $\mathbf{1 6}$ & $\mathbf{1 7}$ & $\mathbf{1 8}$ & $\mathbf{1 9}$ & $\mathbf{2 0}$ & $\mathbf{2 1}$ & $\mathbf{2 2}$ & $\mathbf{2 3}$ & $\mathbf{2 4}$ & $\mathbf{2 5}$ & $\mathbf{2 6}$ & $\mathbf{2 7}$ & $\mathbf{2 8}$ \\
\hline HF & 20 & 21 & 85 & 34 & 14 & 22 & 37 & 26 & 30 & 35 & 17 & 21 & 33 & 16 \\
\hline HD & 380 & 379 & 315 & 366 & 386 & 378 & 363 & 374 & 370 & 365 & 383 & 379 & 367 & 384 \\
\hline Contagem & 18 & 24 & 28 & 27 & 33 & 29 & 32 & 32 & 39 & 35 & 30 & 25 & 45 & 29 \\
\hline
\end{tabular}

\begin{tabular}{|c|c|c|c|c|c|c|c|c|c|c|c|c|c|c|}
\hline Campos & $\mathbf{2 9}$ & $\mathbf{3 0}$ & $\mathbf{3 1}$ & $\mathbf{3 2}$ & $\mathbf{3 3}$ & $\mathbf{3 4}$ & $\mathbf{3 5}$ & $\mathbf{3 6}$ & $\mathbf{3 7}$ & $\mathbf{3 8}$ & $\mathbf{3 9}$ & $\mathbf{4 0}$ & $\mathbf{4 1}$ & $\mathbf{4 2}$ \\
\hline HF & 45 & 32 & 53 & 38 & 25 & 24 & 62 & 24 & 35 & 40 & 42 & 46 & 37 & 59 \\
\hline HD & 355 & 368 & 347 & 362 & 375 & 376 & 338 & 376 & 365 & 360 & 358 & 354 & 363 & 341 \\
\hline Contagem & 19 & 42 & 34 & 22 & 33 & 18 & 34 & 38 & 31 & 35 & 28 & 40 & 43 & 57 \\
\hline
\end{tabular}

\begin{tabular}{|c|c|c|c|c|c|c|c|c|c|}
\hline Campos & $\mathbf{4 3}$ & $\mathbf{4 4}$ & $\mathbf{4 5}$ & $\mathbf{4 6}$ & $\mathbf{4 7}$ & $\mathbf{4 8}$ & $\mathbf{4 9}$ & $\mathbf{5 0}$ & Soma \\
\hline HF & 64 & 52 & 93 & 50 & 50 & 48 & 46 & 55 & 1.948 \\
\hline HD & 336 & 348 & 307 & 350 & 350 & 352 & 354 & 345 & 18.052 \\
\hline Contagem & 50 & 22 & 22 & 30 & 31 & 17 & 22 & 32 & 1.594 \\
\hline
\end{tabular}


Animal: 4 Grupo: Adulto

\begin{tabular}{|c|c|c|c|c|c|c|c|c|c|c|c|c|c|c|}
\hline Campos & $\mathbf{1}$ & $\mathbf{2}$ & $\mathbf{3}$ & $\mathbf{4}$ & $\mathbf{5}$ & $\mathbf{6}$ & $\mathbf{7}$ & $\mathbf{8}$ & $\mathbf{9}$ & $\mathbf{1 0}$ & $\mathbf{1 1}$ & $\mathbf{1 2}$ & $\mathbf{1 3}$ & $\mathbf{1 4}$ \\
\hline HF & 46 & 65 & 40 & 29 & 9 & 16 & 12 & 19 & 94 & 55 & 36 & 47 & 9 & 33 \\
\hline HD & 354 & 335 & 360 & 371 & 391 & 384 & 388 & 381 & 306 & 345 & 364 & 353 & 391 & 367 \\
\hline Contagem & 40 & 27 & 27 & 35 & 38 & 50 & 53 & 53 & 32 & 30 & 30 & 23 & 84 & 43 \\
\hline
\end{tabular}

\begin{tabular}{|c|c|c|c|c|c|c|c|c|c|c|c|c|c|c|}
\hline Campos & $\mathbf{1 5}$ & $\mathbf{1 6}$ & $\mathbf{1 7}$ & $\mathbf{1 8}$ & $\mathbf{1 9}$ & $\mathbf{2 0}$ & $\mathbf{2 1}$ & $\mathbf{2 2}$ & $\mathbf{2 3}$ & $\mathbf{2 4}$ & $\mathbf{2 5}$ & $\mathbf{2 6}$ & $\mathbf{2 7}$ & $\mathbf{2 8}$ \\
\hline HF & 14 & 2 & 100 & 15 & 45 & 70 & 17 & 11 & 82 & 37 & 17 & 122 & 104 & 32 \\
\hline HD & 386 & 398 & 300 & 385 & 355 & 330 & 383 & 389 & 318 & 363 & 383 & 278 & 296 & 368 \\
\hline Contagem & 54 & 61 & 24 & 20 & 18 & 15 & 21 & 32 & 21 & 29 & 26 & 15 & 19 & 17 \\
\hline
\end{tabular}

\begin{tabular}{|c|c|c|c|c|c|c|c|c|c|c|c|c|c|c|}
\hline Campos & $\mathbf{2 9}$ & $\mathbf{3 0}$ & $\mathbf{3 1}$ & $\mathbf{3 2}$ & $\mathbf{3 3}$ & $\mathbf{3 4}$ & $\mathbf{3 5}$ & $\mathbf{3 6}$ & $\mathbf{3 7}$ & $\mathbf{3 8}$ & $\mathbf{3 9}$ & $\mathbf{4 0}$ & $\mathbf{4 1}$ & $\mathbf{4 2}$ \\
\hline HF & 28 & 12 & 75 & 52 & 26 & 18 & 25 & 17 & 30 & 40 & 17 & 34 & 20 & 77 \\
\hline HD & 372 & 388 & 325 & 348 & 374 & 382 & 375 & 383 & 370 & 360 & 383 & 366 & 380 & 323 \\
\hline Contagem & 40 & 65 & 15 & 25 & 37 & 44 & 19 & 27 & 22 & 45 & 40 & 35 & 39 & 54 \\
\hline
\end{tabular}

\begin{tabular}{|c|c|c|c|c|c|c|c|c|c|}
\hline Campos & $\mathbf{4 3}$ & $\mathbf{4 4}$ & $\mathbf{4 5}$ & $\mathbf{4 6}$ & $\mathbf{4 7}$ & $\mathbf{4 8}$ & $\mathbf{4 9}$ & $\mathbf{5 0}$ & Soma \\
\hline HF & 13 & 19 & 34 & 14 & 60 & 44 & 8 & 55 & 1.896 \\
\hline HD & 387 & 381 & 366 & 386 & 340 & 356 & 392 & 345 & 18.104 \\
\hline Contagem & 57 & 25 & 46 & 45 & 43 & 29 & 28 & 25 & 1.742 \\
\hline
\end{tabular}


Animal: $5 \quad$ Grupo: Adulto

\begin{tabular}{|c|c|c|c|c|c|c|c|c|c|c|c|c|c|c|}
\hline Campos & $\mathbf{1}$ & $\mathbf{2}$ & $\mathbf{3}$ & $\mathbf{4}$ & $\mathbf{5}$ & $\mathbf{6}$ & $\mathbf{7}$ & $\mathbf{8}$ & $\mathbf{9}$ & $\mathbf{1 0}$ & $\mathbf{1 1}$ & $\mathbf{1 2}$ & $\mathbf{1 3}$ & $\mathbf{1 4}$ \\
\hline HF & 32 & 27 & 43 & 18 & 31 & 41 & 11 & 21 & 35 & 28 & 13 & 44 & 27 & 58 \\
\hline HD & 368 & 373 & 357 & 382 & 369 & 359 & 389 & 379 & 365 & 372 & 387 & 356 & 373 & 342 \\
\hline Contagem & 29 & 32 & 63 & 30 & 30 & 28 & 58 & 30 & 32 & 38 & 46 & 32 & 26 & 26 \\
\hline
\end{tabular}

\begin{tabular}{|c|c|c|c|c|c|c|c|c|c|c|c|c|c|c|}
\hline Campos & $\mathbf{1 5}$ & $\mathbf{1 6}$ & $\mathbf{1 7}$ & $\mathbf{1 8}$ & $\mathbf{1 9}$ & $\mathbf{2 0}$ & $\mathbf{2 1}$ & $\mathbf{2 2}$ & $\mathbf{2 3}$ & $\mathbf{2 4}$ & $\mathbf{2 5}$ & $\mathbf{2 6}$ & $\mathbf{2 7}$ & $\mathbf{2 8}$ \\
\hline HF & 93 & 43 & 54 & 20 & 18 & 34 & 119 & 90 & 30 & 33 & 20 & 23 & 68 & 27 \\
\hline HD & 307 & 357 & 346 & 380 & 382 & 366 & 281 & 310 & 370 & 367 & 380 & 377 & 332 & 373 \\
\hline Contagem & 50 & 35 & 17 & 17 & 16 & 19 & 16 & 29 & 54 & 30 & 21 & 40 & 33 & 25 \\
\hline
\end{tabular}

\begin{tabular}{|c|c|c|c|c|c|c|c|c|c|c|c|c|c|c|}
\hline Campos & $\mathbf{2 9}$ & $\mathbf{3 0}$ & $\mathbf{3 1}$ & $\mathbf{3 2}$ & $\mathbf{3 3}$ & $\mathbf{3 4}$ & $\mathbf{3 5}$ & $\mathbf{3 6}$ & $\mathbf{3 7}$ & $\mathbf{3 8}$ & $\mathbf{3 9}$ & $\mathbf{4 0}$ & $\mathbf{4 1}$ & $\mathbf{4 2}$ \\
\hline HF & 42 & 57 & 41 & 25 & 15 & 38 & 35 & 32 & 25 & 22 & 30 & 30 & 23 & 10 \\
\hline HD & 358 & 343 & 359 & 375 & 385 & 362 & 365 & 368 & 375 & 378 & 370 & 370 & 377 & 390 \\
\hline Contagem & 27 & 23 & 42 & 50 & 23 & 26 & 29 & 25 & 23 & 36 & 18 & 36 & 21 & 22 \\
\hline
\end{tabular}

\begin{tabular}{|c|c|c|c|c|c|c|c|c|c|}
\hline Campos & $\mathbf{4 3}$ & $\mathbf{4 4}$ & $\mathbf{4 5}$ & $\mathbf{4 6}$ & $\mathbf{4 7}$ & $\mathbf{4 8}$ & $\mathbf{4 9}$ & $\mathbf{5 0}$ & Soma \\
\hline HF & 15 & 24 & 15 & 18 & 18 & 29 & 41 & 22 & 1.708 \\
\hline HD & 385 & 376 & 385 & 382 & 382 & 371 & 359 & 378 & 18.292 \\
\hline Contagem & 30 & 43 & 29 & 27 & 35 & 33 & 26 & 18 & 1.544 \\
\hline
\end{tabular}


Animal: $1 \quad$ Grupo: Velho

\begin{tabular}{|c|c|c|c|c|c|c|c|c|c|c|c|c|c|c|}
\hline Campos & $\mathbf{1}$ & $\mathbf{2}$ & $\mathbf{3}$ & $\mathbf{4}$ & $\mathbf{5}$ & $\mathbf{6}$ & $\mathbf{7}$ & $\mathbf{8}$ & $\mathbf{9}$ & $\mathbf{1 0}$ & $\mathbf{1 1}$ & $\mathbf{1 2}$ & $\mathbf{1 3}$ & $\mathbf{1 4}$ \\
\hline HF & 24 & 28 & 50 & 63 & 39 & 39 & 37 & 24 & 28 & 55 & 28 & 19 & 108 & 85 \\
\hline HD & 376 & 372 & 350 & 337 & 361 & 361 & 363 & 376 & 372 & 345 & 372 & 381 & 292 & 315 \\
\hline Contagem & 42 & 32 & 23 & 32 & 24 & 29 & 38 & 39 & 29 & 19 & 15 & 16 & 16 & 14 \\
\hline
\end{tabular}

\begin{tabular}{|c|c|c|c|c|c|c|c|c|c|c|c|c|c|c|}
\hline Campos & $\mathbf{1 5}$ & $\mathbf{1 6}$ & $\mathbf{1 7}$ & $\mathbf{1 8}$ & $\mathbf{1 9}$ & $\mathbf{2 0}$ & $\mathbf{2 1}$ & $\mathbf{2 2}$ & $\mathbf{2 3}$ & $\mathbf{2 4}$ & $\mathbf{2 5}$ & $\mathbf{2 6}$ & $\mathbf{2 7}$ & $\mathbf{2 8}$ \\
\hline HF & 150 & 90 & 54 & 91 & 80 & 33 & 70 & 20 & 26 & 50 & 82 & 26 & 255 & 42 \\
\hline HD & 250 & 310 & 346 & 309 & 320 & 367 & 330 & 380 & 374 & 350 & 318 & 374 & 145 & 358 \\
\hline Contagem & 15 & 13 & 14 & 16 & 17 & 16 & 10 & 8 & 16 & 10 & 11 & 17 & 14 & 15 \\
\hline
\end{tabular}

\begin{tabular}{|c|c|c|c|c|c|c|c|c|c|c|c|c|c|c|}
\hline Campos & $\mathbf{2 9}$ & $\mathbf{3 0}$ & $\mathbf{3 1}$ & $\mathbf{3 2}$ & $\mathbf{3 3}$ & $\mathbf{3 4}$ & $\mathbf{3 5}$ & $\mathbf{3 6}$ & $\mathbf{3 7}$ & $\mathbf{3 8}$ & $\mathbf{3 9}$ & $\mathbf{4 0}$ & $\mathbf{4 1}$ & $\mathbf{4 2}$ \\
\hline HF & 35 & 9 & 21 & 12 & 54 & 70 & 8 & 18 & 17 & 18 & 19 & 73 & 36 & 113 \\
\hline HD & 365 & 391 & 379 & 388 & 346 & 330 & 392 & 382 & 383 & 382 & 381 & 327 & 364 & 287 \\
\hline Contagem & 12 & 20 & 11 & 11 & 13 & 9 & 12 & 11 & 9 & 12 & 20 & 9 & 10 & 17 \\
\hline
\end{tabular}

\begin{tabular}{|c|c|c|c|c|c|c|c|c|c|}
\hline Campos & $\mathbf{4 3}$ & $\mathbf{4 4}$ & $\mathbf{4 5}$ & $\mathbf{4 6}$ & $\mathbf{4 7}$ & $\mathbf{4 8}$ & $\mathbf{4 9}$ & $\mathbf{5 0}$ & Soma \\
\hline HF & 15 & 6 & 19 & 6 & 20 & 14 & 150 & 7 & 2.436 \\
\hline HD & 385 & 394 & 381 & 394 & 380 & 386 & 250 & 393 & 17.564 \\
\hline Contagem & 16 & 18 & 14 & 10 & 23 & 8 & 7 & 12 & 844 \\
\hline
\end{tabular}


Animal: 2 Grupo: Velho

\begin{tabular}{|c|c|c|c|c|c|c|c|c|c|c|c|c|c|c|}
\hline Campos & $\mathbf{1}$ & $\mathbf{2}$ & $\mathbf{3}$ & $\mathbf{4}$ & $\mathbf{5}$ & $\mathbf{6}$ & $\mathbf{7}$ & $\mathbf{8}$ & $\mathbf{9}$ & $\mathbf{1 0}$ & $\mathbf{1 1}$ & $\mathbf{1 2}$ & $\mathbf{1 3}$ & $\mathbf{1 4}$ \\
\hline HF & 40 & 49 & 56 & 84 & 72 & 82 & 33 & 53 & 125 & 35 & 28 & 43 & 39 & 51 \\
\hline HD & 360 & 351 & 344 & 316 & 328 & 318 & 367 & 347 & 275 & 365 & 372 & 357 & 361 & 349 \\
\hline Contagem & 40 & 15 & 22 & 21 & 31 & 40 & 17 & 46 & 39 & 37 & 20 & 14 & 19 & 18 \\
\hline
\end{tabular}

\begin{tabular}{|c|c|c|c|c|c|c|c|c|c|c|c|c|c|c|}
\hline Campos & $\mathbf{1 5}$ & $\mathbf{1 6}$ & $\mathbf{1 7}$ & $\mathbf{1 8}$ & $\mathbf{1 9}$ & $\mathbf{2 0}$ & $\mathbf{2 1}$ & $\mathbf{2 2}$ & $\mathbf{2 3}$ & $\mathbf{2 4}$ & $\mathbf{2 5}$ & $\mathbf{2 6}$ & $\mathbf{2 7}$ & $\mathbf{2 8}$ \\
\hline HF & 32 & 39 & 27 & 37 & 27 & 53 & 11 & 45 & 39 & 32 & 45 & 33 & 30 & 24 \\
\hline HD & 368 & 361 & 373 & 363 & 373 & 347 & 389 & 355 & 361 & 368 & 355 & 367 & 370 & 376 \\
\hline Contagem & 19 & 24 & 38 & 24 & 24 & 20 & 29 & 18 & 9 & 4 & 6 & 14 & 28 & 13 \\
\hline
\end{tabular}

\begin{tabular}{|c|c|c|c|c|c|c|c|c|c|c|c|c|c|c|}
\hline Campos & $\mathbf{2 9}$ & $\mathbf{3 0}$ & $\mathbf{3 1}$ & $\mathbf{3 2}$ & $\mathbf{3 3}$ & $\mathbf{3 4}$ & $\mathbf{3 5}$ & $\mathbf{3 6}$ & $\mathbf{3 7}$ & $\mathbf{3 8}$ & $\mathbf{3 9}$ & $\mathbf{4 0}$ & $\mathbf{4 1}$ & $\mathbf{4 2}$ \\
\hline HF & 41 & 51 & 40 & 15 & 21 & 47 & 9 & 44 & 41 & 65 & 82 & 17 & 86 & 125 \\
\hline HD & 359 & 349 & 360 & 385 & 379 & 353 & 391 & 356 & 359 & 335 & 318 & 383 & 314 & 275 \\
\hline Contagem & 23 & 32 & 46 & 29 & 19 & 28 & 13 & 15 & 52 & 25 & 15 & 19 & 14 & 11 \\
\hline
\end{tabular}

\begin{tabular}{|c|c|c|c|c|c|c|c|c|c|}
\hline Campos & $\mathbf{4 3}$ & $\mathbf{4 4}$ & $\mathbf{4 5}$ & $\mathbf{4 6}$ & $\mathbf{4 7}$ & $\mathbf{4 8}$ & $\mathbf{4 9}$ & $\mathbf{5 0}$ & Soma \\
\hline HF & 50 & 31 & 37 & 74 & 70 & 130 & 200 & 90 & 2.630 \\
\hline HD & 350 & 369 & 363 & 326 & 330 & 270 & 200 & 310 & 17.370 \\
\hline Contagem & 14 & 9 & 15 & 22 & 14 & 18 & 17 & 12 & 1.111 \\
\hline
\end{tabular}


Animal: $3 \quad$ Grupo: Velho

\begin{tabular}{|c|c|c|c|c|c|c|c|c|c|c|c|c|c|c|}
\hline Campos & $\mathbf{1}$ & $\mathbf{2}$ & $\mathbf{3}$ & $\mathbf{4}$ & $\mathbf{5}$ & $\mathbf{6}$ & $\mathbf{7}$ & $\mathbf{8}$ & $\mathbf{9}$ & $\mathbf{1 0}$ & $\mathbf{1 1}$ & $\mathbf{1 2}$ & $\mathbf{1 3}$ & $\mathbf{1 4}$ \\
\hline HF & 33 & 50 & 59 & 48 & 92 & 66 & 58 & 132 & 54 & 23 & 24 & 5 & 25 & 42 \\
\hline HD & 367 & 350 & 341 & 352 & 308 & 334 & 342 & 268 & 346 & 377 & 376 & 395 & 375 & 358 \\
\hline Contagem & 80 & 33 & 31 & 33 & 9 & 30 & 21 & 22 & 31 & 19 & 19 & 18 & 20 & 9 \\
\hline
\end{tabular}

\begin{tabular}{|c|c|c|c|c|c|c|c|c|c|c|c|c|c|c|}
\hline Campos & $\mathbf{1 5}$ & $\mathbf{1 6}$ & $\mathbf{1 7}$ & $\mathbf{1 8}$ & $\mathbf{1 9}$ & $\mathbf{2 0}$ & $\mathbf{2 1}$ & $\mathbf{2 2}$ & $\mathbf{2 3}$ & $\mathbf{2 4}$ & $\mathbf{2 5}$ & $\mathbf{2 6}$ & $\mathbf{2 7}$ & $\mathbf{2 8}$ \\
\hline HF & 80 & 32 & 47 & 60 & 38 & 60 & 88 & 41 & 43 & 57 & 40 & 64 & 25 & 90 \\
\hline HD & 320 & 368 & 353 & 340 & 362 & 340 & 312 & 359 & 357 & 343 & 360 & 336 & 375 & 310 \\
\hline Contagem & 14 & 18 & 9 & 32 & 26 & 32 & 25 & 18 & 26 & 17 & 9 & 17 & 17 & 28 \\
\hline
\end{tabular}

\begin{tabular}{|c|c|c|c|c|c|c|c|c|c|c|c|c|c|c|}
\hline Campos & $\mathbf{2 9}$ & $\mathbf{3 0}$ & $\mathbf{3 1}$ & $\mathbf{3 2}$ & $\mathbf{3 3}$ & $\mathbf{3 4}$ & $\mathbf{3 5}$ & $\mathbf{3 6}$ & $\mathbf{3 7}$ & $\mathbf{3 8}$ & $\mathbf{3 9}$ & $\mathbf{4 0}$ & $\mathbf{4 1}$ & $\mathbf{4 2}$ \\
\hline HF & 158 & 130 & 33 & 83 & 78 & 42 & 22 & 16 & 40 & 34 & 40 & 33 & 53 & 109 \\
\hline HD & 242 & 270 & 367 & 317 & 322 & 358 & 378 & 384 & 360 & 366 & 360 & 367 & 347 & 291 \\
\hline Contagem & 29 & 9 & 17 & 9 & 13 & 11 & 22 & 26 & 12 & 16 & 17 & 22 & 24 & 23 \\
\hline
\end{tabular}

\begin{tabular}{|c|c|c|c|c|c|c|c|c|c|}
\hline Campos & $\mathbf{4 3}$ & $\mathbf{4 4}$ & $\mathbf{4 5}$ & $\mathbf{4 6}$ & $\mathbf{4 7}$ & $\mathbf{4 8}$ & $\mathbf{4 9}$ & $\mathbf{5 0}$ & Soma \\
\hline HF & 21 & 28 & 33 & 48 & 58 & 40 & 25 & 30 & 2.630 \\
\hline HD & 379 & 372 & 367 & 352 & 342 & 360 & 375 & 370 & 17.370 \\
\hline Contagem & 12 & 20 & 24 & 11 & 19 & 12 & 15 & 14 & 1.040 \\
\hline
\end{tabular}


Animal: 4 Grupo: Velho

\begin{tabular}{|c|c|c|c|c|c|c|c|c|c|c|c|c|c|c|}
\hline Campos & $\mathbf{1}$ & $\mathbf{2}$ & $\mathbf{3}$ & $\mathbf{4}$ & $\mathbf{5}$ & $\mathbf{6}$ & $\mathbf{7}$ & $\mathbf{8}$ & $\mathbf{9}$ & $\mathbf{1 0}$ & $\mathbf{1 1}$ & $\mathbf{1 2}$ & $\mathbf{1 3}$ & $\mathbf{1 4}$ \\
\hline HF & 41 & 74 & 24 & 26 & 19 & 78 & 14 & 11 & 64 & 46 & 24 & 12 & 83 & 22 \\
\hline HD & 359 & 326 & 376 & 374 & 381 & 322 & 386 & 389 & 336 & 354 & 376 & 388 & 317 & 378 \\
\hline Contagem & 34 & 21 & 50 & 22 & 32 & 25 & 27 & 33 & 26 & 35 & 11 & 12 & 11 & 10 \\
\hline
\end{tabular}

\begin{tabular}{|c|c|c|c|c|c|c|c|c|c|c|c|c|c|c|}
\hline Campos & $\mathbf{1 5}$ & $\mathbf{1 6}$ & $\mathbf{1 7}$ & $\mathbf{1 8}$ & $\mathbf{1 9}$ & $\mathbf{2 0}$ & $\mathbf{2 1}$ & $\mathbf{2 2}$ & $\mathbf{2 3}$ & $\mathbf{2 4}$ & $\mathbf{2 5}$ & $\mathbf{2 6}$ & $\mathbf{2 7}$ & $\mathbf{2 8}$ \\
\hline HF & 39 & 21 & 17 & 47 & 81 & 10 & 21 & 40 & 10 & 41 & 6 & 32 & 8 & 10 \\
\hline HD & 361 & 379 & 383 & 353 & 319 & 390 & 379 & 360 & 390 & 359 & 394 & 368 & 392 & 390 \\
\hline Contagem & 7 & 12 & 16 & 22 & 15 & 6 & 8 & 20 & 15 & 14 & 16 & 24 & 17 & 15 \\
\hline
\end{tabular}

\begin{tabular}{|c|c|c|c|c|c|c|c|c|c|c|c|c|c|c|}
\hline Campos & $\mathbf{2 9}$ & $\mathbf{3 0}$ & $\mathbf{3 1}$ & $\mathbf{3 2}$ & $\mathbf{3 3}$ & $\mathbf{3 4}$ & $\mathbf{3 5}$ & $\mathbf{3 6}$ & $\mathbf{3 7}$ & $\mathbf{3 8}$ & $\mathbf{3 9}$ & $\mathbf{4 0}$ & $\mathbf{4 1}$ & $\mathbf{4 2}$ \\
\hline HF & 25 & 8 & 12 & 23 & 2 & 2 & 52 & 6 & 8 & 10 & 4 & 15 & 11 & 10 \\
\hline HD & 375 & 392 & 388 & 377 & 398 & 398 & 348 & 394 & 392 & 390 & 396 & 385 & 389 & 390 \\
\hline Contagem & 24 & 30 & 15 & 15 & 35 & 46 & 37 & 25 & 10 & 29 & 17 & 23 & 34 & 21 \\
\hline
\end{tabular}

\begin{tabular}{|c|c|c|c|c|c|c|c|c|c|}
\hline Campos & $\mathbf{4 3}$ & $\mathbf{4 4}$ & $\mathbf{4 5}$ & $\mathbf{4 6}$ & $\mathbf{4 7}$ & $\mathbf{4 8}$ & $\mathbf{4 9}$ & $\mathbf{5 0}$ & Soma \\
\hline HF & 84 & 7 & 20 & 16 & 9 & 37 & 6 & 72 & 1.360 \\
\hline HD & 316 & 393 & 380 & 384 & 391 & 363 & 394 & 328 & 18.640 \\
\hline Contagem & 10 & 12 & 32 & 28 & 16 & 11 & 26 & 21 & 1.073 \\
\hline
\end{tabular}


Animal: 5 Grupo: Velho

\begin{tabular}{|c|c|c|c|c|c|c|c|c|c|c|c|c|c|c|}
\hline Campos & $\mathbf{1}$ & $\mathbf{2}$ & $\mathbf{3}$ & $\mathbf{4}$ & $\mathbf{5}$ & $\mathbf{6}$ & $\mathbf{7}$ & $\mathbf{8}$ & $\mathbf{9}$ & $\mathbf{1 0}$ & $\mathbf{1 1}$ & $\mathbf{1 2}$ & $\mathbf{1 3}$ & $\mathbf{1 4}$ \\
\hline HF & 88 & 69 & 54 & 66 & 55 & 57 & 14 & 13 & 22 & 46 & 69 & 38 & 50 & 182 \\
\hline HD & 312 & 331 & 346 & 334 & 345 & 343 & 386 & 387 & 378 & 354 & 331 & 362 & 350 & 218 \\
\hline Contagem & 27 & 15 & 18 & 21 & 24 & 20 & 33 & 45 & 29 & 26 & 10 & 12 & 10 & 11 \\
\hline
\end{tabular}

\begin{tabular}{|c|c|c|c|c|c|c|c|c|c|c|c|c|c|c|}
\hline Campos & $\mathbf{1 5}$ & $\mathbf{1 6}$ & $\mathbf{1 7}$ & $\mathbf{1 8}$ & $\mathbf{1 9}$ & $\mathbf{2 0}$ & $\mathbf{2 1}$ & $\mathbf{2 2}$ & $\mathbf{2 3}$ & $\mathbf{2 4}$ & $\mathbf{2 5}$ & $\mathbf{2 6}$ & $\mathbf{2 7}$ & $\mathbf{2 8}$ \\
\hline HF & 126 & 50 & 56 & 31 & 21 & 46 & 35 & 48 & 55 & 29 & 50 & 40 & 58 & 60 \\
\hline HD & 274 & 350 & 344 & 369 & 379 & 354 & 365 & 352 & 345 & 371 & 350 & 360 & 342 & 340 \\
\hline Contagem & 8 & 14 & 14 & 9 & 6 & 6 & 11 & 9 & 9 & 13 & 14 & 7 & 12 & 21 \\
\hline
\end{tabular}

\begin{tabular}{|c|c|c|c|c|c|c|c|c|c|c|c|c|c|c|}
\hline Campos & $\mathbf{2 9}$ & $\mathbf{3 0}$ & $\mathbf{3 1}$ & $\mathbf{3 2}$ & $\mathbf{3 3}$ & $\mathbf{3 4}$ & $\mathbf{3 5}$ & $\mathbf{3 6}$ & $\mathbf{3 7}$ & $\mathbf{3 8}$ & $\mathbf{3 9}$ & $\mathbf{4 0}$ & $\mathbf{4 1}$ & $\mathbf{4 2}$ \\
\hline HF & 46 & 13 & 10 & 28 & 90 & 37 & 32 & 30 & 40 & 92 & 13 & 36 & 17 & 25 \\
\hline HD & 354 & 387 & 390 & 372 & 310 & 363 & 368 & 370 & 360 & 308 & 387 & 364 & 383 & 375 \\
\hline Contagem & 15 & 11 & 11 & 19 & 9 & 15 & 19 & 24 & 35 & 19 & 26 & 26 & 16 & 15 \\
\hline
\end{tabular}

\begin{tabular}{|c|c|c|c|c|c|c|c|c|c|}
\hline Campos & $\mathbf{4 3}$ & $\mathbf{4 4}$ & $\mathbf{4 5}$ & $\mathbf{4 6}$ & $\mathbf{4 7}$ & $\mathbf{4 8}$ & $\mathbf{4 9}$ & $\mathbf{5 0}$ & Soma \\
\hline HF & 60 & 15 & 28 & 41 & 10 & 31 & 58 & 46 & 2.326 \\
\hline HD & 340 & 385 & 372 & 359 & 390 & 369 & 342 & 354 & 17.674 \\
\hline Contagem & 19 & 21 & 36 & 31 & 30 & 28 & 26 & 34 & 939 \\
\hline
\end{tabular}


PLANILHA COLORAÇÀO - WEIGERT - OXONA

\begin{tabular}{|c|c|c|c|c|c|c|c||}
\hline PU & CR & DIAS & $\begin{array}{c}\mathrm{f}= \\
\mathrm{PU} / \mathrm{PT}\end{array}$ & AT & $\begin{array}{c}\text { A }=\text { AT X } \\
\mathrm{F}\end{array}$ & $\begin{array}{c}\mathrm{C}= \\
\mathrm{CRX} 2\end{array}$ & $\begin{array}{c}\text { LD }= \\
\text { 2XC/A }\end{array}$ \\
\hline 16.995 & 1.002 & 21 & 0,84975 & 386250 & 328215,93 & 2.004 & 0,0122114 \\
\hline 17.820 & 902 & 21 & 0,891 & 386250 & 344148,75 & 1.804 & 0,0104838 \\
\hline 18.019 & 1.118 & 21 & 0,9009 & 386250 & 347991,93 & 2.236 & 0,0128508 \\
\hline 18.408 & 651 & 21 & 0,9204 & 386250 & 355504,5 & 1.302 & 0,0073248 \\
\hline 17.896 & 854 & 21 & 0,8948 & 386250 & 345616,5 & 1.708 & 0,0098837 \\
\hline 17.685 & 1.640 & 200 & 0,88425 & 386250 & 341541,56 & 3.280 & 0,0192070 \\
\hline 18.209 & 1.789 & 200 & 0,91045 & 386250 & 351661,31 & 3.578 & 0,0203491 \\
\hline 18.052 & 1.594 & 200 & 0,9026 & 386250 & 348629,25 & 3.188 & 0,0182887 \\
\hline 18.104 & 1.742 & 200 & 0,9052 & 386250 & 349633,5 & 3.484 & 0,0199294 \\
\hline 18.292 & 1.544 & 200 & 0,9146 & 386250 & 353264,25 & 3.088 & 0,0174826 \\
\hline 17.564 & 844 & 450 & 0,8782 & 386250 & 339204,75 & 1.688 & 0,0099526 \\
\hline 17.370 & 1.111 & 450 & 0,8685 & 386250 & 335458,12 & 2.222 & 0,0132475 \\
\hline 17.370 & 1.040 & 450 & 0,8685 & 386250 & 335458,12 & 2.080 & 0,0124009 \\
\hline 18.640 & 1.073 & 450 & 0,932 & 386250 & 359985 & 2.146 & 0,0119227 \\
\hline 17.674 & 939 & 450 & 0,8837 & 386250 & 341329,12 & 1.878 & 0,011004 \\
\hline
\end{tabular}

